\title{
Die satirische Kurzprosa Heinrich Bölls
}

Erhard Friedrichsmeyer 
Die satirische Kurzprosa Heinrich Bölls 
From 1949 to 2004, UNC Press and the UNC Department of Germanic \& Slavic Languages and Literatures published the UNC Studies in the Germanic Languages and Literatures series. Monographs, anthologies, and critical editions in the series covered an array of topics including medieval and modern literature, theater, linguistics, philology, onomastics, and the history of ideas. Through the generous support of the National Endowment for the Humanities and the Andrew W. Mellon Foundation, books in the series have been reissued in new paperback and open access digital editions. For a complete list of books visit www.uncpress.org. 


\section{Die satirische Kurzprosa Heinrich Bölls}

ERHARD FRIEDRICHSMEYER

UNC Studies in the Germanic Languages and Literatures Number 97 
Copyright (C) 1981

This work is licensed under a Creative Commons CC BY-NC-ND license. To view a copy of the license, visit http://creativecommons. org/licenses.

Suggested citation: Friedrichsmeyer, Erhard. Die satirische Kurzprosa Heinrich Bölls. Chapel Hill: University of North Carolina Press, 1981 DOI: https://doi.org/10.5149/9781469657530_Friedrichsmeyer

Library of Congress Cataloging-in-Publication Data

Names: Friedrichsmeyer, Erhard.

Title: Die satirische Kurzprosa Heinrich Bölls / by Erhard Friedrichsmeyer.

Other titles: University of North Carolina Studies in the Germanic Languages and Literatures ; no. 97.

Description: Chapel Hill : University of North Carolina Press, [1981] Series: University of North Carolina Studies in the Germanic Languages and Literatures. | Includes bibliographical references and index.

Identifiers: LCCN 80026886 | ISBN 978-1-4696-5752-3 (pbk: alk. paper) | ISBN 978-1-4696-5753-o (ebook)

Subjects: Böll, Heinrich, 1917-1985 - Criticism and interpretation.

Classification: LCC PT2603 .0394 Z64 | DCC 833/.914 


Meiner Frau und meinen Kindern 



\section{Inhalt}

I. Einleitung 3

II. "Doktor Murkes gesammeltes Schweigen":

$\begin{array}{ll}\text { Paradigmatische Linien } & 7\end{array}$

III. Frühe satirische Versuche; Abgrenzungen zur Parabel 51

IV. "Nicht nur zur Weihnachtszeit": Durchbruch als Satiriker

v. Die Berufssatiren: Selbstabrechnungen des Satirikers $\quad 84$

vi. "Der Wegwerfer": System- und Berufssatire 131

vII. Kurzsatire und Muster: Ausnahme, Abkehr und Neuansatz

virI. Ausblick auf die satirischen Langformen 162

Ix. Die neue Kurzsatire: Typologische Varianten 178

$\begin{array}{ll}\text { x. Schluß } & 193\end{array}$

$\begin{array}{ll}\text { Anmerkungen } & 195\end{array}$

$\begin{array}{ll}\text { Literaturverzeichnis } & 211\end{array}$

$\begin{array}{ll}\text { Personenregister } & 219\end{array}$ 

Es würde zu weit führen, allen Kollegen, Studenten und Freunden, von denen ich in Gesprächen und Diskussionen Anregungen und Kritik zu meiner Arbeit erhalten habe, namentlich anzuführen. Ich danke ihnen allen.

Besonderer Dank gilt meiner Frau Sarah, meinem Bruder Ernst und Renée Lang, die das Manuskript durchgesehen und mir wertvolle Hinweise gegeben haben.

Diese Studie wurde finanziell unterstützt vom "Charles Phelps Taft Memorial Fund," University of Cincinnati, vom "Office of the Vice President and University Dean for Graduate Studies and Research," University of Cincinnati, und vom "University Research Council," University of Cincinnati. Für diese großzügige Hilfe, die mir Forschung und Veröffentlichung erleichtert hat, danke ich herzlich.

Alle Werkzitate (siehe "Abkürzungen") erfolgen mit freundlicher Genehmigung des Verlags Kiepenheuer und Witsch, Köln, und des Lamuv Verlags, Bornheim-Merten.

Cincinnati

Erhard Friedrichsmeyer

Juli 1980 



\section{Abkürzungen}

W1-5 = Heinrich Böll, Werke: Romane und Erzählungen, Hrsg. Bernd Balzer, 5 Bde. (Köln: Kiepenheuer und Witsch, 1977).

ESR1-3 = Heinrich Böll, Werke: Essayistische Schriften und Reden, Hrsg. Bernd Balzer, 3 Bde. (Köln: Kiepenheuer und Witsch, 1978).

I = Heinrich Böll, Werke: Interviews, Hrsg. Bernd Balzer (Köln: Kiepenheuer und Witsch, 1978).

HTDG = Heinrich Böll, Werke: Hörspiele, Theaterstücke, Drehbücher, Gedichte, Hrsg. Bernd Balzer (Köln: Kiepenheuer und Witsch, 1978).

$\mathrm{H}=$ Heinrich Böll, Du fährst zu oft nach Heidelberg (BornheimMerten: Lamuv, 1979).

Nach dem jeweils ersten Hinweis innerhalb eines Kontextes wird nur die Seitenzahl angeführt. 

Die satirische Kurzprosa Heinrich Bölls 



\section{Einleitung}

Seit nahezu drei Jahrzehnten steht Heinrich Böll im öffentlichen Leben. In den frühen fünfziger Jahren erlangte er Namen und Ruf als Schriftsteller; hinzu kam sodann stetig wachsende Beachtung als öffentliche Stimme. Im ersteren wie im letzteren ist Böll bis heute umstritten. Aber selbst diejenigen, denen sein politischer Standort nicht zusagt, oder diejenigen, denen er als Schriftsteller überbewertet zu sein scheint, sind nicht unempfänglich für seinen allerseits gern betonten Ruhm im Ausland.

Jedoch auch außer Landes teilen sich die Meinungen. Den einen ist Böll Schriftsteller von Weltrang, den anderen ein moralisches Phänomen, eine vertrauenerweckende Stimme des Menschlichen aus einem Lande mit einer von vielen seiner Leser noch erlebten unmenschlichen Vergangenheit. In den USA ist der Name Böll z.B. unter diesem Zwitteraspekt sogar in den Bereich der "popular culture" gedrungen. Er erscheint in Woody Allens Film "Manhattan," wo diejenigen, die ihn (sowie Mahler und F. Scott Fitzgerald) in die Kategorie der "Überbewerteten" einreihen, in einem satirischen Licht stehen. Wird Böll hier vor einem Millionenpublikum eine Lanze gebrochen, so wertet man Reaktionen dieser Art oft in seinem eigenen Lande in einem sehr fragwürdigen Sinne, als Beweis der Berühmtheit eines Deutschen. Bölls internationales Ansehen erhöht selbst bei denen, die ihm nicht wohl gesonnen sind, den nationalen Stolz.

Bölls außerordentlicher Erfolg im eigenen Lande führte somit in einem nicht unbeträchtlichen Maße auch dazu, ihn und sein Werk in Kategorien und Denkschablonen zu pressen, die Böll selbst verhaßt sind. Sein Werdegang als Schriftsteller ist ganz besonders deutlich gekennzeichnet durch das Bemühen, der Vereinnahmung durch eine Gesellschaft, der er bis zu ihrem Kern kritisch gegenübersteht, zu entkommen. Vornehmlich greift er dabei schon früh zu einer schriftstellerischen Ausdrucksweise, die traditionell als dazu geschaffen gilt, dem Autor eine freie Position zu gewähren. Es ist dies die Satire. In diesem Raum zumindest sollte Böll als Schriftsteller nicht umstritten sein. Der Vorwurf der Anfälligkeit für das Sentimentale und Moralisierende, dessen Diskussion die Böll-Kritik seit ehedem bewegt, gilt hier nicht. ${ }^{1}$

Obwohl Böll sich schon von Anfang an auch in der längeren Erzählung äußert, beschränkt er die aggressive Sprechweise in den fünf- 
ziger Jahren auf die Kurzprosa. Zu deren Bestem gehören zweifellos Texte wie "Nicht nur zur Weihnachtszeit," "Es wird etwas geschehen," "Doktor Murkes gesammeltes Schweigen" und "Der Wegwerfer." Keiner seiner Romane und auch nichts unter seiner unsatirischen Kurzprosa hat so einhellige Anerkennung gefunden wie diese Geschichten. Böll, so darf man behaupten, ist in der Kurzsatire in seinem eigentlichsten Element. ${ }^{2}$

Böll ist der satirisch-aggressiven Schreibart, sei es in der kürzeren oder längeren Form, bis heute treu geblieben. Man kann sogar sagen, seine aggressive Ader schlägt in seinem späteren Werk stärker denn je. Es ist demnach durchaus statthaft, Böll vor allem einen Satiriker zu nennen. Walter Jens bezeichnet ihn als den "bedeutendsten Satiriker der Gegenwart . . . dessen Schaffen in den 'Murke'-Satiren gipfelte. . . ." 3 Theodor W. Adorno bewundert die Verweigerung der Affirmation und Konzilianz bei Böll und bescheinigt ihm einen Grad der Empfindlichkeit, den es seit Karl Kraus unter deutschen Schriftstellern nicht mehr gegeben habe. ${ }^{4}$

In eingehender Analyse seiner satirischen Kurzprosa und auch in Ausblicken auf seine satirischen Langformen soll in dieser Studie versucht werden, Bölls satirische Strukturen und Techniken zu erhellen und somit sein Ansehen als Satiriker als berechtigt zu bestätigen. Es wird sich dabei auch zeigen, daß Bölls Erzähltechnik auf die Traditionen bedeutender Satire zurückgeht.

Fahndet man in Bölls Werk nach Abschnitten, so ließen sich thematische Linien ziehen, wie etwa der Krieg, die unmittelbare Nachkriegs- und die Restaurationszeit. Es ist jedoch ebenso fruchtbar, einen formalen Einschnitt wahrzunehmen. In der Kurzprosa, sei sie satirisch oder nicht, hat Böll seit Jahren nur noch spärlich veröffentlicht. Seine Äußerung, er gerate immer wieder ins "eigene Strickmuster" (I, 67), ist eine ernstzunehmende Erklärung. Sie bezieht sich auf einen einschneidenden Wandel im Werk Bölls gegen Ende der fünfziger Jahre. Böll wendet sich immer mehr von einem intensiv fiktionalen, das Allgemeine betonenden Stil ab und neigt stärker zu einem das Aktuelle verarbeitenden, vielfach dokumentaristischen Realismus. Dieser paßt jedoch nicht recht zu Bölls damaliger Vorstellung von Kurzprosa. Er verstand sie novellistisch, also Formalistisches betonend. ${ }^{5}$ Literatur dieser Prägung entsprach jedoch nicht den Forderungen der Zeit. Hans Magnus Enzensberger äußert sich dahingehend $\mathrm{zu}$ Bölls Kurzsatiren der fünfziger Jahre. Er lobt sie sehr, verlangt aber Zeitgemäßeres: "Wenn es Böll gelingt, die Verschmelzung der Satire mit dem realistischen Roman zu vollziehen . . . so könnte er unserer Wirklichkeit einen Wechselbalg vorhalten, vor dem sie erschräke, weil er ihr ähnlicher sähe als ihr eigenes Spie- 
gelbild." ${ }^{6}$ Die Kurzform bietet für Enzensberger der Satire nicht mehr das rechte Forum. Der realistische Roman hingegen kommt dem Verständnis dieser Zeit, das eine appellative und rezeptionsfreudige $\mathrm{Li}$ teratur verlangt, eher entgegen. Der Text wendet sich jetzt nicht mehr vornehmlich an den beschränkten Kreis der Kenner, sondern an den allgemeinen Leser, der erwartet, seine Welt direkt wiederzuerkennen. Diese kann verfremdet sein, aber die Technik verweist auf die Realität, nicht auf die Kunst als Fiktion. Literarische Direktheit gilt in diesem Sinne jetzt als Bedingung der Intention, das Publikum sozialkritisch zu bewegen.

$\mathrm{Zu}$ den wesentlichen Merkmalen des Böllschen Werkes gehört seine Charakterbezogenheit. Sie trifft auf die Langformen bis heute, die satirische Kurzprosa bis zum Ende der fünfziger Jahre zu. So sind erstaunlich viele seiner Kurzsatiren der damaligen Zeit Ich-Erzählungen, in denen der Erzähler als Beichtender oder als sein eigener Apologet bisweilen die Szene völlig beherrscht. Selbst in den Satiren in der dritten Person herrscht eine Gestalt vor. Die Fabel der satirischen Helden dieser Zeit ist immer dieselbe: Sie geraten in eine Situation, in der ihnen vom Satiriker eine soziale Leistung abverlangt wird, die einen Protest darstellt gegen die Mangelhaftigkeit der Wirklichkeit, in der sie leben. Sie stehen, wie Theodore Ziolkowski formuliert, "in mild rebellion against 'the system.'"7 Bölls satirische Mittelpunktfiguren erfüllen aber unsere Erwartungen in sie nicht, arrangieren sich in der Welt, gegen die sie auftreten, oder entlaufen dem Gefahrenbereich. Dieses Charakterdiagramm mit sinkender Erfolgslinie hat im Satiremuster der fünfziger Jahre grundlegende strukturelle Bedeutung. Obwohl nach Rainer Nägele bei Böll der "rebellische Akt gegen die Ordnung . . . eine typische Konstellation . . ." ist, ${ }^{8}$ hat man ihn bisher noch nicht als Ansatzpunkt zur Sichtbarmachung der Böllschen Satirestruktur herangezogen. Die Erklärung liegt z.T. darin, daß auch einige der nicht-satirischen Texte eine "mild rebellion" veranschaulichen, aber weil sich diese dort nicht in einem aggressiven Stilton äußert, bleibt sie eine "unerhörte Begebenheit" ohne ausdrücklichen Protestcharakter. Das diffuse Gesamtbild führt daher zu sehr zagen ÄuBerungen, wie der Wolfdietrich Raschs, wonach "Bölls Menschen . . . wissen . . da daß ihnen etwas fehlt, etwas Wesentliches," und daß sie sich nicht "allzu willig in die verwaltete Welt unserer Tage fügen." 9 Hinzu kommt, daß in den nicht-satirischen Texten der fünfziger Jahre das Profil der Figuren, die sich als Herausforderer sehen ließen, deutlich anders ist. Böll unterzieht sie nicht verzeichnender Kritik. In den nicht-satirischen Romanen hat das Protestmoment überdies weniger einen Mittelpunktcharakter. Jedoch hat Hans Joachim Bernhard recht, wenn er selbst dort eine novellistische Struktur, die Helden in 
einer "unerhörten Begebenheit," einer "Krisensituation" oder "Entscheidungssituation" sieht. ${ }^{10}$

Ausgangspunkt dieser Studie ist das zentrale Ereignis dieser Prägung. Aufgefaßt als "Plot" bestimmt und eröffnet es die Struktur der Kurzsatiren in den fünfziger Jahren. Die Analyse geht im wesentlichen exemplarisch vor. Anhand von Modelltexten zielt sie auf die Grundmuster in der Böllschen Satire. Mittels eingehender Untersuchung und auch synoptischer Diskussion der restlichen Satiren werden darüberhinaus die Grundmuster in ihren Varianten und unter dem Aspekt der chronologischen Wandlung vorgeführt. 


\section{II. “Doktor Murkes}

\section{gesammeltes Schweigen": \\ Paradigmatische Linien}

Fragt man sich, mit welchem Text die Ermittlung des Exemplarischen an der Satire Bölls zu beginnen habe, so hat man zweifellos einen der eingangs angeführten Texte, "Nicht nur zur Weihnachtszeit," "Es wird etwas geschehen," "Doktor Murkes gesammeltes Schweigen" oder "Der Wegwerfer" zu wählen. Sie sind sicherlich die bekanntesten und gediegensten Satiren der fünfziger Jahre. Für Böll selber ist "Der Wegwerfer" die beste Geschichte, die er geschrieben hat. ${ }^{1}$ Es handelt sich hier wohl kaum um ein gehätscheltes Schmerzenskind. Trotzdem ist es ratsamer, nicht dem Autor, sondern der Kritik zu folgen. Ihr Favorit ist "Doktor Murkes gesammeltes Schweigen" (1955). Cesare Cases, der Böll im allgemeinen kühl gegenübersteht, urteilt, "er hat Dr. Murkes gesammeltes Schweigen geschrieben, und das hat ihm noch kein lebender Schriftsteller nachgemacht." ${ }^{2}$ Für Hans Magnus Enzensberger ist dieser Text der beste unter den oben angeführten. ${ }^{3}$

Die Untersuchung von "Dr. Murke" geht von der Hypothese aus, daß diese Erzählung eine Satire ist. Meines Wissens hat noch kein Kritiker das Gegenteil behauptet. Wie Edgar Johnson sagt, könne jeder eine Satire erkennen, das Problem läge vielmehr darin, daß niemand wisse, was eine Satire sei. ${ }^{4}$ Diese Ratlosigkeit ist verwandt mit der Behauptung, daß es keine Satire, sondern nur Satiren gebe. Ebenso extrem, und dazu zum Scheitern verurteilt, sind die Versuche, eine Satiredefinition $\mathrm{zu}$ erzwingen, die alles über einen Leisten schlägt. Dazwischen liegen jedoch einige Fixpunkte. Satirische Texte desselben Autors ähneln sich oft strukturell. Weiterhin gibt es Satiretypen. Niemand käme auf den Gedanken, Swifts Gulliver's Travels und "A Modest Proposal" als Zwillinge zu erklären, oder zu behaupten, ein Fackeltext von Karl Kraus und Kellers "Tanzlegendchen" seien aus demselben Holz geschnitzt. Dennoch sind sie alle Satiren.

Dem Typus, dem Bölls Satiren der fünfziger Jahre vorgreifend zuzurechnen sind, hat man besonders in der anglo-amerikanischen Literaturkritik Aufmerksamkeit geschenkt. Er ist mit Robert C. Elliott, 
Northrop Frye, Ronald Paulson u.a. als mythus-geprägt zu bezeichnen. ${ }^{5}$ Auf den Terminus Mythus muß zunächst klärend eingegangen werden, da er im deutschen Sprachraum vorderhand ideologisch belastet ist. Wie Peter Demetz ausführt, hat die deutsche Literaturkritik "Angst vor dem Mythus," da er "nach so langer Beschäftigung mit dem Pseudo-Mythus, für lange diskreditiert" ist. Daß Claude LéviStrauss und Frye als Vertreter einer anthropologisch-mythischen Literaturbetrachtung nicht in dieses Kontaminationsfeld gehören, bestätigt Demetz ebenfalls. ${ }^{6}$ Trotzdem meldet er Vorbehalte an, und zwar gegen die unhistorische Basis dieser Ausrichtungen. Daß sie sich hingegen als überhistorisch begreifen lassen, sollte ihnen jedoch eingeräumt werden. Immerhin scheint in der deutschen Satireforschung die Mythus-Phobie durchaus nicht unüberwindlich zu sein. Jürgen Brummack, der den bisher umfassendsten Überblick zur internationalen Satireforschung vorgelegt hat, erkennt ohne Vorurteile z.B. die Bedeutung des Fryeschen Mythus-Konzepts zur Satire an, das an einem so übergreifenden Spektrum der (abendländischen) Literatur gewonnen ist wie kein anderes. ${ }^{7}$ Gleichwohl muß zugesetzt werden, daß Frye sich auf Satire mit einem Plot und die "große Literatur" beschränkt.

Die Verweise auf Frye dienen in dieser Studie zum einen der Erstellung eines analytischen Instrumentariums, zum anderen der Bezugsetzung zu anderen Autoren, hauptsächlich zu Swift. Den aufgezeigten überhistorischen Konstanten schließt sich das historisch Spezifische eigentlich in der Satire von selbst an: Die Herausfordererkonfiguration als Ansatzpunkt dieser Studie ist zwar Archetypus, dies jedoch innerhalb einer spezifischen sozialen Situation, in der sich die historische Wirklichkeit charakteristisch zu spiegeln hat, da diese vom Satiriker auf Veränderung zielend im Werk angegriffen wird.

\section{Die Konfrontationsfelder}

Murke, einem intelligenten jungen Angestellten der Abteilung Kulturwort in einem Rundfunkhaus wird der Auftrag erteilt, die Korrektur zweier auf Band gesprochener Vorträge über das Wesen der Kunst zu leiten. Ihr Verfasser ist der Starkommentator des Hauses, Bur-Malottke. Dieser hat das Bedürfnis, das Wort Gott, das wiederholt in seinen beiden Reden vorkommt, durch die Formel "jenes höhere Wesen, das wir verehren," ersetzt zu sehen. Bur-Malottke konvertierte 1945 und er hat nun, Jahre danach, "über Nacht . . . religiöse Bedenken bekommen." Er fühlt sich "plötzlich angeklagt . . . 
an der religiösen Überlagerung des Rundfunks mitschuldig zu sein." Die Ersatzformel soll demonstrieren, daß er zu der "Mentalität" zurückkehrt, "zu der er sich vor 1945 bekannt hatte" (W3, 174).

Murkes Auftrag ist an sich nicht schwierig. Er hört die Vorträge dreimal ab, ehe er schneidet; es ergeben sich nur zwei technische Komplikationen: Da das Wort Gott nicht nur in einem Kasus vorkommt, ist es nötig, Bur-Malottke Nominative, Genitive, Dative und einen Vokativ in der Ersatzformel auf Band sprechen zu lassen. Hinzu kommt, daß die Vorträge nach der Korrektur um eine Sendeminute länger sind als zuvor. Beide Schwierigkeiten sollten eigentlich leicht zu überwinden sein, zumal die zweite nicht Murkes, sondern des Intendanten Sorge ist. Verwunderlich ist daher, daß der Auftrag Murke überfordert. Nachdem Bur-Malottke seine dekorative Formel zu Band gebracht hat, "taumelt" Murke in die Funkhauskantine. Dort trifft ihn das Wort Kunst, oft lauthals von einigen seiner Kollegen in der Diskussion herausgestoßen, so hart, daß er sich "ausgepeitscht" (181) fühlt. Sein Auftrag ist auch in der Beurteilung eines seiner Vorgesetzten derart anstrengend, daß dieser Murke einen freien Nachmittag gewährt.

Von physischer Überforderung kann nur begrenzt die Rede sein. Die Erklärung des Sachverhaltes liegt darin, daß Murke nicht mechanisch, wie das Bandgerät oder etwa auch der ihm beigegebene Techniker, sondern kritisch reagiert. Obwohl er zum ersten Mal mit BurMalottkes Produkten in Berührung kommt, genügen diese beiden Vorträge vollauf, ihn gegen seinen Chef einzunehmen. Er denkt, so heißt es, über das "niedrige Wesen, das Bur-Malottke verehrte" (175), nach. Seine Abneigung ist demnach vorerst nicht die des Untergebenen gegen den Höhergestellten, sondern weist auf die Sache, um die es in seinem Auftrag geht. Bur-Malottke hat, um im Bilde zu bleiben, Gott erniedrigt, ihn in eine Platitüde umfunktioniert. Dieses Nachdenken ist jedoch nicht als religiöses Zartgefühl zu verstehen, sondern vielmehr als die Erkenntnis eines Symptoms, das BurMalottke als bedrohliches Gesamtphänomen aufdeckt. Bur-Malottke redet und schreibt hochgestochen und mit angemaßter Autorität über alles, was in den Bereich Kultur fallen mag. So sind seine zahlreichen Bücher "essayistisch-philosophisch-religiös-kulturgeschichtlichen Inhalts" (174). Er ist das unförmige Kapazitätenknäuel, das die Satire liebt. Swift tritt als solches in $A$ Tale of $a$ Tub auf, einen Diskurs über das Thema Fleiß ankündigend, den er "Histori-theo-physi-logically" zu sezieren gedenkt. ${ }^{8}$ Bur-Malottke ist Cheflektor des größten Verlages und sitzt in der Redaktion dreier Zeitschriften und zweier Zeitungen. Sein Tätigkeitsbereich geht sicherlich über die Kompetenz selbst eines Genies hinaus. Aber Bur-Malottke ist nichts dergleichen, 
sondern ein gewaltiger Schwätzer, nach einer Wendung Theodor W. Adornos ein Virtuose auf der "Wurlitzer-Orgel des Geistes." ${ }^{9}$ Eine Charakterologie dieser Art ist im Kern in den Schlüssen enthalten, zu denen Murke in seinem Nachdenken gelangen muß.

Murke bieten sich nun zwei Möglichkeiten der aktiven Reaktion. Er hat die Wahl, gegen den Menschen Bur-Malottke, oder aber gegen die Sache, für die dieser steht, Stellung zu nehmen. Richtet sich seine Abneigung in erster Linie ad hominem, so kann er versuchen, seinen Gegner zu demütigen, zielt sie vornehmlich auf die Sache, so ist eine persönliche Erniedrigung fehl am Platze. Vielmehr hat er BurMalottke zu widersprechen, d.h. er darf keineswegs schweigen, sondern muß Bur-Malottke dort angreifen, wo er gemeingefährlich ist, im Bereich Kulturwort. Zweifellos würde dieses Verhalten ein bedeutendes Risiko für Murke einschließen. Man sagt sich im Funkhaus, "man hätte ebensogut Selbstmord begehen können wie BurMalottke zu widersprechen" (175). Derart gefährlich scheint er selbst dem Intendanten, dem nominellen Haupt des Funkhauses. Eine Demütigung, die so getarnt ist, daß Bur-Malottke nicht zurückschlagen kann, ist unvergleichlich weniger riskant als ein Widerspruch. Murke wählt die ungefährlichere Strategie. Er bringt seinen Gegner bei der Aufnahme der Ersatzformel ins Schwitzen und Fluchen. Murkes "so junge, liebenswürdige, so maßlos intelligente Stimme peinigte ihn, wie ihn noch nie etwas gepeinigt hatte." Dabei gibt Murke seinem "jungen Gesicht den Ausdruck tadelloser Bescheidenheit." Er verwahrt sich so geschickt, daß sich seinem Widersacher kein Ziel bietet. Seine Gefühle sind bezeichnenderweise mittlerweile zu Haß geworden: "Murke war zu jung, hatte sich zu gebildet gefühlt, um das Wort Haß zu mögen. Hier aber . . . während Bur-Malottke seine Genitive sprach, wußte er plötzlich, was $\mathrm{Haß}$ ist: er haßte diesen großen, dicken und schönen Menschen . . . und er dachte nicht eine Sekunde daran, diesen Haß zu unterdrücken" (177-79). Von seinem Widersacher sind keine milderen Gefühle zu erwarten. Er haßt Murke ebenfalls.

Obwohl wir als Leser Murke instinktiv beipflichten möchten, wenn er seinen Feind peinigt, ist Zurückhaltung angebracht. Im sozialen Sinne ist Murkes Taktik fragwürdig, schon weil er sich genau wie BurMalottke verhält. Beide bestimmt der $\mathrm{Ha}$, und beide reagieren sich auf gleiche Weise ab. Nach erlittener Schmach läuft Bur-Malottke zum Intendanten und bringt diesen ins Schwitzen. Wenn Murke auf den "großen, dicken und schönen Menschen" Bur-Malottke reagiert, nicht aber auf den intellektuellen Scharlatan, so hat er seinen ursprünglichen Bezug der reflektierten Kritik aufgegeben. Er handelt nicht aus Prinzip, sondern aus Verschlagenheit, wenn er vor dem uneinge- 
schränkten und gefährlichen Machthaber im Funkhaus schweigt, diesen aber zwickt und kneift. Damit tritt er nach derselben Losung an, die Bur-Malottke vertritt. Sie ist das Prinzip hierarchischer Machtordnung, das Böll immer wieder-besonders ausdrücklich in der negativen Utopie Ein Schluck Erde (1961)—als Quintessenz unserer Welt anprangert.

Böll skizziert das Herrschaftsprinzip des Funkhauses sehr scharf. Es hat negativen Wert nicht nur in seinem Spitzenfunktionär BurMalottke, sondern überhaupt, da es im Grunde nur eine Art zwischenmenschlicher Verhältnisse erlaubt, den Mechanismus von Beherrschung und Unterwerfung. Die Stufenleiter geht vom verschüchterten Krochy, der zu seinem Vorgesetzten in einem den unterschiedlichen Rang hervorhebenden Militärstil spricht, bis hinauf zum Chef des Kulturwortes, dem selbst der Intendant gefügig ist. Aber Böll zieht die Linien noch weiter, so daß sich plötzlich Oben und Unten verkehren. Über allen steht das Publikum. Aber es ist kein Herr, dem Ehre gebührt. Es meint hier den öffentlichen Geschmack, der seinen Gefallen an Gott verloren hat, und dem Bur-Malottke willfährig ist. Der Intendant verneigt sich vor dem Publikum in seufzender Unterwürfigkeit, obwohl es als ein Ausbund der Lächerlichkeit erscheint. Böll verkörpert diesen Herrn in einer Hörerin mit dem bezeichnenden Namen Jadwiga Herchen, die vom Intendanten mit unverzüglichem Erfolg eine Sendung über die Hundeseele verlangt.

Neben das anstößige System des Funkhauses stellt Böll eine "Gegen-Hierarchie," die ohne Hackordnung auskommt und nur zwei Ebenen aufweist, den Bereich des Menschlichen und den des Göttlichen. Aus der Warte des Funkhauses gesehen ist das GegenKonzept bedeutungslos. Die Sphäre des Menschlichen ist die im Keller liegende, durch einen zweiten, im "rückwärtigen Flur" (180) liegenden Paternoster erreichbare Kantine. Dort bildet Wulla, die Kellnerin, den Mittelpunkt, ohne jedoch zu "herrschen." Hier sprechen selbst die systemhörigen Angestellten des Hauses ein verhältnismäßig aufrichtiges Wort miteinander. Hier ist die Kellnerin um das leibliche und auch psychische Wohl ihrer Gäste besorgt. Wullas Bereich liegt eigentlich außerhalb des Funkbetriebs. Böll verweist darauf, indem er ihr zwei Figuren außerhalb des Funks, wie Wulla einfache Frauen, zur Seite stellt. Da ist zum einen Murkes Mutter, die für ihn betet und ihm ein religiöses Bild schickt, zum anderen Murkes Freundin Rina, ein "einfaches, nettes, ruhiges Mädchen mit Herz" (182). Wie die Kantine rangiert auch Gott tief im Funkhaus. Man entfernt ihn aus Vorträgen, stückelt ihn in ein Hörspiel, je nach Geschmack und Bedarf. Eine als zu lang wirkende Pause in einem Atheistenstück verlangt eine Füllung. Man verfällt auf das Wort Gott als 
Lückenbüßer, unbesorgt darum, daß es die Tendenz des Hörspiels auf den Kopf stellt. Nur eine Geschmacksfrage ist im Funkhaus auch das Herz-Jesu-Bild, das Murke von seiner Mutter erhält. Man reagiert allein auf den Kitsch des Bildes, nicht aber auf den religiösen Gehalt. Der Nexus zwischen "Gott" und den drei Frauen ist deren gemeinsame Unwichtigkeit für die Hierarchie des Funks und auch ein Assoziationsmoment, das sich bei Böll immer wieder einstellt: Die Niedrigen und Machtlosen stehen Gott am nächsten.

Die Hierarchie des Funkhauses wird durch zahlreiche Details verdeutlicht. Die Gegen-Hierarchie bleibt im Assoziativ-Vagen, vornehmlich Metaphorischen und wird im Bereich des Funkhauses nicht zum wirklichen Machtfaktor. Obwohl nichts zur Schwächung des anstößigen Systems geleistet wird, alles beim alten bleibt, weil Murkes Geste des Widerstands so gut wie nichts erbringt, behält die Gegen-Hierarchie trotz aller Anstrengungen des Funks, sie zu übertönen, bildlich das letzte Wort. So wird "Gott" zur Antwort auf die eschatologischen Fragen des Atheisten im besagten Hörspiel. ${ }^{10} \mathrm{Im}$ letzten Satz der Erzählung spricht Murkes Mutter indirekt die Worte unter dem Herz-Jesu-Bild: "Ich betete für dich in Sankt Jacobi" (194).

Der potentiell dynamische Faktor zwischen den Bereichen ist Murke. Als Gestalt baut ihn Böll so auf, daß wir uns mit ihm als Störungselement des Rundfunks identifizieren, ja von ihm zerstörerisches Verhalten erhoffen. Er ist aggressiv, hochintelligent, liebenswürdig und kritikfähig, besitzt somit die nötigen Vorbedingungen zum Erfolg. Sie befähigen ihn zu einer leitenden Stellung oder auch zum Revolutionär. Als Leser erhoffen wir von ihm das letztere, nämlich den offenen Protest. Böll gibt seinem Helden deutlich eine humane Seite, z.B. in dessen Gefühl der Verbundenheit mit dem Techniker, der ihm beim Aufnehmen der Ersatzformel behilflich ist. Positiv ist auch $\mathrm{zu}$ bewerten, daß Murke vom falschen Schein des Funkbetriebes angewidert ist. Sein Oppositionsgeist macht sich auf eine witzige Art Luft, die unseren Beifall findet und die geschwätzige und hohle Professionalität eines Betriebes entlarvt, der für die Gesellschaft eine bewußtseinserhöhende Funktion haben könnte und sollte. Der leeren Wortproduktion ist das Schweigen vorzuziehen, das Murke eifrigst sammelt. Er schneidet Pausen aus besprochenen Tonbändern. Dieser glänzende Einfall Bölls genügt, Murke außergewöhnlich zu machen. Sein lustiges Hobby erlaubt uns, einen Erfolg $\mathrm{zu}$ ahnen. Murke scheint sich hier einen souveränen Abstand von seiner Arbeitswelt zu verschaffen, und wir sind nur zu willig, ihm eine innere Freiheit zu bescheinigen. Er macht sich über den allmächtigen Apparat, dem er dient, lustig und spricht uns allen aus dem Herzen. So ist er zweifellos eine Art Held, jedoch ein ambivalenter. 
Er ist letztlich ein Narr, der sich zwar spielerisch über die unleidlichen Gegebenheiten erhebt, aber dabei seine Ohnmacht oder sein Versagen gegenüber einer anstößigen, zu verändernden Wirklichkeit zeigt. Murke ist lächerlich, weil sein Schweigensammeln in Anbetracht des Ernstes der Umstände eine skurrile Fehlleistung ist. Meines Wissens hat allein Stefan Heym dies genau erkannt. Er lobt das Schweigen einerseits als dichterischen Einfall_-"Eine Erfindung wie das Schweigen, das der Dr. Murke sammelt, gelingt einem Schriftsteller nur selten" - anderseits warnt er vor falschem Verständnis: "Es wäre . . . verfehlt, zu glauben, Böll empfehle die Flucht des Doktor Murke in sein gesammeltes Schweigen als Rezept gegen das, was uns belastet und quält. . . . Im Gegenteil: Böll verlangt, daß gesprochen wird, laut und deutlich. . . ."11

Murkes Steckenpferd ist jedoch zu Anfang kein Indiz gegen ihn, sondern noch der witzige Einfall, für den wir es halten wollen. Es ist ein moralisch neutraler Akt, in dem sich Murkes kritische Intelligenz spielerisch äußert. Aus Spiel wird erst Ernst, wenn Murke in seinem Zusammentreffen mit Bur-Malottke Farbe bekennen muß. Nicht mehr das Schweigen im Spiel, sondern das Sprechen im Ernst ist die Forderung des Augenblicks. Hier sammelt Murke dem Titel der Satire entsprechend gewissermaßen sein eigenes Schweigen. Er kompromittiert sich. Das Schweigen ist nun ein inhumaner Akt. Das macht Böll völlig eindeutig in der Szene, wo Murke sich von seinem Auftritt mit Bur-Malottke bei seiner Freundin erholt. Er bringt sie zum "Beschweigen" (192) eines Bandes. Schon die erzwungene Transitivierung des Wortes zum Jargonhaften, als Gegenprägung zu "besprechen," deutet an, was inzwischen mit Murke geschehen ist. Nach all dem Geschwätz des Unmenschen Bur-Malottke sollte Murke jetzt ein menschliches Wort hören und reden. Aber Murke wünscht Schweigen und damit etwas, was Rina als erniedrigend empfindet: "[I]ch kann nicht mehr, es ist unmenschlich, was du verlangst. Es gibt Männer, die unsittliche Sachen von einem Mädchen verlangen, aber ich meine fast, was du von mir verlangst, wäre noch unsittlicher als die Sachen, die andere Männer von einem Mädchen verlangen." Um Rinas Protest zu unterbinden, stellt sich Murke selber als ausgenutzt hin. Er beteuert seine Abneigung gegen das Schneiden, das Rina ihm ersparen soll (191-92). Hier ist mehr als ein einfacher Überdruß an einem Arbeitsvorgang im Spiel. Es geht um Wesentliches in Murkes Zustand als Mensch. Zunächst bedeutete das Schneiden Abneigung gegen das Gerede im Funkhaus. Jetzt meint es die Verweigerung des echten Protestes. Schweigen zu schneiden steht Murke nicht mehr zu, er ist eingeordnet und sein Hobby ändert sich entsprechend. Er handelt jetzt nach dem Herrschaftsgesetz des Funks. 
Das ist vorderhand ein hartes Licht, das auf Murke fällt. Es ist aber nicht das einzige. Der später zu besprechende Aspekt des Komischen mildert es erheblich. Aber wie der Satiriker seine Figuren im Lachen dem letzten Ernst und der Tragik entziehen kann, so verlangt er von seinem Publikum, daß es den Ernst nicht unterschätzt. Wir dürfen mit dem Urteil über Murke nicht leichtfertig sein, obwohl oder gerade weil uns unsere Welt nicht viel Grund gibt, an den kompromißlosen Helden zu glauben. Wie kann man erwarten, so wollen wir uns wohl selbstbestätigend fragen, daß es einem Murke, kaum befähigter als Tausende andere, gelingen sollte, einen Apparat zu stören oder gar zu zerstören, der sich in seiner Reibungslosigkeit selbst bestätigt, und in dem Murke selber ein Funktionselement ist? Murke stünde als Vertreter für uns alle, ein vom System erfaßter Mensch, dem nur die Eigenheit des Witzes und die symbolische Störungsgeste bleibt. Unter diesen Aspekten der Resignation wäre Murke eine Spielart des Pikaro, der sich in die schnöde Welt, wie sie nun einmal ist und bleiben wird, einfügt und durch seinen Trickreichtum beim Überwasserbleiben erheitert. Aber diese literarische Zuordnung ist fehl am Platze. Den Pikaro würde das Gerede Bur-Malottkes nicht zu Haß bewegen, sondern nur belustigen. Der Pikaro gehört überdies nicht zur Kaste der Machtausübenden, er bleibt bei allen seinen Aufstiegsgelüsten ein bestenfalls am Rande des Establishments Geduldeter. Vor allem kennt er nicht die Angst, die den zum Aufsteiger bestimmten Murke so stark kennzeichnet. Böll verwendet das Wort Angst achtmal, fünfmal allein im Eingangsabschnitt, in dem von Murkes allmorgendlicher Rundfahrt im Paternoster, seiner "existentiellen Turnübung," die Rede ist. Das Nächstliegende zur Einordnung dieses "Angstfrühstücks" (173-74) findet sich in einer Stellungnahme Bölls zum Thema Christentum:

"In der Welt habt ihr Angst", hat Christus gesagt, "seid getrost, ich habe die Welt überwunden". Ich spüre, sehe und höre, merke so wenig davon, daß die Christen die Welt überwunden, von der Angst befreit hätten; von der Angst im Wirtschaftsdschungel, wo die Bestien lauern; von der Angst der Juden, der Angst der Neger, der Angst der Kinder, Kranken. ${ }^{12}$

Murkes Angst ist nur insofern die Furcht des Opfers, als er noch nicht endgültig in die Funkhierarchie eingereiht ist. Ihn kennzeichnet vornehmlich die Zugehörigkeit zu den Bestien im Wirtschaftsdschungel. Der Intendant ist ein "vitaler und gesunder Mann" (174), der sich seine "vitalen Lippen" (185) leckt. Böll setzt andernorts Vitalität mit Brutalität gleich (I, 410), und somit gehört auch der Intendant sicherlich zum Genus Raubtier. Er weiß darum gewissermaßen in- 
stinktiv, wie Murke einzustufen ist. Er sucht ihn aus und läßt ihn gegen Bur-Malottke antreten, weil er in ihm "eine intellektuelle Bestie" (175) sieht. Entgeht Murke seine morgendliche Tour, so ist er "gereizt und unzufrieden, wie Leute, die kein Frühstück gehabt haben. Er brauchte diese Angst, wie andere ihren Kaffee, ihren Haferbrei oder ihren Fruchtsaft brauchen" (173).

Murkes Angst ist also nur unter dem Gesichtspunkt der noch nicht verlorenen Unbescholtenheit in etwa mit der Lebensangst der Unterdrückten im christlichen Sinne gleichzusetzen. Hans Joachim Bernhard möchte die Angst im Frühwerk Bölls mit Recht nicht eingeengt sehen auf ein "existentialistisches Lebensgefühl schlechthin." ${ }^{13}$ Sie hat zweifellos mit den sozialen Umständen zu tun. Trotzdem bringt uns hier in "Dr. Murke" das Wort "existentialistisch" als Kennzeichnung der Turnübung Murkes weiter. Demnach wäre Murkes Angst in Hinsicht auf seinen Eintritt in das System des Funkhauses als der Zustand zu bestimmen, den Kierkegaard mit dem Prozeß der menschlichen Bewußtwerdung verbindet. Er liegt im Moralischen und meint die in Abneigung und Verlangen erwartete ursprüngliche Entscheidung der Person für Gut oder Böse. ${ }^{14}$

So gesehen sind Murkes Paternosterfahrten symbolisch-psychologische Darstellung des Aufsteigers im Herrschaftssystem. Das Paternosterbild verweist auf beides, das Anziehende wie das AbstoBende in der Wahl. Der Aufzug steigt einmal, im übertragenen Sinne, zum Gipfel der Macht, aber im Steigen ist schon das Fallen vorweggenommen. Der Weg zum Erfolg bedeutet einen Verlust an Menschlichkeit, wie der äußere Weg zudem von der Höhe der Macht unabänderlich nach unten gehen muß. Murkes Aufstieg zielt im hierarchischen Sinne auf Bur-Malottkes Abstieg. Das Schema sagt auch Murkes Ende voraus. Gelangt er zur Spitze der Macht im Funkhaus, so wird ihm ebenfalls über kurz oder lang eine Art Herausforderer auf den Leib rücken. Bezeichnenderweise verspürt Murke die größte Angst, wenn seine Kabine den höchsten Punkt des Fahrtkreises erreicht: "Murke wußte, daß seine Angst unbegründet war: selbstverständlich würde nie etwas passieren, es konnte gar nichts passieren, und wenn etwas passierte, würde er im schlimmsten Falle gerade oben sein, wenn der Aufzug zum Stillstand kam, und würde eine Stunde, höchstens zwei dort oben eingesperrt sein" (173). Es handelt sich also hier klar um Psychologisches und um Symbolisches: Der Höhepunkt der Macht ist gleichzeitig der Zustand größter Einsamkeit und Ohnmacht im Menschlichen. Bur-Malottke führt dafür den Beweis in der Aufnahmekabine. Allmächtiger Herrscher ist er im Funkhaus, doch impotent, wenn er auf menschliche Regungen seiner Untergebenen angewiesen ist. Der Mechanismus des Funkhauses ist gnadenlos und 
roh. Für Murke tritt er psychologisch, für den Leser symbolisch zutage, wenn Murke auf dem Gipfelpunkt seiner Paternosterfahrt ist: "[J]edesmal befiel ihn Angst, wenn die Plattform der Aufzugskabine sich ... knirschend in den Leerraum schob, wo geölte Ketten, mit Fett beschmierte Stangen, ächzendes Eisenwerk die Kabine aus der Aufwärts- in die Abwärtsrichtung schoben, und Murke starrte voller Angst auf diese einzige unverputzte Stelle des Funkhauses" ... (173). Hier oben zeigt sich, um im Bild zu bleiben, das Prinzip des sonst überall "aalglatten Scheißkastens" (188) im Rohbau.

Murkes Alpträume ergänzen das Bild des Paternosteraufzugs. In einem der Träume steht der Intendant am Fuß einer Treppe, "so hoch und so steil . . . wie der Eiffelturm" und ruft, "'Los, Murke, los . . . [sic] zeigen Sie, was Sie können. ...'” Murke beginnt zu steigen, merkt aber bald, daß die Treppe mit Seife eingeschmiert ist. In dem anderen Traum geht er "ahnungslos" zu einer Rutschbahn, bezahlt seine dreißig Pfennig an einen Mann, in dem er später den Intendanten erkennt, und muß plötzlich feststellen, daß die Bahn "mindestens zehn Kilometer lang war . . . daß es keinen Weg zurück gab." Die Verwandtschaft dieser Träume zur Paternosterfahrt liegt auf der Hand. So braucht Murke am Morgen nach diesen Träumen sein "Angstfrühstück oben im Leerraum des Paternosters nicht mehr" (175). ${ }^{15}$

\section{Handlungsstruktur und Mythus}

Die inhaltsbezogene Analyse läßt sich nun auf Formelles zielend zusammenfassen. Zwei sich gegenseitig ausschließende Modelle sozialer Grundstrukturen haben sich abgezeichnet. Das eine ist mit hohem Realitätsgehalt ausgeführt, hierarchisch gestaffelt nach dem Prinzip der Beherrschung und Unterwerfung und darum anstößig; das andere ist nur andeutungsweise entworfen, aber deutlich in der Vorstellung vorhanden und verlangt nach Verwirklichung auf Kosten seines inhumanen Gegenstücks. Zwischen den Vertretern dieser Modelle besteht nur einseitig eine humane Verbindung. Für den Funk sind Murkes Mutter, seine Freundin und die Kellnerin abseitsstehende und unbedeutsame Größen. Von den drei Frauen hingegen geht ein persönliches Interesse für die Sphäre des Funkhauses aus, d.h. nicht für den Betrieb, sondern für die Menschen. Murke steht zwischen den Bereichen und damit im Schnittpunkt der Handlungsstruktur. Von ihm ließe sich der Änsatz zu einer fruchtbaren Dialektik der Felder erwarten. Er gehört einerseits zum Betrieb, hat andererseits 
aber ein Gefühl für die Dinge im Funkhaus wie sie sind und wie sie, ideal gesehen, sein sollten und steht darum schon den Frauen nahe. Es könnte von ihm der Impuls zum Abbau des hierarchischen Modells, zum Aufbau des Gegen-Modells ausgehen. Murke wäre der Sachwalter einer Welt echten Menschentums in der inhumanen Welt seiner Arbeitsstelle, einer mächtigen und verwurzelten, aber unfruchtbaren Konventionssphäre. Er ist für den Leser ein berechtigter und persönlich mit den notwendigen Eigenschaften versehener Herausforderer. Die Verwaltungsspitze erkennt ihn als Gefahr, selbst der "vitale" Intendant fühlt sich durch ihn verunsichert: "[E]r hatte ihn zwar sofort engagiert, als man es ihm vorschlug, er hatte ihn engagiert, so wie ein Zoodirektor, dessen Liebe eigentlich den Kaninchen und Rehen gehört, natürlich auch Raubtiere anschafft, weil in einen Zoo eben Raubtiere gehören . . ." (174-75). Dem Leser drängt sich jedoch nicht das Bild des Raubtiers, sondern das eines Davids auf, der, besonders im Hinblick auf Bur-Malottke, einen Goliath in die Schranken fordert. Wir setzen Hoffnung auf ihn, einen anstößigen Zustand abzuschaffen und dem Bereich, den er vertritt, zum Siege zu verhelfen.

Zweifellos ist dieses Schema ein archetypisches. Es ist als das Grundmuster sozialförderlichen Verhaltens in einer Welt zu bezeichnen, in der Idealität und Realität auseinanderklaffen, die Machtinstanzen jedoch trotz aller Offensichtlichkeit des Gegenteils vorgeben, das Ideale zu vertreten. In seiner dichtesten und suggestionskräftigsten Form ist es der Mythus des Helden. Der Held, der, das Neue und Vielversprechende darstellend, sich dem Alten und Überholten widersetzt, ist literarisch gerade dann höchst geeignet, wenn die Beseitigung des Alten geradezu ein Auftrag der Wirklichkeit ist. Ohne Vorbehalt läßt sich das für die der Bundesrepublik der fünfziger Jahre behaupten. Diese Jahre sind im Abriß eine Zeit, in der sich die Nachkriegshoffnungen einer nationalen Besinnung in Anbetracht reaktionärer Entwicklungen verflüchtigen. Das Ahlener Programm von 1947, in dem sich selbst die CDU zu einer sozial gerechteren Neuordnung bekennt, ist vergessen, die Bundesrepublik wird in das Netz der Konfrontationen zwischen West und Ost eingespannt und zum Vorposten in John Foster Dulles' Strategie der "Brinksmanship." Führungskräfte des Nazistaates werden zu Spitzenkräften der Politik und Industrie. Die Reaktion auf den verlorenen Krieg ist vor allem ein Besitzstreben, zu dessen Erklärung die Kompensation für kriegsbedingten Mangel nicht ausreicht. Die "Schmach" des verlorenen Krieges wird wettgemacht im erfolgreichen Kampf auf dem Feld der Ökonomie. Der Gegner ist nicht nur das Ausland, sondern der Mit- 
bürger. Im Kampf eines jeden gegen jeden ist das symbolische Objekt der Vernichtung die Ware, sei diese etwa ein Automobil oder eine Rundfunksendung. Das Gebot ist der Verbrauch. Da die Ware gleichzeitig Besitz bedeutet, ist sozialökonomische Leistung gleichbedeutend mit der Vernichtung gerade dessen, was die Grundlage der Werte der Gesellschaft bildet. Besitzerwerb und Verbrauch sind damit Formen der Zerstörung des Menschen. Mensch und Ware werden zu ein und demselben im Verbraucher. Darin liegt die Einigkeit einer "pluralistischen" Gesellschaft, in der die Unterscheidung zwischen CDU und SPD, Staat und Kirche sich verwischt. Zeigt diese Skizze ein tristes Bild, so entspricht sie im wesentlichen der Sicht einer Intellektuellengeneration, für die Böll in den fünfziger Jahren als repräsentativ bezeichnet werden kann. Sie ist jung genug, an das Neue zu glauben, und alt genug, die Gefahren der Restauration zu erkennen und zu fürchten. Die Zeit bedeutet für Böll eine Welt der Angst: “. . . Angst im Wirtschaftsdschungel, wo die Bestien lauern. . . . die Angst vor dem Leben und den Menschen, vor den Mächten und Umständen . . . Angst vor dem Krieg." 16

Als Antwort auf diese Entwicklungen eröffnet der Satiriker Böll durch die Zentralstellung der Herausfordererkonstellation eine Sicht der Radikalität, die Hans Werner Richter 1946 als das Gebot der Nachkriegssituation bezeichnet: "[A]us der Gewalt der Erlebnisse, die der jungen Generation zuteil wurden und die sie erschütterten, erscheint ihr heute die einzige Ausgangsmöglichkeit einer geistigen Wiedergeburt in dem absoluten und radikalen Beginn von vorn zu liegen." ${ }^{17}$ Diese Forderungen haben in den fünfziger Jahren eine um so erschreckendere Eindringlichkeit, als sie im Rückspiegel einer schon weitgehend versäumten Chance erscheinen.

Im archetypischen Handlungsgefüge der Herausforderung, die den epiphanischen Punkt bildet, wo sich Wirklichkeit einerseits und personifiziertes Ideal andererseits treffen, liegt die Brücke zur Sichtbarmachung der Struktur des hier untersuchten Textes. Bestimmend in Murke als Figur ist seine Ausnahmestellung, seine Einmaligkeit. Der Intendant denkt spontan an ihn, wenn es gilt, jemand gegen BurMalottke zu schicken. Zur Überprüfung seiner ersten Eingebung mustert er in Gedanken anderes Personal, findet sich aber bestätigt: Murke ist der rechte Mann; er allein ist der potentielle Kämpfer, der gegen einen Bur-Malottke, welcher selbst dem Intendanten über den Kopf gewachsen ist, vorgehen kann. So unterschätzt ihn Dieter E. Zimmer, indem er nicht zwischen Murkes Fähigkeiten und seiner Leistung unterscheidet: "Doktor Murke-das ist der Typ des kleinen Diversanten, der Böll schon immer lieb war. . . Sie machen mit, 
weil sie keine andere Wahl haben; aber wo die Mitwirkung ganz zu verweigern ihnen nicht freisteht, verweigern sie wenigstens ihre Approbation. Sie sind Störfaktoren, wo etwas zu gut und unbezweifelt funktioniert." ${ }^{18}$ Murke hat sowohl die Gaben wie auch die Wahl, mehr als nur ein Störenfried im Funkhaus zu sein. Es drängt sich darum geradezu die Vorstellung eines gegen den Riesen vorgehenden Davids auf. Dieses Bild ist sämtlichen satirischen Herausforderern der fünfziger Jahre gemäß und gibt auch deren Größenordnung an. Potentielle Helden sind sie zwar, aber keine Heroen. Siegfried Lenz erkennt diesen Kern. Bölls kleine Leute sind ihm klein in "einem außerordentlich protesthaften Sinn." ${ }^{19}$ Sie erscheinen keineswegs hoch zu Roß, sondern agieren trotz ihres Anspruchs bisweilen in einem winzigen Raum, wie etwa der Familie oder dem Hundesteueramt. Trotzdem läßt sich auch im Kleinen und Privaten die archetypische Situation nicht verleugnen. Sie meint aber nicht eine der "Privatmythen," die Hans Mayer beim späteren Böll-wie in der Lamm-Büffel-Verklammerung in Billard um halb zehn-rügt, sondern ist Merkmal des "früheren" und "genuinen" Schaffens. Was Mayer in bezug auf die früheren Romane feststellt, ist durchaus auf die Kurzsatire der fünfziger Jahre übertragbar. Auch sie ist Erzählkunst, "die auf ihrem Höhepunkt-wie bei aller potenten Erzählkunst von Goethe bis Thomas Mann, von Stendhal bis Proust-unversehens aus dem Alltäglichen ins Mythische hinüberführte." 20

Gleichwohl, das Mythische bei Böll als Heldenmythus festzulegen, mutet auf den ersten Blick wie eine Unterstellung an. Man würde zunächst eher James Henderson Reids Fazit, "Böll does not believe in heroes," akzeptieren wollen. ${ }^{21}$ Besonders gilt das im Hinblick auf die leidenden "Helden" des Krieges. In der Rede "Heldengedenktag" (1957) heißt es:

Waren sie alle Helden, die in den Stellungen, in Lazaretten, auf Fluren, in Kellern, auf Lastwagen und Bauernkarren, in Eisenbahnwaggons schrien und beteten, fluchten oder auf eine Weise still wurden, die der Verachtung gleichkam?

Ich glaube, die meisten hätten diesen Titel, der als Ehre gedacht ist, nicht angenommen, hätten sie von den Morden gewußt, die unter dem Zeichen geschahen, unter dem sie starben. Wir können sie nur würdigen, wenn wir sie vom Fluch dieses Zeichens befreien. . . . Nicht von einem einzigen von ihnen wissen wir, welche Räume er im Angesicht des Todes durcheilte, die Worte schuldig oder unschuldig gehören unserer Welt an, der Tod einer anderen. 
Offensichtlich entwickelt Böll hier ein Indiz gegen ein ins Böse verfälschtes Heldentum. Daß er jedoch an der Kategorie des Heldischen festhält, wird klar, wenn er fortfährt:

Das Wort Held setzt ein anderes Wort voraus: Aktion. Helden handeln, opfern sich auf eigenen Entschluß für eine Idee, eine Sache, sie werden hingerichtet oder ermordet, sterben unter den Schüssen eines Pelotons und rufen der Nachwelt zu: Freiheit. Überlebende Helden halten nie, was sie im Augenblick der Heldentat versprachen. Der Glanz des Augenblickes, der Ruhm der Tat erlischt (ESR1, 219-20).

Böll unterscheidet hier zwischen Hypothese und Aktualisierung. Die Heldenkategorie ist ihm hypothetisch gültig und intakt. ${ }^{22}$

Steht der Herausforderer Murke schon im Mittelpunkt eines archetypischen Gefüges, so keinesfalls in einem Sinne, der den Heldenmythus ausfüllt. Murke ist nicht etwa der Held eines Heldenepos, der Romanze oder des Märchens, sondern das Produkt satirischer Prägung. Satirische Prägung-und demnach Satire-wird hier verstanden als Ausdruck einer "Empfindungsweise," wie Schiller formuliert, ${ }^{23}$ oder als "Ton," wie Jörg Schönert-in Anlehnung an Friedrich Sengles Begriff des Tons-und Paulson satirische Schreibart begreifen. ${ }^{24}$ Der satirische Ton läßt sich bestimmen als aggressiv reflektierter Widerwillen gegen eine empörende Gegenwart. Bei Böll äußert er sich in den gemischten Stimmlagen des Elegischen und Komischen. Bei generischen Unterscheidungen, die auf Empfindungsweisen beruhen, liegen Kategorien wie etwa Kurzgeschichte oder Roman abseits. Stellenwerte auf der Skala der Töne sind Termini wie idyllisch, elegisch, parabolisch, komisch und tragisch. Konsonant mit gewohnten Gattungsbezeichnungen sind vor allem die komischen, tragischen und lyrischen Empfindungsweisen. Je extensiver oder intensiver der jeweilige Ton vernehmbar ist, desto zutreffender wäre es, als hauptsächliches Formmerkmal jeweils Bezeichnungen wie Idylle, Elegie, Parabel oder Satire zu verwenden. Die Bezeichnungen Roman für Ansichten eines Clowns, oder Kurzgeschichte für "Dr. Murke" verweisen demnach auf sekundäre Zuordnungen.

In "Dr. Murke," wie in allen Kurzsatiren der fünfziger Jahre, schlägt sich der satirische Ton Bölls am deutlichsten nieder in der "Tönung" des Herausforderergefüges. Murke, und darin liegt seine Prägung aus satirischer Empfindungsweise, wird als satirischer Held zwar am Heldenarchetypus gemessen, dessen Konstellation Böll klar ausleuchtet, aber die Erwartungen, die diese Konstellation hervorruft, werden von der Person enttäuscht. Murke wird zum Versager verzeichnet. Die unverwirklichte Norm des Heldischen ist Eigenart der Satire. 
Sofern sie nicht die simple Konfrontationsstruktur des Fluchs oder der Parodie hat, ist für Paulson ihr Merkmal eine Fiktion, "in which a villain combats a hero, with the impression emergent that evil is either the victor or simply more prevalent. . . ." ${ }^{25}$ Böll selber bestätigt diese Ohnmacht. Er redet vom sozial aggressiven Autor und dessen Wirkung, spricht aber damit auch das Urteil über seine Herausfordererfiguren: "[F]ür einen Stein, der Goliaths Stirn gestreift haben könnte, kommt es aus hundert Schrotflinten zurück ..." (ESR2, 35).

Um die Regel des Versagens und gleicherweise die strukturprägende Funktion des Herausfordererkomplexes eingehender zu verdeutlichen, muß auf Frye, den einflußreichsten Theoretiker der Satire im angelsächsischen Raum verwiesen werden. ${ }^{26} \mathrm{Er}$ setzt sich mit den Varianten des Helden in der Literatur auseinander, und zwar im Rahmen eines übergreifenden Schemas: Menschliche, mit dem Rhythmus der Natur gekoppelte Urerfahrungen prägen die Literatur "generisch." So spricht Frye von vier "Mythoi," dem "Mythus" des Frühlings als Raum der Komödie, des Sommers als dem der Romanze, des Herbstes als dem der Tragödie und des Winters als dem Bereich der Satire. Kennzeichen der Satire ist "Sparagmos oder das Empfinden, daß Heldentum und Tatkraft nicht vorhanden oder wenigstens desorganisiert und zum Niedergang verurteilt sind und daß vielmehr Verwirrung und Anarchie in der Welt vorherrschen. . .." ${ }^{27}$ Ein Mythus im Sinne Fryes ist somit Strukturprinzip für Archetypen, d.h. Wunsch- und Schreckbilder. Die Heldenkonfiguration ist beispielsweise im Sommermythus, den Hoffnung und Gewinn bestimmen, im wesentlichen realisiertes Wunschbild, im Wintermythus, den Bedrückung und Empörung, also satirische Empfindungsweise kennzeichnet, hingegen realisiertes Schreckbild. Wichtig ist vorderhand, daß nur Sparagmos unter den vier Mythusthemen dem Plot keine Lösung erlaubt. Filtriert man die generischen Profile der Helden aus Fryes vier Mythuskreisen heraus, so sind sie im Abriß diese: Der Held der Komödie (Frühlingsmythus) löst sich aus den Intrigen im Sinne einer aufsteigenden Erfolgslinie. Die neue Gesellschaft zeigt sich in Umrissen und der Anspruch des Helden bestätigt sich. Der Held der Romanze (Sommermythus) ist der gesteigerte, ins Numinöse übergehende Held der Frühlingsmythe. Statt sich in komische Intrigen zu verwickeln, kämpft er gegen wichtige Riesen oder Drachen und sichert das in der Frühlingsmythe Gewonnene ab. Stirbt er, so ist er erhöht. Der Anspruch des Helden der Tragödie (Herbstmythus) ist gerechtfertigt, aber Gewalten, die ein mysteriöses, übermenschliches Bezugssystem vertreten, setzen den Anspruch des Helden außer Kraft, vereiteln den Triumph und führen den Helden in die Katastrophe. Er bleibt jedoch erhöht. Seine äußere Erfolgslinie 
sinkt, seine innere jedoch nicht. Für den Helden der Satire gibt es keine Erhöhung.

Bölls Satiremuster der fünfziger Jahre fügt sich in diesen archetypischen Plot. Die Erscheinungsform des Helden ist das David-Bild. Es entspricht Bölls bevorzugtem Heldenmaß, das er in hierarchisch Tiefstehenden findet. Er ist "Autor der kleinen Leute," weil er das Große am ehesten unter diesen $\mathrm{zu}$ finden glaubt (ESR2, 39). In seinem spezifischen Bild des satirischen Herausforderers-Böll hat sich als sozial-kritischer Autor auch selber als David gesehen (ESR 1 , 596) - schließt er sich einer Prägung des Heldischen an, die als die eigentlichste der Satire überhaupt gelten muß. Für Frye sind deren Antagonisten "ein Goliath, dem ein winziger David mit seinen widerlich schmerzhaft treffenden Steinen begegnet, ein Riese, den ein kalt beobachtender, aber fast unsichtbarer Gegner zur weißglühenden Raserei bringt. . . ." ${ }^{28}$ Es muß festgehalten werden, daß der satirische David seinen Widerpart, sofern dieser das gesamte Objekt vertritt, keineswegs zur Strecke bringt. $\mathrm{Zu}$ den wesentlichen Kennzeichen der Satire gehört nach Frye das "Verschwinden des Heldischen." ${ }^{29}$ In Grass' Die Blechtrommel wird das wunderbare Kind Oskar zum Gnom, in Swifts Gulliver's Travels der wagemutige Abenteurer Gulliver zum im Pferdestall hausenden Narren (gull= Narr), in Heines Deutschland. Ein Wintermärchen der heldische Sprecher in einer seiner Angstvorstellungen zum Eunuchen.

Ist der Versager Schreckbild der Satire, so geht es nach Frye in der Dichtung ebenfalls um das Gestalten von Wunschbildern. Sind diese in der Satire schon sehr beschränkt, so erscheint nichtsdestoweniger im Schattenriß hinter dem Versager sein Gegenbild, der Satiriker selber. Sparagmos, das Empfinden des fehlenden Heldentums kennzeichnet zwar die satirische Szene, nicht aber das Tun des Satirikers. Er ist als der eigentliche Held der Satire zu sehen, der ästhetisch siegt und der den Goliath, um Fryes Bild in dessen eigenen Worten zu vervollständigen, "nach Belieben erledigt." " Hier berührt sich Fryes Konzept mit dem Schillers der Satire als "Empfindungsweise." Diese meint Aggression im Satiriker. Selbst Schiller räumt ein, daß dessen Seele nicht frei von "Bitterkeit" ist. Die Aggressivität des Satirikers ist jedoch hauptsächlich als Reaktion zu verstehen. So schon rechtfertigt sie Juvenal (Satire I). Für Schiller ist sie Folge einer Spannung, die sich zwanglos auf die Dialektik der Bilder, von denen Frye spricht, übertragen läßt. Nach Schiller geht die Satire bekanntlich aus dem Zwiespalt von Ideal und Wirklichkeit hervor: "Die Wirklichkeit ist also hier ein nothwendiges Objekt der Abneigung, aber worauf hier alles ankömmt, diese Abneigung selbst muß wieder nothwendig aus dem entgegenstehenden Ideale entspringen." ${ }^{31}$ Pope beleuchtet die 
satirische Dialektik deutlicher noch als Funktion einer Empfindungsweise und verleiht ihr dazu Gewicht als praktizierender Satiriker: "Ask you what Provocation I have had? / The strong Antipathy of Good to Bad." 32 Die satirische Antipathie kann sich nach Schiller "scherzhaft" oder "ernsthaft" äußern. In beiden Fällen mißt sie "den Widerspruch der Wirklichkeit mit dem Ideale," 33 oder im Sinne Fryes, das Schreckbild am Wunschbild.

Inwieweit der Satiriker als Teil des Wunschbildes zu begreifen ist, hat Samuel Butler am treffendsten erkannt. Der Satiriker ist der Held, "a kinde of Knight Errant that goe's upon Adventures, to Relieve the Distressed Damsel Virtue, and Redeeme Honor out of Inchanted Castles, And opprest Truth, and Reason out of the Captivity of Gyants or Magitians." ${ }^{34}$ Dieses archetypische Bild hat erstaunlicherweise sogar ein Quantum geschichtlicher Wahrscheinlichkeit. Die Forschung gibt Butler recht, insofern als der Ur-Satiriker bisweilen im physischen Sinn Kämpfer war, und zwar mit dem Wort. Wie Elliott ausführt, nahmen keltische Satiriker an Schlachten teil, in denen sie den Feind durch die Macht ihrer Flüche überwanden. ${ }^{35}$ Der Satiriker als Held und Wortmagier bemüht sich um Neuerung in der von ihm dargestellten Welt. Er leistet dies durch die fiktionale Vernichtung des Feindes. Held ist er zumal, weil er seine Aggressivität am Ideal, oder weniger streng gesagt, an ausdrücklichen oder angedeuteten sozialförderlichen Normen mißt.

\section{Subjekt- und Objektsphäre; Normen; Dialektik}

Wenn Zimmer das Schweigen Murkes eine "ganz ins Private zurückgenommene Rebellion" nennt, so liegt darin eine Beschönigung des Sachverhalts. Gerade im Privaten gebührt Murke kein Lorbeer. Die privateste Szene ist die, wo er seine Freundin zum "Beschweigen" eines Bandes bewegt, und gerade hier unterstreicht Böll den Verlust an Menschlichkeit. Ungeachtet dessen kommt Zimmer Murke sehr weit entgegen. Die Rebellion verändert "nichts, sie hat auch keine Absicht, zu verändern, sie entwirft keine Gegenbilder. Ihr Gehalt ist der Widerspruch. Ein fast stummes, aber hartnäckiges Nein; aber es hält einen großen Argwohn wach." ${ }^{36}$ Hier biegt Zimmer das Versagen Murkes um zu einem Triumph. Das Schweigen verwandelt sich merkwürdigerweise zu Widerspruch. Die Rebellion, die hier gelobt wird, ist der totale Rückzug, und Böll wird dabei unter der Hand zum affirmierenden Satiriker.

Man kann Zimmer überdies nicht folgen, wenn er keine "Gegenbilder" wahrnimmt. Böll befürwortet einen im Text selber angelegten 
Bereich des Positiven, die Subjektsphäre. Der Satiriker stützt und vertritt diese, verzeichnet und bekämpft ihr Gegenstück, die Objektsphäre. Mittels ebenfalls im Text angelegter Normen, d.h. sozialer Wertvorstellungen, läßt sich die Zugehörigkeit des Personals zur Subjekt- oder Objektsphäre überprüfen. Das satirische Objekt ist die Objektsphäre als Konzept. Die Ermittlung der Normen geht der genauen Erfassung des Objekts voraus. In der fiktionalisierenden Satire sind Normen vorwiegend versteckt angelegt. Der Satiriker predigt nicht, sondern überzeugt mit ästhetischen Mitteln. So sind Fragen nach der Norm immer auch ästhetische, also Form- und Strukturfragen.

Wie immer man die Satire angehen mag, kann man nicht daran vorbeisehen, daß sie dialektisch ist. Darauf verweist besonders die Satire mit ausdrücklichem Konfliktgehalt zwischen Held und Unhold. Neues steht gegen Altes und verlangt nach Raum, jedoch letztlich ohne Erfolg. Nach Alvin B. Kernan läßt sich sogar eine Verschlimmerungstendenz des Zustandes feststellen: "Whenever satire does have a plot which eventuates in a change, it is not a true change but simply intensification of the original condition." 37 Wenn Astrid Swift darüberhinaus behauptet, daß die Satire die "Unwandelbarkeit, Unheilbarkeit der dargelegten Malaise impliziert," ${ }^{38}$ so gilt das für die fiktionale, nicht aber gemeinte Wirklichkeit. Denn diese muß als wandelbar angesehen werden, schon um den aggressiven Ton der Satire zu rechtfertigen. Zu spotten oder zu strafen, wo sich nichts ändern läßt, wäre verfehlt. Der gemäße und vorwiegende Ton müßte dann elegisch, Resignation die Haltung des Satirikers sein. Eben weil dieser jedoch nicht resigniert, steigert er die Malaise, stellt sie sogar als unheilbar dar, so daß ihm um so mehr Anlaß gegeben ist, gleichermaßen seine Fähigkeiten in der Normerstellung zu erweisen. Er treibt die Krankheit bis zum Endpunkt, wo sie sich selbst aufhebt. Dialektisch läßt sich sein Amt so formulieren: In der Durchleuchtung des Alten erscheint das Neue, und in der Sichtbarmachung des Neuen erscheint das Alte überholt.

Die Malaise des Funkhauses, die finsteren Zeiten, in die es gefallen ist, wie auch deren Überwindung werden im nächsten Auftrag des soeben eingereihten Murke augenscheinlich:

"Sie wissen doch, daß wir jetzt anfangen müssen, an das Winterprogramm zu denken. Ich brauche Schneelieder, Schneegeschichten-wir können doch nicht immer und ewig auf Schubert und Stifter herumhocken.-Kein Mensch scheint $\mathrm{zu}$ ahnen, wie sehr es uns gerade an Schneeliedern und Schneegeschichten fehlt. Stellen Sie sich einmal vor, wenn es einen 
harten und langen Winter mit viel Schnee und Kälte gibt: wo nehmen wir unsere Schneesendungen her. Lassen Sie sich irgend etwas Schneeiges einfallen" (192).

Die Namen Schubert und Stifter sind der Schlüssel. Für das Funkhaus sind sie überholt, verweisen aber auf eine Dialektik der Erneuerung. Die fraglichen Werke sind zweifellos Schuberts Winterreise und Stifters "Bergkristall" mit dem Grundton der Melancholie im ersteren, der Hoffnung im letzteren. Die Dialektik der Erneuerung, die sich im Funkhaus nicht findet, wird vom Satiriker hergestellt. Er ist, in einem Bild Paulsons, "purifier and savior," er bringt "fertility to the wasteland." 39

Sofern die satirische Szene einen Herausforderer einschließt, so ist die Dialektik auch in ihm angelegt. Der Satiriker erhöht und erniedrigt ihn gleicherweise. Um diese Manipulation der Person als konstruktive Aggressivität zu erhärten, führt Böll deren Gegenstück, ein Beispiel negativer Dialektik vor. Wenn Murke und Bur-Malottke im Studio aneinandergeraten, führt er uns beide in der Doppelperspektive des Siegers und gleichzeitig des Unterlegenen vor. Er stattet sie beide mit einem Plus- wie auch einem Minuszeichen aus, die sich gegenseitig auslöschen. Bur-Malottke ist der stärkste Mann im Funkhaus. Trotzdem setzt ihm Murke bei der Aufnahme derart peinlich zu, daß Bur-Malottke deutlich als Verlierer das Feld verläßt. Aber der Sieger Murke ist nichtsdestoweniger ein Feigling, und dazu noch ein Schwächling, der einem Bur-Malottke, der gewissermaßen in der Aufnahmekabine im Käfig sitzt, durch die Stäbe hindurch Stiche verabfolgt, die alles andere als tödlich sind. Er ist seinem Feind willfährig in dessen überheblichem Projekt des Wörtertauschs. Im dialektischen Kalkül sind letztlich beide Befehlserteiler und -empfänger. Murke erteilt seine Befehle dazu mit unterwürfiger Geste. In dieser Anordnung heben sich die Gegengrößen auf, doch nicht im Sinne des Kampfes, sondern des Antagonismus. In ihrem Haß sind Murke und Bur-Malottke falsche Gegner. Ihre Konfrontation erweist den Kampf an sich durchaus als rechtmäßig, denn sie führt den Leser zum Abzug gerade jenes Elements, das die Gegnerschaft als anstößig statisch, die Dialektik als negativ ausweist. Nicht Kampf, sondern dieser $\mathrm{Haß}$ ad personam ist die falsche Sozialisierung der Aggressivität. Er ist insofern hier eine unfruchtbare Emotion, als er das richtige Ziel verfehlt; er verzettelt sich vollauf an der Person und läßt unangetastet, was sie vertritt.

Im Anschluß an diese Szene führt Böll vor, daß sich Aggressivität durchaus an der Person auslassen kann, ohne diese zu verletzen. Die Abteilung Unterhaltung ist im Studio zur Aufnahme. Auch jetzt kon- 
frontiert man einander, aber unter den Vorzeichen der Offenheit und eines allerdings sehr drastischen Humors: "Drinnen sang die rothaarige junge Frau: 'Nimm meine Lippen, so wie sie sind, und sie sind schön.' Huglieme schaltete sich ein und sagte ruhig ins Mikrofon: 'Halt doch bitte noch für zwanzig Sekunden die Fresse, ich bin noch nicht ganz soweit.' Die junge Frau lachte, schürzte den Mund und sagte: 'Du schwules Kamel'" (180). Von Haß findet sich keine Spur. Auch gibt Böll den Personen keinen hierarchischen Stellenwert. Anhand der Abteilung Unterhaltung drängt der Satiriker die Leute des Kulturworts noch endgültiger in die Objektsphäre. Zwar reibt sich seine ästhetische Aggressivität an der Person, aber vor allem eröffnet und vernichtet sie relativierend das Prinzip, nach dem Murke und sein Chef handeln. Der Mechanismus von Beherrschung und Unterwerfung ist unmenschlich, ja animalisch, er ist das Gesetz des Zoos, in dem sich der Intendant wähnt. Zerfällt dieses Prinzip durch die Anstrengungen des Satirikers als unerbittlicher Kämpfer im ästhetischen Raum, so wird er der "absoluten" oder "hohen" Norm der Satire gerecht. Als Sieger ist ihm jedoch eine zweite Norm möglich. Sie ist gewissermaßen die Gnade des Überlegenen, der das Böse ausgeschaltet hat und nunmehr Leben und Lebenlassen erlauben kann. Dem Leser eröffnet sich diese Norm bei Böll vornehmlich im Prisma des Humors, meint aber eigentlich die ganze Stilleistung, jetzt als Spiel mit Fiktionen, nicht, wie der Heldennorm gemäß, als fiktionale Vernichtung des Feindes gesehen. In der zweiten Norm ist darum das Wie des Kampfes wichtiger als dessen Zweck. Die moralische Perspektive erweitert sich vom engen Entweder-Oder eines hohen Siegens und Verlierens zum Horizont der Erfahrungswelt mit ihren Relativierungen der Werte, wie dies schon an der Abteilung Unterhaltung wahrzunehmen war. Diese niedrigere Norm bemüht sich nicht um das Hypothetische, sondern um das, was jedem Menschen guten Willens möglich ist. Sie bezweckt nicht das grundlegend Neue, sondern ein Beweglichmachen der Dinge, den Abbau der Verhärtungen des Lebens, die Auflösung von erstarrten Konventionen. Sie läßt sich formulieren als "Norm des rechten Lebensflusses" und gehört zu den ältesten Wertungsperspektiven der Satire. Sie liegt schon Lukians Verkauf der Philosophen zugrunde. Nichtsdestoweniger ist sie modern in dem von Helmut Arntzen geforderten Sinne. Sie entzieht die Dinge dem Zwang der Ideologie, der "bloßen Behauptung von Verbindlichem." 40

In der Perspektive der niederen Norm verübeln wir Murke nicht, daß er Bur-Malottke nicht auf Biegen und Brechen angreift, sondern ihm mit Vorsicht auf den Leib rückt. In Anbetracht des Risikos, das die Erfahrungswelt diktiert, verhält sich Murke zwar nicht helden- 
haft, aber er leistet etwas, wennschon nicht in idealer Weise. In dieser Sicht ist Murke nicht der ernste Versager, der Fokus verschiebt sich auf das Wie der Leistung. Murke erscheint als leichtgewichtiger Pfuscher, der seinen Auftrag "vermurkst." Er verwechselt Falsches mit Richtigem, sammelt ostentativ Schweigen, statt zu reden und verwechselt Moralisches mit Ästhetischem in dem Glanzbild, das seine Mutter ihm schickt. Es dünkt ihn ein Protest gegen die leere Eleganz des Funkhauses, während es jedoch die Sorge der Mutter um ihren Sohn ausdrückt. Der Pfuscher steht augenscheinlich der Grenze zur Subjektsphäre näher als der Versager. Er ist weniger verantwortlich für sein Tun. Das zeigt der Aspekt von Zeit und Rhythmus, unter dem er vielfach antritt. Er ist falsch koordiniert. Es fehlt ihm das "Timing." Überspitzt formuliert begeht er eine Taktlosigkeit, seinen Auftritt, um im Sinne Fryes zu sprechen, nicht im Frühling, sondern im Winter zu inszenieren.

Der Held stammt aus dem Raritätenkasten der Idealität, der Pfuscher aus dem Alltag. Darum erlaubt dieser als Wirklichkeitsgröße keinen Rückbezug auf den Helden, sondern bestenfalls den Ingénu. Dieser wird zum Pfuscher ob seiner Unerfahrenheit in den Dingen der Welt. Aber was "vermurkst" werden kann, das ist schon im Wort enthalten, kann glücklicherweise auch richtig gemacht werden, und das eben in der Erfahrungswelt, und zwar im Maßnehmen an der niedrigen Norm des freien Lebensflusses. Im Sinne dieser empirischen Wertordnung gibt es die second chance, nicht das einmalige Versagen als Urteil ohne Berufung. Machen wir die Rückübersetzung der Pfuscherei Murkes ins richtige Verhalten in der Erfahrungswelt, so wäre dies nicht der heldenhafte Widerspruch auf Gedeih und Verderb in der Aufnahmekabine, sondern der kollektive Protest. Es liegt auf der Hand, daß Murke dazu Verbündete hätte finden können, ehe es überhaupt zu der unaufrichtigen Szene im Studio gekommen wäre. So scheint es den freien Mitarbeitern in der Kantine in ihrem Gespräch über Kunst auch noch um die Sache, nicht nur um Selbstblähung zu gehen. Sie diskutieren noch, während Bur-Malottke dem Monolog verschrieben ist. Selbst der Intendant und Humkoke lassen sich als Verbündete denken. Der erste schickt einen Herausforderer gegen Bur-Malottke, da dieser ihm über den Kopf wächst, der letztere bringt Bur-Malottkes Unzumutbarkeit sogar in Verbindung zu Hitler. Ein Kampf dieser Art wäre durchaus ehrlich, zwar nicht heldenhaft, aber auch nicht erniedrigend. Die Aufwertung des Pfuschers richtet sich auf den Vir bonus, der als Träger der niedrigen Norm in der Satire seit Horaz und Juvenal erscheint. Er ist der vernünftige, biedere, offenherzige Mann. Eben als solcher will auch Murke gesehen werden. In der Rina-Szene bittet er diese, doch 
Vernunft anzunehmen, damit er, geplagt wie er durch all die Unsinnigkeiten im Funkhaus ist, sein wichtiges Werk des Schweigensammelns fortführen kann.

Es liegt, zusammenfassend gesagt, die Dialektik des Herausforderers bei Böll in der Verschränkung seiner positiv-potentiellen und negativ-realen Prägung. Der Held erscheint als Versager, dieser ist aber auch der Pfuscher, der auf den Vir bonus deutet. Der Held vertritt im hypothetischen Sinne die hohe Norm, der Versager bricht sie; der Vir bonus ist Ausdruck der niederen Norm, der Pfuscher verletzt diese. Bölls doppelbödige Norm ist kein Novum. So vertritt Swift, nach Paulson, "both an impossible ideal and a humanly possible norm." Wo die hohe Norm meint "in this world heroes cannot survive," ${ }^{41}$ steht nichtsdestoweniger die niedere in Swifts eigenen Worten daneben: "His Satyr points at no Defect / But what all Mortals may correct." ${ }^{42}$ Auch die Doppelansicht des Herausforderers als Versager und Pfuscher-die meines Wissens jedoch in ihrem Verhältnis zur satirischen Doppelnorm bisher noch nicht gesehen worden istverweist auf Swift. In A Tale of $a$ Tub ist John (Calvin) als Reformator ein Versager, steht aber auch als Pfuscher vor uns. Die Religion, die es zu reformieren gilt, sind symbolische Röcke, die der Vater seinen Söhnen Peter, Martin und John vermacht hat. Unter der schlechten Führung Peters werden die Stücke im Laufe der Zeit mit Gold, Silber und allerlei Firlefanz benäht. John will als Reformator seinem Rock all diesen Behang nehmen. Er geht jedoch sehr unbeholfen vor, zerrt in seinem Zorn und Übereifer derart hitzig an seinem Rock, daß dieser zerreißt. Darauf näht er ihn aufs gröbste mit Packnadel und Tau zusammen. In diesem Narrenkleid schickt ihn der Satiriker auf die Straßen, wo er zum Gespött der Gassenjungen wird.

Zeichnen sich in "Dr. Murke" die Linien des Normgefüges am Herausforderer ab, so beleuchtet dieser als Versager und Pfuscher die Objektsphäre. Deren Hauptvertreter, Bur-Malottke, ist an der hohen Norm gemessen ein derart vollkommener Versager, daß er als $\mathrm{Pa}-$ rodie des Helden - nicht aber der Heldennorm — gelten muß. Da sein Tätigkeitsbereich weit über das Sinnvolle hinausgeht, ist er ein HansDampf-in-allen-Gassen, folglich ein Pfuscher, und zwar wiederum so übler Art, daß er geradezu eine Parodie des Vir bonus ist. Kennzeichen dieser entleerten Figur ist Macht, und diese eröffnet die Objektsphäre als Konzept. Macht bedeutet Beherrschung und Unterwerfung. Die Ritualisierung dieses Mechanismus ist die Hierarchie, eine negative Sozialisierung von Aggressivität. Das so organisierte Funkhaus steht synekdochisch für so gut wie alle Organisationen unserer Welt. Nicht, daß in der Praxis das Herrschaftsprinzip der kommunistischen Welt fremd wäre; im Gegensatz zu dieser ist es jedoch 
Teil unserer Ideologie, besonders in dem Komplex Erfolg und Konkurrenz. Die Normen Bölls richten sich gegen diese Ideologie, rükken ihn damit jedoch nicht in den Gesichtskreis eines ideologisierten Sozialismus, sondern des Anarchismus. Bölls dahingehende Neigungen sind bekannt. ${ }^{43}$ Nach Carl Amery sind sie ein Befürworten der "Realität der Ur-Beziehungen, das heißt . . . das Wehen des Geistes." ${ }^{44}$ In dieser Zone residiert das positive Personal.

\section{Das Elegische und Komische}

Der satirische Ton bei Böll ist aggressive Sprechweise in den Stimmlagen des Elegischen und Komischen. Für Schiller sind diese nichts weniger als das Merkmal einer Zweiteilung der Satire in eine ernste und scherzhafte. ${ }^{45}$ Zunächst einmal sind das Elegische und Komische Empfindungsweisen. So gesehen ist das Elegische die Reaktion auf einen in der Wirklichkeit nicht gutzumachenden Verlust des Menschlichen, sei dieser soziales Leiden oder moralische Substanz. Die Empfindungsweise des Komischen unterstellt diesen Verlust einer Sicht, in der dieser nicht schwer genug wiegt, um das Menschliche zu erdrücken. Ferner sind das Elegische und das Komische Stilmittel des Satirikers. So verstanden ist das Elegische ein aggressiver Verweis auf eine vorgestellte, aber real nicht verfügbare Ideensphäre, wo der Verlust des Menschlichen nicht unumgänglich ist; das Komische transzendiert den Verlust im Ästhetischen als vorgestelltes Korrektiv der Wirklichkeit und bedeutet somit einen Sieg des Satirikers, den er mit den sozial verletzten Personen teilt.

In fast allen Satiren Bölls sind die Stimmlagen gemischt. In der Mehrzahl der Texte ist jedoch das Elegische die schwächere Komponente. In "Dr. Murke" erscheint das Elegische am reinsten im Radiostück. Der Atheist stellt verzweifelte Fragen zum menschlichen Dasein, die unter den Terminus Verlust fallen. Das Wort Gott antwortet diesem Verlust. Aggressiv ist das Elegische dieser Szene, weil das Wort Gott einen dem Funkhaus zuwiderlaufenden und herausfordernden Sinn hat. Dem Funk kommt es nicht auf die Antwort, sondern die Füllung einer dramaturgischen Lücke an. Was sonst an die Kategorie des Elegischen anklingt, erweist sich überwiegend als Mittel des Komischen. Man spricht im Funkhaus im Pathos des Leidens, um seine Teilhabe am Herrschaftsprinzip zu verschleiern. Erschöpft von seinem Auftritt mit Bur-Malottke auf der Couch liegend, erheischt Murke in leidenden Tönen von Rina das Schweigen. Bei Bur-Malottke wird das Pathos völlig hohl und zum Beleg ätzender Komik. Das gilt vornehmlich für die Szene, in der Bur- 
Malottke beim Intendanten vom Tode und dem Fortleben seines Werkes spricht:

"Ich wäre Ihnen dankbar", sagte Bur-Malottke, "wenn wir gelegentlich darangehen könnten, alle Bänder zu korrigieren, die ich seit 1945 besprochen habe. Eines Tages", sagte er-er fuhr sich über die Stirn und blickte schwermütig auf den echten Brüller, der über des Intendanten Schreibtisch hing-, "eines Tages werde ich" - er stockte, denn die Mitteilung, die er dem Intendanten zu machen hatte, war zu schmerzlich für die Nachwelt-, "eines Tages werde ich—sterben werde ich—," und er machte wieder eine Pause und gab dem Intendanten Gelegenheit, bestürzt auszusehen und abwehrend mit der Hand zu winken-"und es ist mir unerträglich, daran zu denken, daß nach meinem Tode möglicherweise Bänder ablaufen, auf denen ich Dinge sage, von denen ich nicht mehr überzeugt war. Besonders zu politischen Äußerungen habe ich mich im Eifer des fünfundvierziger Jahres hinreißen lassen, zu Äußerungen, die mich heute mit starken Bedenken erfüllen und die ich nur auf das Konto jener Jugendlichkeit setzen kann, die von jeher mein Werk ausgezeichnet hat" (187).

Auch Wanderburn verfällt dieser Taktik des Satirikers. Er hat soeben "viel Geld" für eine "leichte Bearbeitung des Buches Hiob" (188) eingesteckt, warnt aber dennoch wortstark und mit klagender Stimme vor dem Funkhaus. Trotz der Komik in diesen Beispielen eines hohlen Pathos wird das Elegische in der Empfindungsweise des Satirikers in einem Ton der Trauer greifbar. Besonders klingt dieser in der Wanderburn-Szene an, da dieser trotz seines hohen Bewußtseins systemhörig ist. Umgekehrt ist in der Radioszene das Komische als Empfindung und Lachen des Satirikers enthalten, der uns die Funkmenschen als Narren vorführt, die letzte Dinge als ästhetisches Problem verkennen.

Zum Beleg des Komischen als Strategie hat man weiterhin an die Bandaufnahmen im Studio zu denken. Bur-Malottke und Murke, die Sängerin und Huglieme werden als lächerliche Barbaren hingestellt, die einen in ihrem Haß ad hominem, die anderen in ihrer Vulgarität, obwohl das letztere vergleichsweise human ist.

Ist der Verlust moralisch zu sehen, so werden die Figuren Teilhaber der Objektsphäre. Je größer der Verlust, desto stärker der Spott. Ist der Verlust soziale Verletzung, oder auch Machtlosigkeit und darum Verletzbarkeit, so stehen die Figuren in der Subjektsphäre. Das Komische stützt sie im Humor. Das gilt besonders für die Mutter Murkes, Rina und Wulla. Da der Humor jedoch vom Satiriker einge- 
setzt wird, ist er nicht frei von Aggressivität. Der an diesen Personen als sozial Verletzten oder Verletzbaren wahrzunehmende Verlust bedarf des ästhetischen Korrektivs. Dieses ist stützend oder schützend, insofern es die Figuren in einen ästhetischen Raum versetzt; es ist aber auch verzeichnend, insofern es die soziale Verletztheit oder Verletzbarkeit spiegelt. Die Aggressivität des Satirikers duldet keine Perfektion in seinen Figuren, selbst und gerade nicht im ästhetischen Kontext. Der Held kann den Lämmern der Welt nicht ohne Vorbehalt gegenüberstehen. In den Augen des Satirikers sind sie in etwa Schafe. Wyndham Lewis, selber Satiriker von Rang, erklärt darum den "verletzenden" Humor als allgemeingültig:

[E]ven the most virtuous and well-proportioned of men is only a shadow, after all, of some perfection; a shadow of an imperfect, and hence an "ugly," sort. And as to laughter, if you allow it in one place you must, I think, allow it in another. . . . And in a sense, everyone should be laughed at or else no one should be laughed at. It seems that ultimately that is the alternative. ${ }^{46}$

In diesem Sinne sind die Frauen in "Dr. Murke" "ugly." Wahrnehmung der Imperfektion an diesen meint eine ästhetisch-scheinbare Verletzung durch den Satiriker, die im Gegensatz steht zur Verletzung oder Verletzbarkeit der Person in der Wirklichkeit. Der Verlust wird im Humor in die Perspektive des Scheinbaren übertragen und stützt in diesem Sinne die Person in ihrer sozialen Gefährdung. Böll verwendet diese verletzende Rettungstaktik, indem er entweder die Person unter den Aspekt des "Un-ästhetischen" oder auch des Disproportionierten stellt.

Für Murkes Mutter trifft das erstere zu. Der Satiriker beschränkt sich in seinem Portrait auf das Wesentliche. Wir kennen die Frau nur durch das grellbunte Herz-Jesu-Bild, das sie ihrem Sohn schickt. Sankt Jacobi, wo sie für ihn betet, ist ein Gegenstück zum Funkhaus und liegt in dem Kontrast des Subjekt- und Objektbereichs, wie auch die Kantine, klar im ersteren. Nichts deutet darauf hin, daß die Mutter Zynikerin ist, die das Bild als eine Art Witz verschickt. Es ist zwar geschmacklos, erhält aber einen durchaus positiven Stellenwert im Vergleich zur perfektionierten Geschmackskultur des Funkhauses. Dieser Wert ergibt sich aus dem moralischen Rang der betreffenden Personen. Die Kunst des Funkhauses ist falsch, weil seine Vertreter ethisch mangelhaft sind, der Kitsch unanstößig, weil Murkes Mutter den Bereich des Humanen vertritt. Moralisch gesehen ist das Portrait der Mutter Murkes makellos; trotzdem verzeichnet das Kitschbild sie als Persönlichkeit. Sie ist sentimental, darum leicht lächerlich, denn sie schickt das Bild wohl nicht als Protest gegen die Künstlichkeit 
des Geschmacks im Funkhaus an ihren Sohn, also in dem Sinne, in dem Murke es an den Türrahmen heftet, sondern weil es ihr als rechter Ausdruck der Sorge um ihren Sohn erscheint. Das Kitschbild ist ästhetische Verzeichnung, und daher eine aggressiv-humoristische, also dem Kontext der Satire gemäße Skizze der Mutter Murkes, weil es für den Leser einen doppelten Wert hat. Im Werk ist dieser positiv als Gegensatz zur Geschmacksbeflissenheit des Funkhauses, außerhalb des Textes ist er negativ, da Kitsch der Gegensatz zu Kunst ist. Diese Art der Beleuchtung einer Person im "Un-ästhetischen" ist bei Böll durchaus kein Einzelfall. In "So ein Rummel" erscheint die soziale Verletzbarkeit der Person in der Groteskerie einer "Dame ohne Unterleib," in Entfernung von der Truppe in der Fäkalienaura des "Lochnerengels" Engelbert. ${ }^{47}$

Viel häufiger als diese aufwendige Taktik findet sich im Humor der Verweis auf Disproportioniertheiten in den Personen. Man stolpert in der Satire über die eigenen Füße, spricht verworrene Dinge, verdreht den Ablauf von Tätigkeiten. Es fehlt die Anmut. Im Fazit sind die im Zeichen des Humors stehenden Personen, wie Marie Collins Swabey feststellt, "clowns, freaks, and fools," die sich durch "odd appearance or erratic behavior" darstellen. ${ }^{48}$ In "Dr. Murke" sind die Unzulänglichkeiten sehr subtil, aber dennoch deutliches Merkmal der Imperfektion. Rina erscheint zunächst geradezu als perfekt. Sie ist nett und hat Herz. Dazu ist sie "bildschön." Dann beschreibt sie jedoch der Satiriker mit den Wörtern "starr" und "stumm" und gibt ironisch vor, daß Rina dadurch noch gewinne: "Man hätte das Mädchen für ein Fotomodell halten können, so schön und so stumm war es" (191). Das Bild Rinas hat hier unverkennbar die Perfektion eingebüßt, als Mensch steht sie aber gestützt vor uns, da in der selben Szene auch ihre soziale Verletztheit deutlich gemacht wird.

Wullas Imperfektion liegt in der Disproportion von Namen und Person. Sie zieht ihren anspruchsvollen Doppelnamen Wilfriede-Ulla zusammen. Dadurch sticht sie positiv gegen Bur-Malottke ab, dessen Name als Spreizung zu verstehen ist. Aber wir wissen auch, daß Wulla auf dem Taufschein einen Spreiznamen hat. Obwohl dieser nicht ihr zu Lasten gelegt werden kann, bleibt er in der Vorstellung des Lesers zugegen und erwirkt Komik in Bezug auf die Schrumpfform. Diese paßt zwar auf den Charakter, nicht aber auf die Person, die als "groß und kräftig" (181) beschrieben wird. Damit wächst wiederum der Doppelname, dessen erster Teil männlich anmutet, quasi ins Hünenhafte.

Obwohl jede Person in "Dr. Murke" am Elegischen und Komischen teilhat, steht auch in diesem Feld der Herausforderer zentral, denn ihm gilt sowohl der stützende Humor wie auch scharfer Spott. In der 
Darstellung des unbescholtenen Murke, der sich vor dem Funkhaus ängstigt, wird die Trauer des Satirikers sichtbar. Das Komische desselben Bildes macht Murkes Verletzbarkeit wett. Als Turnübungen und Frühstück sind die Rundfahrten lachhaft. Dem kompromittierten Aufsteiger gilt noch eine gewisse Note der Trauer, besonders wenn er sich nach seinem Auftritt gegen Bur-Malottke erschöpft in die Kantine schleppt. Aber der Zorn des Satirikers bestimmt das Bild. Die "intellektuelle Bestie" Murke wird jetzt mit einem Frosch verglichen, den elektrische Stöße zum Zappeln bringen. Das Elegische erscheint hier wie auch in der Rina-Szene in dem angepaßten Murke mit umgekehrtem Vorzeichen als falsche Empfindung, als angemaßtes Leiden, mit Hilfe dessen er seinen Verlust an Menschlichkeit $\mathrm{zu}$ verdecken trachtet.

Der stützende Humor ist im vorigen eingehend behandelt worden, weil Böll als Theoretiker sich nicht darüber im klaren ist, daß der Humor in der satirischen Praxis sich selbst an den positiven Gestalten reiben muß. In den "Frankfurter Vorlesungen" identifiziert sich Böll mit dem weltenthobenen Humor Jean Pauls: “'Es gibt für ihn keine einzelne Torheit, keine Toren, sondern nur Torheit und eine tolle Welt'" (ESR2, 88). Dieses Konzept des reinen Humors meint bei Böll und auch, wenn wir Klaus Lazarowicz folgen, bei Jean Paul die sprichwörtliche Apologie des Satirikers ${ }^{49}$ dem seine Aggressivität besonders gegenüber seinen positiven Personen zu schaffen macht. Das Argument der Apologeten Böll und Jean Paul beruht letztlich darauf, daß sie sich in dem Verflüchtigungsprozeß des Aggressiven als Theoretiker auf das Eigentliche der Theorie festlegen. Diese abstrahiert, und wo sich in der Praxis die Aggressivität an der Person reibt, zielt sie in der Theorie somit auf das reine Konzept. ${ }^{50}$

\section{Die satirische Signatur}

Redet man vom archetypischen Gehalt oder Kern eines literarischen Textes, so weist das auf generelle Züge und damit auf eine Typologie. Ist diese ermittelt, haben die Fragen nach der spezifischen Prägung des Typus in den Besonderheiten von Stil und Technik den Vorrang zu erhalten. Auch hier ist zunächst Allgemeines festzustellen. Was ist typisch für den Stil der Satiren Bölls, was ist seine-unverwechselbare-satirische Signatur? Da die Zugehörigkeit zu einem Typus im gleichen Maße wie Stil und Technik die Struktur eines Werkes bestimmt, muß die Homologie der Komponenten ermittelt werden. Die Typologie der "Murke"-Satire als Herausfordererkonstellation meint nicht nur die Dialektik im Protagonisten selber, sondern auch die der 
Gegensphären der gesamten dargestellten Szene. Homologisch wird die Entsprechung von Typologie und Stil sofern sich die am ersteren aufgezeigte Dialektik auch im letzteren spiegelt. Der Stil zeigt demnach den Anspruch beider im Text dargestellten Bereiche, weist einerseits auf Antagonistisches, wie er andererseits aufgrund der Herausfordereridee die Vorstellung der Überwindung des Antagonistischen erzeugt. Für den Leser erhält sich zwar der Konfrontationsgehalt in moralischer Wertung als Verweis auf die Realität, verflüchtigt sich jedoch im Verweis auf die Idee. Einerseits ist Satire, so Arntzen, "auf die Aufhebung ihrer selbst aus," zielt also auf Harmonie, $^{51}$ andererseits kommen Konfrontationen der Gemütsart des Satirikers nicht ungelegen. Sein Ehrgeiz, so Schönert, richtet sich darauf, "bei aller Indirektheit des satirischen Vorgehens und der Normierung dennoch eindeutige Positionen zu beziehen." ${ }^{52}$ Lazarowicz betont das dualistische Vorgehen des Satirikers noch nachdrücklicher:

Das Werk verrät, was der jeder platten Harmonisierung abholde Satiriker selbst auszusprechen sich scheute: seinen Glauben daran, daß der "Lauf der Welt" doch zum Guten hinzulenken sei. Nicht als ob der Satiriker damit durch sein Werk widerlegt würde. Wohl aber läßt sich sagen, daß der von ihm beschworene Dualismus zwischen Ordo und Perversion, zwischen Idee und Wirklichkeit auf einer höheren Ebene aufgehoben wird. ${ }^{53}$

Diesen Forderungen nach Gegensätzlichkeit und deren Aufhebung wird Böll in den Satiren der fünfziger Jahre anhand eines Stilmittels gerecht, das, bislang von der Forschung unbemerkt, als wesentliches Charakteristikum zu gelten hat. Es ist gewissermaßen ein Wappenschild mit Schwert und Taube. Böll setzt in seinen Texten Wortgegensatzpaare ein, die eine zeichenhafte Dialektik herstellen. Diese besteht aus Antinomien, die sich als Plus und Minus insofern aufheben, als beide Seiten der Gleichung sich ihren eigenen Gegenwert zuerteilen. Diese Technik wird an der Herausfordererfigur besonders deutlich, und zwar schon vielfach dadurch, daß die Wortantithetik vorwiegend Tätigkeiten meint, an denen sie bestimmend Anteil hat. Die Wortpaartechnik liegt also auch in der Handlungsschicht des Textes. Dadurch, daß die Wortpaare sich im Radius einer Person ergeben, wird eine Vorbedingung zur Überbrückung der Gegensätzlichkeiten geschaffen, denn trotz der Wandlung des Böllschen Herausforderers zum Versager bildet er als Persönlichkeit insofern eine Einheit, als der Versager auch Pfuscher ist, und dieser wiederum auf den Vir bonus weist.

Von der Bewußtseinslage der Objektsphäre her gesehen zeigen die 
Wortgegensatzpaare überwiegend nur einschichtige, unkomplexe oder nur antithetische Bedeutung, aus der Warte der Subjektsphäre hingegen eröffnen sich dem Leser komplexe, figurative und vor allem ausgeprägt dialektische Werte. Formelhaft ausgedrückt hat der Herausforderer Teil an einer Tätigkeit bzw. Verhaltensweise-Wort A-, wenn deren Gegenteil_-Wort B — sozial erforderlich ist. Wird diesesWort B-zur realen Tätigkeit bzw. Verhaltensweise, wäre wiederum das Gegenteil-Wort A-notwendig. Die Dialektik entsteht dadurch, daß die soziale Wertzuordnung der Wortpaare sich aus der gegenseitigen Beziehung ergibt. Dadurch, daß beide Teile eines gegebenen Wortpaares konträre Werte vereinen-z.B. hypothetisch positiv einerseits, real negativ andererseits-entsteht eine Art mathematische Gleichung, d.h. eine Aufhebung der Gegensätze. Diese Gleichung als Synthese verstanden ist auf die Wirklichkeit bezogen im sozialen Sinne eine erhoffte; sie zielt auf eine unantagonistische Welt. Im ästhetischen Sinne ist die Synthese gleichsam eine reale, denn Böll entwickelt besonders in seinen besten Satiren ein nachdrücklich geprägtes Variantensystem der Dualitäten in den Wortpaaren.

In "Dr. Murke" setzt Böll zwei miteinander verzahnte Wortpaare ein. Sie sind das Schneiden und Kleben, und das Reden und Schweigen. Die Paare werden so nachdrücklich verwendet, daß sich Aufzählungen erübrigen. Aus der Sicht des Funkhauses, besonders der BurMalottkes, tragen sie nur konventionellen Sinn. Schneiden und Kleben sind nichts weiter als technische Vorgänge und Gegensätze. Aus der Subjektsphäre gesehen ist das Schneiden und Kleben wesentlich mehr. Vor allem ist das erste Ausscheidung von echter, das letztere die Herstellung von synthetischer Substanz. "Gott" wird aus dem Kontext entfernt, "jenes höhere Wesen" wird eingestückelt. Murkes Reaktion auf seinen Auftrag zeigt an, daß er sich der über das Technische hinausgehenden Bedeutung seiner Arbeit bewußt ist. Seine Folie, Wanderburn, ist in diesem Kontext das Sprachrohr der Subjektsphäre, obwohl er dort bestenfalls eine kurzfristige Gastrolle spielt: "Sie schneiden uns," so lamentiert er, "zehren unsere Substanz auf, kleben uns, und wir alle werden es nicht aushalten" (189). Hier stellt Wanderburn sich und das ganze Funkhaus an den Pranger. Wanderburn ist zwar ein Opportunist, hat aber Einsichten, die sein Gegenstück, den Herausforderer durchscheinen lassen. Verschieben wir den Blick von der Folie zum Original Murke, so verschärfen sich die Konturen vermittels des hohen Aggressionspotentials, das bei Murke außer Frage steht. Angebracht wäre bei Murke-und figurativ bei Wanderburn, da dieser selber an diesen Tätigkeiten keinen direkten Anteil hat-ein gegen das System gerichtetes Schneiden und Kleben. Murke sollte demnach nicht geschnittenes Schweigen sammeln, son- 
dern alles leere Funkgerede schneiden und im Sinne von Wanderburns Metapher einen edierten, geschrumpften Bur-Malottke zusammenkleben. Genau das tut Murke auch, als Versager und Pfuscher jedoch im Sinne eines In-die-Gewaltbekommens. Wenn Bur-Malottke im Aufnahmestudio ins Schwitzen gebracht wird, will er sich davonmachen, aber Murke bringt ihn zum Stehen, "als sei er durch Murkes Stimme festgeklebt" (179). Murkes konkrete Schneidetätigkeit bezieht sich auf Bur-Malottkes Reden über Kunst und Gott. Das Schneiden hat dabei doppelten Wert. Es ist einerseits ein negativer Akt, insofern Murke das von Bur-Malottke Verlangte vollzieht und das Wort Gott aus den Vorträgen entfernt. Andererseits ist das Schneiden nicht nur Beseitigung, sondern auch Bewahrung. Murke hebt das Wort Gott aus einem Kontext, in dem es leere Floskel ist, und ermöglicht den Einschub in einen Zusammenhang, den es grundlegend bestimmt. Wenn "Gott" - und zwar ohne Kirchenakustik—statt des ursprünglich geplanten Schweigens in dem Atheistenstück auf die Fragen nach den letzten Dingen die Antwort ist, so wird die Leerform Gott aufgefüllt.

Die Klebetätigkeit Murkes erhält ihren zu befürwortenden Sinn darin, daß die zusammengeklebten Schweigenbänder als Bild einen Protest gegen das Funkhaus ausmachen. Aber dasselbe Kleben ist nicht minder ein figuratives Aneinanderreihen des eigenen feigen Schweigens bei Murke. Selbst im konkreten Sinne ist sein Schweigen anstößig, wenn er sich hergibt, das "höhere Wesen, das wir verehren," in Bur-Malottkes Vorträge hineinzustückeln. Er trägt damit bei zur Erhöhung der Mängel des Funkhauses. Sein Kleben ist gewissenlos, wie alles Handeln im Funkhaus. Aber gerade dieser Akt verwandelt sich, Murke allerdings unbewußt, ins Positive, wenn "Gott" letztlich seinen Weg in einen sinnvollen Kontext findet. Durch die gegenseitige Beziehung aufeinander erhalten das Schneiden und Kleben also doppelten Sinn, der über die soziale Wertzuordnung der Wörter als Gegensätze hinaus die Erfassung der Wortpaare als ästhetischen Komplex erwirkt, in dem nicht nur gedankliche Gegensätzlichkeit, sondern auch die Einheit in der Vorstellung bestimmend ist.

Das gilt ebenfalls für das Wortpaar Reden und Schweigen. Zunächst ist wieder festzustellen, daß aus dem Blickwinkel der Objektsphäre die Bedeutung der Wörter auch hier konventionell und einfach ist. Reden und Schweigen erhalten ihren Sinn in der Produktion von syntaktischen Gebilden im Bereich Kultur. Der Zweck ist die Wirkung, wie etwa das Reden und Schweigen im Atheistenstück. Sie sind aber nicht ganz ohne persönlich-menschliche Bedeutung. Man hat im Funkhaus zu schweigen, wenn Bur-Malottke spricht, und 
zwar aus Selbsterhaltungstrieb. Schweigen und Reden sind jedoch aus der Sicht des Funkhauses lediglich gegensätzlich, nicht dialektisch. Dazu werden sie erst im Bezug auf Murke und den Subjektbereich. Murke sollte gegen Bur-Malottke als den Vertreter einer anzugreifenden Idee reden, aber er schweigt. Wenn er gegen ihn redet, sollte er schweigen, da sein Reden ihn zum Versager macht, der sich aus dem sicheren Winkel heraus abreagiert. Im Aufnahmestudio ist sein Reden haßerfüllte, doch hinter Höflichkeit getarnte Aggressivität. Zu befürworten ist das Schweigen als Protestgeste, wie es sich in Murkes Sammlertätigkeit vor seiner Konfrontation mit Bur-Malottke zeigt; danach ist es kein beredtes Schweigen, sondern Angleichung an das Herrschaftssystem. Nicht erst in der Rina-Szene, sondern schon im Moment seiner Abdankung als Herausforderer ist Murke gewillt, das Schweigen zu erzwingen. Er schaltet Bur-Malottke im Studio ab, läßt ihn ins Leere reden, also schweigen. Wanderburn, auch hier Folie Murkes, redet, wo er schweigen sollte und schweigt, wo ein offenes Wort am Platze wäre. Seine Demaskierung des Funkhauses ist leere Geste.

Der dialektische Einsatz der Wortgegensatzpaare SchneidenKleben und Schweigen-Reden stellt ein Koordinatensystem sogar aller vier Wortfelder im Text her, denn Schweigen und Reden werden geschnitten und geklebt, so daß sich diese Technik durchaus als ein formal-stilistisches Spezifikum vom Inhaltlichen abhebt, obwohl es auf dieses, wie auf der Hand liegt, zurückverweist. Böll arbeitet gewissermaßen mit roter Tinte und genau abwägendem Kalkül. Dieses trägt auch zur Setzung des historischen Stellenwerts bei. Der Kontext der Wortpaare als Tätigkeiten ist die Technik und das Massenmedium des Radios. Im Funk leidet die Wahrheit des Wortes aufgrund des Abzugs vom Persönlichen in nur mittelbarer Kommunikation. Diese gilt einem beliebigen Publikum und vermittelt darum Beliebiges. Das Wort ist Bestandteil des Kommunikationsmarktes und erhält seinen Sinn in erster Linie durch diese Funktion. Es folgt der Nachfrage, wie sich an Jadwiga Herchen zeigt. Das Ungeheure der Beliebigkeit geht historisch über alles Vergangene hinaus. Das einzige Massenmedium vor dem Rundfunkzeitalter, die Zeitung, war in ihrer kommunikativen Beliebigkeit jedoch schon darum beschränkter, da ihr der weite Radius des Aktuellen fehlte, den gerade Telegrafie und Funk als Informationsquellen erst herstellten.

Neben der Technik der Wortgegensatzpaare setzt Böll eine Strategie ein, die zu den beliebtesten des Satirikers gehört. Sie meint aggressiv forcierte Dimensionsverwandlungen, in denen das Kleine groß, das Große klein wird. Gilbert Cannan nennt diese Strategie nach Voltaires Werk gleichen Namens "Micromegas" und hält sie für 
das Charakteristikum des satirischen Geistes schlechthin. ${ }^{54}$ Bekannt ist das Prinzip vor allem durch Gulliver's Travels, wo Swift seine Zeitgenossen einerseits $\mathrm{zu}$ Liliputanern schrumpft, sie anderseits $\mathrm{zu}$ Brobdingnagianern bläht. Die Spiegelung des Herausfordererkomplexes in Micromegas ist unverkennbar, besonders wenn er in der David-Goliath-Prägung erscheint. Das Kleine deklassiert das Große und wächst dadurch selber ins Große. Micromegas ist prinzipiell immer erfolgreich, da der deklassierende Held der Satiriker selber ist. Der Gegenstand der Strategie sind alle Personen des Werkes. So beschränkt der Satiriker sich etwa nicht darauf, das positive Kleine zu vergrößern und das negative Große zu verkleinern. Eine Verkleinerung kann auch eine Vergrößerung meinen, diese wiederum eine Verkleinerung, allerdings bleiben die moralischen Relationen dabei klar. So reduziert Böll den Namen Wilfriede-Ulla zu Wulla, um die Anspruchslosigkeit dieser Frau zu zeigen, erhöht aber die Kellnerin in Hinsicht auf Bur-Malottke. Diesen bläht er wiederum ins Überdimensionale auf, um seine wahre Winzigkeit zu demonstrieren. Böll handhabt Micromegas zum einen im engeren, physikalischen Sinne, so daß z.B. quantitativ Großes für Kleines steht, erzeugt damit aber auch zum anderen im Leser das Verständnis dieser Technik in einem übertragenen Sinn. So ist Bur-Malottkes Sorge um die Unsterblichkeit seines Werkes nicht nur falsches Pathos, sondern auch Übersteigerung der eigenen Wichtigkeit.

Ist die Micromegas-Technik als Entsprechung des Herausforderergefüges zu verstehen, so ist sie jedoch insofern weniger homologisch als die Wortgegensatz-Technik, als diese sich vielfach auf den Tätigkeiten des Herausforderers aufbaut. Der Zweck der MicromegasTechnik ist die Perspektivenverschiebung als ein auf Überzeugung des Lesers gerichteter Kommentar des Satirikers zu den Tätigkeiten und Vorgängen im Werk. So redet Wanderburn vom Schneiden und Kleben, nicht aber etwa vom Schrumpfen und Blähen. Micromegas läßt in den Satiren der fünfziger Jahre das Bewußtsein selbst der positiven Figuren aus dem Spiel. Sie sind in dieser Technik nur Objekt des Satirikers, nicht mittätige Subjekte. Murke ist in einem Detail die Ausnahme. Er denkt über "das niedrige Wesen" nach, das BurMalottke "verehrte." Die unterschiedlich enge Bindung der beiden Techniken an die Herausfordererkonfiguration erweist sich auch später, wenn Böll seine Satireschemata der sechziger Jahre entwickelt. Er behält Micromegas bei, läßt mit dem Herausforderer hingegen auch die dialektische Wortpaartechnik fallen. Somit ist diese für die satirische Signatur Bölls im früheren Satiremuster kennzeichnender als Micromegas.

Aufgrund ihrer charakteristischen Aggressivität betont die Micro- 
megas-Technik mit deutlicher Parteilichkeit Unvereinbares. Sie ist Verzeichnungstaktik der Objektsphäre, Stützung der Subjektsphäre. Als ersteres ist Micromegas in die Klammerbegriffe Schrumpfen und Blähen, als letzteres in die Termini Oben und Unten zu fassen. Im Auge zu behalten ist, daß das Schrumpfen des positiven Kleinen als Sichtbarmachung des positiven Wertes, also ironisch zu verstehen ist, obwohl eine ästhetische Verzeichnung auch hier im Spiel ist, die aber vergleichsweise zu der des Objektbereichs stützend ist. Der primäre Gegenstand satirischer Schrumpfung ist der aufgeblasene BurMalottke. Er verdient die Therapie, weil er sich selber bläht, und zwar auf Kosten Gottes, den er hinterrücks degradiert, indem er dessen Herabsetzung als Erhöhung kaschiert. Er provoziert also gleichsam den Satiriker, der ihm in gleicher Münze heimzahlt. Das "höhere Wesen," das Bur-Malottke zu verehren vorgibt, ist offensichtlich er selbst. ${ }^{55}$ Seine Ersatzphrase ist ein pseudo-eleganter Euphemismus, aber gleichfalls passendes Etikett für den Chef des Kulturwortes selber, der im Funkhaus Verehrung seiner Macht erheischt. Sehen wir Micromegas als rhetorische Strategie, etwa im Sinne Kernans, dem die Rhetorik der Satire u.a. aus "Reversing," "Magnifying" und "Diminishing" Tropen und Figuren besteht, ${ }^{56}$ so nimmt nicht wunder, daß der Satiriker sich ebenfalls in den Erscheinungsformen falscher Rhetorik auskennt. Aristophanes entlarvt diese in Die Wolken, Erasmus in Lob der Narrheit. Für Karl Kraus ist die Presse-Sprache Prostitution des Geistes schlechthin. Was das Funkhaus mit der Sprache treibt, ist falsche Rhetorik als deren Erniedrigung wie auch Blähung, und zwar in einem sehr zeitnahen Sinn. Es macht die Sprache zur Ware und zum Massenartikel, so daß man nicht von Geist, sondern vom Geist der Ware zu sprechen hat. Der Funk verfertigt seinen Massenartikel, der durch ein Massenmedium einem Publikum angeboten wird, das gereizt zu werden verlangt. Es will das Bessere, Größere, und somit versteht Bur-Malottke die Marktlage richtig, wenn er seinen Artikel umfangreicher gestaltet. Das Quantitative soll Qualität verbürgen. Das "höhere Wesen" ist das unbestreitbar Uneigentliche, das als das Eigentliche angeboten wird, weil es angeblich das Wesen der Kunst selber ausmacht. Die Beziehung von Kunst und seinem "Eigentlichen" kann, da dieses ein falsches ist, nicht logisch erwiesen werden, sondern hat im wiederholten Anruf, der Autorität herstellen soll, forciert zu werden:

... [sic] und wo immer, wie immer, warum immer und wann immer wir das Gespräch über das Wesen der Kunst beginnen, müssen wir zuerst auf jenes höhere Wesen, das wir verehren, blicken, müssen uns in Ehrfurcht vor jenem höheren Wesen, das wir verehren, beugen und 
müssen die Kunst dankbar als ein Geschenk jenes höheren Wesens, das wir verehren, entgegennehmen. Die Kunst . . . [sic] (191).

Bur-Malottke fordert Verlaß nicht auf das Wort, sondern auf das Kulturwort seiner höchst persönlichen Prägung, das er ehrfurchtgebietend und kraft seines Auftrags als Star-Intellektueller wie eine Monstranz vorweist. Damit ernennt sich Bur-Malottke zu einer Art Kunstpriester, dessen Heiligtum dem Hörer nur durch ihn zugänglich ist. Aber sein Herrschaftsprinzip ist schon insofern unterhöhlt, als er nicht mehr als Priester, sondern als Produzent beim Publikum ankommt. Er hat es mit Konsumenten zu tun, die je nach Laune Kunst oder einen Schlager verbrauchen. Wanderburn begreift dies alles sehr genau. Er erstrebt das lückenlose Angebot, indem er alles und jedes "verfeaturet," sei es das Buch Hiob oder seine Großmutter.

Der historische Stellenwert der "Murke"-Satire liegt ganz besonders offen im dem Aspekt der Reduktion alles und jedes zur Ware. Die Kriterien dieses Prozesses werden in Adornos Jargon der Eigentlichkeit in einer Form ermittelt, die sich zwanglos auf den Sprachstil Bur-Malottkes übertragen läßt und diesen beleuchtet. "Der Jargon wird praktikabel auf der ganzen Skala von der Predigt bis zur Reklame." Er stilisiert die Worte zum Massenartikel "im Pathos von Einzigartigkeit, das sie sich anmaßen und das selbst herstammt vom Markt, dem das Seltene ein Tauschwert ist." Das Wort ist "eigentlich," und das besonders, weil die objektive Qualität der Ware durch den Echtheitsanspruch der anpreisenden Person verbürgt werden soll. Diese hat einen "Auftrag," macht eine "Aussage," es findet "echtes Gespräch" statt und es wird "Bindung" beschworen. Gebunden wird die Kunst in "Dr. Murke" an ein höheres Wesen. Dieses als Beispiel von einem "absolut Ersten, Zweifelsfreien, wird im Jargon der Eigentlichkeit desto terroristischer, je selbstherrlicher er sein Erstes außerhalb des gedanklichen Gefüges ansiedelt." Der Jargon ist für Adorno "existentielles Geschwätz," das das "Seßhafte" und das "Wurzelechte" feiert, das "mit den geschichtlichen Siegern es hält." Darum ist der Kontrapunkt des Jargons "Wortkargheit und Schweigen." "Die Ordnung, auf die es abzielt, greift selber zur Sprachlosigkeit von Zeichen und Befehl." ${ }^{57}$ Überträgt man diese Verklammerungsperspektive, so fällt weiteres Licht auf Murkes Schweigen, wie dieser es an Rina vollzieht. Es handelt sich im Grunde um dasselbe Phänomen wie das Reden im Funkhaus.

Trotz der Verunglimpfung Bur-Malottkes im Bombast der Eigentlichkeit ist Böll erstaunlich zurückhaltend in seinem Spott über die äußere Person. Die Formen der Blähung, die Bur-Malottke zuerkannt werden, sind im physischen Sinne nicht sonderlich verzerrend. Wir 
sehen ihn als einen "großen, dicken und schönen Menschen, dessen Bücher in zwei Millionen und dreihundertfünfzigtausend Kopien in Bibliotheken, Büchereien, Bücherschränken und Buchhandlungen herumlagen" (178). Das Schrumpfende liegt im Assoziationsmoment der gereihten Merkmale. Auf Bur-Malottke bezogen ist "schön" gleichbedeutend mit hohl, "groß" mit gebläht, insbesondere in der Zusammenstellung mit seiner beruflichen Selbstvermarktung. Eine Kontraststelle aus Dickens' Hard Times unterstreicht, wie milde Böll verfährt. Der Gegenstand ist ein Unhold ganz vom Schlage BurMalottkes: "A man with a great puffed head and forehead, swelled veins in his temples, and such a strained skin to his face that it seemed to hold his eyes open and lift his eyebrows up. A man with a pervading appearance on him of being inflated like a balloon." ${ }^{58}$ Ist Böll in der physischen Verzerrung der Person vergleichsweise zurückhaltendmöglicherweise, weil ihm hier nicht der Raum des Romans zur Verfügung steht-, so erwirkt er im Simile die Verzerrung, wenn er BurMalottke mit einem "dicken, sehr schönen Fisch" vergleicht. Darin liegt eine Blähung wie auch eine Schrumpfung. Die Verkörperung der gefallenen Welt erscheint in der Satire oft, wie z.B. in Hobbes' Leviathan, als Seeungeheuer. Der Leviathan Bur-Malottke, der im Aquarium der Aufnahmekabine im eigenen Wutschweiß schwimmt, ist gleichzeitig ein lächerlicher Zierfisch, der stumm sein Maul aufreißt, da man seine Stimme ausgeschaltet hat.

Ist Bur-Malottke "schön," so liegt in diesem Wort der Schlüssel zum bevorzugten Blähungsmodus des Funkhauses im internen Sinne. Es schminkt sich mit "Kunst." Zum Erbrechen geschmackvoll und schön ist alles. Dem falschen Schein schenkt der Satiriker ganz besondere Aufmerksamkeit in den Aschenbechern im Paternoster. Sie sind handgetrieben, sogar preisgekrönt und so "schön," daß keiner sie zu benutzen wagt. Ihr Micromegas-Preisschild unterstreicht ihren Wert. Sie kosten "zweihundertachtundfünfzig Mark und siebenundsiebzig Pfennig." Dementsprechend ist auch ihr Name: "Schrörschnauzaschenbecher" (180-81). Zum ersten ist das Wort an sich schon ein Ungeheuer, selbst in Anbetracht der Toleranz des Deutschen für Komposita, zum anderen stellen sich Assoziationen im Leser ein, die sich schlecht mit dem Begriff des Schönen vertragen. In der Silbe "Schrör" läßt sich eine Zusammenziehung von Schreien und Röhren vermuten. Demnach hätten wir es etwa mit Schreihalsaschenbechern zu tun. ${ }^{59}$ Sie sind ein Echo der Wortkakophonie im Funkhaus.

Der Erzähler stapelt die schönen Gegenstände bis zum Überdruß. Überall im Funkhaus sind "schöne Teppiche, schöne Flure, schöne Möbel und geschmackvolle Bilder ... schöne ... Aschenbecher" 
(180). Das Ästhetische erhält hier seinen Stellenwert im Bezug auf das Moralische. Im Funkhaus gilt die Formel "Ästhetik statt Ethik," oder anders, "Ästhetik ohne Ethik," wie das Edieren der Kunstreferate Bur-Malottkes nachdrücklich belegt. Ohne Ethik ist die Kunst im Funkhaus wertloser als das Kitschbild der Mutter Murkes, denn die Tendenz des Textes erlaubt die Umkehrung der Funkhausformel "Ethik ohne Ästhetik" durchaus. Das Ästhetische im Funkhaus ist falsch, weil es eine anspruchsvolle Kultiviertheit darstellt, hinter der sich das Herrschaftssystem verbirgt. Im Funkhaus ästhetisiert man Aggressivität, statt sie zu sozialisieren. Kunst hingegen, wie beispielsweise die des Satirikers-und darin unterscheidet er sich von den Kunstbeflissenen im Funkhaus-ist nur als Produkt sozialisierter Aggressivität möglich. Die Kennzeichen unsozialisierter, aber offenkundig ästhetisierter Aggressivität sind im Funkhaus nicht zu übersehen. Über dem Tisch des Intendanten hängt ein "echter Brüller." Bur-Malottke verwendet das Wort Kunst mit einer Häufigkeit-einhundertvierunddreißigmal in den beiden Vorträgen-, die dem endlosen Geklapper einer Betmühle nahekommt, und zwar nicht zum Lobe Gottes, sondern zum Eigenlob des unumschränkten Machthabers im Bereich Kultur. Das Geklapper überfordert Murke derart, $\mathrm{da} ß$ er in der Kantine reagiert, als höre er das Feuer von Granatwerfern, selbst wenn es nicht Bur-Malottke ist, der das Wort Kunst im Munde führt. Murke hat seine Tortur allerdings verdient. In seiner aggressiv-servilen Höflichkeit gegenüber Bur-Malottke spreizt und mindert er sich gleichzeitig. Der potentielle Herausforderer Murke ist nicht klein und tapfer, sondern in der Verzeichnung der MicromegasTechnik ist er als Teil der Objektsphäre arrogant und feige. Demselben Prozeß wird das Radiopublikum, wie es sich in der Figur Jadwiga Herchen darstellt, unterzogen. Böll erhöht es, indem er es zum Herrn über den Funk macht, und mindert es gleichzeitig zum "Herrchen," weil es den Funk auf höchst lächerliche Weise beherrscht. So nötigt die Herchen dem Intendanten nicht weniger als fünfunddreißig Manuskripte über die Hundeseele auf.

In den Relationen der Namen treibt der Satiriker ganz besonders virtuos sein Micromegas-Spiel. Auf die Namen Wulla und BurMalottke ist schon eingegangen worden. Die Kellnerin zieht den ihren "der Einfachheit halber" (182) zusammen, der Chef des Kulturworts spreizt sicherlich den seinen. Messen wir die Namen Bur-Malottke und Murke aneinander, so sind sie ihre gegenseitige Schrumpf- wie auch Blähform. Es läßt sich denken, daß eines Tages, wenn Murkes "maßlos intelligente Stimme" Allgemeingut der Nation geworden ist, er sich etwa als Murke-Balott anbieten wird. Den Intendanten bläht der Satiriker in dem Etikett "vital." Zwar reicht es bei diesem zur Ein- 
schüchterung Krochys, aber nicht zum Triumph über Bur-Malottke. Dieser stellt mit Erfolg Territorialansprüche, da er für die edierten Reden mehr Sendezeit braucht. In diesem Aspekt der Selbstverbreitung eröffnet sich eine weitere Micromegas-Nuance. Nicht die Substanz des Gesendeten, sondern die Zeitdauer der Ätherbeherrschung ist ausschlaggebend im Funkhaus: Es herrscht die Quantität. So wimmelt es im Text von meist sehr hohen Zahlen, die dazu noch ausgeschrieben werden. Sekunden, Stunden, Tage, Stockwerke, Kilometer, Geld, Preise werden mit aufreizendem Nachdruck angeführt, addiert, subtrahiert, zerlegt. Aber der Panzer des Quantitativen ist durchaus nicht kugelfest. Der als intelligent ausgewiesene Murke stellt fest, das Wort Gott käme "genau siebenundzwanzigmal" (176) in Bur-Malottkes Reden vor. Er irrt sich, es erscheint auf die fünf Kasus verteilt nach Murkes Aufstellung respektive zehn-, fünf-, sieben-, fünf- und einmal. Die Summe ist nicht sieben-, sondern achtundzwanzig. ${ }^{60}$

Die Strategie des Blähens und Schrumpfens richtet sich gegen die Objektsphäre und kommt so der Subjektsphäre indirekt zugute. Aber Böll sichert dieser auch ein direktes Plus, und zwar in einem weiteren Micromegas-Aspekt. Da sich dieser auf den Subjektbereich bezieht, zeigt er nicht den boshaften, sondern den kühl-defensiven Satiriker. Dieser ist gewissermaßen Architekt einer Stützkonstruktion, bei der vornehmlich die Berechnung von Relationen auffällt. Böll stellt Kontraste von Oben und Unten her, die er hauptsächlich im physikalisch-dimensionalen Sinne zeichnet. Schon im Traum von der beseiften Treppe, der Rutschbahn und auch im Paternosterbild lassen sich diese ausmachen. Besonders wichtig werden sie aber in bezug auf das Unten der Kantine. Der Weg dorthin per Aufzug wird überwiegend in physikalischen Verweisen angezeigt, nicht in moralischen, wie etwa der Weg Murkes ins Büro. Die Versetzung ins PhysikalischObjektive erklärt sich daraus, daß somit die Kantine außerhalb eines hierarchischen Vorstellungsraums, also ohne die Kontamination mit einem Herrschaftsprinzip "erhöht" werden kann. Im Gegensatz zum Funkhaus mit seinen Stockwerken ist die Kantine ungestaffelt. Dreht man unter Beibehaltung der physikalischen Vorstellung das Oben und Unten im Sinne der Subjektsphäre um, so ist diese ein unhierarchisches Oben. Im Keller-Oben sind alle Anwesenden eher Leidende als Herrschende. Sie bedürfen der Stärkung durch Nahrung oder Trost. Das Funkhaus hingegen hat fünf Stockwerke, die seine hierarchische Organisation andeuten. Im Kontext einer Staffelung des Oben und Unten erfährt man, daß Murkes Büro im zweiten Stock liegt. Als Aufsteiger geht sein Weg an deutlich als hierarchisch gekennzeichneten Etappen vorbei. Sie sind die Stockwerke des Hauses: "[E]r sprang in den Paternosteraufzug, stieg aber nicht im zweiten 
Stockwerk, wo sein Büro lag, aus, sondern ließ sich höher tragen, am dritten, am vierten, am fünften Stockwerk vorbei." Geht es in die Abwärtsrichtung, so wiederholt sich der Verweis auf die Stockwerke. Die Kabine sank "am fünften, am vierten, am dritten Stockwerk vorbei" (173). Geht sein Weg hingegen zur Kantine, schaltet Böll nicht nur das Wort "Stockwerk" und damit die Anspielung auf das Hierarchische aus, sondern nivelliert dieses geradezu. Erinnern wir uns daran, daß man in einem zweiten Lift, der im "rückwärtigen Flur" liegt, in den Keller kommt. Die Fahrt geht jetzt an Ziffern vorbei. Es kommen auf Murke zu "eine rote Vier, ein Schrörschnauzaschenbecher, eine rote Drei, ein Schrörschnauzaschenbecher, eine rote Zwei, ein Schrörschnauzaschenbecher." Der Keller kommt Murke als "roterleuchtete Null" (180-81) entgegen. Verstünden wir die Null als Ziffer der Wertlosigkeit, so sähen wir den Keller mit den Augen des Funkhauses, also falsch. Offensichtlich ist die Null hier der höchste Wert. Das kann sie sein, weil Böll in der Ziffernserie einen Kontrast zur falschen Moralperspektive des Funkhauses in der Herstellung einer ästhetischen Perspektivität erwirkt, die wiederum auf richtige Moralität verweist. Die Schrörschnauzaschenbecher zeigen schon ex negativo auf die ästhetische Dimension. Die Serie von fünf bis null ist darum nicht Paradigma der Entwertung des Kellers, sondern Reduktionsreihe, in der die Organisation des Funkhauses, die Stratifizierung des Hohen zum Niedrigen in der Null nivelliert wird, da diese den menschlichen Ort der Kantine meint.

Eine seit Juvenal (Satire XV) besonders beliebte Variante des Prinzips Micromegas ist der Kannibalismus. Nach Paulson ist er Teil der zentralen Metapher der Gewaltsamkeit in der Satire. ${ }^{61}$ Das Große, wie etwa der Drache oder Leviathan, schluckt das Kleine und wird dadurch so ungeheuerlich, daß es seine Zerstörung und Verwandlung ins Winzige als gerechtfertigt herausfordert. Das Komplementärbild ist das des Satirikers als Arzt oder Chirurg, der das maßlos Ungeheure aufs Normale zuschneidet, wie es das Narrenschneiden im Fastnachtsspiel und bei Murner vorführt. Das Verhältnis zum Kannibalismus wird besonders bei Murner augenscheinlich. Die vom Ungeheuer, dem "großen lutherischen Narren" gewissermaßen geschluckten und zur selben Zunft gehörenden Bissen werden aus ihm wieder herausbeschworen. In "Dr. Murke" ist der Kannibalismus ebenfalls nur verhalten zugegen in einer der "Kultiviertheit" des Funkhausdschungels entsprechenden Verblümtheit. Wanderburn kommt der Erkenntnis der Menschenfresserei im Funkhaus am nächsten in seiner Phrase "Sie schneiden uns . . . zehren unsere Substanz auf." Preist sich Wanderburn hier als Opfer an, so ist er jedoch selber ein eifriger Zuhälter des Kannibalismus. Humkoke, sein Vetter, 
warnt vor ihm: "Dieser Bursche wird uns eines Tages noch seine eigene Großmutter als Feature servieren, und das Schlimmste ist eben, daß eine seiner Großmütter auch meine war" (189-90). So alt das Fiktionselement Kannibalismus ist, so trägt es wesentlich zur Fixierung des historischen Stellenwerts dieses Textes bei. Das Fressen als "Feature" ist zeitspezifisch. Es ist eine Verdinglichung und Vermarktung der Person, die durch das Massenmedium generell dem Konsum verfügbar gemacht wird..$^{62}$

Wo Menschen sich fressen, liegen Tiervergleiche nicht weit. Auch sie sind als Varianten der Micromegas-Strategie verständlich. Der Mensch erniedrigt das Menschliche, erhöht das Tierische und verdreht die natürlichen Relationen. Die Satire schwelgt in Tiervergleichen und berührt sich darin am deutlichsten mit der Fabel. Orwells Animal Farm ist ein besonders ausgeprägtes Beispiel dieser Verwandtschaft. In der Fabel sind Tiere eine Verfremdungskategorie, durch die Menschliches allegorisch objektiviert werden kann. Darum sind Tiere mit positivem wie negativem Stellenwert möglich. In der Satire läßt sich jedoch ein Reduktionsprinzip selbst an den positiven Tieren feststellen. Die ausgebeuteten Tiere in Animal Farm und die Houyhnhnms in Gulliver's Travels meinen kein menschliches Ideal, die ersteren, weil sie sich den Schweinen fügen, die letzteren, weil sie nur Vernunft sind. Die Relation von Mensch und Tier ist in "Dr. Murke" im Gegensatz zum Kannibalismus ausdrücklich. Das Funkhaus wird als Zoo bezeichnet. Als solchen sieht der Intendant seine Welt und rechtfertigt damit die Schrumpfung der Funkleute durch den Satiriker zum Tierischen.

Auch Wanderburn scheint zu wissen, wo er sich befindet, denn er umschreibt das Funkhaus in Metaphern, die auf das Animalische zielen: "Ich warne Sie vor . . . diesem Scheißkasten-vor diesem geleckten, geschniegelten, aalglatten Scheißkasten" (188). Das Funkhaus ist als "geleckter" ein tierisch gesäuberter, als "aalglatter" ein tierisch glatter Käfig, der aber trotzdem schmutzig ist. Der Tiervergleich schließt ein, daß Exkremente geleckt, also gefressen werden. Die Sauberkeit beruht auf dem Fressen von Fäkalien. Murke ist in diesem scheußlichen Käfig eine "Bestie" undefinierter Art, Bur-Malottke ein Fisch, den wir uns jedoch nur als Raubzierfisch denken können. Gegenläufig zur Erniedrigung des Menschen ist die schon erörterte Erhöhung des Tieres zum Menschen-Ähnlichen. Dabei kann dem Funk bisweilen etwas "Unmenschliches" unterlaufen. Man denke an Jadwiga Herchen, die sich über die Sendung "Wie Katz und Hund" (185) beschwert. Sie geht davon aus, daß Tiere eben bessere Menschen sind. Dazu ist sie auch berechtigt, wenn sie den Funk beim Wort nimmt, der die Kuh siebenfach mit dem ausstattet, was traditionell 
ausschließlich dem Menschen zugestanden wurde, nämlich die Seele.

Es ist bezeichnend für Böll, daß er letzten Endes das Menschliche seinem satirisch erfaßten Personal nicht abspricht. Das Tier ist nicht Metapher, sondern Simile. Der Erzähler läßt den stark beanspruchten Murke in der Kantine auf das Wort Kunst reagieren "wie der Frosch, an dem Galvani die Elektrizität entdeckte" (181). Die Personen des Textes selber kennen diese Art der Unantastbarkeit des Menschlichen nicht. Für den Intendanten ist Murke eine "intellektuelle Bestie." Bölls Zurückhaltung scheint die Ausnahme, nicht die Regel in der Satire zu sein. In Gulliver's Travels erscheinen Menschen als Tiere, dasselbe gilt für Animal Farm, oder Georg Grosz' Circe, wo ein Menschenpaar sich die Schweineköpfe küßt. Bölls Menschen hingegen sind lediglich "auf den Hund gekommen." Das Tierische ist in ihnen gefährliche Tendenz, nicht aber absolutes Kennzeichen.

Es liegt nahe, den Stil in "Dr. Murke" als ironisch zu bezeichnen. Er ist verzeichnend und vielfach dialektisch. Bölls Ironie ist jedoch nicht etwa modern im Sinne Thomas Manns, von dem sich Böll in seinem Humorverständnis distanziert (I, 142). Bei Böll bleiben die Wertverhältnisse im sozialen Sinne klar antithetisch, die ästhetische Aufhebung der Gegensätze läuft nicht, wie bei Mann, auf eine Gleichschaltung der Gegensätzlichkeiten in der moralisch-intellektuellen Einschätzung durch das Publikum hinaus. In einem traditionelleren Sinne darf man aber durchaus in "Dr. Murke" von Ironie sprechen. Diese meint, daß der Autor nicht direkt angreift, sondern rhetorische, d.h. gesellschaftlich akzeptierte Mittel einsetzt, um sein Anliegen verschleiernd $\mathrm{zu}$ rechtfertigen und durchzusetzen. So beschimpft er z.B. nicht die Narren, sondern singt das Lob der Torheit. Er zeichnet vordergründig die Konturen der Idylle, hinter denen jedoch eine verdorrte Landschaft erscheint. Es sind somit die Taktiken des Blähens und Schrumpfens, des Täuschens und Entlarvens, kurz alles zur Micromegas-Technik Gehörende Schemata der Ironie als Ausdruck einer sozialisierten Aggressivität.

\section{Satirische Aggression:}

\section{Autor-Satiriker-Persona; das Publikum}

Das unverkennbarste Merkmal der Satire ist ihre Aggressivität. Arntzen fordert, daß sie "zersetzend," "aggressiv" und "beißend" zu sein habe..$^{63}$ Brummack formuliert: "Satire ist ästhetisch sozialisierte Aggression." ${ }^{64}$ Kernan erklärt: "In short, aggression lies at the heart of satire." ${ }^{65}$ Paulson bestimmt anhand reichen Materials die Gewaltsam- 
keit als das zentrale Symbol der Satire. ${ }^{66}$ Bisweilen weisen die Satiriker selber mehr oder weniger direkt auf dieses Faktum hin. Karl Kraus scheint sich damit geradezu zu brüsten, wenn er behauptet: "Ich schimpfe nicht, ich verstümmle!" ${ }^{67}$ Auch Böll ziert sich nicht: "[I]ch geb's ihnen gern, zugegeben, aber das ergibt sich einfach aus dem Stoff" (ESR2, 249). Wie sich hier zeigt, ist der Satiriker Urheber satirischer Aggression, darum möglicherweise ein boshafter, streitsüchtiger Mensch. Sein Tun wird fragwürdig, auch für ihn selber. Darum legt er immer wieder Apologien vor. Er stellt sein Amt als hohes, seinen Zorn als berechtigt hin. Zweifelhaft ist der Satiriker nichtsdestoweniger, weil er Teil der Wirklichkeit ist, die ihn empört. Das gilt um so mehr, je erfolgreicher er ist. Letztlich steht er im Sold der Welt, die er angreift. Darüberhinaus ist sein Kampf Wortgefecht, das die Wirklichkeit wenig oder gar nicht beeinflußt; er ist nur Sieger im Werk und darum oft verlacht. Man mag ihn mit einem Pinscher vergleichen, der zwar bellt, aber zum Beißen zu winzig ist, oder man mag seine Bemühungen als possierliche Tricks mit Applaus belohnen. Dieser unersprießlichen Lage könnte der Satiriker nur entkommen, wenn er zum Helden in der Wirklichkeit würde. Solschenizyn kam dieser Rolle nahe, indem er seinen Feind immer vorbehaltloser herausforderte. Auch Böll ist über die Jahre mit wachsender Schärfe zum Herausforderer in der Wirklichkeit geworden. Er äußert sich mehr und mehr im außerliterarischen Kontext und will auch seine literarischen Arbeiten als direkte Herausforderungen verstanden wissen.

Das Infragestellen satirischer Aggression ist zumindest unter Teilen eines jeweiligen Publikums unabdingbar. Wird der Text nicht vornehmlich als Fiktion verstanden, so ist es durchaus verständlich, daß der satirisch Angesprochene sich zur Wehr setzt. So unterstellt man dem Satiriker einen schlechten Charakter und die übelsten Motivationen; man spricht von seiner Streitsüchtigkeit und Menschenfeindlichkeit und will in ihm eine gesellschaftsgefährdende Figur sehen. Schon Horaz (Satire I, 4) setzt sich damit auseinander. So erklärt sich, daß selbst noch Böll das Handwerk des Satirikers für riskant hält: "[F]ür einen Stein, der Goliaths Stirn gestreift haben könnte, kommt es aus hundert Schrotflinten zurück, multipliziert . .." (I, 35). Schon Rom kannte Gesetze gegen "böse Verse," ${ }^{68}$ und, wie man weiß, gibt es heute noch Strafmaßnahmen gegen sozialkritische Autoren in totalitären Staaten. Es sind aber gerade diese Umstände, die den Satiriker nicht in der Rolle eines mit Lachen abzutuenden Narren versinken lassen. Er kann gewissermaßen zurückfallen auf seine Ursprünge. Es sind die des Magiers, der seine Feinde verfluchen und dessen Wort töten konnte. Für Elliott liegt die Furcht vor dem Satiriker darin, daß sein Angriffsobjekt als Pars pro toto verstanden wird: "[A]n attack by 
a powerful satirist on a local phenomenon seems to be capable of indefinite extension in the reader's mind into an attack on the whole structure of which that phenomenon is part. Significantly, I think, this imaginative process is magical; it functions by synecdoche, which is one of the foundations of magic. . . the part does not merely represent the whole, it is the whole." ${ }^{69}$ Enthält die Wirkung des Satirikers noch die Rückstände des Magischen, nimmt es nicht wunder, daß er selbst irgendwo in seinem Herzen noch an seine atavistische Macht zu glauben scheint. Wenn Böll sich über den Spießer entrüstet, der "in seinem fürchterlichen Lachen sich selbst zu einem Nichts zerlacht" (ESR2, 88), so ist das eine Metapher, in der noch ein leises Echo der magischen Vernichtung zu hören ist. ${ }^{70}$

Es ist diese Aura des Fluches als Beleg boshafter Aggressivität, die dem Satiriker so oft eine Art Gegenfluch eingetragen hat, selbst von namhaften Kritikern, die den Satiriker und Sprecher oder Erzähler als ein und dieselbe Person sehen. Darum plädiert Maynard Mack für eine scharfe Trennung von Autor und satirischem Sprecher, der als Persona oder Maske, also als Fiktionselement zu begreifen sei. ${ }^{71}$ Die neuere Satireforschung folgt im allgemeinen dieser Trennung. Wenn Paulson die Gewaltsamkeit satirisches Symbol und "poetic strategy" nennt, ${ }^{72}$ so wird sie Teil einer Fiktion, die satirische Aggression abziehbar vom Autor. Dennoch ist nicht zu leugnen, daß der Satiriker im Eifer des Gefechts bisweilen so unverkennbar hinter seinen Masken auftaucht, daß es nicht sinnvoll erscheint, das Problem streng formalistisch zu lösen.

Selbst in "Dr. Murke," wo die Boshaftigkeit nicht derart scharf ist, daß die von Mack befürwortete Trennung unbedingt geboten wäre, wird klar, daß der Satiriker sich sowohl vom Sprecher abhebt, als er diesem aber auch unverkennbar ins Konzept fällt. In Umkehrung des Normalen erscheint der Satiriker hier jedoch hinter seiner Maske nicht in extrem boshafter Antipathie, sondern in unangebrachter Sympathie für eine Figur. Wenn z.B. der käufliche WanderburnZimmer nennt ihn "geradezu rundfunkgeil" und seine Reden "opportunistische Lügen" 73 - aufs Korn genommen wird, bestätigt der Erzähler ihm, daß die Warnung vor dem Funkhaus, die er seinen Kollegen gibt, "aufrichtig" (188) sei. Diese Warnung ist durchaus nicht mehr am Platze bei diesem Opportunisten, erklärt sich aber leicht dadurch, daß der Satiriker in Wanderburn als warnender Stimme momentan sein eigenes Echo hört und falsch Partei ergreift. Aber selbst wenn nicht das gutmütige, sondern das boshafte Gesicht des Satirikers greifbar wird, ist nicht unbedingt ein Verlust zu verzeichnen. Zwar mag ein Formbruch geschehen, aber dafür entstehen Verbindungslinien zur Wirklichkeit und damit zum Publikum. 
Auf die Sympathien des Publikums ist der Satiriker angewiesen. Er will es überzeugen und zu sozialer Tat bewegen. Auch hierbei spielt das Aggressionsmoment eine bedeutende Rolle. Es fasziniert schon an und für sich, selbst oder gerade wenn es als Boshaftigkeit begriffen wird. Es gilt auf dieser Primitivstufe eine Formulierung aus Büchners Leonce und Lena: "Es steckt nun aber doch einmal ein gewisser Genuß in einer gewissen Gemeinheit." 74 Frye stellt fest: "Es ist eine unumstößliche vorliterarische Grundtatsache, daß wir alle gern hören, wenn andere Leute beschimpft werden, daß uns ihr Lob aber langweilt." 75 Bleibt die Rezeption jedoch nicht auf dieser Ebene, so tritt zu dem Genuß ein soziales Moment. Zuweilen kommt dieses sogar dem Genuß zuvor, wie in Swifts "A Modest Proposal," wo die erste Reaktion sich auf ein Tabu bezieht. Das schockierte Publikum sucht nach Anhaltspunkten, die die maßlose Aggressivität des Satirikers, oder Sprechers, rechtfertigen, der das Schlachten von Kindern vorschlägt. Die Anhaltspunkte finden sich in der Anstößigkeit des satirischen Objekts. Wird z.B. erkannt, daß Swift in dessen Stimme spricht, stellt sich gleichzeitig der Genuß an diesem Spiel ein, das als Maskierung und Entlarvung sozialisierte Aggression ist. Dem Satiriker sind alle Mittel recht, das Empörende des Objekts aufzubauen, sei es eine schreckliche Strategie wie Swifts Empfehlung des Kindermords, sei es Lob und Preis, wie in Erasmus' Lob der Narrheit oder in Bölls "Hauptstädtisches Journal," wo das Objekt als schrecklicher Miles gloriosus auftritt. Jede Nuance der satirischen Entlarvung dient dazu, die Ungeheuerlichkeit des Objekts in vollem Ausmaße erkenntlich zu machen. Unterzöge man den "Murke"-Text einer Wort-für-Wort-Analyse, so ließe sich dieser Energieaufwand leicht nachweisen. Gerechtfertigt ist der Satiriker in seinem Vorgehen, weil das Dargestellte an sich vorgestellte Normen verletzt. Um diese dem Publikum auf dem Wege der Identifikation zugänglich zu machen, greift er mit Vorliebe zu einer auf Anhieb sympathischen Figur, wie etwa Murke. Man identifiziert sich nicht nur mit der Stimme des Satirikers, sondern mit einer ganzen Persönlichkeit. Geht der Satiriker davon aus, daß das Publikum dem satirischen Gegenstand sehr nahe steht, so ist eine Figur wie Murke insofern fast unerläßlich, als diese selber von der Objektsphäre erfaßt ist. So kann sich das Publikum in "Dr. Murke" mit dem Herausforderer im positiven Sinne identifizieren, und, sofern es konsequent ist, auch mit dem Versager. Da dieser wiederum bei Böll der Pfuscher ist, sein Tun korrigierbar, so kann die Verbindung mit dem Protagonisten im positiven Sinne, z.B. als Vir bonus, gewahrt, und die Trennung vom Gegenstand der Satire möglich werden. Jedoch ist die konsequente, zweifache Identifikation durchaus nicht garantiert. Wie wir gesehen haben, fühlt sich z.B. Stefan Heym zur Zeit seiner Re- 
zension als DDR-Bürger und Marxist dem Herausforderer Murke verbunden, Zimmer als BRD-Journalist dem Versager, den er allerdings elegisch verbrämt als Schelmen sehen will.

Erschwert wird die Trennung in einer System-Satire wie "Dr. Murke" dadurch daß das Publikum gewissermaßen den Boden unter den Füßen verliert. Es soll seine Welt, in der es sich vermutlich recht wohl fühlt, selbst im Kern als fragwürdig erkennen und richten. Sehr leicht wird die Trennung andererseits unter den Umständen, in denen beispielsweise Rolf Schneiders "Metamorphosen" und Wolf Biermanns Der Dra-Dra rezipiert werden können. Schneiders antikapitalistische Pointe fällt gewiß in der DDR nicht auf taube Ohren, wie in der BRD Biermanns Drachenbrut ohne Umschweife als das DDRRegime identifiziert wird.

Die richtige Rezeption aller technischen Mittel, die der Satiriker zum Zwecke der Verfremdung der Wirklichkeit und deren Erkenntnis als anstößig verwendet, ist zweifellos nicht leicht für das Publikum. Wie Böll dieses einerseits rügt, weil es ihm nicht gerecht wird (ESR2, 36), betont er andererseits, daß Kunst eine hohe Zumutung und Ausdruck von Respekt ist (ESR2, 199). Das Publikum hat den Angriff des Satirikers ästhetisch ernst zu nehmen. Leider mag die Hoffnung des Satirikers, daß die richtige ästhetische Aufnahme soziale Wirkungen zeigt, nur ein frommer Wunsch sein. Wie Kernan im Hinweis auf die Ethologie glaubt, zeigt sich die Satire in Techniken, die Freund und Feind als allgemein sanktionierte Ritualisierungen von Aggression erkennen. ${ }^{76}$ Die Satire ist in dieser Sicht nur etwa eine Knallerbse, nicht Dynamit. Sie führt literarische Konventionen vor, die zwar erregen mögen, aber nicht das Bewußtsein des Lesers erweitern. Gibt man Kernan recht, so sind Bölls Bemühungen der sechziger und siebziger Jahre insofern begrüßenswert, als sie traditionelle satirische Techniken abzubauen trachten. Anstelle dessen, was als "Kunst" kulinarisch eingehen könnte, treten Dinge, die als Kampfmittel irritieren sollen, obwohl diese zweifellos die richtige Aufnahme nicht verbürgen können. Sie mögen auf primitiver Ebene als auktoriale Boshaftigkeit genossen und damit abgetan werden. 


\section{Frühe satirische Versuche; Abgrenzungen zur Parabel}

Der Protest als Kern der Herausfordererkonfiguration ist schon in der 1950 erschienenen Sammlung von Kurzgeschichten Wanderer, kommst du nach Spa . . . auszumachen. Ist der satirische Ton zugegen, richtet er sich überdies gegen einen Objektbereich, der den Herausforderer teilweise einschließt, so ergeben sich die Umrisse des oben erstellten Satiremusters. Allerdings sind diese vorerst nur schwach, vor allem der satirische Ton ist in den Spa-Texten nicht laut und nur stellenweise vernehmbar. Die Gründe liegen bei den Herausforderern selber. Diese erscheinen in zwei Prägungen des Heldenarchetyps, einer religiösen und einer säkularen. Die maßgebende erste geht zweifellos auf Bölls Kriegserfahrungen zurück, unter deren Eindruck er in der Spa-Sammlung noch sehr weitgehend steht. Die Kriegseindrücke schlagen sich als Erfahrung des Leidens als Martyrium nieder. Bölls Reaktion zum Krieg ist somit im Grunde religiös bestimmt. Für den angehenden Satiriker dieser Periode liegt folgerichtig auch der Gegensatz zur empörenden Wirklichkeit im Religiösen. Statt des Helden vom Schlage Murkes stellt er zunächst eine Variante des Archetypus auf, in der Züge des Märtyrers, Engels und Heiligen hervortreten. Siegfried Lenz erkennt diese Merkmale, wenn er Bölls Protagonisten eine "manchmal lächelnde, manchmal kohlhaassche, immer aber herausfordernde Leidenswilligkeit" zuerkennt. ${ }^{1}$ Wenn Carl Amery so etwas wie eine Legendenstruktur bei Böll wahrnimmt, ${ }^{2}$ so bezieht er sich ebenfalls auf den Raum, den der religiöse Heldenarchetypus bestimmt.

Trotz der Leidenskomponente läßt sich die religiöse Heldenvariante, wie schon die Formulierung von Lenz zeigt, auf den Herausfordererkomplex beziehen. In Billard um halb zehn nennt Johanna Fähmel ihren Sohn Robert "meinen Erzengel: der bringt mir dunkle Botschaften, die nach Blut schmecken, nach Aufruhr und Rache." Böll ist offensichtlich bestrebt, die religiöse und profane Variante des Archetyps in ein und demselben Rahmen zu sehen. Robert Fähmel erscheint im selben Kontext auch als Ikarus (W3, 395-96). In "Dostojewskij-heute?" (1971) heißt es, "Held ist ja nur ein anderes Wort für Heiliger" (I, 189). In dem Hörspiel "Mönch und Räuber" (1953) thematisiert Böll diese Verklammerung. Der Heilige begreift, daß der 
Räuber der Mensch ist, der ihm "auf dieser Welt . . . am ähnlichsten ist" (HTDG, 133). Beide sind Herausforderer als Befürworter der Armen und Ausgebeuteten. Das Tun des Räubers ist Antwort auf das zu Verändernde, das im Elend der Armen liegt, wie der Heiligenennen wir ihn hier Engel_ein "Bote der Hoffnung" ist, als den man den Engel bei Böll zu recht verstanden hat. ${ }^{3}$ Der Engel fordert durch sein Erscheinen das Bestehende im Hinweis auf das Vorgestellte heraus.

Böll hat sich eindringlich mit dem Engelbild befaßt, und zwar gewissermaßen mittels einer Kontrastdefinition in zwei Texten mit dem Engel als Titel, 1952 in einer Prosaskizze, 1967 in einem Gedicht. In dem Prosastück nimmt er Abschied vom Engel als Archetypus. Es handelt sich um eine große Marmorstatue, die im Schlamm liegt. Von der Macht des Engels ist nicht viel übrig geblieben. Er "erweckte den Eindruck, er sei erschlagen worden;" sein Schwert ist zerbrochen, "ein längliches Stück Marmor, das er weggeworfen zu haben schien." Selbst die Kommunikationsfähigkeit ist ihm fast völlig genommen. Es heißt zweimal, daß er schweigt. Möglich ist, daß er noch hört, denn es "sah aus, als lauschte er." Wirkung hat nur noch ein vermeintliches Lächeln. Auf einen Augenblick verunsichert dieses einen Geistlichen, der eine trostlose Grabrede intoniert. "Langsam," so heißt es gegen Ende der Skizze, "versank der Marmorengel." Neben der allgemeinen Pointe, dem Verlust des Religiösen, ist meines Erachtens dieser Text ein auf Bölls Werk beziehbares Paradigma für die Problematik der Engelnorm. Wie die Protagonisten einiger der Spa-Texte ist der Engel hier eine verwirrende Kombination von Spott und Leiden, die Böll in einem Entweder-Oder bestimmt: "[N]iemand konnte erkennen, ob sein Gesicht Hohn oder Schmerz ausdrückte" (W2, 40-41). Erweist sich die Wirkung des Engel-Archetypus in dieser Skizze als derart minimal, so ist in dem satirischen Werk Bölls für diese Variante des Heldenbilds fortan wenig Raum. In dem späteren Gedicht läßt Böll den im Schlamm versunkenen Engel wieder auferstehen, jedoch nicht als Urbild, sondern als Menschen:

Engel-wenn Du ihn suchst

er ist Erde . . .

bereit aufzustehn

wenn Du ihn rufst . . .

ohne Macht

ohne Herrlichkeit

ruf wie ein Bruder

wenn Du ihn suchst

Germane war er Jude Christ . . . 


\author{
Wenn Du ihn suchst \\ wenn Du ihn findest Engel \\ mach ihn neu \\ nicht aus Blut \\ nicht aus Galle \\ aus Tränen und \\ ein Paar Tropfen Rheinwasser . . . (HTDG, 22)
}

Dieser Menschen-Engel ist nicht archetypisch, sondern real, etwa in dem Sinne der Figur des Engelbert in Entfernung von der Truppe (1964). Wenn Böll der Heldenarchetypus in den späten fünfziger Jahren als Normwert fragwürdig wird, so gilt das auch für die religiöse Variante. Er läßt diese allerdings schon sehr viel früher fallen, wie die EngelSkizze aus dem Jahre 1952 bezeugt. Die Erklärung ist in Bölls religiöser Sensibilität und, gleicherweise, seiner satirischen Ader zu suchen. Der profanen Form des Helden bekommt eine satirisch-aggressive Tönung wesentlich besser. Er opfert seine Feinde, der religiöse Held hingegen, in kraß archaischem Kontrast gesehen, opfert sich selbst. Darüberhinaus ist der Engel, Heilige oder Märtyrer eine Glaubensangelegenheit mit transzendentem Bezug. Böll macht ihn daher nur sehr zurückhaltend zum Versager; Pfuscher wird der Protagonist nur innerhalb der säkularen Heldenkonfiguration. Mit dem Helden läßt sich eher spielen und spaßen; er ist weniger erhaben. Wäre beispielsweise Engelbert in Entfernung von der Truppe das geglaubte Urbild der frühen Engelvorstellung Bölls, so wäre die Fäkaliengloriole, die Böll ihm verabfolgt, undenkbar.

Welcher der beiden Varianten des Archetypus bei Böll auch erscheint, das Hauptgewicht liegt auf dem Protest als Bewahrung des Individuums. Diese Prüfung ist Vorbedingung für den Veränderer. Das Individuum ist dabei in den Spa-Texten so wichtig, daß man sagen kann, Böll erhofft das Neue zunächst im einzelnen, nach den Spa-Texten erst vom einzelnen. Die Betonung des Individuums ist dadurch zu erklären, daß es diesem gerade im Krieg möglich war, die Verantwortung von sich abzuwälzen und sie der Truppe, dem Befehl, zuzuschieben. Die Forderung einer individuellen Entscheidung ist darum nach dem Krieg eine Vorbedingung für die Rückkehr zum Menschlichen. Der Protest als Prüfung des Individuums zeigt Abwandlungen in den Spa-Geschichten. Ist Leiden zugegen, so steht er vornehmlich unter dem Aspekt des Willens zum Überleben, das allerdings im Zeichen einer Integrität, zu deren Bewahrung das Leiden Kraft gibt. Fehlt dieses Leiden, oder erscheint es im Rahmen der Nachkriegswelt nur im Verweis auf Durchstandenes, oder tendiert der Archetypus schon zum Profanen, so meint der Protest Selbstbehaup- 
tung angesichts einer nicht wünschenswerten, sich neu formierenden Gesellschaft, die den einzelnen zur Integration zwingt. In den Satiren der fünfziger Jahre ist diese Formierung ein Faktum, der Protest bedeutet ein Herantragen unkonventioneller Normen durch den Herausforderer. Selbstbewahrung und -verwirklichung werden zu Selbstbewährung angesichts eines Feindes, der angegriffen werden muß. Der Rückzug nach innen oder in die persönliche Sphäre ist in der Sammlung Spa der religiösen Variante des Herausforderers noch gestattet, der zur säkularen neigenden schon nicht mehr.

Die Texte "Mein teures Bein" (1948), "Der Mann mit den Messern" (1948), "An der Brücke" (1949), "Mein trauriges Gesicht" (1950), "Wanderer, kommst du nach Spa ..." (1950), "So ein Rummel" (1950), "An der Angel" (1950) und die getrennt erschienene Arbeit "Die schwarzen Schafe" (1951) sind andeutungsweise satirisch vor allem, weil sie ein Moment der Herausforderung gegen eine meist mit Spott belegte Objektsphäre enthalten. Darüber geht das satirische Element in nur einem Text, "Wanderer, kommst du nach Spa . . . , nicht hinaus. Ist der Herausforderer schon überwiegend von der säkularen Prägung, so kommt seine Ambivalenz hinzu, die ihn zum Versager, und sofern das Leiden minimal ist, zum Pfuscher macht. Versager sind die Sprecher in "Mein trauriges Gesicht" und "Mein teures Bein." In den restlichen Texten sind sie auch Pfuscher. Überdies arbeitet Böll schon bisweilen deutlich mit Wortpaaren. Je ambivalenter der Herausforderer ist, desto präziser wird Bölls Signatur dialektisch. Trotzdem sind auch diese Texte nur erst schwach satirisch, insofern als Böll den satirischen Kern noch verhüllt vorweist. In "Der Mann mit den Messern" verlegt er das Gewicht auf die religiöse Variante des Helden, nachdem der Messerwerfer sich kompromittiert hat. Der Stilton wird dadurch allzu sehr zum Elegischen hin verschoben. In "So ein Rummel" wird die Subjektsphäre so breit aufgebaut, daß sie die Objektsphäre verundeutlicht und die Satire eher als Idylle endet. In "An der Angel" relativiert Böll das Satirische, indem er den Herausforderer unter Wahnvorstellungen leiden läßt. Besonders interessant ist dieser Text, weil der mythische Kern der Herausforderung in dem zwanghaft denkenden Protagonisten unverwischt hervortritt. Das Land ist verdorrt und trostlos. Alle Nahrung wird von einem Drachen, der als schnaubender Eisenbahnzug erscheint, und von seiner Brut, den Bahnleuten, in den "Klauen" $\left(W_{1}, 263\right)$ gehalten. Gefangen hält die Drachenbrut vor allem die Braut, um die der Sprecher kämpfen will. Besitz der Braut und Sieg sind ihm ein und dasselbe. In "Die schwarzen Schafe" macht sich Böll den Weg frei als Satiriker, aber gewissermaßen erst im zweifachen 
Anlauf. Er kehrt dabei das Schema, das wir in "Der Mann mit den Messern" finden, um, indem er zunächst die Heiligenvariante, allerdings eine schon weitgehend säkularisierte, auf die Bühne stellt und nach deren Abtritt einen voll ambivalenten Herausforderer folgen läßt.

Bölls satirische Instinkte scheinen ihm zu dieser Zeit noch nicht recht geheuer zu sein. So hält er "Die schwarzen Schafe," wo der Sprecher einen sehr aggressiven Ton anschlägt, zwei Jahre von der Veröffentlichung zurück. Erst in "Nicht nur zur Weihnachtszeit" (1951) bricht Böll voll zum Satirischen durch. Außerhalb der satirischen Praxis scheint er seinen Vorbehalten erst später entkommen zu können. Vollkommen deutlich wird dies 1954 in der Erzählung “Unberechenbare Gäste." Böll kann hier dem Konzept Aggression klar eine soziale Komponente abgewinnen. "Gäste" ist eine Parabel zum Thema Aggression. Böll befürwortet zwar ein Menschenbild des Mitleids, das selbst Tiere einschließt, rückt aber ab von dem Gedanken, daß Menschlichkeit mit Leidenswilligkeit identisch ist. Die Mutter in "Gäste" beherbergt und versorgt Mensch und Tier unbegrenzt und unterschiedslos, bringt auch gegen die Händler, die ihr massenhaft Unnützes anbieten, keinen Widerstand auf. Als Folge gerät die Familie wirtschaftlich in eine bedrohliche Lage, unter der besonders die Erzählerfigur, der Vater, zu leiden scheint, da er für den Broterwerb verantwortlich ist. Die symbolische Abhilfe ist ein Löwe, den die Frau zur Beherbergung aufnimmt. Er ist das einzige Raubtier in der Familienmenagerie und das einzige Tier, das das Herz des Vaters und dessen "volle Sympathie" gewinnt. Den Löwen zeichnet ein "ruhiger, freundlicher Ernst" (W2, 503) aus. Er ist Freund der Kaninchen und der Kinder, signalisiert aber, wie deutlich aus dem Text hervorgeht, trotz seiner einwandfreien Sozialisierung Gefahr. Gerade darin unterscheidet er sich beispielsweise von den Kaninchen oder auch dem Elefanten und dem Nilpferd in der Badewanne. Es ist somit sein Genus als Raubtier oder, genauer, sein Aggressionspotential, das ihm die Zuneigung des Vaters der Familie gewinnt. Weil dieses Aggressionsvermögen sozialisiert ist, ist es ethisch unanstößig. Es beugt der potentiellen Ausnutzung vor. Dem Löwen gilt nicht etwa Mitleid, sondern "Sympathie." In dieser existiert kein Gefälle vom Subjekt zum Objekt wie im Mitleid, dessen Basis die reale Verletztheit des Objekts, jedoch nur die vorgestellte des Subjekts ist. Mitleidhaben bestätigt die Überlegenheit des Subjekts und den Leidensstatus des Objekts, Sympathiehaben dagegen weder das eine noch das andere. Im Fazit befürwortet die Parabel "Gäste" das Aggressionspotential als Gegenmittel zu Repression und Ausbeutung, 
denen absolute Leidensbereitschaft Vorschub leistet. Wie der Löwe zeigt, ist Aggression prinzipiell sozialisierbar.

Es läßt sich nun rekapitulieren: Indem Böll vom Ideal der Leidensbereitschaft abrückt, steht er dem Konzept Aggression nicht mehr absolut ablehnend gegenüber wie der Christ der Sünde. Der Aggression darf eine sozialstützende Bewandtnis zuerkannt werden. Dadurch ergibt sich die Voraussetzung für einen aktiven, klar ambivalenten und die satirische Bestrafung einladenden Herausforderer, wie wir ihn in der "Murke"-Satire finden. Durch ein verändertes Verständnis des Begriffs Aggression verschafft sich Böll die Voraussetzung zum vollgültigen Satiriker, der einerseits einen Helden als Herausforderer mit aggressivem Anspruch als möglich aufstellen, diesen andererseits auch klar in die Objektsphäre verweisen kann, wenn er sich als Versager kompromittiert. Das Versagen ist Selbstkompromiß des Herausforderers und erlaubt dem Satiriker verzeichnend zu strafen.

Innerhalb der Suche Bölls nach dem ihm eigenen satirischen Schema entsteht schon in der Sammlung Spa eine weitere Formtendenz, die sich mit der Satire berührt. Böll verfaßt Texte, die satirische Elemente aufweisen, wie etwa ein diskreditiertes Objekt, aber letztlich nicht auf den satirisch geprägten Herausforderertopos hinzielen und vor allem den satirischen Ton nur schwach oder gar nicht, sondern hauptsächlich oder ausschließlich parabolisches Sprechen vernehmen lassen. Aufgrund der vermischten Töne hat man einige der frühen Arbeiten Satiren genannt, die meines Erachtens eher oder hauptsächlich Parabeln sind. Klaus Jeziorkowski führt z.B. fünfundzwanzig Titel in seiner Liste Böllscher Satiren auf. Er beschränkt sich jedoch auf die Untersuchung von "Der Wegwerfer" und rechnet darüberhinaus nur sechs Titel zum Konzept der "utopischen Satire," das er an "Der Wegwerfer" gewinnt. Die restlichen Texte ordnet er entweder als "zwar reine Satiren" einer nicht-utopischen Prägung ein oder als Erzählungen, "die satirische Elemente nur als Einsprengsel enthalten." In der Offenheit seines Spektrums macht Jeziorkowski den Weg frei zu anderen Satirevorstellungen und auch zur generischen Ansiedlung gewisser Texte außerhalb der Satire. Für die Erzählungen "satirischen Charakters" räumt er ein: "[Es] kann sich der satirische Charakter dieser Erzählungen so weit verflüchtigen, daß wir an die Grenze dessen kommen, was noch als Satire bezeichnet werden kann. Manche Arbeiten, z.B. 'Unberechenbare Gäste', werden zutreffender komische Erzählungen zu nennen sein." ${ }^{4}$ Über diese Kategorie hinaus ist für "Unberechenbare Gäste" eine weitere Zuordnungsmöglichkeit vorhanden, nämlich die der Parabel, wie soeben unter dem Aspekt des Aggressionsproblems angedeutet 
wurde. Dieses Genre ist meines Erachtens neben der Satire das aufnahmefähigste im Rahmen der Kurzprosa Bölls. Seine Leseerfahrungen der Paraboliker Kafka, Kleist und Hebel schlagen sich hier vermutlich nieder.

Es soll im folgenden versucht werden, einige der gemeinhin als Satiren geltenden Texte-_Unberechenbare Gäste," "Der Lacher," "Über die Brücke," "Schicksal einer henkellosen Tasse" —im Ansatz als Parabeln zu verstehen. ${ }^{5}$ Auffallend an diesen Arbeiten im Gegensatz zu den Satiren ist zunächst ihre Tendenz zu einer Tonart, die den Leser auf Distanz hält. Sie fordert von diesem nicht die von der Satire verlangte subjektiv-objektive Mischung der Reaktion, sondern gewinnt die Parteinahme des Lesers allein durch dessen Erkenntnis, daß ein gegebener Fall in seiner Veranschaulichung Gleichnischarakter für andere Fälle hat. Darin schon liegt ein zentrales Merkmal der Parabel. Andere ergeben sich aus Vergleichen und Abgrenzungen zu den naheliegenden Formen der Fabel und Allegorie. Der Unterschied zwischen Parabel und Fabel ist geringfügig. ${ }^{6}$ Hauptsächlich besteht er darin, daß diese ihren Gleichnischarakter unverhüllter zeigt; ihr Sprechen ist uneigentlicher, weil sie von der real unmöglichen Voraussetzung ausgeht, daß ihr Inventar-Tiere, Pflanzen, leblose Dingereden kann. ${ }^{7}$ Es soll deshalb auf die Erzählung "Schicksal einer henkellosen Tasse," wo die Tasse spricht, nicht eigens als Fabel eingegangen, sondern ihre Verfügbarkeit als Parabel erörtert werden.

Die Trennungslinie zwischen Parabel und Allegorie ist hingegen scharf. Allegorisches Sprechen ist auch uneigentliches Sprechen, wie das der Parabel, aber es weist Stück-um-Stück Entsprechungen von Gesagtem und Gemeintem auf und eröffnet seinen Sinn erst durch einen von außerhalb zugegebenen Schlüssel. ${ }^{8}$ Bei der parabolischen Rede hingegen bedarf es keines Schlüssels zur Klärung und zum Verständnis; sie bringt einen Einzelfall, der an sich schon seinen Sinn enthält, aber dabei ähnliche Fälle erhellen kann. Die Allegorie hingegen stellt ein Gleichnis vor, dessen einzelne Ingredienzen nur durch eine beigegebene Erklärung in ihrer Parallelität zu einem höheren oder wichtigeren Sinnzusammenhang deutlich werden.

Man hat versucht, die Parabel stärker auf eigentliches Sagen einzuengen, indem man das Element des Verweises auf ein Gemeintes abzog und nur dem Gleichnis zubilligte. Aber diese am Gleichnisreden Jesu gewonnene Differenzierung hat sich nicht durchgesetzt. ${ }^{9}$ So läßt sich mit Werner Brettschneider zusammenfassen: "Das erste Gattungsmerkmal [der Parabel] ist das uneigentliche, gleichnishafte Sagen: Das Gesagte ist nicht bereits das Gemeinte, sondern es ist die Darbietung des Gemeinten durch Konkretisierung und Hinweis auf das Gemeinte." ${ }^{10}$ Das Gemeinte der Parabel ist ein Sinnzusammen- 
hang in Bereich des Moralischen, dabei ist das konkret Veranschaulichte nicht zu trennen von dem zu Erkennenden. Die Parabel beschränkt sich auf einen Fall (Kasus) und spitzt diesen auf ein Wort oder Zeichen zu. ${ }^{11}$ Sie ist also eine sinnbezogene Form und zumindesten darin der normgebundenen Satire ähnlich. Daß Satire und Parabel Hand in Hand gehen können, beweist Brecht. Der Satiriker erwirkt durch aggressive Emotionalität die Überzeugung des Publikums, der Paraboliker überzeugt auf Distanz durch Argumente. Die Sinnbezogenheit der Parabel meint Vorstellungen von übergreifenden Ordnungen und sicheren Orientierungspunkten, die der Paraboliker und das Publikum voraussetzen können. Im Mittelalter waren diese Fixsterne die Glaubenssätze, in der Aufklärung-und noch bei Brecht-die Ratio.

Merkwürdigerweise existiert die Parabel heute selbst dort, wo man keine ideologische Gebundenheit vorfindet, also ohne die ihr traditionell gemäßen Vorbedingungen. Kafkas Welt ist alles andere als sinnvoll geordnet. Trotzdem ist man allgemein bereit, den parabolischen Charakter solcher Prosastücke wie "Vor dem Gesetz" oder "Auf der Galerie" anzuerkennen. Sich vornehmlich auf Kafka beziehend hat man den Parabelbegriff zu erweitern versucht. Wo in der traditionellen Parabel der Kasus in seinen Einzelheiten und Vorgängen durch den Hinweis auf das über das Gesagte hinaus Gemeinte sich deutet und das gleichnishaft Gemeinte erkennbar wird, fehlt in der Parabel der Prägung Kafkas jede Eindeutigkeit, und somit ist die Übertragung zum gleichnishaft etwaigen Gemeinten in nur offener Weise möglich. Der Schwerpunkt dieser modernen Art der Parabel liegt nicht auf ihrer zielgerichteten Konsequenz zur Erkenntnis, sondern bleibt bei den Vorgängen selber. Man spricht deshalb von der "offenen" oder "schwebenden" Parabel. Nach Norbert Miller ist sie letztlich eine Umkehrung des Gewohnten: "Für die Antwort tritt also die Frage, für die Lösung das Rätsel ein, für das Ende die Unbegrenztheit. ..."12 Sie ist im Grunde ein ratloses Erläutern, das dennoch eine Einsicht im Leser bezweckt. In diesem Sinne sind Kafkas Parabeln Übungen, deren zentraler Sinn und das Gemeinte die Strukturintegrität des Textes als Medium der Erläuterung ist. Das Gemeinte, die Erkenntnis von Sinnzusammenhängen im Leben, die die herkömmliche Parabel bezweckte, kann nicht mehr im Leser erzielt werden. Insofern aber die offene Parabel Formsklett und Ton der herkömmlichen Parabel wahrt, hat sie einen Sinn. Sie macht aus der Not eine Tugend. Wie Alfred Bourk im Anschluß an Ionesco feststellt, entkommt man mit ihrer Hilfe der Beliebigkeit, die einer Dichtung weltanschaulichen Charakters heute anhaftet. ${ }^{13}$ Die offene Parabel gilt nach Miller nicht nur für Kafka. Neben diesen stellt er als 
prototypisch Joyce, weiterhin Ingeborg Bachmann, Benn, Pound, T.S. Eliot, García Lorca, Beckett und Camus. Reinhard Dithmar erweitert diese Aufstellung. Neben Kafka und Brecht rechnet er u.a. Buber, Bloch und Frisch zu Vertretern der parabolischen Form. ${ }^{14}$ Wenn Böll auf diesen Listen der repräsentativen Paraboliker unserer Zeit nicht erscheint, so liegt der Grund wohl darin, daß er einerseits nur in sehr wenigen Texten an Kafka erinnert und andererseits keine seiner Erzählungen eine ausdrücklich didaktische Parabel traditionellen Stils ist. Deswegen ist Bölls Zug zur Parabel jedoch nicht übersehen worden. Hans Schwab-Felisch bestätigt, daß bei ihm "Parabelhaftes angestrebt" werde. ${ }^{15}$ Hinton Thomas und Wilfried van der Will verweisen auf eine eklatant gleichnishafte Stelle in dem Essay "Der Zeitgenosse und die Wirklichkeit," die als Vorlage für "Hier ist Tibten" gelten muß. ${ }^{16}$ Für Marcel Reich-Ranicki ist das Parabolische in Bölls Erzählungen so gewichtig, daß er sie generell zu Parabeln erklärt. ${ }^{17}$

Der offenen Parabel kommt die Arbeit "Über die Brücke" in etwa nahe, der herkömmlichen hingegen "Der Lacher," "Unberechenbare Gäste" sowie die Fabel "Schicksal einer henkellosen Tasse." Zum schon erörterten Text "Unberechenbare Gäste" ist unter dem Gesichtspunkt des Parabolischen Folgendes hinzuzufügen. Das parabolisch Gemeinte ist die sozialisierte Aggression als ein vor Ausnutzung schützendes, dem Leben substanzvermittelndes Element. Diese Pointe wird aufgezeigt am Beispiel eines durchaus abstraktethisch zu bejahenden, aber nur künstlich und insularisch auf begrenzte Zeit aufrechtzuerhaltenden Paradieses, in dem Mensch und Tier friedlich, wennschon nicht allzu glücklich zusammenleben. Obwohl die Tiere hier nicht sprechen, gibt es doch eine gewisse Kommunikation zwischen ihnen und den Menschen; die Spuren eines fabulösen Elements sind also vorhanden. Das erhärtet sich vor allem daran, daß dem Löwen-er ist das parabolische Zeichen, auf den sich der Text zuspitzt-die ihm in der Fabel zugeordneten Attribute auch hier gegeben sind. Er zeigt die sozialisierte Aggressivität, die ihn zu dem König der Tiere macht. Er stellt einerseits als Großraubtier ständig eine Gefahr dar, ist aber andererseits, weil Katzen bekanntlich das Mäusefangen zur Natur gehört, nicht gehaßt, sondern respektiert in seiner gezügelten Aggressivität. So ist er wie der Löwe der Fabel: gefährlich und mächtig, nicht aber etwa mörderisch wie Fuchs und Wolf. Dieser gefahrbedeutende Löwe, der aber zu lächeln scheint, gewinnt das Herz des Erzählers, während der mindestens ebenso imposante Elefant, der aber kein Raubtier ist, als albern empfunden wird.

Der Erzähler hat zwar prinzipiell nichts gegen das Paradies in seinem Hause, aber in der Praxis ist es unrealistisch und bedrückend, 
da die Unterhaltsfrage nur von außen gelöst werden kann. Damit kommt der realistische Rahmen der Idylle, das Problem der Aggression im Konzept des Handels, ins Bild. Böll läßt die Außenwelt in parabolischer Zuspitzung als extrem kapitalistisch erscheinen. Er trennt sie in die ausbeutenden Händler und Vertreter einerseits und die ausgebeutete Familie des Sprechers andererseits. Mag diese Form der Aggression systembegründet sein, so liegt ihr Antidot in diesem Text im Bild des Löwen und damit in einer naturbedingt erscheinenden Aggressivität. Am Löwen nun könnte der Sprecher lernen, wie die Verhältnisse seiner Familie sich stabilisieren ließen. Er hätte deutlich zu machen, daß mit ihm nicht länger zu spaßen ist. Die Forderung der verfahrenen Situation und zielgerichtet sozialisiertes Aufbegehren wären Proteste gegen das bedrückende Paradies. Statt dessen beschränkt der Sprecher sich darauf, sein Aggressionsvermögen in einer symbolischen Geste zu sozialisieren: Er beschließt sich zu rasieren. Indem Bölls Parabel sich um das Prinzip Aggression als sozialen Wert bemüht, enthält sie sowohl eine antikapitalistische wie auch antiutopische Spitze.

"Gäste" hatte in einer ursprünglicheren Fassung einen längeren Schluß, in dem der Löwe an Blutwurst gewöhnt ist, was "ja nur scheinbar eine Fleischspeise ist." ${ }^{18}$ Es liegt auf der Hand, warum Böll dieses Ende fallen ließ. Es entmächtigt den Löwen allzu sehr, seine Pointe als Metapher sozialisierter Aggression geht verloren. Darauf wirft Theodor Haeckers "Dialog über die Satire," in dem der Anstoß zu diesem Text Bölls zu vermuten ist, weiteres Licht. Es geht darum, ob vom christlichen Standpunkt aus Satire gerechtfertigt sei. Der "Freund" argumentiert, daß die Satire gegen das christliche Liebesgebot verstoße, kommt aber letztlich dem "Satiriker" so weit entgegen, daß er ihm die Möglichkeit des Segens Gottes zugesteht. Ehe er sich dazu überwindet, rät er jedoch zur Aufgabe der Satire, die zwar für die Heiden Pflicht gewesen sein mag, nicht aber für den Christen, der höhere Pflichten habe. Der Satiriker postuliert als Entgegnung eine Satire als Substanz einerseits und als Modus der Ausübung andererseits und deutet an, daß die rechte Ausübung die Satire auch dem Christen ermögliche. Darauf der Freund:

[N]un tun Sie sich selber und Ihrer Gabe unrecht. Nun muß ich auch noch die Satire gegen den Satiriker verteidigen. Ich habe Sie in einen Gewissenskonflikt gebracht, der Sie im Augenblick der Verwirrung vergessen läßt, daß Wesen und Modus Ihrer Kunst eins sind. Ich gestehe Ihnen, daß ich mir vorläufig nichts Rechtes vorstellen kann unter einem Löwen, der Gras frißt. Und eine Satire, die weder schlagen noch treffen, noch ver- 
wunden, noch töten kann, die nicht anstößt, es sei denn mit dem Glase, ist ein Spaß, der mir keinen macht. Zunächst muß eine Definition dem Dinge nachkommen, das vor ihr da ist, dann aber muß das Ding auch die Definition erfüllen, sonst ist es nicht das Ding, das wir meinen. ${ }^{19}$

Der Satiriker mag Gottes Segen haben und schreibt er schon Satiren, so müssen diese ihrer Substanz entsprechen. Sie haben, mit einem Wort, aggressiv zu sein. Schlägt sich diese Problematik in "Gäste" nieder, so verfaßt Böll hier eine überzeugendere Apologie seiner satirischen Praxis als die unter dem Zeichen des weltenthobenen $\mathrm{Hu}-$ mors in den "Frankfurter Vorlesungen." Es liegt weiter auf der Hand, daß die Parabel die geeignete Ausdrucksform dieser Problematik ist. Sie ist Niederschlag von Reflexion über ein Sujet, noch nicht Angriff gegen einen überwundenen Fehlschluß, nämlich, daß es die zahnlose Satire, den gras- oder nur blutwurstfressenden Löwen gebe. Aber da es immerhin auch um den Satiriker geht, so unterläßt dieser nicht, als solcher im Text auch zu signieren, wennschon nur in einer Abbreviatur. Der Erzähler verliert seine Fassung, als der Elefant das Haus mit der Gewalt "eines mittleren Erdbebens" $\left(W_{2}\right.$, 501) erschüttert, und läßt hier punktuell die Herausfordererthematik aufklingen. Aber dieses momentane Aufbegehren richtet sich nicht gegen etwas eindeutig Anstößiges; von Protest kann also keine Rede sein, wie auch schon das Rasieren des Sprechers zeigte. Satirisch wirkt auch der Gegensatz von Löwe und Elefant als Wortpaar. Es hat doppelten Wert, der Löwe als Gefahr und Reiz, der Elefant als Belastung der Familie wie auch Beglückung der Frau und der Kinder. Die Dialektik reflektiert sich zwar in dem Erzähler, der die Menagerie einerseits mag, andererseits aber nur dem Löwen seine volle Sympathie entgegenbringt. Im Gegensatz zu den Satiren jedoch spiegelt sich die Ambivalenz des Wortpaares nicht in einer doppeldeutigen Zeichnung des Erzählers. Diesen würde der Satiriker gerade hier, wo Böll das Konzept Aggression annimmt, zum Versager und Pfuscher machen. So hat man trotz der "satirischen Signatur" nicht etwa von einer parabolischen Satire zu sprechen, weil sich weder der Erzähler-im Gegensatz zu den Ich-Satiren der fünfziger Jahre-noch irgendetwas anderes außer ihm als konkretes satirisches Objekt ausmachen läßt. Läge hingegen ein aggressiv behandelter Gegenstand vor, so fiele das wichtige Kriterium des uneigentlichen Sprechens der Parabel fort, und es würde sich um satirisch-synekdochische Taktik handeln. Ginge nämlich der Satiriker den Einzelfall "uneigentlich," aber aggressiv an, so hätte man ihm das Verschulden anzurechnen, sich an einem Surrogatobjekt abzureagieren. 
Sollte sich die Erzählerfigur in "Gäste" gewissermaßen eine Löwenmäne umhängen, so schlüpft sie in der Parabel "Der Lacher" (1952) ins Fell eines einzigartigen Herdenschafs. Diese Erzählung ließe sich betiteln als "Parabel vom ewigen Ja-Lacher." Er konstatiert, er "lache ... alle Jahrhunderte, alle Gesellschaftsklassen, alle Altersklassen durch" (W2, 42). Das Parabolische liegt im Gleichnischarakter dieses spezifischen Falles, der zwar nicht so uneigentlich ist, wie wir es aus der Fabel kennen, wo Tiere sprechen; aber immerhin sind berufliche Lacher wie der Sprecher wohl eine Seltenheit. Uneigentlich ein Lacher, ist er eigentlich der ewige Zeitgenosse, der alles, selbst das ihn als Menschen Mindernde bejaht, solange es ihm zum Einkommen verhilft. Sein Lachen ist künstlich, eine vorgetäuschte Emotion, hat somit keinen sozialen Wert. Privat ist er ein "todernster" (43) Mensch. Nur hin und wieder erwidert er das Lächeln seiner Frau. Er beklagt sein Geschick hauptsächlich, weil sein Beruf anstrengend ist, aber zu einem Protest rafft er sich nicht einmal im Ansatz auf. Obwohl er ein Schaf ist, darf er im elegischen Tonfall des Lammes sprechen. Nicht, daß darin der Satiriker sich ironisch einmischen würde. Dieser tritt auch nicht die Arbeitgeber des Protagonisten verspottend in Erscheinung.

Der elegisch-resignierende Ton des Sprechers schafft dem Leser eine Distanz, die nicht zur Satire paßt. Obwohl der Lacher im spezifischen Sinne seines Berufes ein sehr modernes Phänomen ist, ist seine Resignation ein existentialistisch anmutendes Ja und Amen als wie vor ewigen Befindlichkeiten. Was sich auf den ersten Blick als Nähe zur Satire sehen ließe, ist der Ansatz zur Wortpaartechnik. Der Sprecher klagt, "mein eigenes Lachen kenne ich nicht" (44) und unterteilt damit das Lachen in ein richtiges und falsches. Das richtige ist jedoch nur hypothetisch und positiv, das Berufslachen nur negativ. Von der am "Murke"-Modell ersichtlichen Dialektik des Wortpaares, die sich aus dem doppelten Wert jedes der beiden Kontrastwörter ergibt, kann keine Rede sein. Der Hinweis auf das richtige Lachen erscheint erst im Schlußsatz des Textes. So wäre es angebracht, hier nicht von einem Wortpaar, sondern vom Lachen als parabolischem Zeichen zu sprechen, das sich im Schlußsatz durch den Kontrast vom falschen und richtigen Lachen zur Sinnfälligkeit zuspitzt. Hier erweitert sich die parabolische Pointe vom total affirmierenden zu dem sich selber entfremdeten Menschen.

Die zur parabolischen Rede nötige Uneigentlichkeit ist schon in "Schicksal einer henkellosen Tasse" (1952) durch den Fabelcharakter dieser Geschichte gewährleistet. Die Erzählstimme ist die henkellose Tasse selber. Sie hat eine Familie, hat menschliche Gefühle und besitzt vor allem Lebensweisheit. In ihrer milden, beschaulichen A.rt 
der Lebensbetrachtung liegt nichts Aggressives. Sie bezeichnet zwar die Menschen als töricht und beklagt, daß das Altern diese verhärtet, aber die Feststellung der Torheit schlägt sich nicht in irgendeiner Verzerrung der menschlichen Figuren ins Närrische nieder. Nur die hochnäsige Hurz, die fast vor Schreck stirbt, als die Tasse ihr einen Heiratsantrag macht, ist lächerlich. Aber weil die Hurz kein Mensch ist, ist ihre Verzeichnung nicht etwa satirische Bosheit. Hinter der distanzierten, weisen und humorvollen Betrachtung der Welt durch die Tasse steht nicht der Satiriker, sondern der seinen Kasus kühl unter die Lupe nehmende Paraboliker. "Tasse" ist das Produkt einer serenen Stimmung; die Dinge werden sub specie aeternitatis gesehen. In dieser Sicht geht es nicht um spezifische Sozialkritik. Obwohl die Geschehnisse ungefähr in die Spanne zwischen den dreiBiger und fünfziger Jahren fallen, handelt es sich nicht um Vorkriegszeit, Krieg und Nachkriegszeit in einem politischen Sinne, sondern um Allgemeineres, nämlich um die Verhärtung des Menschlichen, die das Leben und die Erfahrung des Alterns mit sich bringen.

Die Geschichte spielt am Weihnachtsabend und läßt schon dadurch eine Note der Hoffnung aufklingen, die im Gegensatz etwa zu "Nicht nur zur Weihnachtszeit" nicht satirisch zurückgenommen wird. Julius, der Besitzer der Tasse, ist im Begriff, diese zu zerschmettern, weil sein Sohn Walter, der sie liebt, sie als Spielzeug seiner nagelneuen Eisenbahn vorzieht. Doch Julius' Frau Diana hindert ihn daran. Für Diana hängen an der Tasse Erinnerungen an die ersten Jahre ihrer Liebe. Es waren karge, aber glückliche Zeiten, in denen die Tasse eine wichtige Rolle spielte. Zum Schluß der Erzählung herrscht Frieden; die Familie sitzt glücklich beisammen. Man hat dem Drängen Walters nachgegeben und die Tasse ins Zimmer genommen. Ihren Bericht hatte sie frierend auf der Fensterbank begonnen, voll von zu Eis erstarrter Seifenlauge, die Walter zum Blasenmachen gebrauchen möchte. Walter sitzt auf dem Schoß seines Vaters und wartet darauf, daß die Lauge auftaut. Julius' Gesicht, so urteilt die Tasse, "sieht so aus, als habe er etwas begriffen." Dieses Etwas entspricht der Lebensweisheit der Tasse, die daran glaubt, daß die Liebe die Verhärtungen des Lebens erweichen kann. Schon als sie draußen im Schnee steht, sagt sie voraus, daß sie "spätestens in einer halben Stunde im warmen Zimmer sein" wird, weil sie weiß, daß Julius sein Kind liebt und dessen Wunsch nachgeben wird. Sie weiß dies aus Erfahrung, denn die Liebe triumphierte schon einmal über die Verhärtungen des Lebens, als sich Julius und Diana kennenlernten. Die hochnäsige Hurz, aus dem "Geschlecht derer von Hurlewang . . . in Hürzenich an der Hürze," hatte gehofft, daß ihre Besitzerin Diana eine standesgemäße Ehe eingehen, nicht aber auf Julius, "diesen ordi- 
nären Burschen" (W2, 58-63) hereinfallen würde. So ließe sich der Titel parabolisch umformulieren als "Gleichnis vom Leben, das sich verhärtet, und der Liebe, die es erweicht." In dieser Formulierung wird eine Ähnlichkeit zu den Satiren sichtbar. Es ist die Norm des Lebensflusses, um die sich Böll auch hier bemüht, jedoch nicht aggressiv und frustriert, sondern beschaulich und mit der Hoffnung als Hauptton. Auch das idyllische Schlußbild des Textes erinnert an einige der Satiren. Hier aber ist die Idylle echt. Weiterhin fehlt hier begreiflicherweise die Technik des Wortgegensatzpaares, wohl schon, weil durch den gewählten Fabelrahmen die Intention von vorneherein nicht satirisch war. Es wird zwar mehrfach die Eisenbahn erwähnt, die dem Kind gerade geschenkt worden ist, und der es die Tasse vorzieht, aber weder sie noch die Tasse sind ambivalent. Wie in "Der Lacher" ergibt sich keine satirische Dialektik, sondern Zuspitzung auf ein parabolisches Zeichen, dort ist es das Lachen, hier die henkellose Tasse.

Der Form der offenen oder schwebenden Parabel nähert sich Böll in "Über die Brücke" (1950). Die Erzählerfigur fährt mit der Bahn regelmäßig während der Vorkriegszeit an einem Haus vorüber, wo man jedesmal putzt. Die Bewohner wirken verkümmert, säuerlich. "Es sah fast ungastlich aus, dieses Haus, obwohl es sauber war. Es war ein sauberes und doch unfreundliches Haus" (W1, 182). Dieses bedrückende Gebäude ist das parabolische Zeichen, der Kern der Erzählung, um den sich konzentrischen Ringe lagern, die den Gleichnischarakter des Hauses begründen. Der Erzähler berichtet rückblickend aus der Warte der unmittelbaren Nachkriegszeit, und zwar weil in dem Hause genau noch wie vordem gereinigt wird, wie er nun bei einem zufälligen Vorüberfahren feststellen muß. Das Bild "rundete sich" für ihn. Das säuerliche, spinnenhafte Kind, das er vor zehn Jahren mit einer Puppe im Arm vor der Haustür sitzen sah, ist jetzt eine Erwachsene, die an Stelle ihrer Mutter putzt. Vom Krieg ist keine Spur an diesem beklemmenden Uhrwerk sichtbar, obwohl er im Text als einschneidendes Ereignis erscheint. Die urfeste Rheinbrücke, "eisern wie die Brust Bismarcks," die zu überqueren ist, ehe man am Putzhaus auf der Strecke "Königstadt . . . Gründerheim" (181) vorüberfährt, existiert nicht mehr. Stattdessen fährt man auf zwei wippenden Schienensträngen. Die Notbrücke verursacht in den Passagieren eine vom Erzähler recht breit ausgemalte Angst, fast die Gewißheit des unabwendbaren Absturzes. Aber man kommt sozusagen wieder noch einmal davon und ans andere Ufer.

Das Putzen ist noch nicht etwa das Gemeinte als Metapher für ein nur vermeintliches Positives. Das manische Säubern ist Teil eines Bildkomplexes, in dem das Haus, seine Bewohner und ihr Verhalten 
sich verdichten zu einer Gleichung von Deutschland und dem Putzhaus. Eine präzise parabolische Pointe im Sinne einer Moral liegt nicht vor, nur die Bildhaftigkeit einer erschreckenden Statik oder nur leeren Mechanik in einer unausgefüllten Zeit. Der Erzählerfigur enthüllt sich dieses Gleichnis nicht. Es ist ihr zwar ein gerundetes Bild, aber letztlich doch nur ein Rätsel, ähnlich wie den Figuren Kafkas ihr eigenes Leben, weil sie kaum Beschauer, sondern selber Teil des Bildes sind. Obsessiv bemüht der Erzähler sich um das Vordergründige im Gleichnis. Er will den zeitlichen Putzplan des Hauses erschließen, als ob es um diesen ginge. Was der Erzähler ergründen will, hält der Erzählgestus offen. Der Nachdruck liegt auf dem sich ewig widerholenden und angsterregenden Vorgang des Säuberns; Perspektiven, die dem Leser erklären könnten, wonach die Erzählerfigur vordergründig sucht, fehlen zwar nicht ganz, beschränken sich aber auf Zeichen wie die Ortsnamen Königstadt-Gründerheim, die an der Strecke liegen. In diesen vagen Anspielungen liegt allerdings unverkennbar eine kritische Perspektive, und im Putzen ein negatives Beispiel richtigen Lebens. Darum ist diese Geschichte jedoch noch nicht der Satire zuzurechnen, und das eben wegen der Art, in der das negative Beispiel gegeben wird. Es flößt Angst ein, jedoch entwickelt weder die Erzählerfigur eine aggressive Sicht noch läßt sich eine Zerstörungstechnik des Satirikers gegen das Haus als Gegenstand ersehen. Das Haus steht am Ende nicht nur real intakt, sondern auch figurativ unangefochten vor uns. Der Leser wohnt nicht einem ästhetischen Vernichtungsakt bei, wie in der Satire, sondern er wird bewegt, parabolisch-distanziert das Negative als Phänomen in der Veranschaulichung wahrzunehmen.

In jedem dieser als Parabeln bezeichneten Texte fehlt trotz gewisser Ähnlichkeiten zu den Satiren eine klare dialektische, anhand der Wortpaartechnik profilierte Struktur. Nicht aggressive Gegenüberstellung und aggressiver Ton, sondern distanzierte Darstellung kennzeichnet das Sprechen. Diese hier im Ansatz gegebene Analyse des Parabolischen bei Böll erhebt nicht den Anspruch, Böll als Paraboliker auszuweisen. Sie soll lediglich belegen, daß das Satireetikett nicht ausschließlich auf motivähnliche und bisweilen satirisch anmutende Texte Bölls angewendet werden kann. Allerdings läßt sich das satirische Siegel weitaus häufiger als das parabolische zur Einordnung eines Textes innerhalb der Kurzprosa Bölls verwenden. 


\section{IV. "Nicht nur zur Weihnachtszeit": Durchbruch als Satiriker}

Wie sich die Leidensbefürwortung Bölls in der Sammlung Wanderer, kommst du nach Spa . . . durch seine Kriegserfahrungen und sein Christentum erfassen läßt, so erhellt sich seine wachsende Aufgeschlossenheit für den Komplex Aggression in den fünfziger Jahren aus den Erfahrungen der Nachkriegszeit. Die politische und soziale Entwicklung in der Bundesrepublik gibt zu immer stärkeren Befürchtungen Anlaß. Es sind reaktionäre Tendenzen festzustellen, so daß Parallelen zwischen dem Faschismus der Vergangenheit und dem immer schärfer werdenden Leistungskapitalismus der Gegenwart entstehen. Diese Fortdauer der Unmenschlichkeit wird, so glaubt Böll, vom Durchschnittsbürger bejaht. Rückblickend äußert sich Böll 1975 in seinem Gespräch mit Christian Linder unter dem Schlüsselwort "Bürgerlichkeit" zu den Hoffnungen und Versäumnissen der frühen Nachkriegsjahre:

Ich glaube, daß das, was wir Chance genannt haben und nennen und was ich auch weiterhin so nennen würde, doch zu sehr eine aufgezwungene Chance war; nicht eine akzeptierte. Man hätte natürlich nach diesem Krieg, ganz unabhängig von Entnazifizierungsgeschichten, etwas anfangen müssen, was man möglicherweise Sozialismus genannt hätte. Verbindungen von christlichen und sozialen Ideen oder sozialistischen. Und das gab es ja auch, ansatzweise. . . . Aber es hat sich letzten Endes eben gezeigt, daß das, was wir Restauration nennen und was man so nennen muß, die alten Formen fast zwanghaft wieder kreiert hat: wieder Familienegoismus, wieder Besitzstreben, wieder Bürgerlichkeit. Bürgerlichkeit ist sicher eine Möglichkeit zu leben . . . aber als rekonstruiertes Modell hat sie sich eigentlich nach 1950, glaube ich, nicht mehr als tragfähig erwiesen (I, 394).

Die richtige Reaktion auf die aufgebürdete Chance und auf die Restauration ist Aggressivität als Konsequenz enttäuschter Hoffnungen. Böll läßt ihr zum ersten Mal in "Nicht nur zur Weihnachtszeit" (1951) freien Lauf. Er weiß jetzt genau, was er als Satiriker will und zu tun hat. Nichts zeugt von Unsicherheit. Es steht kein religiöser 
Heldenarchetyp im Hintergrund, der satirische Boshaftigkeit verbietet. Statt dessen stellt Böll einen frommen Boxer vor, der seinem Gegenstand mit Gewaltmaßnahmen begegnen möchte. Wenn ein Engel zugegen ist, so setzt ihn der Satiriker auf die Spitze eines Weihnachtsbaums, wo er mechanisch und unentwegt Frieden flüstert. Darum fehlt jedoch das Leiden in diesem Text nicht. Es ist aber eine Variante, der wir unser Mitleid vorenthalten können. Es handelt sich um die Neurose einer verhätschelten alten Frau. Diese ist nicht etwa das Opfer irgendeiner Form der Unmenschlichkeit, sondern selber der Ursprung vielfältiger Torturen ihrer Umwelt, die wiederum ihrerseits nicht unverdient leidet, da sie sich nicht wirkungsvoll wehrt. Tante Milla ist ein Haustyrann, der aufs ärgste schnaubt und tobt, dessen Plagen uns aber nur zum Lachen bewegen. Die Distanz zum Konzept Leiden ist ein zentrales Kennzeichen der Böllschen Satiren der fünfziger Jahre. Sie ermöglicht eine konsequent satirisch geprägte Herausfordererkonfiguration.

Zentral in dieser steht Franz, Vetter der Erzählerfigur und Sohn Millas. Vetter Franz ist aggressiv sogar von Berufs wegen. Er ist der fromme Boxer. Leider scheitern seine Vorschläge, Tante Millas Tyrannei zu brechen, einerseits an dem hartnäckigen Widerstand der restlichen Familie wie andererseits am fehlenden Durchhaltevermögen Franzens selber. Der Satiriker deklassiert ihn. Franz hängt seine Boxhandschuhe an den Nagel, seine Frömmigkeit wird zur Melancholie, und er entläuft ins Kloster. Um Vetter Franz gruppieren sich als Herausfordererfolien seine Schwester Luzie, sein Bruder Johannes und auch sein Vater. Nach und nach, wenn Millas Regiment immer unerträglicher wird, fühlen sie sich bewegt zu Protestaktionen, die allerdings von vorneherein ins Leere zielen. Weiterhin gehört teilweise in die Herausforderersphäre die Erzählerfigur. Sie und Vetter Franz entsprechen einander. Der Boxer, der sogar Meister wird, verkörpert die Heldennorm und dankt erst am Ende der Geschichte ab. Der Sprecher tritt nach der niederen Norm an. Er will zwar als Ingénu und Vir bonus gesehen werden, ist aber die unter ihrer Potenzschwelle handelnde aristotelische Eiron-Figur. ${ }^{1}$ Ihre "Ironie" tut sich dar in bescheiden äquivokem Sprechen. Sie gibt ihre Chronik mit besorgter Stimme zum besten, sieht wohl bisweilen, wie schlimm die Dinge in der Verwandtschaft stehen, legt sich aber geflissentlich Scheuklappen an und interpretiert darum die Ereignisse immer wieder falsch.

Sind die Familienmitglieder einerseits mit der Subjektsphäre verbunden, so bilden sie mit Ausnahme von Vetter Franz andererseits Stützringe um die Repräsentationsfigur des satirischen Objekts, Tante Milla. Obwohl man allerlei Finten entwickelt, um sich deren 
Autorität zu entziehen, geht nur Vetter Franz resolut, wenngleich erfolglos gegen Milla vor. Nur die Enkelkinder sind nicht ambivalent gezeichnet. Sie stehen voll im Subjektraum. Da sie Kinder sind, stellt der Satiriker keinen Anspruch an sie als Herausforderer. Ihre gelegentlichen spielerischen Störungsgesten gegen Tante Milla geben der Subjektsphäre Kontur und haben somit figurativen Wert. So ist der Sockel, auf dem Tante Milla steht, am Ende der Geschichte zwar voller Risse, im Grunde aber intakt. Die satirische Szene dauert an. Es heißt: "Jedenfalls: die Feier wird fortgesetzt" $\left(\mathrm{W}_{2}, 34\right)$.

Die familienzerstörende Missetat Tante Millas, um die es hier geht, ist eben diese Feier und gehört zu Bölls besten Eingebungen. Das Schweigensammeln in "Doktor Murkes gesammeltes Schweigen," die Wegwerftätigkeit in "Der Wegwerfer" oder das Berufstrauern in "Es wird etwas geschehen" sind nicht skurriler. Es ist Millas atemberaubende Obsession, mit ihrer Familie das ganze Jahr hindurch, Abend für Abend, Heiligabend zu feiern. All dies beginnt wie eine harmlose Schrulle. Milla liebt ausgesucht und reichlich geschmückte Weihnachtsbäume. Sie zeichnen sich besonders aus durch hitzebewegte Glaszwerge, die auf Ambosse hämmern, und einen Baumspitzenengel, der ad nauseam "Frieden, Frieden" (24) flüstert. Als jedoch eines Jahres bei Saisonende der Baum entfernt werden soll, bricht Milla in ein durch Mark und Bein dringendes Geschrei aus. Mannigfaltige Versuche, es zu unterbinden, versagen. Milla beruhigt sich aber sofort, als man endlich einen neuen Baum schmückt. Sie besteht fortan darauf, allabendlich mit der Familie die Feier zu wiederholen. Es werden dieselben Weihnachtslieder gesungen, dieselben weihnachtlichen Glückwünsche ausgetauscht. Man knabbert an Gebäck und Süßigkeiten, man hört die Glaszwerge hämmern und den Engel flüstern. All dies beansprucht die Nerven der Familie aufs ärgste. Man beginnt Ungewöhnliches $\mathrm{zu}$ treiben. Johannes wird Kommunist, Luzie gibt sich "existentialistischen" Tänzen hin und will mit Mann und Kindern auswandern in ein Tropenland, wo es keine Weihnachtsbäume gibt. Der Mann Millas, ein "christlicher Kaufmann," entschließt sich trotz recht hohen Alters zu einer Geliebten. Der Sohn Franz macht als einziger den verewigten Weihnachtsrummel nicht mit, warnt vor diesem "Getue" und "Unfug" (12), "wütet" (22) in der Familie herum mit dem Ansinnen, seine Mutter in eine Anstalt zu bringen, schlägt einen regelrechten Exorzismus vor und versucht, die gefährdeten Enkelkinder unter Jugendschutz zu stellen.

Es ist also Vetter Franz, der konstruktive Ideen zum Phänomen Tante Milla hat. Es zeichnet ihn Aggressivität aus, die schon dadurch gerechtfertigt ist, daß sie auf Entfernung des Anstößigen zielt. Obwohl er seine eigene Mutter im konventionellen Sinne nicht ehrt, ist 
er alles andere als ein Unmensch. Er wird als einzige Figur mit dem Zeichen humanen Bekennertums ausgestattet. Als Soldat hat er sich bei seinen Vorgesetzten unbeliebt gemacht, "indem er Russen und Polen wie Menschen behandelte" (15). Leider hat seine Mutter das größere Stehvermögen. Sie feiert, er flüchtet ins Kloster. Für Vetter Franz gilt, daß seine Pflichten nicht hinter den Klostermauern, sondern in der Welt liegen. Er desertiert vom Leben. Wenn Böll hier schon ausdrücklich "Entfernung von der Truppe" propagieren würde, so wäre diese die Entfernung vom Kloster. Vetter Franz bietet darum in seiner Kutte keinen harmonischen Anblick. Der Sprecher ist "erschreckt: diese große Gestalt mit der zerschlagenen Nase und den dicken Lippen, sein schwermütiger Blick-er erinnerte mich mehr an einen Sträfling als an einen Mönch" (34).

Das Kloster ist hier nicht Zufluchtsort des Verfolgten, sondern ein Gefängnis, ein Ort der Strafe. Das Strafwürdige an Vetter Franz ist sein Versagen vor dem Feind, seine Schwäche als Kämpfer. Er macht einen Versuch, seine Flucht zu kaschieren, indem er behauptet, "[w]ir sind mit dem Leben bestraft" (34). Ist ihm das Leben an sich Strafe, so sieht er es auf die Erbschuld bezogen. Damit entfiele zum einen zwar die Verantwortung, weil er nicht im Stadium des Vergehens, sondern schon in der Folge des Vergehens lebt, und zum anderen aber auch der Grund zur Flucht. Aber Vetter Franz zielt zweifellos auf eine Apologie für seinen Eintritt ins Kloster. Die Klostermauern bieten mehr Sicherheit gegen die Strafen des Lebens als der von seiner Mutter beherrschte Boxring der Familie. Vetter Franz muß als Flüchtling vom Leben gesehen werden, denn von Straffreudigkeit ist an ihm keine Spur zu entdecken. Er fordert keine härtere Rolle, sondern eine sanftere, etwa wie sich der Sprecher in "So ein Rummel" auf dem Rummelplatz nicht mehr an der Front, sondern in der Etappe wähnt. Selbst das Gespräch, das die Erzählerfigur mit ihm am Ende der Erzählung führt, ist Vetter Franz eine Belastung im Vergleich zu seinen Mönchspflichten: “Wir unterhielten uns stockend, und er war offenbar erleichtert, als die Glocke ihn zum Gebet in die Kirche rief. Ich blieb nachdenklich stehen, als er ging: er eilte sehr, und seine Eile schien aufrichtig zu sein" (34). Die Mönchskutte ist Sträflingskleidung, die der Satiriker ihm anmißt. Franz ist zwar Versager, aber unter mildernden Umständen. Der Satiriker nimmt ihm nicht alle Integrität. Seine Flucht wäre demnach Eile zum Gebet. Hier eröffnet sich Vetter Franz als Pfuscher. Er verwechselt die Fronten. Das Gebet hält er für ein Antidot gegen die Strafe des Lebens. Aus dem Kämpfer ist ein Bittsteller geworden. Als solcher ist er nicht frei von Lächerlichkeit. Bringen wir nämlich seine Bittstellungen an Gott in Beziehung zum Problem Tante Milla, so ergibt sich Komik, die allerdings 
stark im Zeichen der Trauer um den Versager steht. Daß der Eintritt ins Kloster ein negativer Akt ist, geht aus der später zu behandelnden Norm dieser Satire klar hervor. Sie verträgt sich keineswegs mit der Auffassung des Lebens als Strafe. Bölls Norm in "Weihnachtszeit" meint Lebensbejahung.

Auch die Geschwister von Vetter Franz sind Spielarten des Wegläufers. Johannes entläuft zur Truppe, indem er Kommunist wird, während Luzie mit Mann und Kindern in exotische Regionen auszuwandern sich anschickt. Das Gemeinsame an den Fluchtzonen Kloster, Kommunismus und Tropen ist das Assoziationsfeld des Utopisch-Idyllischen. Im Kloster herrscht der weltfremd-kontemplative Geist, der Kommunismus träumt von einer befriedeten Welt, die Tropen meinen eine romantisierte Zivilisationsferne, wo es keine Schrecknisse wie Weihnachtsbäume und Spekulatius gibt. Diese Gefilde jenseits des harten Lebens sind nichtsdestoweniger für Böll Illusion. Die vollkommene Welt gibt es nicht. Er macht das in einem Streiflicht klar. Als Kommunist ist Johannes nicht damit beschäftigt, einen Bezirk seiner Partei zu organisieren, sondern "umzuorganisieren" (34). Wenn der Gedanke der Perfektion in der Ideologie oder in geographischer Ferne für Böll ein Trugschluß ist, so liegt darin ein Indiz gegen die Flucht und eine verhaltene Aufforderung zur Standfestigkeit und zum Kampf an Ort und Stelle. Wie die Satire vielfach auf Utopie zielt, so ist die Skepsis gegen die verwirklichten Utopien eine ihrer stärksten Konventionen. Was Swifts Gulliver auch immer in wunderbaren Fernen findet, und seien es die Houyhnhms mit ihrem vollkommenen aber darum unmenschlichen Rationalismus, so liegt dort nicht das ideale Leben. Swift schickt Gulliver zurück in den heimischen Pferdestall. Orwell zerstört die Utopie des Kommunismus in Animal Farm, Huxley kehrt den Glauben an die Erlösung durch die Technik in Brave New World in einen Alptraum um.

Als Wegläufer sind Johannes und Luzie weniger ernst zu nehmen als Franz. Sie stehen deutlicher im Lichte des verlachend Satirischen. Im Gegensatz etwa zu Murkes Mutter stützt sie der Humor nicht, weil sie ihrerseits Tante Milla stützen. Ihre Verletzung ist ihr eigenes Tun. So haben wir mit Luzies Nervenkollaps kein sonderliches Mitleid, sondern lachen sie aus, wenn sie ihr Mütchen am falschen Objekt kühlt, indem sie bei Freunden einen Weihnachtsbaum zerstörtwobei "anhaltendes Gebrüll ihrem Munde entströmte" (26). Die Komik, mit der Johannes und Luzie gezeichnet sind, meint nicht soziale Verletzung, sondern Mitwirkung an der Groteske Tante Millas. Luzies Anfall von Verrücktheit ist Nachahmung Tante Millas. Der Glanz des Weihnachtsbaumes spiegelt sich in dem Fanatikerblick, den Johannes zur Schau trägt. Ungefähr denselben Stellenwert auf 
der Skala des Lachens nimmt der Sprecher als Figur ein. In schwulstigen Metaphern und im Pathos tunlicher Besorgtheit intoniert er zu Anfang der Erzählung, "Schimmelpilze der Zersetzung haben sich unter der ebenso dicken wie harten Kruste der Anständigkeit eingenistet, Kolonien tödlicher Schmarotzer, die das Ende der Unbescholtenheit einer ganzen Sippe ankündigen." Der Leser rechnet auf den ersten Blick mit einem kritischen Erzähler, der dazu im selben Atemzug noch Vetter Franz lobt: "Heute müssen wir es bedauern, die Stimme unseres Vetters Franz überhört zu haben, der schon früh begann, auf die schrecklichen Folgen aufmerksam zu machen, die ein 'an sich' harmloses Ereignis haben werde" (11). Das Gerede von der "harten Kruste der Anständigkeit" klingt nach Ironie. Das "Ereignis" bezieht der Leser zunächst ohne Vorbehalt auf Millas Reaktion zur Entfernung des Baumes bei Saisonende. Aber nach und nach wird klar, daß die Pietätlosigkeiten der Familie gegenüber Tante Millader Ehebruch ihres Mannes, der Kommunismus Johannes', die Auswanderung Luzies und Franzens Beruf als Boxer-für die Erzählerfigur ebenso ernste Untergrabungen der Anständigkeit sind wie das Benehmen der Tante. Von Ironie, in der sich eine Gegenposition zur Formulierung des Gesagten reflektierte, kann nur die Rede sein, wenn wir erkennen, daß sie vom Satiriker hinter dem Rücken seiner Persona entwickelt wird. Die Floskel "dicke wie harte Kruste der Anständigkeit" ist ein Wulst, den der Sprecher allen Ernstes von sich gibt, aber auch satirische Verzerrung durch den Satiriker. Der Sprecher ist ein Narr, der seinen Scharfblick und seine Anständigkeit durch einen stilistischen Kraftakt unter Beweis stellen will. Als angeblicher Befürworter der Vernunft stellt er Tante Milla als äußerst nervenbelastend hin. Nichtsdestoweniger belegt er sie immer wieder mit Vokabeln wie "reizend" und "liebenswürdig." Onkel Franz, der das Feiern aufs energischste unterstützt, ist für ihn "dieser herzensgute Mensch" (15). Da man sein eigenes Nest nicht beschmutzt, verniedlicht der Sprecher die Probleme seiner Verwandten, indem er sie als nur "ins Kraut geschossen," und die Ursachen als "harmlos" und "geringfügig" (11-12) abtut.

Der Sprecher ist an all dem gemessen kein scharfblickender Moralist, der die Dinge klar zu trennen und werten vermag. Im Grunde ist er ein hausbackener Typ, dem nur einmal in den Sinn kommt, aufgrund der Familienkrise die Weihnachtskonventionen an sich in Frage zu stellen. Nur einmal glückt ihm die grundsätzliche Beobachtung, gewissermaßen gegen die dicke Kruste seiner Konventionalität, daß die Ereignisse in seiner Familie nicht zufällig und nicht relativ harmlos sind: "Wir hätten früher auf die Idee kommen können, es stimme etwas nicht. . . . wenn überhaupt jemals irgend etwas ge- 
stimmt hat-ich zweifle daran" (13). Gegen diese Aussage stehen allerdings seine konventionellen Vorurteile, die letztlich bestimmend sind, wenn er sich z.B. gegen die Generation der Jungen entscheidet, "von der sich ja inzwischen herausgestellt hat, daß sie nichts taugt." Er ist Konservativer der engstirnigen Prägung, für den alles Beachtenswerte der Vergangenheit angehört. So wundert er sich, daß Vetter Franz die "fragwürdigen Aufregungen" der Gegenwart mehr interessieren als die "erregenden Geisteskämpfe früherer Jahrhunderte" (11). Dem gelegentlichen Anschein widersprechend sind die Äußerungen der Erzählerfigur nicht ausgewogen kritisch, sondern die Pose eines Beschränkten, der dessen ungeachtet als Bildungsrichter auftreten will. So urteilt er, daß sein Vetter Johannes "trotz des akademischen Grades, den er errang, ein ungebildeter Mensch war" (28). Diese Bemerkung leistet übrigens nichts im Zusammenhang der Textstelle. Sie ist pure Boshaftigkeit, die sich der Sprecher gelegentlich nicht versagen kann. Sie richtet sich aber vornehmlich nicht gegen Milla, sondern deren Kinder, zweifellos weil diese sich gegen seine Vorstellungen von Anständigkeit vergehen. Der Nachtlokale besuchenden Luzie hängt er zur Strafe gewissermaßen ein Parteiabzeichen an, indem er erwähnt, daß sie im Krieg in einer "Hakenkreuzstickerei" (11) tätig gewesen sei.

Zentral in der Objektsphäre, die der Sprecher immer wieder stützt, steht Tante Milla. Sie erinnert an den Matriarch in Haus ohne Hüter, der mit seinem Getue und Geschrei über den bluthaltigen Urin die Familie in Schrecken hält. Tante Milla ist der einzige weibliche Antagonist in den Kurzsatiren Bölls. Wie die Wahl des Matriarchen als beherrschende Erscheinung sich in Haus ohne Hüter aus der vaterlosen Nachkriegswelt ergibt, so erklärt sich Milla als Antagonist dadurch, daß Frauen traditionsgemäß die Rolle der Sittenpflege oblag. Man denke an Goethe: "Willst du genau erfahren, was sich ziemt, / So frage nur bei edlen Frauen an." 2 Was aber für das Bürgertum noch angehen mochte, ist in dessen Restauration für Böll ein Unwert. Milla wird vom Satiriker mit ironisch $\mathrm{zu}$ verstehenden modernen Entsprechungen des Wortes edel belegt. Sie ist, wie gesagt, "reizend" und "liebenswürdig." Was sich hier "ziemt," ist eine Groteske, die Milla wie eine Schatztruhe verwaltet. Wenn nämlich das Weihnachtsfest aus seinem rhythmischen Zusammenhang des Jahreszeitlichen gerissen und zur dauernden Feier der Erneuerung verabsolutiert wird, ist es eine Konvention im übelsten Sinne des Wortes, d.h. die Observanz einer Verhaltensweise um ihrer selbst, nicht aber ihrer Wirklichkeitsbedingtheit willen.

Sinnentleerte Konventionen haben für den Satiriker natürlicherweise eine antagonistische Dimension. Sie stehen der freien Entfal- 
tung des Lebens entgegen, sind letztlich ein aggressives Moment gegen das Neue, oder genauer, gegen das Prinzip der Erneuerung. Darum geht es in "Weihnachtszeit." So hieße es, die Erzählung zu eng zu interpretieren, wenn man die Pointe als gegen die autoritäre Familie gerichtet sähe. Tante Milla ist Familienoberhaupt, aber darüberhinaus synekdochisch ein sittenhütendes Schreckbild, in dem sich irgendeine Instanz erblicken läßt, die geehrte Konventionen als Machtmittel einsetzt. Dabei löst Milla eine derart hektische Tätigkeit um sich her aus, so daß man in den irr auf die Ambosse schlagenden Zwergen das Spiegelbild der Familienangehörigen erkennen kann, die sich um einen völlig unnachgiebigen Gegenstand bemühen. Die Hämmerei erweckt zwar Geräusche, übertönt aber keineswegs den "Frieden, Frieden" flüsternden Baumspitzenengel, in dem die über dem Geschehen thronende Tante Milla bildlich erscheint. In dem Geflüster liegt mehr als nur deren Aggression, die sich mit der Weihnachtsidee tarnt. Das Wort Frieden schließt das satirische Objekt auf wie ein Sesam. Die Baumschmückerei, so erfahren wir, wurde durch den Krieg unterbrochen. Bei Kriegsende will Milla ihre Art Baum wiederhaben, so daß alles wieder "so sein sollte wie früher" (16), d.h. wie im Frieden. Dieser war aber ein ganz besonderer, nämlich die Hitlerfriedenszeit, für Milla im Gegensatz zum Krieg etwas Angenehmes. Im Kontext der Weihnachtsbaumneurose Millas ist jedoch der Krieg als das Positivere zu sehen. Bombeneinwirkung zerstört Zwerge und Engel; erst "nach harten Kämpfen, endlosen Disputen, nach Tränen und Szenen" (15) bequemt sich Milla, den Baum für Kriegsdauer aufzugeben. Im Verhältnis zum Hitlerfrieden erscheint der Krieg hier als Umbruchsmoment zum Neuen. Nach 1945 hätte nicht alles wieder so sein sollen wie im Vorkriegsfrieden Hitlers. Aber man besteht nichtsdestoweniger darauf, und so nimmt es nicht wunder, daß selbst gewissermaßen sakrale Konventionen wie der Weihnachtsbaum mit zerstörerischer Aggressivität in Berührung kommen. Man feierte schließlich in der Hitlerfriedenszeit Weihnachten unbekümmert darum, daß der christliche Neuerungsgedanke und der vom Engel des Evangeliums verkündete Frieden unverträglich waren mit dem Chiliasmus des Faschismus. So verlangt letztlich die Satire "Weihnachtszeit" vom Leser ein kritisches Befragen aller Traditionswerte, die man glatt in die Welt des Faschismus und ebenso glatt in die Nachkriegswelt einfügte. Man frönte einer Vergangenheitsnostalgie, die H. M. Waidson wie folgt umreißt: "Bölls Satire richtet sich gegen den Geist der Restauration, wie er ihn im Westdeutschland der Nachkriegszeit entdeckte, gegen diese Sehnsucht, in die 'gute alte Zeit' zurückzukehren und jeder moralischen Verpflichtung gegenüber in Erinnerungen an die Jahre 1930-40 aus- 
zuweichen." ${ }^{3}$ Als Konzept ist das satirische Objekt diese Restauration, deren Destruktivität sich an sozialen Strukturen wie z.B. die der Familie erweist.

Das Thema Krieg ist dem Sprecher peinlich. Er entschuldigt sich, ihn überhaupt erwähnen zu müssen: "Im Krieg wird gesungen, geschossen, geredet, gekämpft, gehungert und gestorben-und es werden Bomben geschmissen-lauter unerfreuliche Dinge, mit deren Erwähnung ich meine Zeitgenossen in keiner Weise langweilen will" (13). In diesen Verharmlosungen verbeugt sich der Sprecher vor seiner Mitwelt, indem er ein Echo ihrer Ansichten gibt. Der Krieg kann offensichtlich kein Auslösemoment zur Erneuerung sein, wenn er als Banalität abgetan wird. Der erschreckende Grad der Verharmlosung läßt den verzerrenden Satiriker hinter seiner Maske erkennen. Grauenhaftes wird als Alltägliches hingestellt, um es zu entlarven. In typischer satirischer Manier spricht Böll mit verstellter Stimme. Was auf den ersten Blick als das Normale gelten kann, läßt er an Stelle des gemeinten Negativen erscheinen, gibt aber gleichzeitig Signale, die das Lesen mit umgekehrtem Vorzeichen verlangen. Er erreicht dies durch den übertriebenen Grad des Euphemistischen, der den Sprecher auf den zweiten Blick fast in den Bereich des Zynischen stößt. Swift führt in "A Modest Proposal" nach diesem Rezept die ökonomische Vernunft, ein dem Publikum durchaus genehmes Prinzip ins Feld, um unmenschliche Ökonomie zu entlarven. Das Kinderschlachten und der Konsum von Kinderfleisch werden als rational hingestellt, um die Schrecknisse der irischen Hungersnot und die Unmenschlichkeit derer zu verdeutlichen, die sie kaltblütig geschehen lassen. Ebenso kaltblütig stehen die Zeitgenossen des Sprechers in "Weihnachtszeit" dem Kriege gegenüber. Eine moralische Frage ist er beileibe nicht. Für den Sprecher ist er etwa eine ästhetische. Millas Baum bezeichnet er als Opfer des Krieges und fügt hinzu, "von anderen Opfern zu sprechen, verbietet mir der rote Faden" (14).

Diesem schlimmstenfalls "unerfreulichen" Krieg folgt ein "erfreulicher" Friede, den die Tagesgeschichte mit dem Terminus Wirtschaftswunder belegte. Das Medium der Zerstörung sind jetzt nicht mehr Dinge wie Bomben, sondern die Konzepte Konsum und Verschleiß. Millas Mann versteht sich gut auf die neue Wirklichkeit. Er kann trotz des Verbrauchs ungeheurer Mengen von Baumschmuck, Gebäck und Marzipan das Vermögen der Familie unvermindert erhalten. Es bleibt, wie gesagt, alles beim alten. Darin liegt zum Teil der bedrückende Effekt dieser Satire und auch die Erklärung für ihre Breite. Wenn über fast zwei Jahre hinweg die ewige Weihnacht gefeiert wird, so meint das die Fortdauer eines anstößigen Zustandes, der 
die Hitlerzeit und die Nachkriegszeit miteinander verklammert. Das Ende dieser Ära ist nicht abzusehen. Tante Milla, die sie verkörpert, erfreut sich robuster Gesundheit. Das ärztliche Urteil, das man einholt, ist für die Hoffnungen auf ihr baldiges Ableben "vernichtend" (27).

Ist das satirische Objekt die Restauration, die mittels entleerter Konventionen vorgeführt wird, so ist deren Dingsymbol der Weihnachtsbaum. Geputzt, wie er in Millas Familie steht, ist er kein Erneuerungs- und Hoffnungsbild, sondern Zeichen erstarrten Lebens. Augenfälligeres zur Darstellung eines Konventionalisierungsprozesses ist kaum vorstellbar. Die in der Natur stehende immergrüne Tanne wird gerade dadurch zum Symbol menschlicher Hoffnung auf ein neues Leben, daß sie aus der Natur entfernt und in die Mitte eines menschlichen Kreises beim Weihnachtsfeiern gesetzt wird. Damit ist allerdings schon der Prozeß der Sinnentleerung eingeleitet, denn abgehauen verspricht der Baum nicht mehr die grünen Sprossen und den Glanz des Frühlings. Man gibt ihm das Verlorene künstlich zurück, indem man ihm Kerzen aufsetzt und ihn mit Schmuck versieht. Je reicher der Schmuck, desto ärmer wird der Baum in seinem Wert als lebendes Symbol und desto stärker profiliert er sich als Konventionschiffre, die Leben nur vortäuscht. Der Prozeß zum Konventionellen wird von Böll mit Nachdruck als dem Menschlichen unzuträglich hingestellt. In der Familie Millas ist das Baumschmücken ein die Gemüter stark belastender Vorgang. Die Stimmung, die es hervorruft, ist "einfach gräßlich," man hat "vor Nervosität keinen Appetit," und es kommt zu "schrecklichen Szenen" (14), wenn der Schmuck bisweilen vom Baum fällt. Die Plünderung des Baumes, von der die Rede ist, umreißt Millas Baum weiter als Konventionssymbol. Es sind die "gierigen" (18) Enkelkinder, die ihn plündern. Hier regt sich das junge Element gegen das alte. Es vergreift sich am Hergebrachten, zollt ihm keinen Respekt. Es ist weiter die Rede von "nichtsnutzigen Kindern," die bei Saisonende die ausgedienten Bäume durch "Asche und sonstigen Unrat" (17) schleifen. Böll konfrontiert hier das ewige Weihnachtsfest als starre Konvention mit den unaufhaltsam fortschreitenden Jahreszeiten. Karneval kommt; Gruppen "jugendlicher Trunkenbolde" und "maskierte Kinder" feiern ihn (21). Millas verewigtes Weihnachtsfest ist absurd, weil das Leben, sofern es in natürlichen Bahnen läuft, weitergeht. Hier liegt Bölls Norm: Er befürwortet den natürlichen Fluß des Lebens. Er bettet seine Norm in eine invertierte Erneuerungsmythe, d.h. eine "Wintermythe," wie man sich keine beispielhaftere für das Konzept Northrop Fryes denken könnte. Die Familie, die den ewigen Winter feiert, heißt "Lenz." Bezeichnenderweise wird dieser ironische Name nur einmal 
erwähnt, und zwar in Verbindung mit Vetter Franz, also der Person, die den Winter hätte besiegen können. So nimmt nicht wunder, daß der Name in Anspielung auf ihn als Kämpfer fällt. Allerdings ist er schon nicht mehr der Herausforderer, sondern schon der Abdankende zu diesem Zeitpunkt. Ein Plakat kündigt den letzten Kampf des "Altmeisters Lenz" (31) an. Wie Böll einerseits die Starre des Winters in der Domäne Millas nach rechter satirischer Manier andauern läßt, so bringt er andererseits durch Bild und Technik die Dinge wieder in Fluß. Frye erörtert die gegen leere Konventionen gerichtete Satire als ein Beweglichmachen des Lebens. Sie räumt auf mit dem "Gestrüpp von stereotypen Formen, versteinerten Glaubenssätzen, abergläubischen Geistesknebelungen, Sonderlingstheorien, pedantischen Doktrinen, tyrannischen Moden und allen anderen Erscheinungen ... die die freie Entfaltung (wenn auch nicht notwendigerweise den Fortschritt) der Menschheit behindern." ${ }^{4}$ Der Fluß des Lebens mag zwar in "Weihnachtszeit" unter einer dicken wie harten Kruste verborgen sein, aber man fühlt ihn trotzdem. Die Zwerge leiern aus, das Zuckerwerk fließt in der Sommerhitze davon. Der Baum verliert seine Nadeln und muß von Zeit zu Zeit erneuert werden. Millas Baum ist darin gerade das Gegenteil eines Neuerungssymbols, zeigt jedoch auch die Macht der Zeit und damit die Unzeitigkeit der verabsolutierten Weihnachtsfeier.

Wenn Böll in "Weihnachtszeit" hohle Konventionen in ihrer zerstörerischen Funktion im Rahmen der autoritären Familie zeigt, so wählt er als Schauplatz eine Struktur, die die Gesellschaft im Großen reflektiert. Böll versteht es in dieser Erzählung - und darin liegt ein guter Teil ihrer Überzeugungskraft und historischen Relevanz-die Starrheit der Konventionalität in der Lenzfamilie mit dem Grundprinzip des Konsums und Verschleißes in unserer Gesellschaft zu verquicken. Totes wird mit falschem Leben verknüpft. Im Schnittpunkt der Linien steht der Weihnachtsbaum. Wenn er in der Natur seine Nadeln verliert, so ist das Phänomen Ausdruck des natürlichen Lebensflusses. Im Hause ist der Verlust der Nadeln gewissermaßen unnatürlich, da er unersetzbar bleibt. Man tarnt diesen Verlust des Lebendigen mit Schmuck. Das ist zwar schon Konventionalität, aber nicht pervers, da man normalerweise das Weihnachtsfeiern unter dem Aspekt der richtigen Zeit ablaufen läßt. Fällt dieser Aspekt fort, wie in der Lenzfamilie, begeht man sozusagen Völlerei. Der Baum Millas treibt den Fluß des Lebens ins Hektische und ist gleicherweise tote Konvention, da er außerhalb des Zeitlichen steht. Damit ist er geradezu Dingsymbol der generellen satirischen Szene. Wie Astrid Swift formuliert, "hat man es bei der Satire bei aller wilden Geschäftigkeit mit einer im wesentlichen statischen Handlung zu tun." ${ }^{5}$ 
Millas Baum und sein Zubehör bedeuten Verschleiß, weil er einen künstlichen, sogar einen pathologischen Bedarf deckt, der Millas Neurose entspringt. Von der Völlerei der Lenzfamilie geht der synekdochische Schritt zu der Völlerei einer Gesellschaft, deren Vermögensbegriff sich zu einem beträchtlichen Teil aus dem Grad der Konsumhöhe bildet und deren Formel des Verschleißes man durchaus als pathologisch bezeichnen könnte. In der Konsumgesellschaft ließe sich Verschleiß definieren als geplanter und intendierter Verlust, der wettgemacht wird durch einen geplanten und intendierten Verlust. So gesehen ist das Prinzip Verschleiß zweifellos zerstörerisch. Zwar reagieren Millas Angehörige instinktiv noch richtig, wenn sie um die Langlebigkeit des Baumes und seines Zubehörs bemüht sind, und der Sprecher über die Unkosten klagt: "[D]er Verschleiß an Zwergen, Ambossen und Hämmern [ist] enorm. . . . Der Verbrauch an Kerzen, Spekulatius, Marzipan, das Baumabonnement, Arztrechnungen und die vierteljährliche Aufmerksamkeit, die man dem Prälaten zukommen lassen muß, alles zusammen, sagte mein Onkel, komme ihm täglich im Durchschnitt auf elf Mark" (25-26). Dieser unbewußte Tribut an einen Wert, den man als natürliche Sparsamkeit bezeichnen könnte, ist allerdings überflüssig. Konsum führt bekanntlich in der Konsumgesellschaft-vorerst-nicht zu Armut. So kann die Lenzfamilie ihren Vermögensstand wahren. Ermöglicht wird dies durch eine folgerichtige Entwicklung in den Geschäftsmethoden, die Onkel Franz jetzt anwendet. Sie sind rabiater. Onkel Franz ist nicht mehr der "christliche Kaufmann" von ehedem. Darum ist er beileibe nicht kriminell. Er tut, was die Gesellschaft verlangt, er leistet ihr einen Dienst wie die Firma Söderbaum, die versteht, worum es beim Prinzip Verschleiß geht; konsequenterweise unterhält sie einen "Tannenbaum-Frischdienst" (23).

Totenstarre und manischer Verschleiß markieren die extremen Möglichkeiten eines falschen Lebensflusses. Der richtige Fluß des Lebens wäre gekennzeichnet durch die christlichen Inhalte der Weihnachtsvorstellung. Um diese zu erhellen, ist für Böll hier vornehmlich das Konzept der Zeit wichtig, nicht das der Ewigkeit. Bei der niederen Norm des Lebensflusses geht es um die verpfuschte Zeit. Man ist in der Lenzfamilie zeitlich falsch koordiniert. Wenn die Zeit der Satire im figurativen oder wörtlichen Sinne der Winter ist, so gibt der Satiriker bisweilen die richtigen Zeithinweise, wie z.B. invertiert in der "Murke"-Satire, wo man bemüht ist, sich Schneegeschichten einfallen zu lassen. Tante Millas Weihnachtsbaum ist Symbol des ewigen Winters im Gegensatz zum Weihnachtsbaum an sich, in dem der Satiriker auf den Frühling deutet. Millas Baumengel verkündet einen Toten-Frieden. Die Verkündigung des Engels im Evangelium 
hingegen meint das Leben. Sie bedeutet Aussöhnung von Gott und Mensch als Vorbedingung eines Kampfes, den Christus mit seiner Auferstehung im Frühling als Sieger abschließt. Dieser Frieden verweist auf dynamische Lebenssicht im Gegensatz zur statischen der verbissenen Utopisten, als deren ganz besonders lächerlicher Vertreter Tante Milla verstanden werden kann. Im figurativen Sinne wollen alle diese eine ewige Weihnacht haben. Böll gehört gewiß nicht zu ihnen. Das fanatisch Absolute sucht man bei ihm vergebens. Das Utopische an seiner Heldennorm muß in Verbindung zur relativierenden der freien Lebensentfaltung gesehen werden. Das Utopische ist letztlich bei Böll die Sehnsucht nach verwirklichter Menschlichkeit, und diese läßt sich im Ansatz bei vielen seiner Figuren, besonders aber potentiell bei seinen Herausforderern entdecken. Als utopischer Satiriker dieser Prägung ist es sein Anliegen, den mannigfaltigen Formen der Unmenschlichkeit zu begegnen und die Aufforderung an den Leser ergehen zu lassen, ebenso zu handeln. In der satirischen Praxis hat Böll somit seit "Weihnachtszeit" nichts gegen Kampf-Einmischung erwünscht!- als Ingredienz eines freien Lebens.

Das Konzept Aggression ist in "Weihnachtszeit" folglich kein notwendiges Übel oder eine unbequeme Notwendigkeit. Wo es am Platz ist, gibt Böll ihm freien Raum. Die Enkelkinder begehren auf, ohne daß sie apologetisch in den Rahmen des Leidens gestellt werden, wie z.B. noch die Kinder in "So ein Rummel." In "Weihnachtszeit" ist das Leiden lächerlich, weil selbstverschuldet. Selbst die ausschließlich positiv gesehenen Enkelkinder verlangen kein Mitleid, sondern nur Mitgefühl. Mehr wird vom Publikum auch nicht im Hinblick auf die Erwachsenen gefordert. Der Druck, unter dem sie stehen, ist die Spiegelung der Verrücktheit Millas. Hysterie ist für Böll kein Tabu gegen satirische Hiebe. So ist die Verschrobenheit in Milla und ihren Kindern unter dem symbolischen Aspekt der Konventionalität etwas sehr Ernstes, aber in der direkten Erscheinung auch etwas sehr Komisches. Besonders die Perspektive des Komisch-Leichtgewichtigen ermöglicht es dem Publikum, sich der Problematik zu nähern. Daß es diese allerdings konsequent als auf sich bezogen versteht, ist durchaus nicht garantiert. Denn so entleert die Weihnachtsidee auch sein mag, man liebt sein Weihnachten nichtsdestoweniger. Es ist die Apotheose des Konsums, d.h. der Erneuerungsidee unserer Gesellschaft.

Um das Publikum gegen sich selber zu animieren und für die Subjektsphäre zu gewinnen, greift Böll zu einem Arsenal von Figuren, die mit einem Fuß im Subjektraum stehen und damit verschiedentliche Möglichkeiten der Identifikation bieten. Jedoch leistet dieser Kunstgriff allein die ästhetische Überzeugung nicht. Die satirische Technik, an der sich die Überzeugungsintention ablesen läßt, beruht 
auch in "Weihnachtszeit" vornehmlich auf dem Einsatz der Wortpaardialektik. Während Böll es in seinen kürzeren satirischen Erzählungen bei einem leitmotivischen Wortgegensatzpaar als Aufhänger dialektischer Bezogenheiten bewenden läßt, setzt er in den relativ langen Texten "Doktor Murkes gesammeltes Schweigen" und "Weihnachtszeit" zwei sogar miteinander verschränkte Paare ein. Hier sind sie das Schreien und Singen sowie das Schmücken und Plündern.

Ein wesentlicher, die Wortpaare betreffender Unterschied zu "Doktor Murkes gesammeltes Schweigen" soll sogleich hervorgehoben werden. Im Gegensatz zu Murke hat Vetter Franz nicht direkten Anteil an den Wortpaaren als konkreten Tätigkeiten. Er schreit, singt, schmückt und plündert nicht. Darin liegt noch eine gewisse Imperfektion in der Herausfordererkonzeption. Sie ist nicht vollauf mit der satirischen Technik verbunden. Trotzdem lassen sich die Wortpaare ohne Schwierigkeit dialektisch verstehen. Aus der Objektsphäre gesehen gilt das natürlich nicht. Im Bewußtsein Tante Millas können sie nur Gegensätze sein. Für sie sind das Schreien Ausdruck von Unzufriedenheit, das Singen Ausdruck von Glück. Das Schmücken schätzt sie, das Plündern ist ihr ein Greuel. Im Bewußtseinshorizont der Subjektsphäre und bezogen auf die Norm des Lebensflusses sind das Schreien und Singen der Kinder zur Karnevalszeit positiv zu wertende Reaktionen zum Jahreszeitlichen. Das erstere dient zur Vertreibung des Winters, das letztere bestätigt die Ankunft des Frühlings. Das Singen der Familienmitglieder zum Zwecke der Besänftigung Millas ist negativ zu werten. Es ist Kompromittierung des herausfordernden Elements. Was Milla erfolgreich begegnen könnte, wäre etwa exorzierendes Geschrei.

Das Schmücken und Plündern haben positiven Wert, wenn sie in die richtige Zeit fallen; sie sind falsch, sofern sie sich der Jahreszeit ungemäß ereignen. Zur Weihnachtszeit, im übertragenen Sinne einer Zeit echter Einkehr und Hoffnung auf ein richtiges Leben sind sie sinnvoll als Teil eines Erneuerungsritus, im Sommer dagegen nicht. Es ließe sich hier einwenden, das Plündern sei auch dann eine wünschenswerte Tätigkeit, da es zeitweilig den Baum außer Funktion setzt. Aber das Plündern ist außerhalb der Saison nur Vorbereitung zum Schmücken des neuen Baumes, somit Teil einer anstößigen Tätigkeit. Hier verschränken sich die Wortpaare. Eine Tätigkeit löst die andere aus oder zieht sie nach sich. Das Plündern des Baumes führt zu Millas Geschrei, dieses zum Schmücken eines neuen Baumes. Verstehen wir die Tätigkeiten temporal statt kausal, so läßt sich die zweite Verschränkungslinie ziehen. Man singt, bis der Baum seine Nadeln verliert und geplündert werden muß.

Was man an "Getue" und "Unfug" in der Lenzfamilie zur Be- 
schwichtigung Millas entwickelt, steht zum großen Teil unter dem Aspekt der Tarnung und Täuschung. Es ist Teil des Prinzips Micromegas. Das falsche Große tarnt sich als echt. Auf "Weihnachtszeit" bezogen hat man abzuwandeln: Das Kleine, hier Millas Kinder, trägt zur Machtbewahrung des Objekts bei. Ihr Singen, das Baumschmücken, das Anstellen von Schauspielern, das routinemäßige Austauschen von Weihnachtsglückwünschen sind zwar im vordergründigen Sinn Täuschung Tante Millas, aber da es sich nicht um wirkungsvolles Vorgehen handelt, sondern nur um Selbstschutz, stützen diese Anstrengungen den Objektbereich und sind letztlich dessen eigene Täuschung und Tarnung. Nur Franz schlägt echte Herausforderungsstrategien vor. Zwar wäre unter diesen der Exorzismus eine erfolgversprechende Schocktherapie, doch allerdings insofern auch eine Pfuscherei, als Milla kein religiöses Problem ist. Was man sich sonst an Maßnahmen einfallen läßt, sei es der Kommunismus, die Auswanderung oder auch der Klostereintritt, sind klare Verirrungen. Der Aspekt der Tarnung und Täuschung verliert in einem Fall das Moment der Herausforderung so total, daß er voll und ganz im Sinne Millas ist. An dem "reizenden" (23) alten Prälaten eröffnet sich eine direkte Selbsttarnung der Objektsphäre, die um so interessanter ist, weil sie quasi eine reine Selbsttäuschung ist. Der Prälat feiert im Gegensatz $\mathrm{zu}$ seinen beiden Vorgängern ohne Vorbehalt die ewige Weihnacht mit und ist so echt bei der Sache wie Tante Milla selber. Das nimmt nicht wunder; die hochkonventionalisierte Welt der Kirche, in der er sein Leben verbracht hat, hat ihn für das Weihnachtszimmer Millas geschult. Die Erzählerfigur blickt ausnahmsweise klar, wenn sie bezweifelt, der Prälat wisse überhaupt, "daß er eine und welche [Rolle] er spielt" (25). In diesem Würdenträger verbindet Böll zwar die Geistlichkeit mit dem Prinzip Konventionalität, aber gerechterweise nicht pauschal. Zwei andere Geistliche distanzieren sich von den Unsinnigkeiten in Hause Lenz. Besonders einer der beiden verdient erwähnt $\mathrm{zu}$ werden. Neben den alten Prälaten stellt Böll den jungen "Proleten," wie Milla diesen Priester nennt. Während seiner ersten Feier fällt er in einen Lachkrampf, wenn man mitten im Sommer singt, "nein, auch im Winter, wenn es schneit." Da Millas Meinungen grundlegend falsch sind, läßt ihre Invektive gegen den "Proleten" einen Satiriker erkennen, der selbst für den Klerus Hoffnung hat. Mit dem Terminus Prälat verbinden sich ekklesiastische Vorstellungen hierarchischer und konventioneller Art, mit Millas Formulierung "Prolet im Priestergewande" (23) das Gegenteil. Es wird das Kleine und Niedere gegen das Große und Hohe ausgespielt. Millas Bezeichnung unterschiebt dem jungen Geistlichen eine Täuschung, als sei dieser unter falscher Flagge im 
Weihnachtszimmer. Dieses entlarvende Indiz fällt offensichtlich in die Kategorie der Tarnung des Objekts zum Zwecke der Selbstbestätigung. Es unterschiebt der Gegenzone die eigene anstößige Taktik. Millas Trick schlägt aber auf sie enthüllend zurück. Die Formulierung "Prolet im Priestergewand" weist auf eine Diskrepanz von Träger und Kleid. Als Hohepriesterin des Konventionellen ärgert Milla verständlicherweise das Mißverhältnis nicht im Sinne des traditionellen Problems von Sein und Schein, wie wir es etwa aus Kellers "Kleider machen Leute" kennen. Wird Konventionalität hochgeschätzt, dann machen Kleider Leute. Für Milla ist der gewahrte Schein das Wesentliche. Für den die Tarnung aufhebenden Satiriker, sei es Böll oder Keller, sollten Leute eben Kleider machen. Der Prolet macht das Priestergewand richtig, indem er lacht. Der Sprecher ahnt dies. Er bezeichnet das Lachen des jungen Priesters erst als Beispiel "klerikaler Albernheit," ist aber dann "geneigt," es als "Ausbruch natürlicher Heiterkeit" (23) aufzufassen. Der Prolet ist natürlich und klerikal im rechten Sinne, wenn er lacht, der Prälat unnatürlich und klerikal im unrechten, wenn er zelebriert.

Die regen Täuschungstaktiken des Objektbereichs sind in Hinsicht auf die Norm vorgespiegeltes Leben, wo in Wahrheit Totenstarre herrscht. Man ahmt die Norm des Lebensflusses nach als Tarnung, und zwar erfolglos, und gibt damit ungewollt der Norm des Satirikers recht. Es lassen sich auf der Hand liegende Verbindungslinien zu Thomas Manns "Tristan" ziehen, wo das Sterbeinstitut "Einfried" sich als Sanatorium tarnt. In Manns Wintergeschichte herrscht dieselbe fieberhafte Energieentfaltung zur Verschleierung schlimmer Dinge. Das Sterben der Patienten wird wie folgt kommentiert: "In stiller Nacht wird der wächserne Gast beiseite geschafft, und ungestört nimmt das Treiben in 'Einfried' seinen Fortgang, das Massieren, Elektrisieren und Injizieren, das Duschen, Baden, Turnen, Schwitzen und Inhalieren. . . . Ja, es geht lebhaft zu hierselbst. Das Institut steht in Flor." ${ }^{6}$ Wächserne Gäste finden sich ebenfalls in Millas Weihnachtszimmer. Am Ende der Erzählung vertreten Wachspuppen die Enkelkinder, aber auch die lebenden Teilnehmer an der Feier wirken wie eine "Versammlung von Gespenstern" (33). Was im Weihnachtszimmer Millas und in "Einfried" geschieht, ist letztlich dasselbe:

Inzwischen haben die abendlichen Feiern im Hause meines Onkels eine fast professionelle Starre angenommen. . . . die Zwerge beginnen zu hämmern, und der Engel flüstert "Frieden, Frieden", dann singt man einige Lieder, knabbert Gebäck, plaudert ein wenig und zieht sich gähnend mit dem 
Glückwunsch "Frohes Fest auch" zurück—und die Jugend gibt sich den jahreszeitlich bedingten Vergnügungen hin. . . . Die Zwerge, ein wenig phosphoreszierend, bleiben starr in der Dunkelheit stehen, die Arme bedrohlich erhoben, und der Engel läßt sein silbriges, offenbar ebenfalls phosphoreszierendes Gewand sehen (24).

Hier bemüht sich der Satiriker darum, die Wirklichkeit hinter dem Weihnachtsschleier zu zeigen. Seinem Sprecher kann er nur bedingt trauen und so tritt er hinter seiner Persona hervor, wenn es um den Kern des Übels geht. Es ist nämlich sehr unwahrscheinlich, daß die Erzählerfigur in dem dunklen Raum zurückbleibt, nachdem die engere Familie den Raum verlassen hat und entweder zu Bett gegangen oder außer Hauses ist. Bleibt der Satiriker jedoch nach all dem Treiben im Raum zurück, so kann er gewissermaßen Ursache und Wirkung verbinden und zeigen, was weit über den Horizont der Erzählerfigur geht. Es leuchtet im Dunkeln die Farbe von Tod und Verwesung als Wirkung des weihnachtlichen Treibens. Durch den Hinweis auf Verwesung leistet der Satiriker nicht nur einen Beitrag zur Entlarvung des Objekts, sondern gibt auch ex negativo einen Fingerzeig auf die Norm des Lebensflusses, die sich am Natürlichen orientiert. Nichts unterbindet den Lauf der Dinge, wie nichts den Nadelfall und das sommerliche Schmelzen der Süßigkeiten verhindert.

In den reichlichen Euphemismen entlarvt sich die Objektsphäre ohne das Zutun des Satirikers. Sie stammen deutlich aus dem Munde der Erzählerfigur. Die anzüglichste Beschönigung ist die schon zitierte Beschränkung des Krieges, dessen Horror der Sprecher-nach dem Prinzip Micromegas-mindert, dabei aber ungewollt den Schrecken, den Milla erzeugt und darstellt, erhöht. Vom Leser wird jedoch verlangt, diese absurde Verdrehung der Verhältnisse wieder umzukehren. Das Resultat ist eine Schrumpfung des Objekts. Die meisten Euphemismen des Sprechers sind allerdings nur simple Verbeugungen vor der Familie. Es ist immer wieder die Rede von Onkel Franz als "herzensgutem Menschen" und Tante Milla als "liebenswürdiger" und "reizender" alter Dame. Ihr Zetergeschrei verharmlost der Sprecher zu einem "unerfreulich schrillen Konzert" (17). Er beschränkt sich jedoch nicht auf die Familie in seiner Schönrednerei. Als z.B. der Baum während des Krieges durch Bombeneinwirkung zerstört wird, versteigert er sich zu dem Satz "fremdländische Ballistiker löschten seine Existenz vorübergehend aus" (14). Der Sprecher will unbedingt als Vir bonus überzeugen, der gerecht und tolerant nach allen Seiten verfährt. Letzten Endes ist er aber ein stockkonventio- 
neller Typ, der es sich mit keinem verderben will und damit um so sicherer zum Narren wird.

Neben die bisher besprochenen Tätigkeiten, die gleichzeitig Tarnung und auch Entlarvung bedeuten, stellt der Satiriker eine Enthüllungstaktik, die in einem direkteren Sinne Technik ist als das bisher Besprochene. Wie Böll in "Doktor Murkes gesammeltes Schweigen" das Prinzip Häufung verwendet, um den Sturz des Funkhauses ins Quantitative zur Verschleierung abhandengekommener Qualität aufzuzeigen, setzt er, wie Hans Magnus Enzensberger ausführt, in "Weihnachtszeit" die Wiederholung ein, um die in der Lenzfamilie sich als Leben anbietende Starre zu bestimmen. ${ }^{7}$ Die Weihnacht ist ewig, aber im engeren Sinne allabendliche Wiederholung. Das Singen, das Gebäckknabbern, das Engelgeflüster stehen unter dem Zeichen des Immerselben. Dieses ist aber gewissermaßen das Ticken einer Uhr ohne Zeiger, ist tote Zeit im Gegensatz zur Zeit in der Wirklichkeit, wo die Geschehnisse sich natürlich ablösen. Das unzeitgemäße Singen der Weihnachtslieder enthält den Gedanken der toten Zeit besonders in dem Lied "Stille Nacht." Jede Nacht ist "stille" Nacht in Millas Weihnachtszimmer, während draußen die Nächte voller Karnevalslärm und -leben sein mögen. Das Prinzip des Jahreszeitlichen, das Böll stark betont, gibt dem Uhrwerk der leeren Zeit das Zifferblatt. Das Jahreszeitliche beinhaltet zwar Wiederholung, meint aber auch die Folge der Zeit als Änderung und als Abweichung vom Immerselben. Man kann darum Böll mit dem Hinweis auf das Prinzip "Wiederholung in der Zeit" gegen den Vorwurf Günter Blöckers, Böll variiere einen "ohnehin kargen Einfall" allzu lange, in Schutz nehmen. ${ }^{8}$ Messen wir jedoch seinen Einfallsreichtum an "Doktor Murkes gesammeltes Schweigen," so läßt sich hier eine gewisse Kargheit in der satirischen Technik nicht abstreiten. Es fehlen z.B. vergleichbare Stützpfeiler wie die Jadwiga-Herchen-Episode oder das Radiostück. Darüberhinaus entwickelt Böll in "Weihnachtszeit" kein vergleichbar weites Abwandlungspektrum des Micromegas-Prinzips. Trotzdem ist dieser Text ein satirisches Glanzstück. Der Reichtum an Komik sowie die Virtuosität, mit der Böll seine Vorstellung von Konventionalität in ökonomischer wie auch geistigreligiöser Perspektive in die Familie und Gesellschaft einbettet, sind unbestreitbar. 


\section{v. Die Berufssatiren:}

\section{Selbstabrechnungen des Satirikers}

Traditionsgemäß betont der Satiriker gern, ein Menschenfreund zu sein, besonders dem einzelnen gegenüber. Um gerade das glaubhaft zu machen, stellt er diesen als Typus hin und reiht ihn mit Vorliebe in einer Kategorie ein, die das Publikum herausfordern soll. Ganz besonders beliebt ist der Beruf, da diese Einordnung den Typus vor die Gesellschaft stellt, um deren Veränderung es dem Satiriker-neben der des einzelnen-geht. Wenn Böll sich in den fünfziger Jahren z.B. in "Die unsterbliche Theodora" einen Dichter, in "Im Lande der Rujuks" und in "Hier ist Tibten" Akademiker vornimmt, so vermeint man sich in der Tradition der Standessatire zu befinden. Aber Assoziationen, die beispielsweise in die Richtung der "Elenden Skribenten" Liscows oder in die der albernen Gelehrten und Professoren bei Rabener, Lessing oder Heine führen, sind unergiebig. Böll führt nicht etwa ein Spektrum sozialer Schichten in den verschiedenen Berufen auf, sondern er bemüht sich immer wieder um ein und dieselbe Kategorie, den Beruf des Satirikers, den er in chiffrierter Prägung anhand einer Reihe außergewöhnlicher Formen des Broterwerbs beleuchtet. ${ }^{1}$ Böll schreibt jetzt pro domo. Pocht der Satiriker den einzelnen schonend auf dessen Beruf im Angriff seiner Mitmenschen, so ist ihm sein eigener Beruf eher Mittel zur Beleuchtung seines Charakters, also nicht Schutz, sondern Eröffnung seiner selbst. So ist in Bölls Berufssatiren die erstaunlich breite Ansiedlung der Protagonistenmit der Ausnahme von "Mein Onkel Fred" und "Die unsterbliche Theodora" sind diese auch die Sprecher-ihrem Anspruch nach in der Subjekt-, ihrer Leistung entsprechend in der Objektsphäre, nicht etwa Zeichen arroganter Selbstbespiegelung, sondern eingehender Selbstkritik des Satirikers Böll.

Die Auseinandersetzung mit der eigenen sozialen Funktion ist unter Satirikern ein Charakteristikum, wenn nicht gar Gütezeichen. Wie Robert C. Elliott sagt, "it is a measure of the greatest satirists . . . that they recognize their own involvement in the folly of human life and willingly see themselves as victims, in obscure ways, of their own art." ${ }^{2}$ Beachtenswert ist zunächst bei Böll, daß er sich in einem zeitlich sehr gedrängten Textekomplex-es geht um sieben Arbeiten im Zeitraum 1951-1956-mit seinem Beruf befaßt. Der Anlaß ist 
offensichtlich. Böll verzeichnet seine ersten Erfolge zu Beginn dieser Periode. Der Preis der "Gruppe 47" fiel 1951 an ihn, und damit die Anerkennung der damals wichtigsten Jury. Nennenswerte Beachtung fand Böll nicht etwa schon mit seinem ersten Roman Der Zug war pünktlich (1949), sondern erst mit den Wanderer, kommst du nach Spa ...-Geschichten und dem Roman Wo warst du, Adam? (1951). Das Jahr 1951 ist somit als bestimmender Zeitpunkt anzusetzen. Bis dahin lebt Böll noch nicht ausschließlich von der Schriftstellerei. Arriviert und als freier Autor kann er nicht umhin, sich mit den Bedingungen seines Gewerbes und mit seinem Status auseinanderzusetzen. Gegen die Süße des Erfolgs steht dabei die saure Aufgabe, sich der Verantwortlichkeit seines neuen Ranges als öffentliche Stimme bewußt zu werden. Es "kommt ein Widerstand," so Böll, "der den merkwürdigen Namen Erfolg trägt. . . . Die Frage ist nur, ob [man] sich zwingen läßt und sich verderben läßt" (I, 22). Die Gefahr ist besonders groß, weil der Schriftsteller in Bölls Worten nicht "strafbar ... da er nur ungeschriebenen Gesetzen unterworfen ist" (ESR1, 304). Auf sein Gewissen zurückgeworfen erarbeitet Böll ein regelrechtes Paradigma dieser Problematik. Er gewinnt ihr immer wieder neue Nuancen $a b$ und beschränkt sich dabei übrigens nicht auf die Satire. Auch in der Parabel "Der Lacher" schlagen sich offensichtlich diese Belange nieder. Aber die Satire ist das geeignetere Medium. Ihr Aggressionsgehalt unterstreicht die Schärfe der Problematik als persönlich bedingt, während die Parabel eine distanzierte, wenn nicht gar transzendierende Position voraussetzt.

Für Böll ist zunächst bezeichnend, daß er als Erfolgsautor nunmehr seinen Neigungen zur privaten Idylle, seiner Sehnsucht nach grünen Inseln der Anonymität und Geborgenheit, seinem Verlangen nach einem Dasein rollenfreier Menschlichkeit in seinem eigenen Leben nicht mehr oder nur noch sehr begrenzt stattgeben kann. Er muß sich immer wieder gestehen, daß der Künstler die Welt zu konfrontieren hat. Ist diese Entscheidung gefallen, so folgt die Suche nach integren Möglichkeiten zur Verwirklichung des Entschlusses. Da der Weg in die Welt seinen Ausgangspunkt im Erfolg hat, ist er vorderhand sehr gefährlich. Wie ist das Phänomen Erfolg zu sezieren? Sind Bölls gesellschaftliche und künstlerische Normen, die, am kommerziellen Erfolg gemessen, das weitere Publikum zu bestätigen scheint, echte Kritik an der Gesellschaft oder dem Autor unbewußte Stützung des Bestehenden? Ist man als Schrifsteller, in Bölls Worten, etwa "ein Wolf im Lammfell" (ESR1, 314)? Ist man möglicherweise letzten Endes käuflich, ein schlimmer Narr (ESR1, 304)? Diese Fragen sind für den noch unbekannten Schriftsteller offensichtlich weniger drückend. Er macht sich zwar ebenfalls Gedanken über die zu vertretenden Werte, aber 
so lange das öffentliche Echo aussteht, sind diese Probleme nur erst theoretisch.

Obwohl der Erfolg eine Fallgrube sein kann, ist er auch eine Auszeichnung. Die Berufssatiren lassen hie und da, z.B. wenn sich der Autor als junger König sieht, einen gewissen spielerischen Stolz desjenigen erkennen, der um seine Talente weiß und es sich nicht versagen will, sie darzustellen. Das lenkt darum nicht von der Tatsache $a b$, daß Böll sich mit den Problemen des Bekanntwerdens hartnäckig auseinandersetzt. Nicht zuletzt erklärt dies, warum er persönlich diesen frühen Fährnissen weitgehend standhalten konnte. Allerdings gilt dasselbe durchaus nicht für seine Protagonisten. Sie stehen am Ende allesamt kompromittiert da. Das nur als Forderung satirischer Struktur zu sehen, genügt nicht. Im Gegenteil, die satirische Struktur ist dem Problem gemäß. In den Berufssatiren legt Böll ein sehr strenges $\mathrm{Maß}$ an sich und seinen Typus an, gewiß ein strengeres als die Gesellschaft. Wo diese ihm bisweilen heroische Statur bescheinigt, bestätigt er sich selber in seinen Chiffren Schwächen und Unzulänglichkeiten. Besonders vornehmlich unter diesen rangiert, kraß ausgedrückt, die Versuchung, sich auf und davon zu machen. Der Protagonist als Wegläufer gehört zum eisernen Bestand der Satire und verbindet sich gern mit den Fiktionen des Abenteuerromans. So sind Voltaires und Swifts Helden in Candide und Gulliver's Travels auf der Normsuche, aber auch Wegläufer, die nichts gegen die empörende heimische Welt vermögen. Böll setzt diese Spielart des Schrumpfhelden so wiederholt ein, daß sich schon daraus ermessen läßt, wie schwer es ihm bisweilen war, als Persönlichkeit der Öffentlichkeit standzuhalten. Die überwiegende Zahl der Protagonisten der Berufssatiren geben der Versuchung, sich abzusetzen, nach, der Satiriker hingegen befürwortet hinter ihrem Rücken nicht Flucht aus der Welt, sondern Distanz von Dingen, die einer Konfrontation der Welt im Wege stehen. An der Feigheit der Protagonisten gemessen sind die Berufssatiren im Grunde Mahnungen des Satirikers an sich selber und auch eine Form der Bewältigung des Problems durch das Schreiben.

Obwohl ein ganzes Spektrum von Texten zur Klärung dieser Dinge vonnöten ist, begreift Böll hier noch im Gegensatz zu Ansichten eines Clowns (1963) die Situation des Satirikers nicht als nahezu tragisch. Die Protagonisten sind zwar Versager, aber die Zeichnung stellt besonders die Pfuscher heraus. Das Narrentum dieser Figuren ist vornehmlich zum Lachen. Es rührt zum guten Teil daher, daß der Satiriker sie in die Welt schicken will, sie sich aber durch diverse Ausfluchtstaktiken dieser Bürde entziehen. Sie marschieren am Ende mit der Truppe, wennschon nicht im Gleichschritt. Für sie läßt sich eine Formel aufstellen, die dem Durchschnittspublikum in einer 
Leistungsgesellschaft bedeutsam werden könnte. Sie manifestieren einen ihnen weitgehend unbewußten menschlichen Mißerfolg im beruflichen Erfolg oder sie tarnen als Herausforderer, soweit es die Bewußteren unter ihnen sind, ihren mit beruflichem Versagen verknüpften sozialen Mißerfolg als menschlichen Erfolg im biedermeierlichen Winkel. Dieser Abriß stellt eine Forderung an den Autor selber dar. Da er als Satiriker auftritt, kann er nicht umhin, zum mindesten dann und wann auch als Person das zu leisten, was er von seinen Herausforderern in der Fiktion verlangt. Aber da er auch selbst beim schärfsten Protest im Beruf steht, d.h. eine gesellschaftlich sanktionierte Rolle spielt, geht ihm, streng genommen, schon ein Arrangement zu Lasten. Auch seine Situation ist leicht als lächerlich zu begreifen. Mit der einen Hand züchtigt er die Gesellschaft, mit der anderen empfängt er Einkommen, Lob und Lorbeer. So nimmt es nicht wunder, daß die Sprecher der Berufssatiren als eifrige Apologeten ihrer selbst auftreten oder sich bisweilen scheuen, ihren Bericht publik zu machen.

Versetzt sich der Satiriker gewissermaßen zwangsläufig in seine satirischen Helden, wenn er seinen Beruf beleuchtet, so ist ihm die Identifikation mit Versagern zweifellos peinlich. So findet sich in den Berufssatiren die Suche nach dem richtigen Spezifikum der Norm, das den Weg aus dem Mißerfolg und den rechten Weg in die Welt zeigt. Eben weil der Satiriker nicht nur "ästhetischer Sieger," sondern gleichfalls ein Suchender ist, muß er gewillt sein, seine versagenden Protagonisten nicht in Grund und Boden zu verdammen oder sie scheitern zu lassen.

Dem Heldenarchetypus in den Berufssatiren fehlt jeglicher Anklang an seine religiöse Variante. Ließe sich in der Frömmigkeit des Boxers Franz in "Nicht nur zur Weihnachtszeit" noch ein leises Echo des Engels hören, so wartet Böll jetzt eher mit "Bengeln" auf, mit Bodo Bengelmann in "Die unsterbliche Theodora" sogar namentlich. Verweise auf den Zustand charakterlicher Unbescholtenheit meinen nicht einen Leidensnimbus, sondern die Kindheit oder ein kurzfristiges und zumeist zufälliges Außenseitertum. In zwei der sieben Texte, "Mein Onkel Fred" und "Die unsterbliche Theodora," sind die Sprecher, wie schon in "Nicht nur zur Weihnachtszeit," nicht identisch mit der Herausfordererfigur. Es fehlt ihnen die Heldendimension und sie klingen an den Typus des Eiron an, der als Sprecher oder Protagonist oft in der Satire auftritt. Er ist nach Aristoteles der "hintergründig Bescheidene;" er "scheint seinen tatsächlichen Wert $\mathrm{zu}$ verneinen oder herabzusetzen," ${ }^{3}$ was vielfach darauf hinausläuft, daß er größer erscheinen will, indem er sich kleiner macht. Auch die als Sprecher auftretenden Herausforderer der anderen fünf Texte- 
"Bekenntnis eines Hundefängers," “Erinnerungen eines jungen Königs," "Im Lande der Rujuks," "Hier ist Tibten," "Es wird etwas geschehen" - stehen dieser Kategorie als Abgedankte nahe. Sie kaschieren ihr Versagen, indem sie es als Harmlosigkeit herauskehren. Damit wollen sie jedoch die Umrisse des Ingénu oder Vir bonus andeuten. Man spürt aber, daß sie unter ihrer Potenzschwelle bleiben, da wir von ihnen letztlich mehr erwarten können, als sie halten.

Die Texte "Mein Onkel Fred" und "Die unsterbliche Theodora" lassen sich als Auftakt zu den Berufssatiren verstehen. Der Herausforderer steht in ihnen zwar zentral, seine Verantwortlichkeit und Gewichtigkeit sind aber trotzdem beschränkt, weil er im Gegensatz zu den Protagonisten der Ich-Satiren nicht auch Sprecher ist und damit erzählerisch nicht beides, die Subjekt- und Objektfunktion hat. Die Sprecher der Satiren in der Ich-Form hingegen können ihre Konflikte unmittelbar äußern. Zu "Mein Onkel Fred," der frühesten Satire des Berufskomplexes, ist zusätzlich zu bemerken, daß der Protagonist hier noch nicht in erster Linie Zeichen für den Künstler, sondern Repräsentant des allgemeinen Erfolgsmenschen ist.

Die Berufssatiren in der Ich-Form beginnen 1953. Da Böll an dieser Form festhält, ist anzunehmen, daß sie ihm die seiner beruflichen Selbsteröffnung gemäße schien. $\mathrm{Zu}$ einer weiteren Neuerung findet er im selben Jahr. Im Gegensatz zu den Protagonisten in "Mein Onkel Fred" (1951), "Die unsterbliche Theodora" (1953) und "Im Lande der Rujuks" (1953), die freiberuflich arbeiten, stehen die Mittelpunktfiguren der restlichen Texte in einem Angestelltenverhältnis. Dieses Kriterium verschärft die Problematik, besonders wenn wir den Protagonisten als Chiffre des Satirikers verstehen. Es stellt ihn vertragsmäßig in die Gesellschaft und macht ihn damit zu deren Komplizen. So ist er schon von vorneherein ein verträglicher Außenseiter, ein Herausforderer ohne eigenen Boden unter den Füßen. Die Erklärung dieses konfliktverschärfenden Details liegt auf der Hand. Es spiegelt Bölls eigene, mit wachsendem Ruf fortschreitende Integration in die Gesellschaft und damit auch eine Abnahme seines Freiheitsgefühls.

Sind die Berufssatiren Selbstabrechnungen des Satirikers, so erschöpfen sie sich darin nicht. Man kann sie auch generell als Niederschlag berufsbedingter Krisen lesen. Wenn das Individuum in dieser Situation seine Menschlichkeit verletzt, so wird es zum satirischen Gegenstand. Darüberhinaus liegt auf der Hand, daß man diese Geschichten als Angriffe auf diverse Mißstände in der Gesellschaft auffassen kann. So wäre z.B. "Die unsterbliche Theodora" ein Indiz gegen den Literaturbetrieb, "Im Lande der Rujuks" gegen amerikanischen und europäischen Kulturmissionarismus, "Es wird etwas geschehen" gegen die Leistungsgesellschaft. Nichtsdestoweniger 
muß festgehalten werden: Durch das Prisma des Protagonisten erhalten die Subjekt- und Objektzonen dieser Geschichten erst ihre menschliche Substanz, ihre komplexe Dialektik und ihren Beziehungsfaktor zum Publikum. Aus dieser Charakterbezogenheit ergibt sich der Schritt zum Begreifen der Texte als Satiren auf den Satiriker gewissermaßen von selbst, denn erst als Chiffren für den Satiriker objektivieren sich die Protagonisten in ihrer berufsbedingten Problematik voll und ganz.

Wie in "Nicht nur zur Weihnachtszeit" ist in "Mein Onkel Fred" (1951) die Familie die Hauptbühne des Konflikts. "Onkel Fred" unterscheidet sich allerdings dadurch, daß die Spannungen innerhalb der Familie in den Augen des Sprechers zur Zufriedenheit aller Beteiligten gelöst werden. Die Erzählerfigur bemüht sich, eine Idylle darzustellen. Die Familie steht aufs beste versorgt vor uns. Obwohl diese schöne Welt recht neu ist, hat sie das Bewußtsein des Sprechers schon so tief geprägt, daß er sich kaum noch in die Sorgen der Vergangenheit hineinversetzen kann. Diese erklärt er aufgrund der Leistungen seines Onkels Fred für endgültig überwunden. Als dieser aus dem Krieg heimkehrt, findet er eine vaterlose Familie vor, zu deren Ernährer er sich aufschwingt. Als höchst erfolgreicher Geschäftsmann schaltet er sich in die Gesellschaft ein. Seine Gegenwart ist dem Sprecher so großartig, daß es heißt: "Die ganze Stadt schien mir verändert" (W1, 459). Onkel Fred ist ein Retter in der Not, ein Held, wäre aber somit in der Satire fehl am Platze. Wir hätten es im Sinne Northrop Fryes mit dem Helden der Komödie oder Romanze zu tun. Onkel Fred ist Blumenhändler, der die triste Ruinenwelt der Nachkriegszeit zum Blühen bringt. All dies ist jedoch nur scheinbar. Trotz seiner spektakulären Erfolge ist der Protagonist kein Held, selbst wenn er etwas von einem "Marmordenkmal" (457) hat. Wir erwarten eine Tat von ihm, die über seine geschäftlichen Glanzleistungen hinausgeht, finden uns aber in unseren Hoffnungen getäuscht. Die Erzählerfigur will jedoch ihren Onkel ohne Makel sehen und nicht wahrnehmen oder eingestehen, daß das Land trotz aller Blumenpracht brach liegt.

Vaterlos ist der Sprecher schon als Vierzehnjähriger ein über die Maßen eingespanntes Ersatzoberhaupt seiner Familie, muß Tauschhandel auf dem Schwarzmarkt treiben und gelegentlich Kohlen stehlen. Er glaubt, das Erscheinen seines Onkels habe die Reste des Ingénus in ihm gerettet und ihm damit ermöglicht, zum Vir bonus heranzureifen. Mit biederem Stolz berichtet er vom Aufschwung der Familie. Aber trotz der Idylle, die er uns glauben machen will, hat er noch Erinnerungen, die ihn plagen. Die Zeit, die mit dem Eintritt seines Onkels ins Geschäftsleben ein Ende nahm, war im Gegensatz 
zur Gegenwart eine Periode krasser Daseinsprobleme. Aber selbst das nackte Überleben, das Essen, Trinken und Wohnen waren von moralischen Fragen nicht zu trennen. Wenn die Erzählerfigur ihren Bericht mit dem Satz, "Onkel Fred ist der einzige Mensch, der mir die Erinnerung an die Jahre nach 1945 erträglich macht," beginnt, so spielt er auf die Schuldgefühle an, die die Vergangenheit begleiteten und läßt uns vermuten, daß diese in ihm durchaus nicht bewältigt ist. Schuldbewußtsein, oder im weiteren Sinne moralische Sensibilität, war selbstverständlich nicht fehl am Platze nach dem Krieg, sondern Vorbedingung einer Bewältigung der Vergangenheit. Onkel Fred verharmlost sie aber für seinen vierzehnjährigen Neffen, da er selbst denkbar unempfindlich in diesen Dingen ist. Zum Krieg Stellung zu nehmen, lehnt er ohne überzeugende Erklärung ab. Das ist um so ungeheuerlicher, da er sechs Jahre Soldat war. Eine Diskussion des Krieges hätte für seinen Neffen auch das klärende Licht auf die Nachkriegszeit werfen können, in der die Mutter des Sprechers diesen ihren vierzehnjährigen Sohn, der schlaflose Nächte wegen seiner Sorgen als Ernährer der Familie hat, nur mit Tränen in ihren Augen "zum Diebstahl oder Verscheuern" ausziehen sieht. In diesen traurigen Umständen soll Onkel Fred der mächtige Retter sein: "Onkel Freds Ankunft weckte in uns allen die Erwartung starker männlicher Hilfe." Er scheint auch wie geschaffen, die Probleme zu lösen, die seinen halbwüchsigen Neffen überwältigen. Fred kehrt gesund aus dem Krieg heim, selbst seine Schlafstellung ist vielversprechend. Sie ist die eines "Sprinters vor dem Start." Interessant ist das Leidensmotiv, das Böll hier in echt satirischer Manier anschlägt. Es krönt nicht, wie in der Sammlung Wanderer, kommst du nach Spa . . ., sondern karikiert. Onkel Fred unterzieht seine im Schlaf bevorzugten Stellungen eingehender Betrachtung, und zwar mit "leidender Stimme." Physisch unverletzt, ist sein geistiges Rüstzeug gleichermaßen vielversprechend. Er ist über "das Zerwürfnis zwischen den beiden Wertwelten" der Nachkriegszeit informiert. Wo andere sich streiten, wenn es um das Thema Schwarzmarkt geht, kann er sogar souverän "theoretisieren" (456-57). Darüberhinaus ist er imstande, kritisch zu urteilen. Er nimmt die Generation seiner Großeltern aufs Korn und belegt sie mit Abschätzung.

Die in Onkel Fred gesetzten Erwartungen erfüllen sich, jedoch nur einseitig. Nach acht überwiegend verschlafenen Wochen wird er plötzlich tätig und binnen kurzem ist er ein gemachter Mann, da er den Blumenhandel in seiner arg zerstörten Stadt erweckt. Ist er schon ein prächtiger Ernährer, so darum noch nicht ein rechter Vater. Seine Rolle als Erzieher seines Neffen hätte selbstverständlich mit der damaligen Kernfrage des Krieges zu beginnen. Aber er lehnt die Erörte- 
rung ab mit der Begründung, "es lohne sich nicht." Zur Erläuterung führt er an, daß man bei seiner Einmusterung von ihm verlangt habe, in ein Reagenzglas zu urinieren, was er aber nicht sogleich habe bewerkstelligen können. Dazu kommentiert er, "daß das lebhafte Interesse des Deutschen Reiches für seinen Urin ihn mit erheblichem Mißtrauen erfüllt habe . . . das er in sechs Jahren Krieg bedenklich bestätigt fand" (457). Er gibt also zu, daß die Vergangenheit etwas zu Bedenkendes ist, aber er weigert sich, daraus die Konsequenzen zu ziehen. Seine Art "starker männlicher Hilfe" ist unzulänglich für einen Halbwüchsigen, der sich in der Welt zurechtfinden will. Die Intelligenz Onkel Freds klammert ethische Fragestellungen aus und verfängt sich dafür in ästhetischen. Böll läßt hier Schwaches sich mit Schönem tarnen, sehr ähnlich wie in "Doktor Murkes gesammeltes Schweigen." Onkel Fred verachtet seine Großeltern nicht etwa, weil sie als Zeitgenossen der Gründerjahre des Zweiten Reiches vermutlich dessen Imperialismus guthießen, sondern weil sie ihm eine geschmacklose Sippschaft scheinen. Er nennt sie "muffig und pyknisch" und zieht als Beweis das ihn irritierende "säuerliche Rosa" (456) des auf sie zurückgehenden Sofas heran, auf dem er die ersten Wochen nach seiner Heimkehr vertrödelt.

Wenn Onkel Fred "bedenkliche" Dinge nicht bedenkt, ist er der ernstzunehmende Versager, denn er verweigert damit die Verantwortung als Erzieher. Betrachten wir ihn jedoch nach dem Vordergründigen als Ernährer, so ist nicht zu übersehen, daß er die Familie festigt und dabei einem Rausch verfällt, der so gut wie alle seine Landsleute ergriff. Der plötzlichen Verfügbarkeit der Ware erlag man um so vorbehaltloser, als hektischer Verbrauch auch damals schon Leistung meinte, und Leistung wiederum war Antidot nicht nur zu Entbehrung, sondern vor allem zum verlorenen Krieg. Von hier aus gesehen kann man Fred als Pfuscher bezeichnen, der Primäres mit Sekundärem verwechselt. Besonders klar wird dies, wenn wir seinen Beruf ins Auge fassen. Er handelt, bildlich, mit Schönem. Böll gibt der Verwechslungsformel Ästhetik statt Ethik Rückhalt in einer Metapher, die Onkel Fred als beschädigten Helden ausweist, der aber in einer quasi ästhetischen Kategorie steht. Das Marmordenkmal, dem Onkel Fred gleicht, wird als "angeschlagen" (457) bezeichnet. Die komischen Konturen Onkel Freds als Pfuscher werden ausgefüllt durch seinen Dauerschlaf. Er denkt wohl gelegentlich über Möglichkeiten des Broterwerbs nach, verschläft aber die Zeit, die er auf die Erziehung seines Neffen hätte verwenden können. Er bietet einen lachhaften Anblick auf dem für ihn zu kurzen Sofa, dösend, genüßlich Brot in sich hineinbröckelnd und über seine unzulängliche Liegestatt zeternd. Zum Verwechsler des Wichtigen und Unwichtigen gesellt 
sich der Narr, der die rechte Zeit zur rechten Tat versäumt. Ist Onkel Fred offensichtlich für den Satiriker der Pfuscher, so glaubt sein Neffe im Heimkehrer Fred einen Helden zu erkennen. Darum ist er empfänglich für Onkel Freds Wertvorstellungen. Wenn er als Erwachsener berichtet, sieht er wie sein Onkel die Dinge unter ästhetischem Aspekt: "Und ich habe den Anblick der gelben und roten Tulpen, der feuchten Nelken noch heute im Gedächtnis und werde nie vergessen, wie schön er aussah, als er inmitten der grauen Gestalten und der Trümmerhaufen stand und mit schallender Stimme anfing zu rufen: 'Blumen ohne!'. . . . . Die ganze Stadt schien mir verändert" (459). Böll gibt in diesem Portrait Onkel Freds ein Echo der Denkmalmetapher. Aber nicht Monumente, sondern Helden bringen ein Land zum Blühen. So bedeuten Onkel Freds Erfolge nur eine Scheinblüte.

Böll betont den Gedanken der versäumten Zeit, um dieses Denkmal zu entwerten. Es ist nicht etwa Frühling, sondern Spätsommer, wenn Onkel Fred seine Laufbahn beginnt. Wie unzeitgemäß er vorgeht, verrät sich besonders darin, daß er Tulpen feilhält, die bekanntlich Frühlingsblumen sind. Wie der Satiriker uns in "Doktor Murkes gesammeltes Schweigen" beim Zählen des Wortes Gott an einen Rechenfehler stoßen läßt, stellt er uns hier vor eine botanische Diskrepanz, um Fehlerhaftes anzuzeigen. Die Zeit ist falsch für das Blühen, und umgekehrt, das Blühen ist falsches Zeichen der Zeit. Hier wird Onkel Fred voll zum Repräsentanten für eine empörende Gesellschaft. Seine Werte sind auch die seiner Landsleute, die ihm die Blumen abkaufen. Ihre Anstrengungen gelten ausschließlich dem wirtschaftlichen Aufschwung, den sie mit "Schönem" verbrämen, um ihrem Materialismus den Anstrich des Höheren zu geben. Die ihnen symbolisch gemäße Farbe wäre somit dasselbe "säuerliche Rosa," das Fred als Merkmal seiner Gründerzeit-Vorfahren verspottet. Wie der Optimismus jener Zeit sich sehr bald als falsch erwies, so steht dieselbe Erkenntnis für Freds Zeit noch aus. Am Ende der Geschichte heißt es: "Onkel Fred ist längst ein gemachter Mann: seine Filialen blühen immer noch" (459). Der mangelhafte Zustand, den der Satiriker ins Auge faßt, ist auch bei Ende dieser Satire unbehoben.

Onkel Fred ist der Versager als Wegläufer im metaphorischen Sinn, ist gewissermaßen Deserteur zur Truppe. Seinen Auftrag als Vater läßt er schnell wie der Sprinter, mit dem er verglichen wird, hinter sich. Indem der Satiriker Onkel Fred als Leichtathleten einordnet, greift er wie in "Nicht nur zur Weihnachtszeit" beim Boxer Franz zum Sportler als Spielart des Kämpfers. Als Athlet ist Onkel Fred leichtgewichtig in noch einem weiteren Sinne. Er ist gewissermaßen nicht genügend potent. In Freds Unvermögen, bei der Musterung auf 
Anhieb zu urinieren, scheint Böll uns nicht ohne Bosheit einen dahingehenden Fingerzeig zu geben.

Wenn Böll seinen Protagonisten mit so offensichtlich in den Bereich des Schönen Gehörendem wie Blumen handeln läßt, so fällt der Schritt, ihn als Chiffre des Künstlers zu sehen, nicht schwer. Zunächst geht es bei dieser Art des Künstlers um die Ausklammerung des Moralischen zugunsten des Ästhetischen. Das "Schöne" verknüpft Böll jedoch auch mit dem Erfolg, denn die Blumen sind Ware und stark gefragt. Der Satiriker meint also den Schriftsteller, der Begehrtes liefert, aber nicht etwa Kunst, die für Böll etwas Unbequemes, "eine ziemliche Zumutung" (ESR2, 199) zu sein hat, sondern Ornamentales, das als Ware genossen wird. Diese falsche Kunst wäre nicht etwa moralfrei, sondern unmoralisch. Böll beschwört in "Onkel Fred" diese Gefahren schriftstellerischen Erfolges. Für Blumen in diesem symbolischen und negativen Sinne besteht zwar Bedarf, jedoch kein echtes Bedürfnis. Daß dies im thematischen Kontext der Fall ist, wird unterstrichen, wenn die Blumen dem Urteil der positivsten Gestalt der Geschichte unterzogen werden. "Meine Mutter," so berichtet der Sprecher, "voller Mißtrauen gegen die Wertwelt . . . behauptete, für Blumen bestehe kein Bedürfnis" (459).

Die Mutter überschätzt ihre Zeitgenossen, beweist aber ihre sicheren Instinkte in Bezug auf Werte. Daß falsche Normen leicht als echte gelten können, demonstriert Böll in der Wahl der Blumen als zentraler Metapher innerhalb des Themas der Erneuerung in diesem Text. Wer ist schon gegen Blumen immun, zumal sie "ohne," d.h. ohne Restriktionen wie Marken oder Bezugscheine, erhältlich sind? Wer kann sich schon dem Phänomen eines blühenden Landes verschließen? Aber die Blumen sind hier nur negatives Zeichen des rechten Lebensflusses. Die Tränen der Mutter und selbst die Ruinen, durchaus nichts Festgefügtes, sind dahingegen dessen gemäßer Ausdruck. ${ }^{4}$ Die Ruinen sind Mahnung an die Vergangenheit des Krieges, und diese hat einbezogen zu werden.

Obwohl Onkel Freds erzieherische Unterlassungen schwer wiegen, ist sein Versagen leicht verständlich. Er ist den Anforderungen des Herausforderers nicht gewachsen. Er besitzt zwar Urteilsvermögen, verfehlt jedoch die richtige Norm, und zwar gewissermaßen aus Anlage. Er sieht die Dinge von vorneherein aus ästhetischer Perspektive. Auch darin ist er Chiffre des Künstlers. Auch dieser ist Pfuscher, sofern ihn das Ästhetische zum Ausschluß des Moralischen in Anspruch nimmt. Er hat diese Falle zu vermeiden, die besonders gefährlich für den jungen Künstler ist, der noch nicht gewitzt genug ist zu erkennen, daß der Erfolg sie tarnt. 
Bölls Signatur der Wortpaartechnik ist in "Onkel Fred" nur erst in einer Abbreviatur vorhanden. Böll relativiert ein allerdings mit Nachdruck angeführtes Konzept. Auf der einen Seite steht der Handel mit Blumen, auf der anderen der Handel auf dem Schwarzmarkt. Aus der Sicht der Objektsphäre, d.h. des Geschäftsmannes Fred und des Sprechers als anmaßender Vir bonus, ist der Schwarzmarkthandel eine negative Größe, der Blumenhandel hingegen das Heil der schönen neuen Welt. Aus der Subjektsphäre ist der Schwarzmarkthandel ein ambivalentes Phänomen. Zwar bedeutet er eine Gefühlsbelastung für den Sprecher als Halbwüchsigen, aber er klammert im Gegensatz zum Blumenhandel moralische Entscheidungen und Stellungnahme nicht aus. Darum ist der Schwarzmarkt im Vergleich zur Blumenwelt trotz der Anstrengungen, die er seinen Händlern, die allerdings nicht halbe Kinder sein sollten, abverlangt, ein Pendant des rechten Lebensflusses. Im Bezug auf den Blumenvertrieb ist bislang nur das Negative betont worden, nämlich die Ausklammerung des Moralischen. Wenn der Sprecher beteuert, die durch den Blumenhandel Onkel Freds ermöglichte Niederlegung seiner Schwarzmarkttätigkeit habe zu seiner "moralischen Festigung beigetragen" (459), so liegt darin ein Plus für den Blumenhandel, trotz der augenscheinlichen Halbwahrheit. Von Festigung kann die Rede sein, denn den Anforderungen des Schwarzmarktes sollte ein Halbwüchsiger nicht ausgeliefert sein. So verringert das Aufgeben dieser Tätigkeit den Druck, unter dem der Junge leidet.

Das Micromegas-Prinzip beschränkt sich auf die Tarnung. Hohles und Anrüchiges wird kosmetisch bedeckt. Die Blumen überglänzen derart alle Probleme, daß "Onkel Fred" einer Idylle beinahe zum Verwechseln ähnlich ist.

Die Erzählung "Die unsterbliche Theodora" (1953) hat augenscheinliche Gemeinsamkeiten mit "Mein Onkel Fred." Diese Texte sind die einzigen Berufssatiren mit einem am Rande stehenden Sprecher als Herausfordererfolie. Überdies steht die Familie stärker im Vordergrund. Böll behält diese zwar als Anhängsel der Herausfordererfigur in den nächsten beiden Texten, "Bekenntnis eines Hundefängers" (1953) und "Erinnerungen eines jungen Königs" (1954), bei, aber der Anspruch des Herausforderers bezieht sich dort ausschließlich auf eine berufsgeprägte Situation. Indem Böll die Familie nach diesen Texten als Ingredienz der Berufssatire fallen läßt, unterstreicht er die Problematik als berufsgebunden.

In diesem Sinne steht "Theodora" erst auf der Schwelle zu den Berufssatiren. Der Protagonist Bodo Bengelmann gerät in Schwierigkeiten, schon ehe er zum Dichter von Beruf wird. Seine Familie haßt 
es, wenn er dichtet, und man verprügelt ihn oft. So ist Bodos Problem noch weitgehend privater Art. Obwohl viel Aufhebens von seinen jugendlichen Qualen gemacht wird, überspielt die drastische Komik die Kategorie Leiden. Bodo dichtet unentwegt weiter, trotz aller "Senge" (W2, 65), die der Leser darum so ernst nicht nehmen kann. Keinesfalls setzt ihm der Satiriker die Märtyrerkrone auf. Sozial wird der Konflikt zwischen Bodo und seiner Umwelt erst, als er gegen das Literatur-Establishment antritt. Sein Anspruch als Herausforderer besteht zunächst darin, daß er trotz des elterlichen Dichtverbots und der eingeheimsten Prügel unerschütterlich beim Dichten bleibt.

Im Alter von neunzehn Jahren betritt Bodo Bengelmann die öffentliche Bühne. Er überschwemmt den Markt massenhaft mit Gebilden, die der Sprecher "reine Poesie" (65) nennt. Er erklärt aber sein Unterfangen für einen kapitalen Witz und stirbt an einem Lachkrampf. Was sein Freund als "reine Poesie" anbietet, meint dasselbe wie die Blumen in "Mein Onkel Fred." Bodos lyrischer Artikel füllt eine Marktlücke und findet reißenden Absatz. Den Beispielen nach zu urteilen, die uns der Sprecher ehrfürchtig unterbreitet, läßt sich die Analogie zu den Blumen weiterführen. Sind die Tulpen unzeitgemäß, so Bodos Kunst nicht minder. Sie ist ein wunderliches, an Wagner erinnerndes Stabreimgeraune, ist also epigonal, d.h. inauthentisch. $\mathrm{Zu}$ dieser Rolle der Kunst gibt Musil in Der Mann ohne Eigenschaften einen Kommentar, der als Auslösemoment zu Bölls Text hätte dienen können:

Es ist wahrscheinlich eine gut begründete Erscheinung, daß in Zeiten, deren Geist einem Warenmarkt gleicht, für den richtigen Gegensatz dazu Dichter gelten, die gar nichts mit ihrer Zeit $\mathrm{zu}$ tun haben. Sie beschmutzen sich nicht mit zeitgenössischen Gedanken, liefern sozusagen reine Dichtung und sprechen in ausgestorbenen Mundarten der Größe zụ ihren Gläubigen. . . . Diese Erscheinung ist ungefähr die gleiche, als ob man über ein hohles Loch zum Ausgleich eine hohle Kuppel setzen würde. ${ }^{5}$

Daß Bodo ein Kitsch herstellender Pfuscher ist, wird allerdings erst zum Indiz gegen ihn, wenn er vor die Öffentlichkeit tritt und die Kritiker herausfordert. Es entsteht kein Konflikt, sondern ein Friedensfest innerhalb der Objektsphäre. Man ist von seinem Geraune entzückt. Der Erfolg bestätigt den Mißerfolg als Künstler. Wenn er sich dazu noch in die "Akademie" aufnehmen läßt, noch ganze zwei Jahre einen Ruhm genießt, an dessen Rechtmäßigkeit er selber zweifelt, so wird er der Versager. Held hätte er sein können als Kritiker, der die Werte des Literaturgeschäfts entlarvt. Er eröffnet sich jedoch nur 
seinem Freund in dem Lachkrampf und dem Geständnis, daß Ruhm eine Frage des Portos, d.h. der Vermarktung sei, und er "es doch gar nicht so ernst gemeint" (66) habe.

Weit deutlicher als den Versager sehen wir hier jedoch den Pfuscher. Als solcher ist er eine Spielart des Schelms, der in C. G. Jungs Formulierung "eine Art zweiter Persönlichkeit von puerilem, inferiorem Charakter" darstellt. ${ }^{6}$ Bodo ist ein Bengel, der seiner Schwester den Federhalter stiehlt und seine Gedichte ohne Rückporto einschickt, "eine Kühnheit," so stellt der Sprecher fest, "die in der gesamten Literaturgeschichte einmalig ist" (66). Vor allem mokiert er sich über das Publikum. Es hat dies zwar verdient, sofern es aus Kritikern besteht, aber der Satiriker läßt seinen Pfuscher deswegen nicht ungestraft triumphieren. Bodo lacht zwar noch schallend, wird aber unverzüglich bestraft, da ihn der Satiriker sich zu Tode lachen läßt. An dem Ausmaß der Heimzahlung eröffnet sich noch einmal, daß der Satiriker Bodo ernst nimmt, trotz aller Bengelhaftigkeit in ihm auch den Versager sieht.

In Bodo Bengelmann greift der Satiriker wie in "Mein Onkel Fred" offensichtlich den Dichter als den Händler mit dem falschen Schönen an. Es gibt aber bedeutende Unterschiede. Onkel Fred hat den Krieg hinter sich und muß als voll verantwortlich für seine Tun gelten. Bodo hingegen hat sehr viel vom Ingénu. Zum Teil ist sein Verhältnis zu Ruhm und Erfolg Spiel. Er steht für den Schriftsteller, der nach seiner ersten Bestätigung sucht und der einerseits mit verzeihlichem jugendlichem Überschwang, andererseits ohne Selbstkritik und -zügelung seinen Durchbruch zur Öffentlichkeit erzielen will. Bodo Bengelmann läßt sich aufgrund seiner Jugendlichkeit noch eher verzeihen als Onkel Fred, zumal er für sein Schelmenstück übermäßig büßt. So dürfen wir durchaus über den leichtgewichtigen Pfuscher lachen, der in seinen possenhaften Bemühungen immerhin den Literaturbetrieb foppt. Neben seiner Nähe zum Ingénu entschuldigt ihn vor allem seine Anlage zum Ästhetischen. Er kann sich nicht helfen; es "war sein Fluch, reine Poesie von sich zu geben." Diese läßt der Satiriker als Pendant der Nahrungsaufnahme erscheinen. Vollgestopft, wie z.B. "nach dem Verzehr zweier Koteletts, eines Haufens Salat, eines großen Vanillepuddings und zweier Käseschnitten" gelingen Bodo seine "besten" Gedichte. Auch die beispiellose "Inbrunst" seiner Liebeslyrik muß im Zusammenhang mit seinem Appetit gesehen werden. Bodo ist gefräßig (65-66). Seine ungeheuere Produktion ist schöpferisch nur als Teil eines. kulinarischen Prozesses. Indem Böll das Instinkthafte der Ergüsse Bengelmanns betont, verdeutlicht er, was diesem zum vollgültigen Dichter fehlt. Seine Gefühle sind zweifellos echt und tief, aber er ist trotz der Anlage zum Künstlerischen 
kein Künstler. Er ist der Typ des künstlerischen Menschen, von dem Böll eingehend in Ansichten eines Clowns redet, und dessen Gefühlsintensität, wie auch Gottfried Benn sagt, bei allem guten Willen zu Kitsch führt. ${ }^{7}$ Dem künstlerischen Menschen fehlt letztlich das Gefühl für Form, wie Bodo Bengelmann, der zum Stabreim greift.

All das begreift der Sprecher nicht im entferntesten. Er ist beschränkt wie die Erzählerfiguren in "Mein Onkel Fred" und "Nicht nur zur Weihnachtszeit" und in einer Hinsicht noch kurzsichtiger als der Sprecher der letzteren Satire, der bisweilen dem Herausforderer gegenüber zu ambivalenter Betrachtung fähig ist. In "Theodora" wie in "Mein Onkel Fred" glauben die Sprecher unerschütterlich an ihre Helden. Der eine merkt nicht, daß der inbrünstige Stabreimler kein Dichter, der andere, daß der Ernährer kein Erzieher ist. Ganz blind ist der Sprecher in "Theodora" allerdings in anderer Hinsicht nicht. Er fühlt, daß der Literaturbetrieb im Gegensatz zum Menschlichen steht. Die Kritik, die in der unsterblichen Theodora der Liebesgedichte Bodos eine zeitgenössische Dichterin erblickt, bezeichnet er als "schamlos." Er bangt um das wirkliche Vorbild, Käte Barutzki, Verkäuferin in "Beckers billigem Laden," wo sich Bodo mit Schreibpapier einzudecken pflegte. Der Sprecher verspricht, das Geheimnis hüten zu wollen, weil er um "Kätes Wohl . . zittere" (66-67).

Käte Barutzki ist der vollgültigste Repräsentant der Subjektsphäre im Text. Sie läßt, wie der Sprecher vermutet, Bodos ihr anonym zugeschickte Gedichte wohl in den Ofen wandern. Trotzdem ist sie für den Sprecher eine reizende Person und für den Leser auch eine kluge, weil sie den Wert der Lyrik Bodos richtig einzuschätzen weiß. Sie ist gewiß ihrem von Bodo gewählten Decknamen gemäß ein Gottesgeschenk, aber man wünscht dieser Muse die Art der Unsterblichkeit nicht, die Bodo beschert wird und auch ihr zufallen würde, sofern man sie als Vorbild der unsterblichen Theodora entdeckte. Ganz makellos ist Käte Barutzki jedoch nicht. Sie lispelt ein wenig, was sich dichterisch in dem Ausdruck Bodos, "zauberischer Zungenschlag, zahmer" niederschlägt. Es läßt sich hier von stützendem Humor sprechen. Kätes soziale Verletzbarkeit-man stelle sich ihr Schicksal vor, wenn der Kunstbetrieb herausfände, wer sie ist!-äußert sich in einem ästhetischen Querstrich, den Böll noch zum Schnörkel macht, indem er ihn in Bodos Stabreimzeile sozusagen ästhetisiert. Noch weitergehend läßt er Käte sogar das dem stützenden Humor zugrundeliegende Prinzip dartun. Wenn es heißt, Käte lispele "wie eine Göttin" (67), so liegt in der Formulierung einerseits ein Erheben, andererseits ein Hinabschauen des Satirikers auf den Gegenstand des Humors.

In der Figur Käte Barutzki läßt sich unschwer eine Parallele zur mythischen Braut sehen, nach der sich der Sprecher in "An der Angel" 
sehnt. Käte Barutzki gilt offensichtlich die Inbrunst der Liebesgedichte, die übrigens den Ruhm Bodos hauptsächlich begründen. Sie ist also gewissermaßen das archetypische Ziel der Wünsche Bodos; wenn er sich trotz seines Ruhmes Käte nicht zu nähern wagt, so entblößt er sich als Herausforderer mangelnder Substanz, der den Preis nicht gewinnen kann.

In seiner Liebe allerdings bleibt Bodo mit der Subjektsphäre verbunden. Jedoch ist sein Abstand zu dieser weitaus größer als zu den Kritikern, die er zwar verlacht, als deren Kumpan im Objektbereich er dennoch zu bezeichnen ist. Wie in "Mein Onkel Fred" wirft der Protagonist als satirischer Gegenstand einen Schatten, und den ebenfalls auf die Leistungs- und Verbrauchergesellschaft. ${ }^{8}$ Repräsentativ ist dort der Blumenhandel, hier der Literaturbetrieb. Bodos Lyrik ist Massenartikel. Er schickt auf einen Schlag dreihundert Gedichte an dreihundert verschiedene Redaktionen. Man druckt nicht weniger als einhundertzweiundfünfzig. Der Auftrieb im Literaturgeschäft ist allerdings keine echte Blüte, da Bodos Lyrik auf dem geradezu bizarren Trick der Erneuerung des Stabreims beruht. Der Markt macht sich diese lächerliche Verirrung mit Fleiß zunutze, weil sie den Verbrauch anregt. Wie auch in "Mein Onkel Fred" äfft man den Fluß des Lebens nach. Unecht ist dieser in "Mein Onkel Fred," weil er allzuschön, falsch hier in "Theodora," weil er allzu schnell ist. Der Ruhm Bodos wächst mit reißender Geschwindigkeit und beweist damit, was seine Gedichte der Verbrauchergesellschaft bedeuten. Er avanciert in vier Monaten vom Lehrling in einer Tapetenhandlung zu einer sensationellen Berühmtheit, ist mit einundzwanzig Jahren tot und unsterblich. Zeichen des richtigen Lebensflusses ist die Liebe. Im Gegensatz zu Bodo, der Käte aus der Ferne zur Göttin macht, hat sich ihr ein Autoschlosser, "weniger schüchtern als Bodo" (67), genähert. Der Sprecher will Käte vor dem Strudel der-falschen-Berühmtheit, die ihr Glück mit dem Autoschlosser gefährden könnte, bewahren und hält deshalb die Identität von Käte und Theodora geheim.

Das Wortgegensatzpaar dieses satirischen Textes ist das Dichten und Schreiben. Von der Objektsphäre her gesehen handelt es sich auch hier um einen einfachen Gegensatz. Das Dichten ist ein Vorgang, der in Bodos Familie Prügel nach sich zieht, das Schreiben ein technischer, dem z.B. Bodos "gemeine" Schwester nachkommt, wenn sie ihre "kümmerlichen" (65) Schulaufsätze schreibt. Aus der Sicht der Subjektsphäre hingegen ist der Gegensatz nicht einschichtig. So verweist der Kontrast von Dichten und Schreiben auf den von Kunst und Ware. In der Dialektik des Wortpaares ist das Dichten nicht nur positiver Wert, vorstellbar anhand der Gedichte Bodos ex negativo, sondern auch als Gefühlstätigkeit Bodos. Es ist Ausdruck 
der "Inbrunst" seiner Phantasie. Ist Bodos Dichten als Gehalt zu befürworten, so ist es abwegig in der Form.

Das Schreiben stellt potentiell die Verbindung des Künstlers mit der Gesellschaft her. Es ist die Schwelle zur Existenz des literarischen Kunstwerks. Ohne das Schreiben wäre der Künstler so etwas wie der wahnsinnige Protagonist in Hoffmanns "Ritter Gluck," der seine Eingebungen nicht durch die Niederschrift prostituieren will. Ohne Geschriebenes gibt es aber offensichtlich keine Rezeption. Das Schreiben ist somit Teil des schöpferischen Prozesses im sozialen Sinne, sogar als Vervielfältigung, als Publikation und unter dem Aspekt des Marktes. Böll bemüht sich mit Nachdruck, dieses soziale Moment des Schreibens als etwas Menschliches herauszuarbeiten. Bodo bedient sich nicht weniger als dreier Instrumente zum Gedichteschreiben, der Schreibmaschine, eines Tintenstifts und eines Federhalters. Besonders die Schreibmaschine, aber auch der Federhalter stehen sehr deutlich im Assoziationsfeld des Humanen. Sie sind regelrechte Spiegel der Sorgen und Nöte, die Bodo und sein Freund durchleben. Die negative Seite des Schreibens liegt in seiner Bedeutung als "Produktion" (65), ein Wort, das wiederholt als Bezeichnung der Tätigkeit Bodos fällt. Er schreibt auf der Maschine "mit jeweils vier Durchschlägen." Er schreibt "ins reine" (64) und immens viel, reproduziert das Geschriebene und unterzieht sich dem Prozeß, dreihundert Redaktionen ausfindig zu machen, an die er seine Gedichte verstreut.

Neben der Wortpaartechnik greift Böll zum Prinzip Micromegas in dem schon bekannten Sinn der Formel Quantität statt Qualität. Der Satiriker spannt dabei den Sprecher ein, der Bodo für einen großen Dichter hält und somit der Objektsphäre Handlangerdienste tut. Der Erzählerfigur fehlt als deren Sprecher ein Konzept des Wesentlichen und sie bietet deshalb Statistik an. Der Zahlen- und Ziffernwulst in "Theodora" geht sogar über den in "Doktor Murkes gesammeltes Schweigen" entwickelten hinaus und ist so offensichtlich, daß sich Belege erübrigen.

Wird das Normalmaß der Dinge wie in "Theodora" extrem überzogen, ergibt sich Micromegas als die Vorstellung des Geblähten von selber, und damit als Reaktion die Schrumpfung des Objekts. Bodo ist kein Unsterblicher, sondern ein Bengel; der Literaturbetrieb meint lächerlich sinnloses Geschehen, das die Kritik allerdings unbedingt wichtig nimmt. Auf Biegen und Brechen will sie das Vorbild für die unsterbliche Theodora ermitteln. Sie dringt darum in das Privatleben einer Dichterin ein und kompromittiert diese. In dem Unterfangen liegt Ironie. Der Literaturbetrieb sucht nach Selbstbestätigung, verletzt aber sich selber, da ja die Dichterin zu den Seinen zählt.

Der Beruf in "Bekenntnis eines Hundefängers" (1953) meint zwar 
nicht so vordergründig wie der Onkel Freds oder Bodo Bengelmanns den Künstler, weil von Schönem nicht die Rede ist, hat aber eine deutlichere soziale Komponente. So wird hier die Problematik nicht mehr im Hinweis auf Ästhetisches, sondern wie in allen folgenden Berufssatiren in Hinsicht auf Moralisches behandelt. Es läßt sich vermuten, daß diese Perspektivenverschiebung Bölls steigendes Gefühl der Sicherheit in künstlerischen Dingen spiegelt. Die Frage, ob Literat oder Dichter ist nicht mehr die wichtigste. Daß es in diesem Text zuvorderst um moralische Berufsfragen geht, liegt schon in der Berufsdefinition. Der Protagonist bezeichnet sich als "Hüter des Gesetzes." Er hat unangemeldete Hunde aufzuspüren: "Als friedlicher Spaziergänger getarnt, rundlich und klein, eine Zigarre mittlerer Preislage im Mund, gehe ich durch Parks und stille Straßen." So ist er eine Art Spitzel, der in einem bieder-apologetischen Tonfall berichtet: "Nur zögernd bekenne ich mich zu einem Beruf, der mich zwar ernährt, mich aber zu Handlungen zwingt, die ich nicht immer reinen Gewissens vornehmen kann." Er liebt Hunde und bringt es nicht über sich, bisweilen seine Amtspflichten nicht zu verletzen: "Es gibt Hunde, die ich einfach nicht melden kann" $(\mathrm{W} 2,207)$. So meldet er auch seinen eigenen, von der ganzen Familie geliebten Pluto nicht. Es sind nun gerade diese gelegentlichen Dienstverweigerungen, die den Sprecher nicht nur in Gewissensnöte versetzen, sondern auch seine Stellung gefährden. Schon zweimal hat sein Chef, dem man mitunter auf sonntäglichen Spaziergängen begegnet, von Pluto knurrende Feindseligkeit geerntet. Der Hundefänger befürchtet Entdeckung, zumal verräterische Schweißtropfen während dieser Vorfälle auf seine Stirn treten.

Die Liebe zu Hunden und die gelegentliche Verletzung der Meldepflicht sind unstreitig begrüßenswerte Dinge, eigentlich etwas sehr Menschliches. Daß der Satiriker Hund und Menschen im positiven Sinne zusammenrückt, offenbart sich schon in der vermenschlichenden Zeichnung der Hunde. Es ist die Rede von einem "Köter, [der] reinen Gewissens an einem Baum steht und sich erleichtert" und von "trächtigen Hündinnen, die der freudigen Geburt zukünftiger Steuerzahler entgegensehen" (207). Wie Böll den Hund einerseits vermenschlicht und die Bande zwischen Mensch und Hund zur Metapher der Menschlichkeit macht, so greift er als Kehrseite auch zur negativen Bedeutung des Wortes Hund mit der Absicht, auf "Hündisches" im Menschen zu deuten. Er verwendet das Wort Zyniker und spielt damit auf die Etymologie des Wortes Hund an. Der Sprecher klagt: "Ich bin verloren, und manche werden mich für einen Zyniker halten, aber wie soll ich es nicht werden, da ich dauernd mit Hunden zu tun habe." Der Hundefänger sieht keinen Ausweg aus der "Para- 
doxie [seiner] Existenz" (208). Er kann sich weder seinem Vorgesetzen eröffnen noch weiterhin hier und da der Neigung folgend gegen das Gesetz verstoßen. Der Weg aus der Sackgasse ist Zynismus. Das so menschliche Prinzip der Hundeliebe hat er in Zukunft fallenzulassen und sich einzig und allein um seine gefährdete Stellung zu kümmern.

Das Wort Zyniker ist der Schlüssel zur Norm dieses Textes. Zynismus-im landläufigen, nicht streng philosophischen Sinne verstanden-ist ein vollauf negativer Terminus. Sein positives Gegenstück ist die Berufspraxis des Sprechers, in der sich der Hundefänger einerseits Freiheiten vom spezifischen Gesetz nimmt, wie er andererseits die prinzipielle Notwendigkeit von Gesetzen zugibt. In dieser undogmatischen Berufsausübung tritt auch hier Bölls niedrige Norm zutage. Der Sprecher kleidet diese sogar in eine Formel. Er verlangt das Recht, Ausnahmen zu machen, indem er die Bibel zitiert: Man soll "dem Ochsen, der da drischt, das Maul nicht verbinden." Zur Erläuterung der positiven Formel in seinem persönlichen Fall hängt er unmittelbar ihren negativen Kontrast an und spielt damit auf die Verhärtungen der Objektsphäre an: "[A]ber ich weiß nicht, ob mein Chef elastischen Geistes genug ist, Bibeltexte gelten zu lassen" (208). Daß es grundsätzlich Ausnahmen zu einer Satzung geben muß, um die rechte Lebensentfaltung $\mathrm{zu}$ wahren, veranschaulicht Böll dadurch, daß er auch hier die Idee der Zeit in seinen Maßstab nimmt. An Sonntagen, wenn der Sprecher sich auf Spaziergängen mit Familie und Hund erholt, ist sein Verhältnis zu Hunden ideal. Er braucht sich "für Hunde gleichsam nur platonisch zu interessieren . . . denn sonntags sind selbst die unangemeldeten Hunde der Beobachtung entzogen." Der Hundefänger glaubt allerdings auch während der Woche einer idealistischen Berufsauffassung nachzukommen und den Punkt zu kennen, wo seine Verpflichtungen zum Amt aufhören: "[D]ie Tatsache, bis zu einem gewissen Grade Hüter des Gesetzes zu sein, stärkt mich in der Gewißheit, es permanent brechen zu dürfen" (207-08).

So gesehen steht der Sprecher als Held da. Er bricht die Verordnungen des Steueramts, wenn diese mit einem höheren Gesetz in Konflikt stehen. In Wahrheit bricht er aber leider auch das höhere Gesetz, mit dem er glaubt seine Ausnahmen rechtfertigen zu können. Dieses höhere Gesetz, das hinter der Liebe zu Hunden steht, ist letztlich das der Menschlichkeit. Er glaubt es zu wahren, indem er seinen Instinkten folgt. Er bildet sich auf deren Zielsicherheit sogar etwas ein und behauptet: "Ich kenne die angemeldeten Hunde, rieche es gleichsam, spüre es." Seine Gefühlseingebungen diktieren seine Wahl: "Es gibt Hunde, die ich einfach nicht melden kann." So hoch und hehr das klingt, so liegt darin doch kein annehmbares Prinzip. 
Die Ausnahmen, die er macht, sind völlig subjektiv und darum beliebig. Sie entbehren die soziale Dimension, ohne die jedoch das Gesetz der Menschlichkeit sich nicht denken läßt. Demzufolge sollte er gegen die Steuerverordnung verstoßen, also nur bis zu dem "gewissen Grade Hüter des Gesetzes" sein, wenn zu befürchten wäre, daß die Steuereinziehung den Besitzer zwingen könnte, den Hund zu entbehren. Kraß gesagt sollte der Hundefänger "beide Augen" zudrücken, wenn es sich um Hunde der Armen handelt. Aber weil er beide Augen aufgrund seiner Gefühle für Hunde, statt Menschen, schließt, und darin liegt schon ein Stich ins Zynische, ist er blind für den sozialen Aspekt des Problems. Er fahndet nicht nur in Parks und stillen Straßen, sondern auch in Armenvierteln: "[I]ch hocke stundenlang in dornigen Gebüschen der Vorstadt, warte darauf, daß Gebell aus einem Behelfsheim dringt oder wildes Gekläff aus einer Baracke, in der ich einen verdächtigen Hund vermute" (207).

Wie wichtig das Einkommen des Hundehalters in der Meldefrage ist, begreift der Hundefänger nur für sich selbst. Er gibt als Grund für seine Steuerhinterziehung an, daß sein Gehalt "gering" (208) sei. Als Beamter, der sich eine Zigarre mittlerer Preislage sogar im Dienst leisten kann, ist er wohl kaum Bewohner einer Baracke, hätte also allen Grund, das Gekläff aus den Häusern der Armen zu überhören, wenn er seinen eigenen Hund aus finanziellen Gründen nicht meldet.

Der Hundefänger ist Versager schon dadurch, daß seine Herausforderungen sich nicht offen gegen das Amt äußern. Darin bricht er das höhere Gesetz "permanent." Nichtsdestoweniger kann man sein Versagen gut verstehen. Es geschieht aus beruflichem Selbsterhaltungstrieb. So tritt auch er sowohl nach der hohen wie niederen Norm an. Die letztere steht stark im Vordergrund. Der Hundefänger ist Pfuscher, weil er das anstößige Gesetz nach einem falschen Prinzip herausfordert und in seiner Blindheit für das Richtige vollkommen überzeugt ist, hochgesinnt $\mathrm{zu}$ verfahren. Trotzdem können wir ihm unser Mitgefühl nicht verweigern, denn Blindheit ist nicht böse Absicht. Das Konterfei des vertrauenerweckenden Vir bonus"friedlicher Spaziergänger . . . rundlich und klein" — steht nicht in einem völligen Mißverhältnis zu seinem Charakter. Zugutehalten dürfen wir ihm auch, daß er nicht mehr zu den Jüngsten zählt. Er ist fünfzig und klagt, "in meinem Alter wechselt man nicht mehr gern." Wir pflichten ihm bei, wenn er sein Lebensrisiko als "permanent" (208) bezeichnet, und hoffen, daß er sich nicht zum Zyniker mausert.

Die Brücke zwischen dem Hundefänger und dem Künstler liegt in dem Attribut "Hüter des Gesetzes." Es gilt ganz besonders für den Satiriker, der in irgendeinem Sinne immer Moralist ist. Sein Auftrag ist es, ein höheres Gesetz zu vertreten, nach dem er die in der Gesell- 
schaft gültigen Gesetze zu messen hat. Das Problem ist für ihn, die richtigen Unterscheidungen zu treffen. Das höhere Gesetz läßt sich nicht leicht normativ fassen. Wären alle Entscheidungen so einfach wie die zwischen Behelfsheim und Villa, so wäre sein Leben leicht, vorausgesetzt, daß er nicht ganz so blind ist wie der Hundefänger. Aber meistens ist der Ausbeuter und Ausgebeutete ein und derselbe im bürgerlichen Sessel. So bleibt dem Satiriker nichts anderes übrig, als seine moralischen Instinkte mit Elementen der bestehenden Ordnungen zu vermischen. Damit kompromittiert er sich wie der Hundefänger. Er ist sowohl Hüter wie Brecher des höheren wie auch des niedrigeren Gesetzes. Sein Lebensrisiko ist in der Tat permanent. Was die moralischen Instinkte angeht, so läßt es Böll nicht damit bewenden, sie nur als verfehlten Ausdruck guten Willens hinzustellen. Sie sind ein sehr zweifelhafter Weg zur Norm. Das Gefühl für das höhere Gesetz muß sich notwendigerweise mit dem Willen verbinden, es zu verwirklichen. Dieser Prozeß, der sich mit dem Wort Aggressivität belegen läßt, kann einen Umschlag ins falsch Zerstörerische bedeuten. In "Doktor Murkes gesammeltes Schweigen" entsteht der falsche Haß, wenn Murke gegen Bur-Malottke antritt. Hier in "Hundefänger" wird der Sprecher boshaft in seiner Arbeit. Er nennt sich zwar einen Hundeliebhaber und ist es auch sicherlich, man darf aber nicht übersehen, daß sein Jagdfieber seine Liebe mitunter überwältigt. Er tarnt sich als harmloser Spaziergänger, läßt sich "freundlich tuend" (207) in Gespräche ein, um seine Opfer zur Strecke zu bringen. Können wir ihm das noch möglicherweise als sportlichen Eifer auslegen, so doch eine weitere Selbstskizze nicht. Er beschattet trächtige Hündinnen, wartet dann, bis die Jungen groß genug sind, daß man sie nicht mehr umzubringen wagt, und greift erst dann zu, um sich einen vervielfachten Erfolg zu sichern. So ist das Lebensrisiko des Hundefängers, und hier ist der aggressive Künstler gemeint, auch zum Teil Anlage. Es verbinden sich in ihm moralischer Wille und fragwürdige Aggressivität. Trotzdem ist er auf seine moralischen Instinkte in der Normfindung angewiesen, weil die von ihm vorgefundenen Gesetze aufgrund ihrer Schwächen ein moralisches Urteil von ihm verlangen. Er kann es nicht vom Christentum oder vom Marxismus beziehen, denn beide sind institutionalisiert. Streift man jedoch die kodifizierten Elemente vom Christentum ab, so bleibt die "Frohe Botschaft," vom Marxismus der Sozialismus, also im Ideellen Ähnliches wie der freie Fluß des Lebens. Hält man sich vor Augen, wie schwer es ist, diesen $\mathrm{zu}$ bestimmen, ohne in die Falle einer Ideologie zu geraten, so läßt sich begreifen, warum Böll das Normproblem so oft angeht und es nicht etwa bei einer Berufssatire bewenden läßt.

Außer dem Bezug zum Ästhetischen fehlt in "Hundefänger" im Ge- 
gensatz zu "Mein Onkel Fred" und "Die unsterbliche Theodora" die Ingredienz des äußeren Erfolges. Darum ist der Hundefänger im Vergleich zu den Protagonisten der beiden vorangehenden Texte ein psychologisch weit stärker gefährdeter Typ. Onkel Fred hat vermutlich keine unruhige Minute im Leben, wenn wir von seiner peinlichen Einmusterung in die Armee absehen. Obwohl Bodo Bengelmann Prügel bezieht und recht grotesk stirbt, zeigt er keine angegriffene Psyche. Der Hundefänger hingegen leidet. Aber wie auch das körperliche Leiden Bodo Bengelmanns verdient das seelische des Hundefängers keine Krone, und sie wird ihm auch vom Satiriker nicht verliehen.

Die Linie vom Protagonisten zum Künstler und zum Leser ist in "Hundefänger" sehr kurz. Die Maße des Hundefängers passen weitgehend auf jeden. Er zeichnet sich nicht durch analytische Fähigkeiten wie Onkel Fred oder dichterische Gemütsart wie Bodo Bengelmann aus. Er ist Durchschnitt. Trotzdem ist er zur Protestgeste fähig, ist Hüter des Gesetzes. Im Kern ist die Heldennorm in diesem wohl unscheinbarsten unter Bölls satirischen Protagonisten durchaus intakt. Die Jedermanns-Größe darf demnach nicht als Verharmlosung der Problematik verstanden werden.

Trotz seiner Kleinheit nimmt der Sprecher als Chiffre des Satirikers fast den gesamten Objektraum ein. Auch die Komik fällt fast ausschließlich auf ihn. Sie verzeichnet ihn als Spitzel und Kobold, der sich in dornigen Gebüschen versteckt und sich hinter Mauerresten duckt. Den Rest des satirischen Objekts macht das Hundesteueramt aus. Es läßt sich zwar hinter ihm der Staat erkennen, aber dieser wird nicht sehr lebendig als. Ungeheuer. Diese Schwäche wie auch der stark elegische Ton mindern das Satirische dieses Textes etwas. Das Elegische ironisiert aber den Sprecher hörbar, den wir auch darum als rechten satirischen Herausforderer bezeichnen dürfen. Daß wir es mit einer Satire zu tun haben, unterstreicht auch die Technik des Wortgegensatzpaares. Es ist das Melden und das Nicht-Melden. Anstatt Gegenverben aufzustellen, beschränkt sich Böll hier darauf, den Kontrast durch die Negationsform eines Wortes zu erwirken. Zwar mindert das im Prinzip den Aktionsgehalt des Wortpaars, es entsteht aber der Vorteil der unwillkürlichen Vorstellung des Gegenteils und dadurch eine Verbindung der Gegensätze. Das Schmücken in "Nicht nur zur Weihnachtszeit" leistet dies z.B. nicht; es führt nicht geradlinig zum Plündern. Die Wortpaartechnik ist in "Hundefänger" besonders eng mit dem Protagonisten verbunden. Die Tätigkeiten, die das Wortpaar ausdrückt, sind ausschließlich die des Sprechers. Aus der Sicht des Hundesteueramtes sind Melden und Nicht-Melden klare und simple Gegensätze. Das Melden ist Berufspflicht, das Nicht-Melden Amtsverletzung. Aus der Subjektsphäre hingegen 
tragen die Wörter ambivalente Bedeutung, wenn wir sie konkret und dazu als Metapher für das Tun des Satirikers verstehen. Im konkreten Sinne ist das Melden und Nicht-Melden des Hundefängers eine Verirrung, weil es nach dem falschen Prinzip geschieht. Als Metapher für das Amt des Satirikers ist Melden und Nicht-Melden Wahrung der Norm und soziale Leistung. Der Satiriker meldet die Verstöße gegen das Gesetz der Menschlichkeit, meldet nicht die Brüche der Verordnungen, wenn diese mit dem Gesetz der Menschlichkeit in Konflikt stehen.

Das Micromegas-Prinzip handhabt Böll hier in einer Weise, die im Grunde auf dasselbe wie die Blähungstaktik in "Doktor Murkes gesammeltes Schweigen" hinausläuft, aber technisch das Gegenteil darstellt. Das falsche Große, das Steueramt, ahmt in der physischen Form des Hundefängers die Größenordnung des Kleinen nach, um ungefährlich zu erscheinen. Ob sich das satirische Objekt bläht oder schrumpft, es will die seinen anrüchigen Zwecken vorteilhafteste. Größenordnung vortäuschen. Im ersteren Fall, wie in "Doktor Murkes gesammeltes Schweigen" z.B., will es einschüchtern, im letzteren, wie hier, das Opfer in falsche Sicherheit wiegen.

Von Unscheinbarkeit des Protagonisten kann in "Erinnerungen eines jungen Königs" (1953) keine Rede sein. Besonders im archetypischen Sinne des Herausfordertopos gibt der Satiriker dem Sprecher großartige Voraussetzungen mit. Dieser ist Anwärter auf den Thron des Königreiches Capota. Als Dreizehnjähriger schon berichtigt er souverän eine unannehmbare Wirklichkeit, und zwar in einer Weise, die die Autorität seines königlichen Vaters, Pig Gi I., herausfordert. Mit einer schlechten Zensur belastet radiert er das "Nicht" in "Nicht genügend" unter einem Aufsatz fort, da dieser dem Vater vorgelegt werden muß. Zu seiner Thronanwärterschaft und seiner Unbekümmertheit über schulische Tabus gesellt sich überdies ein genaues Gefühl für menschliche Würde, wenn er einen kriecherischen Diener "widerwärtig" findet. Es handelt sich im jungen König offensichtlich um eine Persönlichkeitsformel, deren komisch-märchenhafte Stereotypik sich auch darin kundtut, daß der Mord des Vaters mit vollkommener Selbstverständlichkeit aufgenommen wird. Es ist nicht etwa von Vergeltung, Zorn oder Trauer die Rede, sondern der Kommentar des Sohnes beschränkt sich auf den lakonischen Ausruf "Oh diese Rasac." Das meint "Rasante Sadisten Capotas," aus deren Reihen die Täter stammen. Sie stehen im derzeitigen Bürgerkrieg den hoftreuen "Misac" - "Milde Sadisten Capotas" (W2, 209-10) - gegenüber.

Der Text enthält alles Wesentliche des mythischen Stereotyps. Es geht um den jungen Helden, der den alten König deplaciert, das Land befriedet und beglückt und mit der Braut belohnt wird. Die 
Misac behalten die Oberhand, das Volk jubelt dem jungen König zu; er tut ihm Gutes mittels humaner Schenkungen von Wurst, Zigaretten und Freifahrscheinen für Karussells. Die Formel vervollständigend ehelicht er Jadwiga, die Tochter des wichtigsten Mannes im Lande. Trotz des Märchenartigen ist diese Erzählung aber alles andere als ein Märchen. Der junge König ist satirischer Held, der seinem Beruf zum Opfer fällt wie Onkel Fred, Bodo Bengelmann und der Hundefänger. Nach seiner Thronbesteigung erhält er sich zunächst noch die Souveränität, die man von einem jungen Helden mit Ingénuzügen erwartet. Er spielt nach Herzenslust Ball und Hüpfen, wirft auch mit dem Messer nach der Türfüllung, besucht fleißig das Hofkino und setzt sich für eine Schulreform ein. Aber bald schon wird offensichtlich, daß nicht er, sondern ein Drache das Land beherrscht. Dieser repräsentiert sich im Heer Capotas und im Ministerpräsidenten Pelzer. Es ist Pelzer, ein "mächtiger Mann mit gelbem Gesicht, schwarzem Bart und funkelnden Augen," der die Braut in der Person seiner Tochter Jadwiga verwahrt. Diese wird nicht etwa erobert, sondern dem jungen König vom Drachenhaupt Pelzer angetragen. ${ }^{9}$ Der Sprecher ist nicht sonderlich von Jadwiga angetan. Sie ist dünn und klein und gilt als "doof." So lehnt er ab. Es geschieht "Schreckliches." Der Drache spuckt Feuer. Die Reaktion des Sprechers ist sehr unheldisch: "Kurz entschlossen sagte ich: 'Ich bitte Sie um Jadwigas Hand" "(210-11). Indem er diesen Köder schluckt, wird er selber als Versager dem Drachen gleichsam einverleibt. Man macht ihn zum Oberst und Kommandeur eines Regiments. Obwohl er jetzt einer der Häupter der Hydra ist, ist er zum mindesten ein Querkopf. Sein instinktiver Sinn für Menschlichkeit bleibt ihm noch erhalten. So begnadigt er kurzerhand einen Deserteur und verwandelt das Todesurteil in vierzehntägigen Arrest. Die Armee meutert; der Bürgerkrieg bricht aufs neue aus. Das Volk jubelt dem jungen König zu, die Misac stützen ihn. Trotzdem flüchtet er mit Jadwiga ins Ausland.

Hiermit dankt der junge König als Herausforderer endgültig ab. Er ist vollends der Versager und Wegläufer der Satire. Solange er noch in Capota seines Amtes waltet, steht im Vordergrund vornehmlich eine sehr milde Prägung des Pfuschers, der wiederholt in seiner Unerfahrenheit "verwirrt" (209) ist. Auch darin ist der junge König noch weitgehend der Ingénu. Das Regieren ist ihm weit weniger wichtig als der Spielplan des Hofkinos. Es liegt somit auch hier eine Verwechslung des Wichtigen mit dem weniger Wichtigen vor. Aber der junge König hat Glück. Der begnadigte und wie er geflüchtete Deserteur verschafft ihm eine Stellung in einem Zirkus des Nachbarlandes. Der Sprecher nennt sich nun Wilhelm Tückes und beteuert, glücklich 
und zufrieden mit seiner immer mehr erblühenden Jadwiga zu leben. Dieses Märchenende in "König" betrifft aber keineswegs einen "jungen König" im Sprecher; es gilt einem spießbürgerlichen Tückes, der sich zum Vir bonus aufreckt. Seine Idylle erhebt Anspruch auf Permanenz. Gerade das macht sie verdächtig. Zwar ist der Zirkus ein menschlicherer Bereich als der Königshof Capotas, wäre aber Idylle nur als Zufluchtsort auf Zeit. Bei längerem Aufenhalt nimmt sie negative Züge an.

So beginnt Tückes als Limonadenverkäufer, der dann zu den Zigaretten, dann zum Gulasch avanciert und zuletzt die Stellung des Kassierers erklimmt. Im Prinzip diktiert diese sein Leben wie einst Pelzer es bestimmte. Am Ende der Geschichte finden Tückes und Jadwiga auf der Zirkusreise in einem Museum Denkwürdigkeiten aus Capota, sogar einen beschriebenen Fetzen aus dem Schulheft des jungen Königs. Sie können sich jedoch diesen Funden nicht mit Muße widmen: "Wir verließen schnell das Museum, denn es war ein Uhr geworden, um drei fing die Vorstellung an, und ich mußte um zwei die Kasse eröffnen" (214). Lebt Tückes auch hier noch in der fragwürdigen Welt des Oben und Unten, so ist seine Abdankung als König um so bedauerlicher, weil sie ihm nicht allzuviel einbringt und ihn viel verlieren läßt. Er ist zwar glücklich, aber doch ein Zwerg. Die Voraussetzung zu gewichtigen Leistungen-und die meint das KönigSein hier, nicht etwa ein vom Satiriker befürwortetes hierarchisches An-der-Spitze-Stehen-ist nicht mehr gegeben. Die Unscheinbarkeit Wilhelm Tückes ist kein Grund zur satirischen Schonung, denn sie ist selbsttätige Schrumpfung des Wegläufers. Wie Helmut Arntzen generell betont, macht die Satire die "Absolution des 'kleinen Mannes'" nicht mit, sondern zeigt vielmehr, "wie das Objekt sich zum Objekt machen läßt und selbst macht." 10 Als König hingegen hätten Wirkungsmöglichkeiten bestanden, wie sie einem Satiriker für sich selber nur in seinen kühnsten Träumen erscheinen könnten. Den Verlust unterstreicht der Satiriker mit Nachdruck. Der Zettel mit der Handschrift des jungen Königs trägt den Satz "Rehgen bringt Sehgen." Jadwiga setzt mit ihrem Kommentar hierzu gleichsam den Schlußstrich unter die Abdankungsurkunde des Herausforderers: "Das hast du nun hinter dir, für immer" (214). Das regelwidrige "Rehgen bringt Sehgen" meint nicht etwa nur, daß der König seine Kinderschreibweise und seine Schulnöte hinter sich hat, sondern auch seine Krone, die ihm eine Orthographie besonderer und eigenwilliger Art erlaubte. Sie war eine Recht-Schreibung, die Großtaten wie die Begnadigung des Deserteurs signierte. Die Möglichkeiten eines Königs kommen dem Kollektiv zugute, das Regen Wilhelm Tückes bringt 
einem liliputgroßen Privatbereich Segen. Er gehört zu den satirischen Helden, deren Verhalten Ronald Paulson beschreibt als ein "settling for security without honor." 11

Die Analogie von König und Künstler, die seit Schiller im deutschen Sprachraum durchaus nichts Ungewöhnliches ist, wird an dieser Textstelle offensichtlich. Im Beruf findet besonders der Satiriker sein Reich der "Recht-Schreibung." Dort steht ihm ein Forum offen, dort kann er ein Publikum gewinnen und im großen Rahmen sozial wirksam sein. Verläßt er seinen Beruf, so mag er wohl ein privates Glück genießen, aber seine öffentliche Wirkung ist vorüber. Vorauszusetzen ist natürlich, daß der Künstler nicht etwa zum Politiker wird. Aber diese Möglichkeit läßt sich bei Menschen vom Schlage Bölls kaum denken. Entweder ist man ein König oder ein Privatmann; die Pelzers der Welt befinden sich nicht in Zonen, in denen rechtes soziales Wirken möglich ist. Bölls starke öffentliche Stimme als Privatmensch widerspricht nicht der These, daß der Beruf die Voraussetzung der Wirkung ist. Wäre Böll nicht erfolgreicher Schriftsteller, so stünde ihm die Presse wohl nur als Leser offen, etwa wie Tückes das Museum. Einem König eröffnet sich dieses hingegen als Aussteller, sogar wenn es sich um eine lächerliche Reliquie wie einen beschriebenen Fetzen handelt. Der Titel der Erzählung unterstreicht diese relativen Wertmaße. Vom Kassierer Tückes ist nicht die Rede.

Mit diesem Stellenwert des Künstlers und seines Berufs, worin sich zweifellos der erfolgreiche Autor Böll eröffnet, legt der Satiriker eine dem Herausforderertopos in den Berufssatiren höchst zuträgliche Nuance bloß. Von nun ab zeigen die den Künstler chiffrierenden Protagonisten Ausnahmemaße. In "Im Lande der Rujuks" und in "Hier ist Tibten" handelt es sich um hochqualifizierte Akademiker, in "Es wird etwas geschehen" und in "Der Wegwerfer" (besprochen im nächsten Kapitel) um Organisationsgenies. Diese Protagonisten sind einsam. Es erwartet sie keine Familie in der von Text zu Text unwirtlicher werdenden Privatsphäre. So neigen die Berufssatiren dazu, sofern sie den Autor Böll spiegeln, den Künstler als exponierte Persönlichkeit hinzustellen. Bei allem Liebäugeln mit den Wonnen des friedlichen Winkels befürwortet Böll auch in "König" Stehvermögen vor dem Feind. Meint diese Satire, daß der Satiriker sein Amt wichtig zu nehmen hat, so zeigt sie auch, daß er nicht unentbehrlich ist. Die Dinge kommen auch ohne ihn in Fluß. Capota wird ohne den jungen König zur Republik. Die Wendung entschuldigt natürlich nicht die Flucht des Sprechers. Diese ist bestenfalls Anlaß zu den begrüßenswerten Entwicklungen, nicht deren Ursache, die ein standfester junger König hätte sein können. Wenn man gewillt ist, Capotas Wandel zur Republik als Fortschritt aufzufassen, so wäre man ver- 
sucht, in diesem Text nicht nur von ästhetischer Aufhebung des Objekts, sondern seiner Überwindung in der Wirklichkeit zu sprechen. Jedoch geht es nur am Rande um Capota, das Objekt ist fast ausschließlich der Sprecher und deshalb ist Capotas Hinwendung zur Republik nur Hinweis auf ein freieres Leben, nicht eine Überwindung des satirischen Objekts, wie Pelzer, die Armee und die Kasse im Zirkus dem Objektbereich zwar Kontur verleihen, nicht aber dessen Mittelpunkt sind. Die weitgehende Beschränkung des Objekts auf den Protagonisten schmälert diesen Text etwas. Die Identifizierbarkeit der capotanischen Armee, Pelzers und der Zirkuskasse als konkret Anstößiges in unserer Welt liegt nicht höher als die des Hundesteueramtes in "Bekenntnis eines Hundefängers."

Wie der Hundefänger geht auch der junge König rein gefühlsmäßig vor. Das Beliebige daran ist allerdings hier eher eine Art Glücksache, und das Glück lächelt ihm oft. Gerade wenn er den Fehler macht, beim Notenfälschen ein gefährliches Loch ins Papier zu radieren, kommt die Botschaft vom Tode des Vaters. Die dünne Jadwiga blüht nach der Heirat auf, der Deserteur verschafft ihm eine Stelle. Trotzdem genügt Glück nicht, denn über kurz oder lang ist es selbst für den Ingénu mit den schönsten natürlichen Anlagen vorüber. Solange der junge König noch als Ingénu handelt, ist sein Versagen gewissermaßen zufällig und entschuldbar, nach seiner Flucht jedoch nicht. Der Pfuscher Tückes, der eine Chance ausschlägt, in Capota wieder im großen Rahmen wirksam zu werden, ist weiter entfernt vom Vir bonus als der Pfuscher Pig Gi vom Ingénu.

Beziehen wir die Problematik auf den Satiriker, so ist eine Note des Stolzes über Anlage und erste L eistungen nicht zu verkennen. Da aber das Glück nur auf Zeit gilt, hat er selber einen Kompaß zu entwickeln. Die Norm erscheint hier in dem Satz "Rehgen bringt Sehgen." Tückes hat sie hinter sich "auf immer." Das Sprichwort ist Metapher des Lebensflusses. Sie meint aber eine eigene "Orthographie" gegen die Regeln, wie sie beim Autor als Ingénu Glücksache ist und wie sie der Autor als Vir bonus bewußt zu suchen hat und nur dann entwickeln kann, wenn er am Gegner bleibt. Das "Rehgen bringt Sehgen" ist hier ein sehr geglückter Aufhänger der Wortpaartechnik. Es summiert das Tun der Erzählerfigur. Böll behält im schematischen Sinne ein Wortpaar, sogar ein gereimtes, bei, stellt allerdings die Dialektik nicht durch einen Kontrast der Reimwörter, sondern durch eine Formänderung in den beiden Wörtern her, die den Unterschied von Subjekt- und Objektsphäre anzeigt.

Aus der Sicht der Objektsphäre, d.h. in den Augen des Ehepaares Tückes, stellt das Sprichwort einen simplen Kontrast auf. Wilhelm ist beschämt ob seiner ehemaligen Schreibweise; Jadwiga versichert 
ihm, das alles hinter sich zu haben. Gemeint ist einmal die falsche Schreibweise gegenüber der richtigen und damit das für die Tückes falsche Leben des Königs gegenüber dem richtigen des Kassierers. Aus der Subjektsphäre eröffnet sich die dialektische Bezogenheit aufgrund der Spaltung des Sprichworts in Inhalt und Schreibweise. Der Inhalt meint Positives, insofern er auf Dynamik deutet, die, wie Jadwigas Reaktion zeigt, Teil des Königslebens ist. Das Negative des Inhalts ergibt sich aus dem spießbürgerlichen Kontext, in dem man die Formel traditionell versteht, nämlich als Rechtfertigung von Rührigkeit im Kleinzirkel. Das nämlich hat Tückes nicht hinter sich. Er kann schon die dritte, vom Königtum her gesehen allerdings lächerliche Beförderung verzeichnen. Negativ ist auch die Schreibweise, wenn sie in ihrer traditionellen Form erscheint, da die biedermeierlichen Tückes diese schätzen. Erscheint sie in untraditioneller Form, meint sie Positives, denn sie bezieht sich auf den jungen König, damit die Herausfordereridee.

Die Micromegas-Technik in "König" läßt sich am leichtesten verdeutlichen anhand des Sprachprotokolls, das am Hof herrscht. Der Hauslehrer, der Kammerdiener und Pelzer verwenden Floskeln wie "Geruhen Eure Majestät" (210), wenn sie vom jungen König eine Tätigkeit erwarten. Im zeremoniellen Sinne ist die Phrase ein Signal der Unterwürfigkeit. Sie wird aber gebraucht zur Erniedrigung des protokolarisch Höherstehenden. Pelzer will dem jungen König seine Tochter zur Festigung seiner Macht zuschieben; der Hauslehrer ist in der Rolle des Wissenden, der Sprecher in der des Unwissenden; der Kammerdiener benutzt die Untertänigkeitsfloskel, um gutzumachen, daß er den jungen König wegen Rauchens bei Pelzer gemeldet hat.

Das Erniedrigen und Erhöhen durchzieht den gesamten Text, sogar im kleinsten stilistischen Detail. Um Bölls erstaunlich konzentriertes Vorgehen aufzuzeigen, soll ein Abschnitt im Lichte seiner Micromegas-Technik untersucht werden. Es handelt sich um den Eingang des Textes, könnte aber auch irgend ein anderer Ausschnitt aus dieser oder fast jeder anderen Kurzsatire Bölls aus den fünfziger Jahren sein. Er wird also zu paradigmatischen Zwecken beleuchtet, und das auch, da er dem zentralen Text dieses Kapitels angehört:

Als ich dreizehn Jahre alt war, wurde ich zum König von Capota ausgerufen. Ich saß gerade in meinem Zimmer und war damit beschäftigt, aus einem "Nicht genügend" unter einem Aufsatz das "Nicht" wegzuradieren. Mein Vater, Pig Gi I. von Capota, war für vier Wochen im Gebirge zur Jagd, und ich sollte ihm meinen Aufsatz mit dem königlichen Eilkurier nachsenden. So rechnete ich mit der schlechten Beleuchtung in Jagdhütten 
und radierte eifrig, als ich plötzlich vor dem Palast heftiges Geschrei hörte: "Es lebe Pig Gi der Zweite!" (209).

Der Eingangssatz umreißt lapidar eine Umbruchssituation. An sich schon keine Alltäglichkeit ist sie eine Außerordentlichkeit ersten Ranges dadurch, daß ein Kind König wird. Der Sprecher wird an die Spitze eines Landes gestellt. Diese phantastische Erhöhung wird allerdings schon hier im Eingangssatz beeinträchtigt. Das Königtum heißt Capota, das klingt nach Laputa in Swifts Gulliver's Travels oder nach einer Operettenmonarchie. Der zum König Ausgerufene sitzt nicht etwa unter der Krone im Dom, wie sich erwarten ließe, sondern "gerade" in seinem Zimmer. Die Krone ist gewissermaßen Zufall. Wird damit das bedeutende Ereignis heruntergesetzt, so auch durch die höchst unkönigliche Tätigkeit, der er gerade obliegt. Er versucht, den Monarchen hinters Licht zu führen. Er geht dabei nicht etwa auf einmalige Art vor, sondern anhand eines Klischees. Er radiert an einer schlechten Note, genau wie es die Situation eines Schülers in Drangsal eben vorschreibt. Aber hier eröffnet sich schon der Aspekt des Herausforderers im Sprecher. Er ist gewillt, ein bedachtes Risiko einzugehen. In seinem Versuch, das "Nicht" in "Nicht genügend" wegzuradieren, gibt Böll schon sehr genau den Sinn des Textes und das Urteil über den Protagonisten. Die Eröffnungen des Sprechers sind nichts anderes als eine Apologie und dabei ein Täuschungsspiel, um sich selber als "genügend" zu erweisen. Wie wir einige Sätze später erfahren, mißlingt sein Ansinnen. Wir lernen ihn demnach gleichzeitig als jungen König und Pfuscher kennen. So steht der König und mit ihm sein Königtum sogleich im Lichte des Lächerlichen. Der Name des Vaters läßt an "piggy" (Schweinchen auf Englisch) denken. Das liegt um so näher, da Pig Gi I. sich auf der Jagd befindet, wo er sich als das Gejagte erweist. Wenn es heißt, der Vater war "für vier Wochen im Gebirge," so drängt uns die Formulierung in die Vorstellung eines geruhsamen Urlaubs oder einer Kur, wie sie jeder Zeitgenosse bisweilen hat. Daß Pig Gi I. aber zur Jagd dort ist, erhöht ihn deutlich. Das Schweinchen geht einem exklusiven Sport nach. Darin liegt eine Blähung, die später dadurch platzt, daß der Jäger als das Gejagte endet. Ist der König ein "piggy," so doch eins mit deutlichen Privilegien. Er läßt sich den Aufsatz kommen, sogar per "königlichen Eilkurier," als ginge es etwa um die Emser Depesche. Aber er ist auch wieder der echte Kleinbürgervater, der die schulischen Anstrengungen des Sohnes überwacht, und das anscheinend mit Drohungen, da es sonst keinen Grund gäbe, die Zensur zu fälschen. Eine gewisse Erniedrigung des Vaters liegt darin, daß er in einer "schlecht beleuchteten Jagdhütte," der Sohn hingegen im Palast 
haust. Diese Erhöhung wird dem Sprecher stehenden Fußes bestätigt. Man schreit plötzlich “Es lebe Pig Gi der Zweite." Das ist mehr als der Vater war. Diesem erteilt der Sohn als Sprecher nur die Ziffer, in bezug auf sich selbst schreibt er sie aus. Die größere Nachfolge steht aber trotzdem schon unter einem schlechten Omen. Der Sprecher ist dreizehn Jahre alt. Sein Glück, das sich hier schon darin zeigt, daß seine schlechte Note nicht mehr gegen ihn ins Gewicht fallen wird, steht im Kontext einer Unglückszahl. Auf sie läuft das Leben des Sprechers als abgedankter Herausforderer Tückes letztlich hinaus.

"Im Lande der Rujuks" (1953) stellt einen Protagonisten vor, der gleich auf zweifache Weise Chiffre des Satirikers ist. Wie Swift als Gulliver reist er als Arzt und Anthropologe. Dazu ist er noch der Beherrscher einer exotischen, von Böll erfundenen Sprache. Die Vielseitigkeit des Rujukforschers berechtigt zu den schönsten Hoffnungen. Leider führen diese zu nichts. Nach dreizehnjährigem Studium der Rujukkultur aus zweiter Hand und fünfjährigem der Medizin kommt er vollgestopft mit Wissen und durchtränkt mit missionarischem Geist im Lande seiner Sehnsucht südlich Australiens an. Er gleicht einer Offenbarungserscheinung; einsam auf einem Schlauchboot anrudernd deklamiert er schon von weitem: "'Joi wuba, joi wuba, buweida guhal!' (Vom Meer, vom Meer, komme ich, euch zu helfen, Brüder!)" (W2, 230). Mit tiefer Enttäuschung muß dieser Epigone Albert Schweitzers jedoch feststellen, daß man ihn überhaupt nicht beachtet. Die Rujuks sind weit darüber hinaus, den Träumen eines romantischen Akademikers zu entsprechen, der nach unverfälschtem Volkstum fahndet. Sie haben ihren Helfer schon gefunden in der Form des modernen Lebens vornehmlich amerikanisierter und europäisierter Prägung. Die Eingeborenen verstehen das klassische $\mathrm{Ru}-$ juk der Erzählerfigur nicht, da sie nur ein Gemisch von Rujuk und Filmenglisch kennen. Der Rujukforscher ist erschüttert. Er kehrt in die Heimat zurück, züchtet Obst und betreibt die Rujukforschung nur mehr als Privatsache.

Das Bild, das der Sprecher von seiner Ankunft im Lande der Rujuks entwirft, bestimmt ihn innerhalb des Heldenarchetyps als Variante des Heilbringers. Er ist der herrliche Freund mit wunderbaren Gaben. Zweifellos ist er dieser Vorstellung verfallen, denn es kommt ihm nicht in den Sinn, schlicht als Mediziner bei den Rujuks zu bleiben. Sie interessieren ihn nicht als Menschen, sondern als Publikum oder Gemeinde. Da sie ihm nicht die rechte Achtung entgegenbringen, ist er nicht gewillt am Platze zu bleiben, um etwa auch der fortschreitenden Auflösung der Rujukkultur entgegenzuwirken. Das Außerordentliche an dieser Heldenvariante verdeutlicht einerseits 
den Archetypus, wie es andererseits den Sprecher verzeichnet. Keineswegs kommt Böll also auf seinen früheren, christlich-religiösen Archetypus zurück. Vom Heiligen, Engel oder Märtyrer ist an diesem Heilbringer nichts zu verspüren.

Der Satiriker sieht in der Chiffre des Rujukologen seinen Typus in einer Form der Selbstüberhöhung. In einem Winkel seines Herzens glaubt er bisweilen, Gott zu sein, und darum ist er tief enttäuscht, wenn das Publikum seiner Größe nicht den rechten Respekt zollt. ${ }^{12}$ Der Herausforderer in "Rujuks" ist wieder der Versager in der Form des Wegläufers, der sich hier zu lächerlichen Dimensionen bläht und glaubt, das Land der Rujuks, um das es-figurativ-zu kämpfen gilt, habe ihm zu Füßen zu fallen. Darin liegt auch der Pfuscher, der Beruf mit Mission verwechselt. Der verzeichnende Humor tritt ganz besonders für den Pfuscher in Kraft. Das Bild des Heilands, "heftig rudernd und winkend," ist das amüsanteste des Textes. All seinen Bemühungen zum Trotz verpfuscht er seine Ankunft durch schlechtes "Timing." Im konkreten Sinne wird er übersehen, weil gleichzeitig das Postschiff eintrifft. Der stützende Humor schlägt sich in den Rujukzitaten nieder. Ästhetisch, d.h. als Rujuk_-Bruwal doidoi, duraboi" (230) - sind sie zum Lachen. Ihr Inhalt, selbst was die Flüche angeht, wirft hingegen, wie später gezeigt werden soll, ein schmeichelhaftes Licht auf die Kultur der Rujuks.

Die Hauptlinien in dieser Satire laufen offensichtlich parallel zu denen in "Erinnerungen eines jungen Königs." Der Sprecher verläßt einen Bereich, wo er sozial förderlich sein könnte, und entläuft in einen privaten Winkel. Die Idylle ist jedoch hier weniger attraktiv als die in dem vorangehenden Text. Dem Sprecher stehen keine erblühende Frau und keine wohlmeinenden Freunde zur Seite. Seine Kontakte sind nicht erbaulich. Mit seinem ehemaligen Lehrer Wodruff ist er "verkracht" (229), die Obstgroßhändler wollen ihn betrügen. Vom Herausforderer ist nur Lächerliches übriggeblieben. Trotzdem tut er sein Bestes, sein Versagen, das auch sein Lehrer an ihm erkennt, zu vertuschen. Er stellt sich als weise, sein Leben als beschaulich hin:

... Wodruff, dem ich hin und wieder eine Kiste Äpfel schicke und eine Postkarte mit den Worten: "Wahu bahui" (Verehrter Meister, du irrst), worauf er mir zu antworten pflegt, ebenfalls auf einer Postkarte: "Hugai" (Abtrünniger), und ich zünde mir meine Pfeife an und blicke auf den Rhein hinunter, der schon so lange da unten vorüberfließt (232).

Wenn der Sprecher den Rhein ins Bild bringt, versucht er seine Existenz zu rechtfertigen. Er rückt sie in einen Rahmen, in dem sich die Dinge in ewigen Bahnen bewegen. Aber gerade der Verweis auf den 
Rhein ist verfehlt und ein Indiz gegen den stillen Garten des Sprechers. Zwar ist der Rhein zweifellos Metapher des Lebensflusses, aber relative Größenordnungen müssen hier beachtet werden. Ist der Rhein der Kontext des privatisierenden Sprechers, so ist das Meer das Element des Ethnologen. Der Rhein ist Szenerie eines SpitzwegGemäldes, das Meer ist für die vom Fischfang lebenden Rujuks Urelement des Lebens. Liegt das Land der Rujuks inmitten des Wassers, so fließt dieses am Obstgarten vorüber.

Trotzdem ist das Dasein der Rujuks alles andere als ideal. Das Wasser ist zu mächtig. Die Rujukkultur steht in Gefahr, hinweggespült zu werden. Gerade darum wäre der Sprecher dort und nicht im Obstgarten mit seinem Wissen und Können am Platze. Die Eingeborenen wandern aus, denn in Amerika "rollen die Dollars" (231). Filmenglisch überschwemmt ihre Sprache und eine ihrer Inseln ist schon menschenleer. Die Frage nach dem rechten Leben ist auch hier wie so oft in Bölls Satiren eine Frage der Zeit. Der Sprecher kommt zu spät; der rechte Fluß der Dinge gehört im Lande der Rujuks der Vergangenheit an. Er steht im Gegensatz zum modernen Leben, für das man gewöhnlich vor allem Amerika als abschreckendes Beispiel heranzieht.

Die Normfindung liegt hier wie in "Erinnerungen eines jungen Königs" nicht im Kern der Problematik des Satirikers. Er ist fähig, die Norm ziemlich genau ex negativo zu bestimmen. Wichtiger sind die Maße des Herausforderers. Empfiehlt der Satiriker seinem Typus sozusagen königliche Konturen in "Erinnerungen eines jungen Königs," so warnt er in "Rujuks" vor angemaßten göttlichen. Besonders komisch läßt Böll die Seifenblase eines derart wirklichkeitsfernen Dichtertums platzen, indem er den Sprecher im Moment seiner Ankunft, wenn ihm als Heilbringer der Kamm schwillt, offen mit seinem Symbolwert zusammenbringt: "Wäre ich ein Dichter," so jammert der Sprecher, "würde ich sagen: Ein Traum brach mir entzwei, obwohl Träume ja nicht brechen können." Wäre er wie ein Dichter, und zwar wie ein klarsehender, und nicht das Analogon zum anachronistisch verträumten, so verstünde er den Unterschied zwischen vorgestellter und wirklicher Welt. Er würde, empört wie der Satiriker, den Traum an der Wirklichkeit messen und Konsequenzen ziehen, die auf Veränderung des Bestehenden zielen. Statt dessen stellt er seinen Traum als Trophäe in die heimische Vitrine und poliert sie in seinen Mußestunden. Das ist um so erstaunlicher, als er selber die neuen Wirklichkeiten im Rujukland gegenüber seinem Lehrer verficht. Er gerät mit diesem in Streit über das Wort "buhal" (231). Er behauptet, es bedeute Wasser. Für den Altmeister Wodruff meint es Liebe. Zweifellos verweist die Verschiebung der Wortbedeu- 
tung auf den Verfall der Rujukkultur. Was den Rujuks einmal Liebe bedeutete, Teil ihrer Heimat war und Nahrung bot, ist nun nichts mehr als ein Element, das sie ins Land des in Hollywood erzeugten Traums vom Dollar schwemmt.

Die Liebe als Zeichen des rechten Lebens und als Anker in der Flut wird weiter in einem Rujuklied, das der Sprecher besonders schätzt, verdeutlicht:

Woi suhal buwacha

bruwal nui loha graga bahu, graga wiuwa

moha deiwa buwacha.

(Warum treibt es dich in die Ferne, mein Sohn, haben dich alle guten Geister verlassen?

Keine Fische gibt es dort, keine Gnade,

Und deine Mutter weint um ihren Sohn.) (232)

Es liegt auf der Hand, daß der Sprecher die Empfindungen des Liedes teilt. Auch er sähe die Rujuks lieber in ihrem eigenen Lande als in Amerika. Darüberhinaus mag er das Lied apologetisch im Sinne des "Bleibe im Lande und nähre dich redlich" auf sich selber und sein Leben am Rhein beziehen. Dazu ist er jedoch nicht berechtigt. Das Land seiner Sehnsucht hätte dasjenige zu sein, wo er seinem Beruf gemäß wirken kann. Darum ist am Rhein nicht die rechte Heimat für ihn, zumal der rheinische Rujuk hier keine "Gnade" erwarten kann, sondern sich mit betrügerischen Händlern abzugeben hat. Wenn sich jemand um ihn sorgt, so ist es keine Mutter, sondern bestenfalls Wodruff, der seinen geistigen Sprößling lieber im Lande der Rujuks sähe.

Der Satiriker charakterisiert nicht nur die Liebe, sondern auch die Grenzen der Boshaftigkeit unter den Rujuks. Der Sprecher zitiert zwei Flüche, deren er sich gegen die Obsthändler bedient: "'Graga weita' (keinen Segen soll es dir bringen)" und, wie er sagt, "einen der schlimmsten," "'Pichal gromchit' (die Gräte soll dir im Halse stekkenbleiben)" (232). Ein Land, das solche Flüche hat, ist begreiflicherund berechtigterweise attraktiv. Um so bedauerlicher ist, daß dem Sprecher seine Sympathien für die Rujuks nur als Traum wertvoll sind.

Wenn Böll in den Kurzsatiren bisweilen mit dem Gedanken der Auswanderung spielt, so scheint sich dieser nur in "Rujuks" positiv niederzuschlagen. Der Sprecher hat einen für das Land seiner Sehnsucht geeigneten Beruf. Auf den Satiriker bezogen muß das Schema jedoch auf den Kopf gestellt werden. In diesem Sinne ist die Analogie zum Ethnologen nicht direkt. Sein Beruf spricht gegen die Auswanderung, 
seine Sprache ist die seines Landes. Was also für den Sprecher Rückkehr in die Heimat ist, wäre für seine Chiffre die-inkriminierendeAuswanderung in die Fremde.

Auch der Sprecher dieser Satire ist nicht ganz frei vom Bewußtsein seines Versagens. Wie Tückes im vorhergehenden Text seinen Aufstieg zur Kasse betont, so beichtet uns der Obstzüchter, er spiele "immer noch mit dem Gedanken, [sein] medizinisches Studium durchs Staatsexamen zu krönen" (231). Wie der Hundefänger zieht er sich unter Verweis auf sein fortgeschrittenes Alter-er ist fünfundvierzig-aus der Affäre.

Trotz der Zentralstellung des Sprechers zeichnet der Satiriker in den Randzonen des Objektbereichs sehr genaue Konturen. Stärker als in "Bekenntnis eines Hundefängers" und "Erinnerungen eines jungen Königs" enthalten diese identifizierbare Anstößigkeiten unserer Welt. So ist "Rujuks" der einzige Text unter den Kurzsatiren der fünfziger Jahre, in dem sich allgemein bekannte Namen finden. Wenn von "Hollywood," "Rita Hayworth" und "Zarah Leander" die Rede ist, so fällt es dem modernen Leser nicht schwer zu erkennen, daß Böll den westlichen, die Welt durch Film und Funk überschwemmenden Kulturmissionarismus aufs Korn nimmt.

Die dialektische Technik in diesem Text ähnelt der in "Erinnerungen eines jungen Königs." Wo Böll dort ein Sprichwort regelwidrig buchstabiert, greift er hier zur zweisprachigen Form eines Gesagten. Das Prinzip eröffnet sich in dem oben angeführten Rujuklied. Schon das graphische Bild stellt einen Kontrast her. Die Rujukzeilen sind kurz und sind Lyrik; die Übertragung hat ungefähr die zweifache Länge und ist Prosa. Aus der Objektsphäre verstanden ist der Kontrast ein einfacher. Der Sprecher trauert seinem Traum nach, wenn er Rujuklieder, die zweifellos reines Rujuk darstellen, singt. Die Übersetzung bedeutet ihm an sich nichts, er gibt sie in Klammern, also etwa im Rang einer Anmerkung. Wo den Kassierer Tückes sein kindliches "Rehgen bringt Sehgen" beschämt, die Zirkusidylle ihn mit Stolz erfüllt, so ist der Obstzüchter in seinen idealen Vorstellungen von der Rujukkultur eher zuhause als in der Wirklichkeit. Aus der Subjektsphäre gesehen hat das Rujuk wie auch die Übersetzung ambivalente Bedeutung. Was der Sprecher zitiert, ist antiquiert. An der Wirklichkeit gemessen gehört dieses vergangene Rujuk zu dem Traum, der den Sprecher hindert, seinem Auftrag als Arzt und Helfer gerecht zu werden. Das reine Rujuk gehört zwar der Vergangenheit an, diese war jedoch eine Zeit rechten Lebens, als "buhal" noch Liebe bedeutete und die Dollar noch nicht lockten und flossen. Zur Illustration dieser Zeit liegt es nahe, an Bölls "Anekdote zur Arbeitsmoral" zu denken. Dort benimmt sich der Fischer, der 
nach einem guten Fang den restlichen Tag in seinem Boot verträumt, wie ein echter Rujuk. Der Tourist, der die Szene beobachtet, kann nicht begreifen, daß der Schläfer nicht wieder und wieder ausfährt, um Mehrwerte zu schaffen. Aber der Fischer kennt keinen Ehrgeiz dieser Art, obwohl ihm ausgemalt wird, wie er als reicher Fischereiunternehmer "in der Sonne dösen-und auf das herrliche Meer blicken" könnte. Der Fischer weist darauf hin, daß er genau das jetzt auch tue. Der Tourist ist belehrt, "und es blieb keine Spur von Mitleid mit dem ärmlich gekleideten Fischer in ihm zurück, nur ein wenig Neid" (W4, 269). Die Vorstellung des Einfachen und Harmonischen geht auch schon sprachlich aus dem Rujukzitat hervor. Es reimen sich alle vier Zeilen. Die Übertragung hingegen wirkt sprachlich komplexer. Ihr fehlt auch die rhythmische Glätte des Originals. Die Übersetzung legt alles andere nahe als eine ideale Beweglichkeit der Dinge. Die Kehrseite der Münze sagt allerdings etwas zugunsten der Übertragung. Sie ist nicht etwa ein Museumsstück, sondern hat eine Kommunikationsfähigkeit, die dem klassischen Rujuk abgeht, da es die Rujuks selbst nicht mehr verstehen.

Neben der Ankunftsszene sind die Rujukzitate das augenscheinlichste Beispiel des Micromegas-Prinzips. Hier wie dort bläht sich der Sprecher auf. Er übersetzt zwar jedes Zitat, jedoch sind wir im Grunde darauf angewiesen, ihm zu glauben. Ein Element des Zweifels stellt sich schon dadurch ein, daß er sich ein wenig mit seinem Wissen wichtig macht. So gibt er uns in einem Falle erst eine lockere, dann eine genaue Übersetzung und teilt uns darüberhinaus mit, daß er mit Wodruff, dem großen Begründer der Rujukforschung, eine semantische Auseinandersetzung hat.

In "Hier ist Tibten" (1953) wird uns zum zweiten Male ein hochqualifizierter Akademiker als Sprecher vorgestellt. Er besitzt zwei Doktorhüte und hat nicht weniger als fünf Universitäten besucht. Wie auch der obstzüchtende Rujukforscher geht er einer Beschäftigung nach, die nichts mit seiner Ausbildung zu tun hat. Er arbeitet nachts als Ansager in einem Bahnhof. Dabei ist er aber "nachdenklich," demnach nicht nur Akademiker, sondern eine Art Intellektueller, und als solcher ist er komplex und kritisch. Er ist noch weitgehender isoliert von seinen Mitmenschen als der Rujukforscher. So spricht er pauschal von "herzlosen Menschen," die glauben, daß er eine ihm "unwürdige" Stellung hat. Er behauptet dagegen, daß seine Arbeit ihm "Spaß" mache, ist aber so unverkennbar apologetisch in der Darbietung seiner Gründe, daß wir ihm nicht aufs Wort glauben. Als Eiron-Figur redet er von "Demut" und "Befriedigung" (W2, 233-35), um anzudeuten, daß er einerseits den sozialen Rang, der mit einem Akademikerberuf verbunden ist, für sich ablehnt, aber an- 
dererseits als Vir bonus Leistungen bietet, die seiner Bildung gerecht werden.

So sollen wir die Funktion des Ansagers als seinen Titeln entsprechend verstehen, etwa im Sinne der alten Definition der Vokabel Doktor, als zum Lehren befähigter Gelehrter, denn wie er wahrhaben will, ist seine Arbeit durchaus kein platt mechanisches Durchgeben von Auskunft, sondern nichts Geringeres als Aufklärung:

Ich sage den Leuten, wo sie sind. Zeitgenossen, die abends auf dem Heimatbahnhof in die Züge steigen . . . die nachts dann auf unserem Bahnhof erwachen, verwirrt ins Dunkel blicken, nicht wissend, ob sie übers Ziel hinausgefahren oder noch vor dem Ziel sind, möglicherweise gar am Ziel . . . allen diesen sage ich, wo sie sind. Ich schalte den Lautsprecher ein . . . und ich spreche es zögernd in die Nacht hinein: "Hier ist TibtenSie sind in Tibten! Reisende, die das Grab des Tiburtius besuchen wollen, müssen hier aussteigen!" (233).

Der Sprecher, der "Beschwörung" (236) in seine Stimme legt, will seine Tätigkeit nicht nur als Vermittlung von Wissen, sondern auch als Anregung zum Denken verstanden sehen. Dieses Konterfei ist jedoch Anmaßung. Er ist kein Aufklärer, denn sein Publikum erfährt im Grunde nichts Klares. Sein Geraune ist fragwürdiger Effekt, wie der Sprecher selber spürt, wenn er seinen Spruch als Echo des Lautsprechers umreißt: "Dunkle Stimme aus dem Dunkeln, die etwas Zweifelhaftes zu verkünden scheint, obwohl sie die nackte Wahrheit spricht" (233). Die Wahrheit, die er zu vermitteln behauptet, ist "die Weisheit dieser Welt" (235), die er begreift und die in Tibten am Grab des Tiburtius, eines durch Selbstmord geendeten spätrömischen Jünglings zu finden wäre. Obwohl der Sprecher jedoch weiß, daß die Besucher des Grabes unfähig sind, diese Weisheit dort zu finden, verundeutlicht er sie und behält sie damit für sich. So liegt in seinem Tun, streng genommen, eine gewisse Überheblichkeit, die sich von der Erkenntnisträgheit anderer nährt.

Tiburtius kam als Bleikäufer für seinen als Heereslieferant tätigen Vater nach Tibten und wurde hier derart von der Liebe zu einer lokalen Schönheit überwältigt, daß er sich im gefluteten Schacht einer Tibtener Bleigrube ertränkte. Tibten, so Böll, stellt eine Verschleißform des Wortes Tiburtinum dar: Der Tod des Tiburtius ist demnach schon in der Vergangenheit als ein wichtiges Ereignis begriffen worden, da er einem Ort zum Namen verhalf. Als Römer in Germanien wird dieser "römische Werther" (234) durch seine Liebe an sich schon zum Herausforderer, da sie tiefgehende Konventionen in Frage stellt. Allerdings sind diese zu stark; sie brechen ihn. Die 
Liebe wäre gerade das Moment, das dem Lebensfluß Richtung und Maß geben, die sich neigende römische und die aufgehende germanische Welt zusammenführen könnte. Statt diese Weisheit zu begreifen, ist man am Grab des Tiburtius "gerührt" (235). Man legt Rosen ab und erkennt durch die Tränen der Sentimentalität nicht, daß es eine Welt falscher Normen, nicht aber die Liebe ist, die Tiburtius in den Tod schickte. Wie weit man an der Wahrheit vorbeigeht, eröffnet sich besonders an der Interpretation der Tierfigürchen, die man im Grab gefunden hat. Namhafte Autoritäten halten sie für Teile eines schachähnlichen Spiels. Der Sprecher ist dagegen sicher, daß es sich um einfaches Spielzeug handelt, denn Tiburtius war, wie der Grabstein bestätigt, "noch ein Knabe" (233), als ihn die Liebe ergriff. Man muß dem Sprecher hier beipflichten. Es ist begreiflich, daß ein Ingénu an der Konfrontation zweier Wertvorstellungen, der Konventionalität und der Liebe zugrunde geht, nicht aber ein Schachspieler, der schon die Formel vom Gewinnen und Verlieren kennt. Tiburtius, der auf dem Grabstein "vergebens die Hände nach einem Mädchen ausstreckt" (234), ist nicht gegen das Verlieren gewappnet.

Die gerührten Touristen interpretieren den Tod des Tiburtius falsch, wenn sie in der Liebe den Grund der Tragik sehen. Sie verwechseln Ursache und Anlaß. Die Liebe ist nur letzteres, die Welt lebensfeindlicher Konventionalität ersteres. Die Verwechslung ist gleichwohl verständlich. Es ist leicht, die Liebe als Anti-Norm mißzuverstehen, besonders wenn sie im Tod endet. Darüberhinaus stünde sie einem vermeintlich höheren Wertbegriff im Wege, der dem Gedanken der rechten Lebensentfaltung leider eben zum Verwechseln ähnlich ist. Diese Pseudo-Norm ist der Handel, dem Durchschnittszeitgenossen heilig als völkerverbindendes Medium. Dürrenmatt ironisiert den Merkantilismus für dieselbe geschichtliche Periode in Romulus der Große ebenfalls in dieser Perspektive. Der Hosenfabrikant Cäsar Rupf sieht das Geschäft als rechte Bewegung der Dinge im Wirrwar der Politik und sich selber als völkerverbindenden Retter des Imperiums. Wie wenig der Satiriker Böll von dieser Norm hält, gibt er uns in einer subtilen Boshaftigkeit zu verstehen. Er vergiftet den Merkantilismus gleichsam, indem er Tiburtius zum Bleikäufer macht und darin auf die These anspielt, daß Roms Untergang zum Teil zurückzuführen sei auf chronische Vergiftung durch Blei im Eßgeschirr, in der Wasserleitung und in der Weinherstellung. Für die handelsgläubigen Touristen, die aus der ganzen Welt kommen, besonders der angelsächsischen, wo in den Wartesälen Plakate von Tibten hängen, ist somit Tiburtius ein Kind, das leider eben den Lauf der Welt nicht begriff. Für diejenigen, die ihn für einen Schachspieler halten, wäre er sogar ein Dümmling, der das Prinzip vom Gewinnen 
und Verlieren kennt, aber nicht im richtigen Sinne ernst nimmt. Es ist aber ironischerweise das Kind Tiburtius, das die inhumane Macht des falschen Lebensflusses begreift: Es fließen zwar Güter und Touristen von Land zu Land, aber mit Liebe hat all das wenig zu tun. Der Mensch findet deswegen nicht zum Menschen, selbst wenn er weiß, was die Weisheit der Welt ist, wie der Sprecher uns überdeutlich in seiner eigenen Kommunikationsschwäche vorführt.

Der Sprecher ist Versager, indem er zwar um die falsche und damit auch die richtige Weisheit der Welt weiß, diese jedoch andererseits in raunendes Andeuten hüllt, statt sie verständlich mitzuteilen und falsche Wertbegriffe deutlich anzugreifen. Leichtgewichtiger Pfuscher ist er in Anbetracht der Umstände. Wäre er kein Leisesprecher, so würde er in der Nacht eher verschrecken als wecken. Aber da das "Ansagen" sein Beruf ist, müßte er fähig sein, sich richtig vernehmlich zu machen, um der Vir bonus zu sein, als der er erscheinen will. Unbeabsichtigt verrät der Sprecher selber seine Wirkungslosigkeit. Er brüstet sich, daß er die Reisenden aus den Zügen "locke." Aber diese wissen schon, ob sie aussteigen wollen oder nicht, denn sie sind schon auf ihren "heimatlichen Bahnhöfen der Verführung" tibtenscher Plakate erlegen. Das Pfuschen ist auch wieder in diesem Text ein Verwechseln von Echtem und Falschem. Um seinen alleinigen Besitz der Weisheit und seine Überlegenheit über diejenigen zu beweisen, die Ursache und Anlaß zum Tod des Tiburtius verwechseln, stiehlt der Sprecher die Tierfigürchen. Er ersetzt sie durch Plastiktierchen. Diese unterscheiden sich nicht von den Originalen und der Tausch bleibt unbemerkt. Der Triumph des Sprechers führt allerdings zu nichts. Er wirft die gestohlenen Figuren, die er "meine Tiere" (235) nennt, in eine Schublade, in der er weitere, beim Margarine-Kauf zugegebene Figuren aufbewahrt, und kann nun selber nicht mehr die einen von den anderen unterscheiden.

Verstehen wir den Sprecher in "Tibten" als Chiffre des Künstlers, so ist zunächst festzustellen, daß wie in "Im Lande der Rujuks" es auch hier nicht mehr in erster Linie um die Normfindung und -bestimmung geht. Die Liebe als Ausdruck einer rechten Lebensentfaltung ist klar umrissen. Die Kernfrage ist hier, mit welchem Grad der Direktheit die Norm anzubieten ist. Dabei ist zunächst einmal das Publikum in Betracht zu ziehen. Es gibt Reisende, die sich nicht für Tibten interessieren. Auch die Vertreter, die in Tibten ihr Blei kaufen wollen, wären eine Randerscheinung im Publikum des Künstlers: "Nur selten kommen nachts Leute mit geschäftlichen Ambitionen. . . Meist sind es Touristen." Die Anzusprechenden sind diejenigen, die das Grab des Tiburtius besuchen wollen, die "sich besinnen und überlegen, ob Tibten nicht ihr Ziel war" (233-34). Diese den Be- 
schwörungen des Künstlers Zugänglichen glauben allerdings schon zu wissen, warum sie nach Tibten kommen. Sie sind fähig zum Überlegen und Sich-Besinnen. Ein direktes und unverfremdetes Sagen der Norm wäre fehl am Platze. Ist extreme Unverhülltheit des Moralischen in der Kunst unerwünscht, so verengt sich das Problem auf die Frage nach dem Grad des Verhüllens. Die Versuchung für den Künstler ist groß, dem Problem aus dem Wege zu gehen, indem er einen Wertkomplex nur andeutet, statt diesen zum mindesten so deutlich werden zu lassen, daß der Anreiz zum Denken spürbar ist. Der Ansager gibt zwar vor, die Reisenden zu locken, aber die Weisheit, die der Tod des Tiburtius sie lehren sollte, entgeht ihnen trotzdem. Entzieht sich die Norm selbst der Vorstellung, so herrscht Wertfreiheit; es ist gleichgültig, wie eindringlich der Künstler auf seine löblichen Absichten pocht. Er ist Versager und Pfuscher.

Gehen wir davon aus, daß generell in Bölls Satiren die Norm auszumachen ist, so hat man die Tendenz dieses Textes auch als Rechtfertigungsgeste Bölls zu lesen. Er greift hier eine Art des Künstlertums an, als deren Gegenteil man ihn gern kennzeichnete. Die Kritik hat sich des öfteren einen formalistischeren Böll auf Kosten des moralistisch verstandenen gewünscht. Aber so ganz außerhalb des satirischen Objekts dieses Textes steht Böll auch wiederum nicht. Die Versuchung, normativer Kunst aus dem Wege zu gehen, war besonders groß in dem anti-ideologischen Klima der westdeutschen Literatur in den fünfziger Jahren. Wenn Böll von der "guten Gesinnung" spricht, die es in der Kunst. "gratis" (ESR2, 21-22) gebe, so scheint er hier ein gewisses Zugeständnis an wertfreie Kunst zu machen. Besonders kritisch wird das Problem, wenn die verhüllte Prägung der Norm zur Verwechslung mit der Anti-Norm führt, wie möglicherweise sogar in Bölls eigenem Werk, wenn der Kleinbürger, in dem Böll viel Gutes sieht, und sein negativer Doppelgänger, der Spießbürger, sich bisweilen stark ähneln. Ließen sie sich in der Tat nicht auseinanderhalten, so betriebe Böll nicht Kritik der Gesellschaft, sondern deren Affirmation. Ein solcher Künstler ist ein gefährlicher Narr. Stolz auf sein berufliches Können und arrogant im Glauben an den Alleinbesitz der Wahrheit poliert er Blech, das er für Silber hält. Der Satiriker hat allen Grund, diesen Narren zu schrumpfen.

Das Schrumpfen geschieht hier in einem verhalteneren Humor als in "Im Lande der Rujuks." Wie dort wird dieser am deutlichsten, wenn sich der Sprecher bläht. Die Maße, die er als Ansager erstrebt, wenn er nicht weniger als dreimal von seinem virtuosen und bedeutungsschwangeren Sprechen schwärmt, vertragen sich zwar mit seinem hohen Bildungsgrad, aber dieser wird schon dadurch bedeutungslos, daß der Sprecher letztlich nichts Erzieherisches vermit- 
telt. In diesen Szenen wird die Micromegas-Technik dieses Textes am offenkundigsten.

Der Tourismus füllt die Randzone des Objektbereichs aus. Zwar hat dieser Terminus nicht die Suggestionskraft der Namen, die in "Im Lande der Rujuks" zur Identifikation eines falschen Lebensflusses genannt werden, er ist aber gleichwohl als Variante des Merkantilismus ein sehr brauchbares Beispiel für Anrüchiges in unserer Welt. Letzten Endes ist Tiburtius' Grab eine Ware.

Wie in "Bekenntnis eines Hundefängers" fehlt in "Tibten" ein den Herausforderertopos mythisierender Rahmen, nicht aber ein hoher Fiktionalitätsgrad. Der zweifache Doktor als Ansager, der Diebstahl der Grabfigürchen, der Historiker, der eine "Theorie über das Grab des Tiburtius" verfaßt hat, der "Heimatschriftsteller Volker von Volkerson," der einen "ausgezeichneten" Roman mit dem Titel "Tiburtius, ein römisches Schicksal, das sich in unserer Stadt vollendete" (234) geschrieben hat, all dies sind Elemente, die das gewohnte Reale bis an die Grenze des Phantastischen treiben.

In der Wortgegensatz-Technik dieses Textes spaltet Böll das Wort Sagen, bzw. Sprechen in das Laut- und das Leise-Sprechen. Aus dem Blickwinkel des Objektraums, der durch die Erzählerfigur als Ansager im strikten Berufssinn und auch durch die Touristen vertreten wird, handelt es sich auch hier um einen unkomplizierten Gegensatz. Der Ansager spricht laut, er bedient sich des Lautsprechers, dämpft aber dabei seine Stimme, weil er Nachtdienst tut und gegen weniger Lärm anzusprechen hat als am Tag. Da der Sprecher sich jedoch nicht nur als Ansager, sondern auch als Weiser versteht, weist er selber auf die Komplexität einer Dialektik im negativen Sinne hin, indem er die Problematik mit einem Kompromiß überdeckt. Er will gerade in der richtigen Lautstärke sprechen, nicht zu laut, damit die Schlafenden, deren Ziel nicht Tibten ist, nicht wach werden, und nicht zu leise, damit die eventuell Dösenden ihn hören. Was dem Sprecher richtiges Sprechen ist und ihn stolz macht, ist im übertragenen Sinn doch ein Versagen. Es ist nur Information, nicht Weisheit, und somit spricht der Ansager selbst für die, die ihn hören, zu leise.

Das Leise- und Laut-Sprechen wird voll dialektisch, wenn es aus der Subjektsphäre im weiteren Sinne als Tätigkeit des Künstlers begriffen wird. Das Leise-Sprechen hat Wert als ästhetische Forderung, es ist dagegen auch ein Unwert, da es notwendigerweise zur Verdeckung der Norm neigt. Das Laut-Sprechen ermöglicht Klarstellung der Norm und eine unzweideutige Mitteilung an das Publikum im moralischen Sinne, ist aber gleicherweise ein Unwert, als dieses Sprechen nicht in die Kunst, sondern etwa in die Predigt gehört. 
"Es wird etwas geschehen" (1954) gehört verdienterweise zu Bölls bekanntesten Kurzsatiren. Die Objektsphäre ist sehr breit. Die karikierende Komik verschont niemanden. Es existiert zwar ein Raum, der verhältnismäßig attraktive Züge trägt, aber er ist letztlich nur wieder Fluchtort für den abdankenden Herausforderer. Zudem ist er nicht mehr durch positive Gestalten bevölkert wie etwa der Zirkus in "Erinnerungen eines jungen Königs." Die Subjektsphäre entfaltet sich in diesem Text wie in "Hier ist Tibten" aus der Vorstellung. Sie erhält jedoch ihren realen Ankerpunkt in dem Protestakt der Herausfordererfigur, der die Möglichkeit zur Änderung der Situation aufstellt, aber in satirischer Manier nicht über einen Blitz in der Dunkelheit hinausgeht. Auch in diesem Text steht der Sprecher zentral im Objektbereich. Obwohl der Angriff sich auf ihn konzentriert, wird fundamental Anstößiges unserer Welt klarer sichtbar als in den bisherigen Berufssatiren, sodaß man bei diesem Text über die Kategorie Berufssatire hinausgehend auch von einer Systemsatire sprechen kann.

Der Sprecher verabscheut es, eine Anstellung anzunehmen, aber er sieht sich dazu aus finanziellen Gründen bisweilen gezwungen. Das Motiv des Geldmangels charakterisiert nach Peter Thorpe den Satiriker oder seine Persona schon seit Horaz und Juvenal. ${ }^{13}$ Böll macht davon Gebrauch in einigen Texten der Sammlung Spa, in "Die schwarzen Schafe" und hier in "Geschehen." Es geht aber in keinem Fall bei Böll um das Geld an sich, sondern um den Lebensunterhalt. Diesen verklammert er dazu jedesmal mit dem Problem der gesellschaftlichen Einordnung. Er erlaubt nie den Schluß, daß z.B. ein finanzieller Glücksfall die Problematik des Protagonisten aufheben würde. Besonders klar wird das in "Die schwarzen Schafe," wo der Lotteriegewinn Onkel Ottos diesen sogar tötet, der Glücksfall seines Enkels diesen durchaus nicht aus seinen Verwirrungen befreit. Wenn der Protagonist sich in der Fabrik Wunsiedels um Arbeit bewirbt, ist er wieder "einmal auf einem solchen finanziellen Tiefpunkt angekommen." Er spricht zwar von sich und seinen Mitbewerbern als "Leidensgenossen," kann das jedoch nur als rhetorische Floskel meinen, denn er zum mindesten leidet nicht mehr als etwa ein Sportler, der zu einem Wettkampf antritt. Dazu eignet sich der Sprecher hervorragend. Auf Grund seiner außerordentlichen geistigen Gaben-er bezeichnet sich als ein dem "Nachdenken" $\left(\mathrm{W}_{3}, 198\right)$ zugeneigter Typ-erweist er sich als derart fähig bei der Eignungsprüfung, daß ihm die Stelle zufällt.

Für das Produkt der Fabrik interessiert er sich nicht. Wenn es im Schlußsatz heißt, "[e]s wird wohl Seife gewesen sein" (202), so hat dieser Artikel zweifellos negative Bewandtnis, zumal Böll anderorts einmal von der "terroristischen Hygienekultur" (I, 411) in unserer 
Gesellschaft spricht. ${ }^{14}$ Berechnet der Sprecher sein Benehmen bis zum Zeitpunkt seiner Einstellung darauf, als Leistungsmensch zu erscheinen, so wird der Schein jetzt Wahrheit. Seine Erfolge in Wunsiedels Fabrik sind großartig. Binnen kurzem ist er in der Lage, nicht weniger als dreizehn Telefone gleichzeitig zu bedienen. Darin, daß er erst jetzt beginnt, sich "ausgelastet" zu fühlen, beweist er seine außergewöhnlichen Fähigkeiten, die er auch ohne lange Verzögerung $\mathrm{zu}$ einer wesentlichen Tat einsetzt. Er fordert Wunsiedel, der über dem gigantisch-leeren Wirbel thront, heraus. Er ist dabei ein David mit allerkleinstem Kiesel. Wunsiedel verlangt mit dem Satz "Es muß etwas geschehen" die Betriebslosung von ihm:

Doch etwas Unerklärliches auf seinem Gesicht ließ mich zögern, fröhlich und munter, wie es vorgeschrieben war, zu antworten: "Es wird etwas geschehen!" Ich zögerte wohl zu lange, denn Wunsiedel . . . brüllte mich an: "Antworten Sie! Antworten Sie, wie es vorgeschrieben ist!" Und ich antwortete leise und widerstrebend. . . . Nur mit großer Anstrengung brachte ich den Satz heraus: "Es wird etwas geschehen", und kaum hatte ich ihn ausgesprochen, da geschah tatsächlich etwas: Wunsiedel stürzte zu Boden. . . . Ich wußte gleich . . . daß er tot war (201).

Der Sprecher fühlt, daß dieser Tod von Bedeutung ist. Wenn er ihn aber dem Vize-Chef Broschek meldet, setzt er nicht hinzu, daß jetzt alles in der Fabrik anders werden müsse, sondern begnügt sich mit dem selben Leiersatz "Es muß etwas geschehen," der Wunsiedels Betriebslosung und Aufforderung zur sinnlosen Produktivität ist. ${ }^{15} \mathrm{Da}$ er "leise" spricht, macht die Formel nicht zu einer neuen Losung. ${ }^{16}$ Was deshalb auch nur "geschieht," ist Wunsiedels Beerdigung. Es bleibt alles beim alten in der Fabrik. Das gilt auch in gewissem Sinne für den Sprecher. Weil er hinter Wunsiedels Sarg "großartig ausgesehen" (202) hat, erhält er von einer Bestattungsfirma ein Angebot, Berufstrauernder zu werden. Er nimmt an, denn er kann nun seinen Hang zur Nachdenklichkeit befriedigen. Als Berufstrauernder ist er wieder Angestellter, der seine Stellung aufs erfolgreichste bekleidet.

Zweifellos ist der Beruf des Trauerns das kleinere Übel. Der Sprecher kommt jetzt einem vollgültigen Menschen näher. Wo sein atemberaubendes Werkeln in Wunsiedels Fabrik eine Form der Vita activa ist, setzt er jetzt die Vita contemplativa hinzu. ${ }^{17}$ Ist er nun menschlicher, so ist er bei weitem nicht vorbildlich, denn er ist nicht einmal so etwas wie ein "freiberuflich" Trauernder, sondern steht im Sold eines Instituts. Sein Trauerberuf ist nur im relativen Sinne begrüßenswert. Auch jetzt noch ist er im Grunde genau das, was jeder 
der Leistungsfanatiker bei Wunsiedel ist, nämlich ein mechanischer Mensch. Daß Böll so differenziert, macht er auch anderorts klar: "Heimliche Trauer ist angebracht-demonstrative Trauer hat immer etwas Peinliches" (ESR3, 459). Der Sprecher geht zwar bisweilen außerhalb des Dienstes Särgen nach, aber vorwiegend stellt er einen Trauerroboter, somit eine Karikatur der Vita contemplativa dar. Selbst wenn wir sein Trauern als ein kosmisches sehen, so bleibt der Sprecher ein Homunculus. Er akzeptiert die Traurigkeit der Welt und des Lebens als determiniert, wie er vorher die Aktivitätsmechanei bei Wunsiedel de facto uneingeschränkt akzeptierte. Böll beleuchtet besonders die Vorgänge in Wunsiedels Fabrik rigoros als Mechanik und steht auch darin in einer genügsam belegbaren satirischen Tradition, für die Swifts "A Discourse Concerning the Mechanical Operation of the Spirit" repräsentativ ist. Das Prinzip in "Geschehen" ist StimulusResponse. Schon die Fragebögen sind so gestaltet, daß die gewünschte Antwort so gut wie unausweichlich ist. Das Kantinenessen ist diättechnisch herrlich und die Arbeiter sind demzufolge so fröhlich als hätte man ihnen die Soma-Pillen aus Huxleys Brave New World verabfolgt. Allerdings ist der Behaviorismus in Bölls Welt lange nicht so ominös wie der in Huxleys. Die Fröhlichkeit ist natürlicher. So sind die Kellnerinnen "mit ungesungenen Liedern so angefüllt, wie Hühner mit ungelegten Eiern." Nichtsdestoweniger sind die Menschen aber auch wie Puppen, deren Redewerk durch Fingerdruck in Gang kommt: "Es wimmelte in Wunsiedels Fabrik von Leuten, die verrückt darauf waren, ihren Lebenslauf zu erzählen, wie eben handlungsstarke Persönlichkeiten es gern tun. Ihr Lebenslauf ist ihnen wichtiger als ihr Leben, man braucht nur auf einen Knopf zu drücken, und schon erbrechen sie ihn in Ehren" (198-99).

Ist die mechanische Welt der Produktivität in "Geschehen" derart komisch, so kann es aus ihr ein Entkommen geben. Das tut sich besonders an der Betriebslosung dar. Der Sprecher trainiert gewissermaßen für seine Sabotage der Wunsiedelschen Mechanei, indem er die Losungssätze mit erstaunlicher und lächerlicher Beweglichkeit abwandelt: "[E]s machte mir Spaß . . . das Verbum geschehen durch die verschiedenen Tempora, durch die verschiedenen Genera, durch Konjunktiv und Indikativ zu hetzen" (200). So gerüstet und dabei im Leser starke Zweifel an seiner Behauptung erweckend, von Natur aus ein Nichtstuer zu sein, tritt er gegen Wunsiedel an. Das Erstaunliche am Riesentöterakt ist dessen Leichtigkeit. Die Perfektion der Mechanei in Wunsiedels Welt ist offensichtlich nicht Stärke. Wo in den bisherigen Satiren das Objekt, sofern dieses außerhalb des Sprechers liegt, mit der Ausnahme von "Erinnerungen eines jungen Königs," wo es jedoch von selbst verschwindet, real uneingeschränkt bleibt, 
erscheint es hier zum erstenmal als durch den Protagonisten beeinträchtigt. Hier wird der für die späteren Satiren so wichtige Gedanke der Veränderbarkeit der Welt schon greifbar.

Wo die Herausforderung bislang überdies mit einem Risiko, einem Quantum Mut oder Selbstüberwindung zu tun hat, ist sie hier in "Geschehen" etwas Leichtes. Böll begegnet dem äußeren, mechanischen Zwang mit einem inneren Willen zur systemsprengenden Handlung. Der Protest ist völlig ungeplant und verrät wenig von der Nachdenklichkeit, die der Sprecher gerne betont. Etwas "Unerklärliches" auf Wunsiedels Gesicht löst eine Kettenreaktion aus. Die Herausforderung ist eine reibungslose Selbstverständlichkeit, trotz der "Anstrengung," die der Sprecher betont. Die Protestszene verrät jedoch auch einen Wunsiedel gefügigen Sprecher, da dieser die Losung, wenngleich mit Verzögerung, so doch wie befohlen gibt. Darum ist der Sprecher bei allem trotzdem der Versager, der verständlicherweise bemüht ist, Ursache und Wirkung zu trennen und Protest und Versagen als eine Art Kinderspiel hinzustellen, das natürlich kein tödlicher Stein sein könne. So beschreibt er sich als ein "Kind, das man zu sagen zwingt: ich bin ein böses Kind" (201). Indem der Sprecher sich dieses Blickwinkels bedient, schaltet er seine Verantwortung als Herausforderer aus. Ist er darin zwar der Versager, so noch stärker der Pfuscher, der als Analytiker auftritt, aber eine bedauerliche Fehlkalkulation liefert, wenn er das Denken im kritischen Augenblick versucht. Pfuscher ist der Sprecher auch in seinem Trauern. Wunsiedels Sterben bringt ihn zwar zur Einbeziehung des Todes in das Leben, wenn er jedoch Berufstrauernder wird, so klammert er das Leben aus. ${ }^{18}$ Seine Trauer ist Resignation. Sie nährt sich vom Unabänderlichen, statt das Veränderbare flüssig zu machen. Erstarrtes zum Fließen zu bringen, wäre hingegen Sinn lebensbejahender Trauer. Echte Trauer kann daher Teil des Humors sein, wie Böll ihn versteht. In den "Frankfurter Vorlesungen" betont er das Flüssige als etymologischen Bestandteil des Wortes Humor und damit die Träne, die der Humor einschließt (ESR2, 89). Humor fehlt dem Sprecher in der fröhlichen Wunsiedelfabrik wie auch als Berufstrauernder. Wie ihm zunächst das Weinen abgeht, so fehlt ihm am Ende das Lachen. Hier wie dort verletzt er die Norm des Lebensflusses. In Wunsiedels Fabrik ist dieser hektisch, auf dem Friedhof stagniert er. Humor ist in diesem Text wie immer bei Böll eine Erscheinungsform der Norm und geht hier ausschließlich vom Satiriker aus, obwohl er uns aus dem Munde des Sprechers zugetragen wird. Der Humor fällt verzeichnend auf diesen zurück. Der Satiriker setzt ihn ein, um die Dinge durch das rechte Weinen und das rechte Lachen in das richtige Maß der Bewegung zu bringen. Sieht man das Lachen des Lesers als Reaktion zur Norm, so bestimmt diese 
das Lachen im gewissen Sinne. Es sollte über die Geschehnisse in Wunsiedels Fabrik Vorbehalte anmelden, kritisch sein und eine Träne einschließen. Anders gesagt, das Lachen darf nicht von der Hektik bestimmt sein, die Wunsiedels Fabrik kennzeichnet, wie es auch, in Hinsicht auf den Berufstrauernden, nicht ganz fehlen darf. Hier muß es der Starre des weinerlichen Trauerroutinismus begegnen. Das Lachen, das sich am hektischen Leben, wie auch das falsche Weinen im Publikum, das sich am Toten orientiert, führen zur falschen Katharsis. Beides sind Reaktionen, die das Anstößige bestätigen, statt es durch eine gegenläufige Emotion in Frage zu stellen.

Das gilt auch für den Sprecher. So wäre etwa an der Leiche Wunsiedels auch Zorn am Platze über dessen sinnlosen Leben. Aber der Sprecher begnügt sich mit Trauer, obwohl Wunsiedel im Tode noch darauf verweist, wie sehr seine Fabrik ein Gefängnis ist. Er rollt "im Stürzen auf die Seite und lag quer vor der offenen Tür." Er versperrt den Ausweg. Der Sprecher zahlt ihm heim, indem er über Wunsiedels Leiche steigt. Aber gerade das Über-Leichen-Gehen hätte er vermeiden sollen, denn er besinnt sich kurz darauf, daß er Wunsiedel "nie gehaßt" hat und jetzt sogar "fast Zärtlichkeit" für ihn empfindet. In dieser Gemütsverfassung holt der Sprecher das Versäumte nach. Er kümmert sich um Wunsiedel: "Vorsichtig drehte ich Wunsiedel auf den Rücken, drückte ihm die Augen zu und betrachtete ihn nachdenklich" (201). In dieser Szene entblößt der Sprecher sich als der Pfuscher, der die rechte Zeit zur Menschlichkeit vertrödelt. Die zu spät erkannten Gefühle sind sogar doppelt verspätet. Sie hätten zu Lebzeiten Wunsiedels vom Sprecher, der sich als nachdenklich brüstet, entwickelt werden sollen. Vonnöten wäre gewesen eine Herausforderung des Menschen Wunsiedel ohne "Haß" und mit "fast Zärtlichkeit," aber mit Härte gegen den Repräsentanten eines anstößigen Prinzips. Wunsiedel hätte diese therapeutische Aggressivität zuteil werden sollen. Sicherlich sieht ihn der Spreçher richtig, wenn er im Tode etwas Kindliches auf seinem Gesicht entdeckt. Wunsiedel ist kein Bösewicht. In seinem Es-muß-etwas-geschehen-Traum ist er wie ein eigensinniges Kind, daß den Glauben an den "Weihnachtsmann" (202) nicht aufgeben will. Leider aber hat ihn der Sprecher nie mit Argumenten daraufhin konfrontiert, daß die Produktivität keine Weihnachtsbescherung bringt, sondern Zahlung fordert, und er greift auch weiterhin niemanden in diesem Sinne an. Sein doppeltes Versäumen wird zum dreifachen, wenn er seine Stellung aufgibt.

Wo in den bisherigen Berufssatiren der Sprecher zunächst Chiffre für den Künstler und erst danach eine allgemeine Identifikationsfigur ist, so geht Böll in "Geschehen" einen anderen Weg. Als Aktivist ist der Sprecher vor allem der moderne Leistungsmensch, als Trauern- 
der wird er vornehmlich zur Chiffre des Künstlers. Echtes Künstlertum schließt das Trauern ein als Gefühl der Empörung über die Diskrepanz zwischen Ideal und Wirklichkeit. Das Trauern des Sprechers zeigt jedoch keine Empörung. So ist seine Vita contemplativa eine Form des Arrangements mit dem Bestehenden. Er nimmt ohne Widerrede die Vorbedingungen seines Berufs an: Man hat ihn angestellt nach den Praktiken kommerziellen Erfolges, also gewissermaßen nach Wunsiedels Kriterien. Der Unterschied ist im wesentlichen, daß man ihm nun ein windstilles Örtchen im Sturm derselben Welt bewilligt. So ist er wieder der Wegläufer, der sozusagen wie Vetter Franz in "Nicht nur zur Weihnachtszeit" ins Kloster geht, obwohl er nach Wunsiedels Tod weiß, daß die Dinge anders werden müssen und wissen sollte, daß der Protest die Voraussetzung zur Veränderung der Wirklichkeit ist. Darin ist unser Versager wieder der Pfuscher, dem wir glauben sollen, er sei der Vir bonus, der recht und echt trauere. So betont er, bisweilen hinter dem Sarg eines Heimatlosen herzugehen. In dem Fall ist das Trauern zwar kein leeres Berufsrequisit, aber auch nicht mehr als nur abstrakte Menschenliebe und darum nicht frei von Pfuscherei. So ist der Berufstrauernde trotz allen schönen Scheins systemintegriert. Bölls satirische Spitze richtet sich also gegen den Künstler, der den Schein erwecken will, außerhalb des Systems zu stehen und gewissermaßen als weinerliches Gewissen der Nation eine wirkungsvolle Form der Kritik gegen eine leistungsbesessene und unnachdenkliche Gesellschaft zu bieten. Böll zerstört dieses Alibi. Die Möglichkeiten zur Veränderung sind aufgrund der Schwäche des Feindes gegeben. Indem Böll die Achillesferse bloßlegt, wird diese Satire besonders heute zündend, wo man weiß, wie leicht unsere ökonomische Stärke in Ohnmacht zu verwandeln ist. Die Zustände fordern den Herausforderer nicht nur, weil sie anstößig sind, sondern auch, und darauf liegt in diesem Text der Nachdruck, weil sie der Abhilfe Erfolgschancen bieten.

In "Geschehen" erreicht Bölls Technik des Wortgegensatzpaars einen Höhepunkt. Sie bewirkt hier besonders viel, weil ihre Dialektik einerseits betont wird, andererseits aber nicht als Stilmittel kraß ins Auge fällt, da sie zum wesentlichen Bestandteil der komischen Zeichnung gehört. Das Wortpaar ist Handeln und Nachdenken. Es reflektiert die Polarität der Vita activa und contemplativa. Verklammert wird es durch das Verb geschehen. In den Titelsatz "Es wird etwas geschehen" gebettet deutet es im doppelten Sinne auf die Aktualisierung eines Unausweichlichen. Der Titel kann Warnung wie auch Zuversicht meinen. Auf dem Hintergrund der fünfziger Jahre, inmitten des explosiven wirtschaftlichen Aufschwungs in der Bundesrepublik, beschränkt sich die Zuversicht der Gesellschaft auf die Fortdauer dieses 
Aufschwungs. Die Warnung wird durch den Satiriker erteilt, der ein durch unbesonnene Fröhlichkeit und Aktivität geprägtes Geschehen in seiner Welt als gefährlich erkennt. Das Klammerverbum geschehen handhabt Böll in einer höchst belustigenden Weise. Er stellt es zentral in das Leistungsspektrum des Sprechers, der es kauzhaft versessen immer wieder abwandelt. Das Paradigma gipfelt in zwei antinomischen Sätzen: "Es hätte etwas geschehen müssen" und "Das hätte nicht geschehen dürfen" (200). Dieses Satzpaar stellt das Prisma her, in dem das Wortgegensatzpaar Handeln und Nachdenken seine dialektische Zündkraft erhält. Das Satzpaar teilt das Geschehen in Wunsiedels Fabrik in ein abgelehntes Geschehenes und ein befürwortetes zu Geschehendes. Die Protestszene folgt im Text nicht von ungefähr unmittelbar auf das Zitat dieser Sätze, mit deren Sprechen der Protagonist nicht weniger als je zwei Tage seiner Arbeitszeit ausgefüllt hat. Das Handeln ohne Zweck in Wunsiedels Fabrik, das in seinem fröhlichen Optimismus einen beglückenden Sinn vortäuscht und damit um so sinnloser und auch lächerlich wird, "hätte nicht geschehen dürfen." Was "hätte geschehen müssen," ist eine Neuerung, für die der Sprecher übrigens auch Broschek, der ebenfalls vom Tode Wunsiedels betroffen ist, möglicherweise hätte gewinnen können. Das Nachdenken im kritischen Sinne, das über Ansätze nicht hinausgeht, obwohl der Sprecher viel Aufhebens von seiner bedächtigen Natur macht, sinkt ab in ein Routinespiel der Berufstrauerei. Dieses Verpfuschen "hätte nicht geschehen dürfen," wie hingegen ein echtes Nachdenken über die Konsequenzen von Wunsiedels Tod und eine dem Leben verbundene Trauer "hätte geschehen müssen."

Das Prinzip Micromegas eröffnet sich hauptsächlich in einer allerdings sehr nachdrücklich profilierten Perspektive, in der man den hohen Fiktionalitätsgrad dieses Textes besonders klar erkennt. Das Objekt bläht sich bis zum Punkt des völligen Verlachtwerdens. Wunsiedels Leute kennen nur Höchstleistungen. Broschek hat "als Student sieben Kinder und eine gelähmte Frau durch Nachtarbeit ernährt, zugleich vier Handelsvertretungen erfolgreich ausgeübt und dennoch innerhalb von zwei Jahren zwei Staatsprüfungen mit Auszeichnung bestanden." Wenn der Sprecher ihm den Tod Wunsiedels meldet, sitzt Broschek "an seinem Schreibtisch, hatte in jeder Hand einen Telefonhörer, im Mund einen Kugelschreiber, mit dem er Notizen auf einen Block schrieb, während er mit den bloßen Füßen eine Strickmaschine bediente." Wunsiedels Sekretärin ist nicht minder befähigt. Sie "hatte einen gelähmten Mann und vier Kinder durch Stricken ernährt, hatte gleichzeitig in Psychologie und Heimatkunde promoviert, Schäferhunde gezüchtet und war als Barsängerin unter dem Namen Vamp 7 berühmt geworden" (199-201). 
Eine weitere Variante des Micromegas-Prinzips ist das Motiv der Täuschung, das die Prüfungsszene bestimmt. Die Maske des Sprechers als Aktivist liegt ihm so eng an, daß sie sein wahres Gesicht wird. Nicht mit Nachdruck geprägt, jedoch deutlich erkennbar ist eine Spielart der Täuschung, die schon u.a. aus "Doktor Murkes gesammeltes Schweigen" und "Mein Onkel Fred" bekannt ist. Leere, Hohlheit, Versagen werden durch Schönes kaschiert. Hier in "Geschehen" sind Restaurant und Prüfungsräume mit großem Geschmacksaufwand ausgestattet. Es gibt Aquarien mit Zierfischen, "hübsche" Kellnerinnen, "geschmackvolles" Porzellan, "reizende" Tische und "entzückende" Wandtönungen. Die grammatischen Turnübungen des Sprechers sind zwar Training für den Protest, ähnlich wie Murkes Paternoster-Gymnastik, aber auch Vorausnahme des Versagens. Die zwei dem Protest vorausgehenden Übungssätze sind für den Sprecher Arabesken. Er sagt sie tagelang vor sich hin, weil er sie "so schön" (198-200) findet. Auch in der Mechanik des Lebens in Wunsiedels Fabrik liegt das Micromegas-Prinzip als Minderung des Menschlichen im Zerrbild der Vita activa, die als grotesk Lächerliches auf ihr Gegenteil deutet. Ironie liegt darin, daß der Protagonist das alles genau zu begreifen scheint. Als Berufstrauernder betreibt er das Nachdenken dennoch gewissermaßen mechanisch und überzogen. 


\section{vI. "Der Wegwerfer": System- und Berufssatire}

Herrscht in "Es wird etwas geschehen" Erfolgs- und Leistungsbesessenheit, so rührt Bölls Pointe wie in dem Prinzip von Beherrschung und Unterwerfung in "Doktor Murkes gesammeltes Schweigen" an die Fundamente unserer Gesellschaftsstruktur. "Der Wegwerfer" (1957) ist in einem noch zeitspezifischeren Sinne Systemsatire: Böll versteht das Anstößige voll und ganz im wirtschaftlichen Sinne, als das Konzept von Produktion und Konsum.

Unter diesem vorherrschenden Aspekt tritt noch einmal der Protagonist als Chiffre des Künstlers auf. Das Moment der Selbstbestätigung, das in den Berufssatiren im Vordergrund stand, tritt jedoch zurück. Das soziale Moment des Berufs ist in diesem Sinne stärker in "Wegwerfer." So läßt sich dieser Text als Kulmination wie auch Überwindung der Berufssatire vorhergehender Prägung bezeichnen. Der Protagonist bleibt jetzt völlig exponiert im Sozialen. Von privatem Triumph, sei es die Anmaßung des Erfolgs, der Weisheit, der Geborgenheit in der Familie oder in der Idylle, ist nichts zu verspüren. Böll scheint sich inzwischen im persönlichen Sinne als Satiriker seiner selbst freigeschrieben $\mathrm{zu}$ haben.

Unter Bölls Kurzsatiren ist "Wegwerfer" die einzige, über die schon eine eingehende Studie als Satire vorliegt. Klaus Jeziorkowski analysiert sie weitgehend unter dem Aspekt der "verkehrten Welt." ${ }^{1}$ Demnach baut der Satiriker eine in sich stimmige Welt auf, die allerdings völlig falsch ist in einer erschreckend absurden Phantastik und sozusagen auf dem Kopf steht. Dieses Konzept kommt den Absichten Jeziorkowskis entgegen, weil es sich eignet zu zeigen, wie präzise Böll im Aufbau seiner Texte vorgeht. Das Anliegen Jeziorkowskis richtet sich implizite gegen das in der frühen Kritik immer wieder mitschwingende Vorurteil gegen Böll als einen vornehmlich thematisch ausgerichteten, kompositorisch jedoch lockeren Autor. Wie die Formel der verkehrten Welt von großem Wert ist, Jeziorkowskis These der strengen und virtuosen Komposition Böllscher Texte zu erhärten, so beschränkt dieses Konzept jedoch in gewisser Hinsicht die Ausleuchtung des "Wegwerfer"-Textes. Die dem negativen Perfektionsanspruch des Objekts entgegenlaufenden Elemente enthüllen sich nicht völlig. Wäre die Formel der verkehrten Welt hier absolut gültig, 
so bestünde der Text nur aus der Objektsphäre. Das gilt auch anderwärtig oft, wie z.B. für Nathanael Wests Hollywoodsatire The Day of the Locust:

If I put into The Day of the Locust any of the sincere, honest people who work here and are making such a great, progressive fight, those chapters couldn't be written satirically and the whole fabric of the peculiar half-world which I attempted to create would be badly torn by them . . . [sic] I believe there is a place for the fellow who yells fire and indicates where some of the smoke is coming from without actually dragging the hose to the spot. ${ }^{2}$

Für Böll allerdings vertragen sich Löschschläuche mit dem Satirischen. So führt er, wie gezeigt werden soll, in der Pförtnersfrau eine Person vor, die zur Kategorie der "aufrichtigen und ehrlichen Leute, die arbeiten," gehört. Vom Herausforderertopos und der damit gesetzten Subjektsphäre her läßt sich somit eine Komplementärperspektive zum Ansatz Jeziorkowskis entwickeln. Wo dieser in der perfekten Fiktionalität des "Wegwerfer"-Textes den Anklang an die zweck- und moralfreie Satire sieht, ${ }^{3}$ erheben sich vom Ausgangspunkt des Herausforderertopos Fragen der Norm und der Dialektik zwischen Subjekt- und Objektbereich.

Wenn Böll in seinen Satiren nach einem Mittel sucht, das den "Irrenhausdirektor" (ESR2, 253), wie er das System, den Drachen, einmal nennt, außer Gefecht setzen kann, so erfindet er es in diesem Text. Was er dem Wegwerfer als Formel in die Hand gibt, macht diesen zu seiner zweckdienlichsten Herausfordererfigur überhaupt. Potentiell ist die Erfolgslinie des Wegwerfers Sprengschnur zu einer Explosion, die nicht nur die bestehende Welt zu zerstören imstande ist, sondern auch das mögliche Neue nur als einen Rückfall in eine grauenerregende Primitivität ermöglicht.

Getrieben von einem angeborenen Hang zur Ökonomie und dem Wunsche, der Menschheit Zeit zu weltverändernder Tätigkeit zu verschaffen, entwickelt der Wegwerfer, hinter dem nach Jeziorkowski "das Bild des Schlachten-, wenn nicht gar Weltenlenkers" in "Selbstdämonisierung und -glorifizierung" steht, ${ }^{4}$ eine Rationalisierungsformel für die Handhabung unnötiger Reklamepost. Das klingt vorerst noch sehr begrüßenswert. Er erledigt die Post nach einem sorgfältig entwickelten Schema und erreicht dabei, wie er sich technisch ausdrückt, ein Konzentrat von 1:300. In einer Stunde vernichtet er das Dreihundertfache dessen, was in derselben Zeitspanne hergestellt werden kann. Er träumt als Weltverbesserer sogar davon, Wegwerferschulen zu gründen und spricht von Experimenten, die er in Waren- 
häusern vornehmen möchte, so daß ein Wegwerfer soeben Eingewickeltes sofort auspacken und das Packmaterial für den Altwarenhändler bündeln kann. Hier eröffnet sich das Anstößige im Tun des Wegwerfers. Zwar bedeutet dieses im konkreten Sinne nur ein Beiseiteschaffen des Produzierten, nicht Anregung der Produktion, aber trotzdem dürfen wir das erschreckende Analogon nicht verkennen, das sich in der Wegwerfformel verbirgt. Böll macht es nicht offensichtlich, um damit die Bewußtseinsbegrenztheit seiner getadelten Zeitgenossen und des Wegwerfers selber zu spiegeln, die zwar das Überflüssige am Produkt erkennen, jedoch tunlichst vermeiden, dieses mit dem Prinzip der Produktion zu verbinden. Die Wegwerferformel im Kontext der Verbrauchergesellschaft verstanden meint ein rapides Ansteigen des Verbrauchs und konsequenterweise ein Gleichziehen in der Produktion und im Angebot. Im übertragenen Sinne erschafft der Wegwerfer gewaltige Warenlücken, die gefüllt werden müssen. Die Wegwerfformel schmeckt jedoch zunächst nach einem ökonomischen Bonbon. Die Formel meint Verbrauch und Produktion, sie schafft Reichtum und Mehrwerte. Aber sie ist wie das Gold in Shakespeares Timon of Athens, das Timon methodisch einsetzt, um den Zusammenbruch der Gesellschaft zu beschleunigen. So entwickelt der Wegwerfer eine besondere Kostbarkeit; sie ist nichts weniger als die Essenz unserer Welt als Konsumgesellschaft und letztlich ein Gift. Der Reichtum einer hochindustrialisierten kapitalistischen Gesellschaft beruht auf beschleunigtem Verbrauch, verlangt Verschwendung. Böll ist selbstverständlich nicht der einzige Autor, der diese Erkenntnis vertritt. Im Bereich des Satirischen streift sie z.B. schon Aldous Huxley. In Brave New World wird der Verbraucher im Schlaf angeregt, sich nach neuen Gebrauchsgegenständen zu sehnen. Weiterhin hat man besonders an Vance Packard zu denken, da er sich im selben Zeitraum wie Böll mit dieser Problematik befaßt. In The Hidden Persuaders (1957) verweist er auf den stimulierten Konsum und in The Waste Makers (1960) kommt er der Böllschen Wegwerfformel erstaunlich nahe, wenn er ironisch vom "Progress Through the Throwaway Spirit" spricht. ${ }^{5}$

Die Wegwerfformel beschleunigt die Reichtumsentwicklung und den Verbrauchsprozeß auf eine Weise, die zur fundamentalen Frage nach den Rohstoffen führt. Böll deutet keineswegs eine Perspektive an, in der diese etwa unerschöpflich wären. Er kommt darum unserer gegenwärtigen Wirklichkeit äußerst erschreckend nahe. Die Wegwerfformel ist somit apokalyptisch, insofern als sie den Tag der Erschöpfung der Rohstoffe mit dreihundertfacher Beschleunigung heranzieht. In der Nähe des kritischen Endpunktes ist dann keine soziale Neuerung abzusehen, sondern aufgrund des individualisti- 
schen Leistungs- und Konkurrenzprinzips unserer Gesellschaft ein Kampf aller gegen alle, oder die Tyrannei der Besitzenden, in jedem Falle Barbarei. Die Wegwerfformel ist letztlich ein ökonomisches Doomsday-Präparat, das Destillat einer negativen Utopie in den Farben der Endzeit. Im Schlußabschnitt des Textes gibt der Sprecher einen Traum wieder, in dem sich die Wirkung seiner Formel niederschlägt: "[W]enn ich einschlafe, verfolgen mich meine Formeln, rollen ganze Welten nutzlosen Papiers über mich hin; manche Formeln explodieren wie Dynamit, das Geräusch der Explosion klingt wie ein großes Lachen ...." (W3, 281). Die Wegwerfformel ist Sprengstoff. Das Unbewußte des Wegwerfers registriert dies und verhöhnt ihn im Traum, weil die Zerstörung ihn selber mit einbegreift. In dem Traum führt der Satiriker die Wegwerfformel bis zum äußersten ihrer innewohnenden Destruktionslogik. Sie ist eine besonders erschreckende Spielart der Technik der "absurden Konsequenz," die beispielsweise in Liscows "Elende Skribenten," Rabeners "Kleider machen Leute" oder Wielands Abderiten die Unhaltbarkeit des satirischen Objekts bis zum total Vernunftwidrigen vorantreibt. ${ }^{6}$ Diese absurde Konsequenz hat in "Wegwerfer" zwei Aspekte. Der Satiriker korrigiert sie, die Wegwerferfigur versucht sie zu vermeiden. Wird die Apokalypse vom Leser im Bewußtsein vorweggenommen, so erzeugt sie Abschreckung gegen die Zerstörung, auf die die Wegwerfformel zielt. Der Weg zur Vorstellung einer Gegenformel kann frei werden. Geht der Satiriker hier einen Schritt weiter als die absurde Konsequenz, so versucht der Wegwerfer als Theoretiker schon vorher haltzumachen. Seine Formel scheint ihm gut und richtig als praktikables Mittel gegen die Verschwendung. Deshalb bekennt er, solange er noch Theoretiker ist, seine Bemühungen ohne Scheu, ja mit Stolz. Er nennt sich "Erfinder, Privatgelehrter, im Notfall Student... verkanntes Genie" (272).

Ganz unberechtigt ist das Selbstportrait des Wegwerfers nicht. Seine Erfindung macht ihn zum Herausforderer der Gesellschaft. Aber weil er seine Formel nicht bis zur letzten Konsequenz einer Gegenformel durchdenkt, ist sie in der Praxis letztlich nicht Bewahrung, sondern Vernichtung. Die Perspektive des Heldischen steht dem Sprecher darum nicht mehr zu. Er begegnet seinem Versagen zwar in etwa, indem er das Papier zum Altwarenhändler gehen läßt, aber Papier ist nicht der einzige Rohstoff, der beansprucht wird. Das Papierprodukt enthält Tinte, Farbe und vor allem Energie, die der Altpapierhändler nicht reklamieren kann. Bedeutsamerweise schreckt der Sprecher vor dieser Konsequenz seiner Formel zurück. Im Gegensatz zum Satiriker klammert er als Versager das Problem der Rohstofferschöpfung aus. Wir können ihm dies nicht verdenken. Wer 
würde sich schon eingestehen wollen, eine Doomsday-Maschine erfunden $\mathrm{zu}$ haben und sie überdies noch $\mathrm{zu}$ betreiben. Indem der Sprecher sich der vollen Erkenntnis der Gefährlichkeit seiner Formel verschließt, ist er auch wieder der Pfuscher, der Ursache und Wirkung verwechselt. Er glaubt, es mit einem Fieber, also einem Symptom zu tun zu haben, wo es um die Krankheit selber geht: "[Ich] gehe in meine kleine Wohnung hinauf, deren Wände mit graphischen Darstellungen, mit erregten Kurven bedeckt sind, zwischen Abszisse und Ordinate fange ich die Linien eines Fiebers ein, das immer höher steigt: keine einzige meiner Kurven senkt sich, keine einzige meiner Formeln verschafft mir Beruhigung" (280). ${ }^{7}$ Hier wäre nicht Angst, sondern Mut am Platze. Würde er die steigenden Linien konsequent weiterberechnen, so eröffnete sich ihm die volle Tragweite seiner Erfindung, die er dann als theoretische Abschreckungstherapie anbieten, und zu der er eine Spar-Formel für die Praxis entwickeln sollte. Wäre er überdies geneigt, sein Denken nicht auf das Technische zu beschränken, so könnte er den letzten Schritt tun und über eine Spar- wie auch Wegwerfformel hinausgehen. Aber er will sich "grundsätzlich der Moral enthalten" (281) und verbaut sich somit den Ausblick auf eine Erfindung, die ihn zum Vir bonus erster Ordnung machen könnte: Seine Erfindung hätte das Sparen und Wegwerfen unter die Idee der Bewahrung als humanen Akt zu stellen. Das Sparen und Sammeln von Gütern darf nur soweit gehen, daß es keine Bürde und kein Wegwerfen menschlicher Substanz wird. Überschreitet man einen gewissen Punkt, so sollte das Wegwerfen der Güter zur Bewahrung des Menschlichen verlangt werden. Eine solche Formel würde sich gegen unnötige Produktion richten. ${ }^{8}$ Darauf zielt der Wegwerfer zwar schon, aber nicht weitreichend genug, wenn er vorschlägt, daß "Prospekte zwar noch erdacht, gezeichnet, aufgesetzt, aber nicht mehr gedruckt werden." Er läßt zwar die unnütze Produktion einer spezifischen Ware fallen, hält aber am Prinzip unnotwendiger Produktion fest. So können wir ihn nicht recht ernst nehmen, wenn er von freiwerdenden Energien spricht, die "das Antlitz der Erde zu verändern" (278) imstande wären. Sein Denken bleibt letztlich innerhalb des gängigen Bewußtseinshorizontes. Wo er diesen durchbrechen sollte, stützt er die fragwürdigen Grundlagen seiner Gesellschaft in der Maske des Außenseiters und Weltverbesserers. Wo er versagt, übernimmt der Satiriker das Amt des unerbittlichen Herausforderers, indem er dem Leser die logischen Konsequenzen der Wegwerfformel hinter dem Rücken seines Protagonisten nahelegt. ${ }^{9}$ Bündelt man diese Facettierungen, so erhält der Text seinen historischen Stellenwert in einer Aktualität, die sich seit Erscheinen dieses Textes noch von Tag zu Tag zu steigern scheint. 
Böll konstruiert angesichts krankhaften Konsums eine DoomsdayFormel, die uns einen Blick in die Hölle der verbrauchten Rohstoffe tun läßt und als Antidot der Apokalypse eine Perspektivenverschiebung von der Ware zum Menschen eröffnet, um dessen Bewahrung es bei allem letzten Endes geht.

Da der Sprecher selber offensichtlich vernichtet, statt zu bewahren, kann man durchaus verstehen, wenn er des Nihilismus verdächtigt wird. Die ihn so einstufen, reagieren auf seine Formel negativ nicht etwa, weil sie deren Fatalität erkennen und somit klarer blickten als der Wegwerfer selber, sondern weil ihr Bewußtsein bei allem Einvernehmen mit der Verbrauchergesellschaft teils um ein Jahrhundert zurücksteht. Man zollt noch der Idee der Sparsamkeit Tribut, indem man die Konsumgesellschaft auf ihre Vorstufen hin romantisiert, wo Reichtum noch ohne Bezugnahme auf Verschleiß als Aneignung begriffen werden konnte. So glaubt der Wegwerfer, besonders gut gegen seine argwöhnischen Zeitgenossen getarnt zu sein, wenn er sich in der Altstadt bewegt, wo es "angenehm altmodische Kontore, Notariatsbüros und diskrete Kanzleien" gibt, und er den Eindruck eines Mannes erweckt, "der seinen Beruf in einem angenehm altmodischen Kontor ausübt, wo dunkle Ölgemälde handeltreibender Vorfahren an der Wand hängen" (273). Wie der Sprecher nicht zu der vollen Bedeutung seiner Formel vordringt, sind die Zeitgenossen offenbar nicht imstande, in der Wegwerfformel den Spiegel ihrer eigenen ökonomischen Praxis zu erkennen. Gegen den offen als Vernichtung erklärten Verbrauch scheinen noch Hemmungen zu bestehen. So ist ihnen der Wegwerfer Tabubrecher, darum eine verdächtige Erscheinung. Ihn wiederum bedrückt sein Außenseitertum derart, daß er sich energisch um seine Tarnung bemüht. Es gelingt ihm auch, seinen Zeitgenossen zu gleichen. Der Satiriker stellt diese wie auch den sie simulierenden Wegwerfer in eine Perspektive, die sie eng mit dem zerstörerischen Aspekt der Wegwerfformel verbindet. Böll läßt sie als Primitive aufmarschieren. Um von seinen Mitbürgern für ihresgleichen gehalten zu werden, erscheint der Sprecher als Mischung von Soldat und Neanderthaler, in Uniform, mit Kochgeschirr und Keule, und dazu mit einem leeren Gesicht: "[Ich] bin mit einem grauen Zweireiher, einem grünen Hemd, grünlich getönter Krawatte bekleidet, habe mein Frühstücksbrot in einer flachen Aluminiumdose, die Morgenzeitung, zu einer leichten Keule zusammengerollt, in der Hand. Ich biete den Anblick eines Bürgers, dem es gelungen ist, der Nachdenklichkeit zu entrinnen" (272).

Das Kriegsterrain ist gekennzeichnet durch Namen wie die der Generäle Roon und Schlieffen, nach denen Straßen auf der Route der Straßenbahn benannt sind. Die Fahrgäste streiten sich und behaup- 
ten überdies, es bestünde kein Unterschied zwischen "SA und USA" (272). Im Hinblick auf das amerikafreundliche Klima der fünfziger Jahre üben sie hier nicht etwa Kritik an den USA. Sie approbieren vielmehr ihre eigene Welt als eine unter dem Zeichen des Amerikanismus stehende Fortsetzung der Nazijahre. Es geht um die Identität von Faschismus und Kapitalismus. Beide Ideologien bauen sich, überspitzt gesagt, auf dem Gedanken des Daseins als Triumph des Stärkeren auf. Mag die Parallele im nackten Prinzip angehen, so vergessen sie den ausschlaggebenden Unterschied, daß die USA in der Tat eine demokratische Tradition hat. Aber dieser Unterschied stört ihr Konzept nicht, indem sie meinen, es sei alles noch so wie früher. Ihr Bewußtsein hat sich mit dem Ende des Krieges nicht verändert, obwohl man glaubt, "tief in den Grundsätzen der Demokratie" (273) verwurzelt zu sein. In diesem Denken liegt für Böll ein Geschwür, daß jeder Therapie zu spotten scheint. Hans Schwab-Felisch sieht dieses Phänomen generell in Bölls Werk als dessen Objekt und bezeichnet es als "das Walten des Antihumanen . . . das seinen Höhepunkt im Kriege gefunden hatte. Die Vergangenheit lebt fort und fort, weil die Gegenwart sich nicht von ihr freigemacht hat. Hier ist das Grundmotiv für Bölls Protest zu suchen. . . ." ${ }^{10}$ So sind die Zeitgenossen dieses Textes im Grunde Primitive, die ihrer vernichtungszugewandten Vergangenheit wie auch der Wegwerfformel als Destruktionsmedium unbewußt nahe stehen. Man lacht jeden Morgen wie auf Befehl, wenn jemand an der Schlieffenstraße das Zitat vom Starkmachen des rechten Flügels in die Bahn ruft. Allerdings verfehlt der Witzbold den richtigen Wortlaut und redet vom linken Flügel. Der Sprecher erkennt diesen Fehler, wie er auch seine Mitfahrer über die Identifikation von SA und USA aufklärt, da er die Gewohnheit hat, ihre "gröbsten politischen und geschichtlichen Irrtümer" zu berichtigen. Er gibt zu bedenken, daß "ein gewisser Unterschied be-

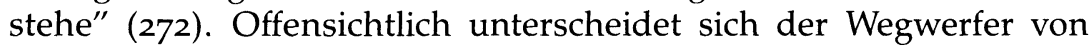
seinen Zeitgenossen in seinen Kenntnissen und seinem Unterscheidungsvermögen, aber nicht so entscheidend, daß er seine Wegwerfformel zur Bewahrungstheorie erweitern könnte, oder daß er etwa seine eigene Tätigkeit als Theoretiker und Praktiker als mit dem Faschismus verwandt erkennen würde. Sein Automatisierungsbestreben meint, was Böll anderorts als "Mechanisierung der Welt" bezeichnet hat, die ihm eine "Erscheinungsform des Faschismus ... eine Weiterentwicklung des Faschismus" ist (I, 171).

Im "Wegwerfer" verweist der Beruf an sich schon unverkennbar auf den Protest. Darüberhinaus konkretisiert die Wegwerferfigur in ihrer Formel wie keine ihrer Vorgänger den Beruf zu einer handlichen Waffe. Auch das Bewußtsein des Wegwerfers ist konkret und 
darum ein leicht zugänglicher Spiegel für den zeitgenössischen Leser. Selbst der Sprecher in "Es wird etwas geschehen" ist noch vornehmlich Grübler, der Wegwerfer hingegen Ingenieur. Obwohl sein Denken technisch ist, so ist er jedoch keine einschichtige Figur. Er geht von einer humanen Voraussetzung an sein Projekt heran. Aber seine Weltveränderungswünsche sind vage Regungen, die zwar sein Denken nicht zum richtigen Endpunkt lenken können, aber dennoch unterschwellig zugegen sind. So empfindet er "Trauer" (274), trotz seiner Überzeugung, daß seine Theorien sich rechtfertigen. Er ahnt zweifellos, daß seine Formel eine gesellschaftsgefährdende Seite hat und mehr als simple Drucksachenbeseitigung ist. Festzuhalten ist, daß sich der Wegwerfer seiner Problematik nicht durch die Flucht entzieht. So ist er zwar ein Versager und Pfuscher im Denken, aber er ist kein Wegläufer. Sein Stehvermögen wie schon seine Jugend als Sammler, seine Gespräche mit der Pförtnersfrau und auch seine Streß-Symptome sind dazu angetan, den Leser zur gefühlsmäßigen Identifikation zu führen. Darum dürfte es diesem ebenfalls nicht allzu schwer fallen, die gedankliche Separation vom Wegwerfer vorzunehmen, aus der heraus er gegen diesen als Verbrauchermenschen Stellung beziehen kann. Dabei hilft ihm der Satiriker, indem er den Finger auf den ökonomisch wohl empfindlichsten Punkt unserer Gesellschaft legt und damit höchst erschreckende Wirkungen erzielt.

Böll verweist auch in "Wegwerfer" auf die Norm des Lebensflusses. Er mißt diesen zunächst negativ, indem er zwei sich widersprechende Einstellungen zur Wegwerfformel identifiziert. Es sind die der Behörde und die der Versicherung, denen der Wegwerfer seine Erfindung anbietet. Die Verwaltungsbehörde verkörpert soziale Statik. Dokumente und Akten werden wohl hin und her bewegt, aber letztlich gestapelt zu einer Pyramide, mit der die Behörde ihr Dasein bestätigt. Das Lebensversicherungsgeschäft baut sich auf dem Gefühl der Unbeständigkeit in der Gesellschaft auf. Man reagiert also auf die Formel als Konzentrat der Gesellschaftsdynamik. Der Amtsschimmel fühlt sich verunsichert durch den Wegwerfer und erklärt ihn für geistesgestört, das Versicherungsgeschäft heißt ihn willkommen. Jedoch meinen beide, Amt und Versicherung, in Kontrastfarben falsches Leben. Zwischen sie fällt der richtige Fluß der Dinge. Um diesen näher zu bestimmen, muß die Subjektsphäre beleuchtet werden. Ihr darf einerseits nicht das Prinzip des totalen Sammelns zugrundeliegen, wie der Behörde, andererseits nicht das Prinzip des hektischen Flusses, wie der Versicherung. Es finden sich zwei Figuren, die diesen Forderungen entsprechen. Die eine ist der Wegwerfer selber. Er berichtet von seiner Jugend, in der er Sammler von Reiseprospekten war: 
Ich machte mir als Elfjähriger schon zur Gewohnheit, das Weggeworfene . . . aus dem Papierkorb zu nehmen, es zu betrachten, zu sortieren, es in einer Truhe, die mir als Spielzeugkiste diente, aufzubewahren. . . . Dalmatien war mir so vertraut wie die Fjorde Norwegens, Schottland mir so nahe wie Zakopane, die böhmischen Wälder beruhigten mich, wie die Wogen des Atlantik mich beunruhigten. . . . Ich überlasse es der Phantasie des Lesers, sich auszumalen, wie meine Sammlung aussah, als ich siebzehn Jahre alt war . . (276).

Bezeichnenderweise lenkt der Satiriker die "Phantasie" des Lesers auf den Schatz in der Truhe des Jungen, als er zur "Enzyklopädie," zur monströsen Sammlung angewachsen ist, und der Wegwerfer sie in "plötzlicher Lustlosigkeit" abstößt (276). Der Satiriker bezieht damit die Phantasie auf das Stadium der Sammlung in quantitativer Perspektive. Der Wert an sich ist nur sieben Mark und sechzig Pfennig, die der Altwarenhändler bezahlt. Offensichtlich steht diese Art Phantasie im Gegensatz zu einer "qualitativen," in der die Wogen des Atlantik rauschen und die Wälder Böhmens auf das Gemüt zu wirken imstande sind. Diese letztere ist die Phantasie des Wegwerfers als Kind. Hier sind die Prospekte Auslösemomente für das vorgestellte Reisen, sie lassen "Kunsthonig" schmecken oder "Kunstgeschichte" sehen (276).

Wenn der Wegwerfer auch Prospekte über Scharniere, Knöpfe und dergleichen sammelt, so ist er der typische Junge, der die sonderbarsten Dinge der Bewahrung für würdig befindet und aus schier unergründlichen Taschen zutage fördert. Offensichtlich sind diese Dinge in der Tasche des Kindes etwas anderes als in der Truhe des Erwachsenen. Im Kind bedeuten sie Spiel, im Erwachsenen Kauzhaftigkeit oder, sofern er quantitativ sammelt, gar Obsession. Aus dem Kreis dieses kindlichen, auf Bewahren gerichteten, mit "qualitativer" Phantasie erfüllten Bewußtseins erwachsen der Anspruch des Sprechers als Herausforderer wie auch das Auslösemoment der Wegwerfformel. Es ist der Wunsch, durch das Abstoßen von Nutzlosem, und das ist die ins Ungeheure gewachsene Sammlung so gut wie die Flut der Drucksachen, die der Wegwerfer beruflich vernichtet, weltverändernde Energien freiwerden zu lassen. Diese Zuversichtlichkeit beschwingt den Wegwerfer im "seligen Zustand der Asozialität" (277), nachdem seine Behörde die Formel entrüstet ausgeschlagen und ihn entlassen hat. Seine Armut ist ihm Ehrenzeichen und sein zerschlissener Kragen eine Freude. So fühlt er sich vollauf berechtigt, auf Kredit zu leben. Hier steht der Wegwerfer durchaus noch im Gegensatz zu seiner Welt, aber nicht wie das Kind, sondern mit 
"prahlerischer Selbstverständlichkeit" (272) als deren verkannter Wohltäter. Mit dem Wort "selig" versucht er mehr zu suggerieren, als er unter der Lupe betrachtet einlösen kann. Dennoch stellt die Asozialität des Wegwerfers unverkennbar einen Störfaktor in einer Welt dar, in der Konformität besonders geschätzt wird.

Die Bewahrung des Menschlichen schlägt sich weiter in der Pförtnersfrau nieder, der zweiten Figur in der Subjektsphäre. Wo den Wegwerfer zwanghaftes Denken und Tun plagen, hat sie sich die kindliche "Leidenschaft" des Prospektesammelns als Freude erhalten und bittet den Sprecher "meistens . . . ihr einige Reiseprospekte zu überlassen." Dieser lächelt darüber, zum einen weil er selber einst ein Sammler war und dieser Zeit eine "sentimentale Erinnerung" (275) bewahrt, zum anderen weil er auch wohl auf die Frau herabsieht, da er selber als Erwachsener nicht mehr das Sammeln, sondern das Wegwerfen befürwortet. Ohne die kindliche Phantasie hat das Sammeln keinen wirklichen Wert. Das Abstoßen seines Schatzes ist darum zweifellos richtig. Es liegt darin und auch in der darauffolgenden Wegwerftätigkeit der begrüßenswerte Versuch, aus dem Verlust die richtigen Konsequenzen zu ziehen. So ist der Wegwerfer der Pförtnersfrau auf dem Weg der Erfahrung und des Bewußtwerdens voraus, darum aber auch unter psychologischem Druck. Ist das kindlichphantasievolle Sammeln ein humanes Bewahren, so begegnet das allmorgendliche gemeinsame Frühstück des Wegwerfers und der Pförtnersfrau als Bewahrung des Humanen dem Streß des Wegwerfers. Die Eßpausen wiegen im gewissen Sinne so schwer wie die Wegwerftätigkeit. Die Zeit, wenn er eine "Stärkung" (275) zu sich nimmt, ist ebensolang wie die morgendliche Vernichtungsarbeit. Außer der Dauer ist der Inhalt, oder genauer, die Substanz der Pause wichtig. Der Wegwerfer ißt nicht allein; die Pförtnersfrau bringt ihm Kaffee und plaudert mit ihm über ihre Kinder:

Ist Alfred inzwischen im Rechnen etwas besser geworden? Hat Gertrud die Lücken im Rechtschreiben ausfüllen können? Alfred hat sich im Rechnen nicht gebessert, während Gertrud die Lücken im Rechtschreiben ausfüllen konnte. Sind die Tomaten ordentlich reif geworden, die Kaninchen fett, und ist das Experiment mit den Melonen geglückt? Die Tomaten sind nicht ordentlich reif geworden, die Kaninchen aber fett, während das Experiment mit den Melonen noch unentschieden steht. Ernste Probleme, ob man Kartoffeln einkellern soll oder nicht, erzieherische Fragen, ob man seine Kinder aufklären oder sich von ihnen aufklären lassen soll, unterziehen wir leidenschaftlicher Betrachtung (275). 
Das Abrasseln des Gesprächsinhalts erklärt sich durch die Formel der "Mechanical Operation of the Spirit," die Swift in der gleichnamigen Satire darstellt und die sich zwanglos auf den Denk- und Sprechstil des Wegwerfers übertragen läßt. Trotzdem dürfen wir dessen Fragen und Teilnahme an der Diskussion nicht als leere Formalität abtun. Die Leidenschaftlichkeit der Betrachtung mag im Sprecher geringer sein als in der Pförtnersfrau, weil er zweifellos von seinem Wegwerftheoretisieren, dem er zu Hause nachkommt, stark angegriffen ist. Aber gerade weil das Denken ihn äußerst beansprucht, müssen ihm die Unterhaltungen mit der Pförtnersfrau Linderung seiner Berufsneurose, also Stärkung des Humanen sein. ${ }^{11}$ Die Vokabel "leidenschaftlich" hat zentrale Bedeutung in dem Zitat. Da sie ebenfalls zur Kennzeichnung des Sammeleifers der Pförtnersfrau eingesetzt wird, bildet sie eine Brücke zum Privatbereich der Pförtnersfamilie und bezieht somit deren Lebensgewohnheiten in den Gedanken der Bewahrung ein. Die Pförtnersfrau sammelt im rechten Sinne, nämlich mit Beschränkung. Sie verlangt, wie es heißt, nur "einige" Reiseprospekte. Die Familie ist offensichtlich nicht restlos in den Kreis des Konsums und der Produktion eingeschlossen. Der Verbrauch der Pförtnersleute hat nichts Zwanghaftes; er wird von diesen selber bestimmt und ist Teil eines privaten Vorgangs. Man züchtet Kaninchen, zieht Gemüse und Obst, geht somit Beschäftigungen nach, die ein rechter Verbrauchs- und Leistungsmensch als Verletzung des Prinzips der Arbeitsteilung, durch das sich Massenherstellung und -verbrauch ermöglicht, abzulehnen hätte. So ist die Pförtnersfamilie letztlich Normträger. An ihr läßt sich die Formel eines rechten, bewahrenden Lebens ablesen.

Obwohl sich ein idyllischer Bereich ausmachen läßt, duldet der Satiriker den Protagonisten dort keineswegs permanent. Die Idylle ist übrigens hier nicht räumlich, sondern zeitlich zu verstehen, da der Wegwerfer am selben Ort arbeitet und sich auch erholt. Der Herausforderer mag seine Stärke zwar aus dem Idyllischen beziehen, aber nicht dies, sondern die Konfrontation ist seine wahre Bestimmung. So gibt ihm auch der "selige Zustand der Asozialität," ehe er zum Wegwerfpraktiker wird, einen gewissen Rückhalt, ist aber nur Vorspiel für seine wahre Aufgabe als Herausforderer, wie auch die Stärkungspausen im Keller lediglich Zwischenspiel sind.

Als Berufssatire gelesen prägt "Wegwerfer" die Analogie von Protagonist und Künstler in besonders genauer Einengung auf den Satiriker. Dieser hält der Gesellschaft im Werk ein Konzentrat des Anstößigen vor. Er beabsichtigt, hinter den oft scheinbar harmlosen oder sich sogar als gesellschaftsstützend darbietenden Erscheinungen das empörende Konzept sichtbar zu machen. In Worten "zwischen 
zwei Zeilen . . . kann man Dynamit genug anhäufen, um Welten in die Luft zu sprengen" (ESR1, 302), sagt Böll in seiner ersten Wuppertaler Rede. Diese Rolle ist leider eine sehr undankbare. Man mißtraut dem Satiriker, und auch mit Recht, denn seine Formel zur Vernichtung ist wohl die rechte im Theoretischen der moralischen Intention, aber in der Praxis etwas sehr Zweifelhaftes. Die Praxis bezieht auch das zu Rettende in die Zerstörung ein, denn der Satiriker hat gegen Menschen vorzugehen, selbst wenn er sie liebt und sie von gefährlichen Ideen befreien will. Es fragt sich hier, ob der Satiriker dieses Dilemma nicht vermeiden könne, indem er im Gegensatz zum Wegwerfer eine Bewahrungsformel nicht nur auf die mitunter unsichere Mitwirkung des Lesers bauend andeutet, sondern ausdrücklich vorlegt. Wäre er nur Moralist, so böte sich dieser Ausweg. Aber er ist Künstler; der einzige Weg zur Norm ist darum der Umweg der Indirektheit, es sei denn es bestünde ein ideologischer Zwang zur Ausdrücklichkeit. Andererseits ist der Moralist kein stummer Partner in der Satire; er geht ungern Kompromisse ein. Je stärker ästhetisiert die Norm erscheint, desto geringfügiger für ihn ihr Kommunikationsvermögen. Gesetzt den Fall, die Norm wird trotz ihres ästhetischen Schleiers rezipiert, so ist das Problem nicht behoben, denn auch dann noch kann das Publikum vermeiden, sie bis zur letzten Konsequenz ihrer sozialen Verwirklichung zu befolgen. Handelt es sich beim Publikum um den Literaturbetrieb, um Kritiker und Verlagsleute, so mag das "Einleuchtende" der Formel erfaßt werden, es interessiert aber wahrscheinlich im Grunde nur, was dem Direktor der Versicherung "einleuchtet" (277); man berechnet die Formel in Sinne ihres ökonomischen Wertes und akzeptiert sie, wenn sie den Fluß des Betriebs $\mathrm{zu}$ beschleunigen verspricht. Sie wird zur ökonomischen, statt zur moralischen "Lebensversicherung."

Es kann so gesehen nicht wunder nehmen, daß der Satiriker all diesem entkommen möchte. Allerdings gibt er dem Verlangen in diesem Text in keiner Weise nach. Seine Chiffre, der Sprecher, gibt sich selbst in seinen vier Wänden keine Ruhe. Seine Wohnung gleicht einem Laboratorium. Er trinkt seinen Kaffee "im Stehen," ißt rasch. Hier schluckt er seine Nervenstärkungspillen. Die Wände sind voller Formeln und Abszissen, die ihm fieberhaft scheinen und ihn beunruhigen. Er stöhnt unter der Belastung seiner "ökonomischen Phantasie" (280). Die Wohnung ist ihm nicht weniger Arbeitsplatz als das Versicherungsgebäude. Wenn Böll hier keinen Wegläufer mehr duldet, so äußert sich darin seine wachsende Sympathie für den Gedanken der Veränderbarkeit der Welt. Er gelangt zu einer völlig entromantisierten Sicht seiner Situation als Autor. Das Paradigma seiner 
vorangehenden Berufssatiren hat alle Schlupfwinkel als Ausflüchte entlarvt.

Trotz allen Ernstes ist viel Komik in der "Wegwerfer"-Geschichte. Offensichtlich geht der Humor auch in diesem Text durch die Person, dringt dabei im Sprecher ganz besonders deutlich zur Idee vor. Seine in der Anschauung lachhaften Tätigkeiten erzeugen die Perspektive eines gigantischen Mißverhältnisses zwischen Energieaufwand einerseits und der Formel als Fehlleistung andererseits. Diese Perspektive wiederum führt zur Idee des Verlustes und der Bewahrung. Der stützende Humor gilt vornehmlich der Pförtnersfrau in Anspielung auf Disproportioniertheit, und zwar im psychischen Sinne. Die Frau ist wohl erwachsen, hat Kinder, diskutiert Erziehungsprobleme, ist aber auch wie ein Kind in der Art ihres Sammelns. Ihr Hobby verbindet sie mit der satirischen Norm, meint somit ein moralisches Plus, aber auch eine belustigende Minderung ihrer Person, da der Satiriker sie gewissermaßen nicht aus den Kinderschuhen herauswachsen läßt.

Das Wortgegensatzpaar in diesem Text ist das Wegwerfen und das Sammeln. Es wird mit deutlichem, leitmotivischem Nachdruck gehandhabt. Für die Zeitgenossen als Repräsentanten der Objektsphäre ist das Wegwerfen tägliche Lebenspraxis, während sie ideell das Sammeln befürworten. Aus der Subjektsphäre ergibt sich unter dem Prinzip humanitärer Bewahrung eine dialektische Beziehung der Kontraste. Das Sammeln, wie es der Wegwerfer als Kind und die Pförtnersfrau praktizieren, ist fraglos ein zu befürwortender Wert. Wird es zur Bürde, wie in der Prospektenhäufung des Sprechers, so verwandelt sich das Sammeln zum Unwert. Das Wegwerfen wird unter dem Aspekt des den Menschen überflutenden Besitzes ein ethisches Mandat. Wertvoll ist es überdies als theoretische Schreckformel. Die Art, wie der Sprecher das Wegwerfen ausübt, ist jedoch in einer Verbrauchergesellschaft gleichsam Öl aufs Feuer.

Neben der Wortpaartechnik findet auch das Micromegas-Prinzip Anwendung, und zwar in einem Sinne, der sich mit dem von Jeziorkowski angelegten Aspekt der verkehrten Welt verträgt. Zur Kaschierung seiner Fehlleistung als Herausforderer gibt der Wegwerfer seiner Tätigkeit den Anstrich der Perfektion, die aber gewissermaßen auf dem Kopf steht, da sie als Ausdruck des Versagens die Objektsphäre stützt. Der Wegwerfer bemüht sich, uns von der bruchlosen Systematik und vollendeten Präzision seiner Technik zu überzeugen. Es wimmelt deshalb von technischer Terminologie wie "Ordinate," "Kurven," "Theorien," "Experimente," "Statistik" u. dgl. m. Diesem Bereich der Objekttarnung steht ein Wortfeld gegenüber, in dem sich 
die Subjektsphäre darlegt. Vorderhand scheint es unwichtig oder banal, aber Wörter wie "nachdenklich," "schmerzlich," "lächeln," "traurig," "frühstücken," "plaudern," "Kummer," "gute Eltern," "Kartoffelneinkellern" u. dgl. m., relativieren das Wortfeld der Technik und tragen zur Minderung des Objekts bei. ${ }^{12}$ 


\section{vII. Kurzsatire und Muster: Ausnahme, Abkehr und Neuansatz}

In "Hauptstädtisches Journal" (1957) fehlt der Herausforderer. Die Erklärung geht aus dem Thema hervor. Es ist die Wiederbewaffnung der Bundesrepublik, und zwar nicht als Bestimmung eines gegebenen, sondern eines zukünftigen Zustandes. Da die "Truppe" noch nicht existiert, sondern nur erst deren exklusiver Kern, haben Jedermannsfiguren wie Bölls Herausforderer dort nicht einmal im Selbstkompromiß Platz. Die Objektsphäre ist ein verhältnismäßig kleiner Kreis hoher Militärs und führender Politiker. Dieser ist jedoch für Böll derart empörend, daß er ihn als die Szene ausschließlich beherrschend darstellt.

Bölls zornige Stellungnahme gegen die befürchtete Wiederbewaffnung ist als natürliche Konsequenz und Fortführung seiner Kriegstexte zu betrachten. Zwar ist der Krieg in diesen fast ein verabsolutiertes Böses, aber es gehören immerhin Menschen zum Töten, selbst wenn diese bei Böll oft wie einfache Werkzeuge des Molochs Krieg erscheinen. Diese Menschen sind Soldaten, diese wiederum meinen eine Armee. Psychologisch lassen sich Bölls früheste Werke als eine Art Exorzismus des Krieges sehen, der für Böll als Teilnehmer nicht nur prinzipiell und objektiv ein Ungeheuer war, sondern auch, weil er in dessen Dienst stand. Der Teufel, den man, auch als Sprecher seines Landes, dazu auch wohl noch aus Gründen persönlicher Schuldgefühle verbannt zu haben glaubte, soll mit der Remilitarisierung wieder inthronisiert werden. Das kommt einem Landesverrat gleich, aber nicht des Bürgers am Staate, sondern des Staates am Bürger. Bölls offensichtlicher Zorn in diesem Text ist also nicht verwunderlich. Greift der Satiriker seinen Gegenstand ohne einen Herausforderer, d.h. unter Ausschluß einer Identifikationsfigur und konkreten Subjektdimension an, so kann die verkehrte Welt so perfekt sein, daß sie den Grad einer perversen Natürlichkeit erreicht. Sieht man das Empörende nur aus dessen eigener Sicht, so kann der Schock der entlarvenden Erkenntnis und die Separation vom Objekt im Leser um so tiefer gehen. Swift verwendet diese Strategie in "A Modest Proposal." Das Schlachten und der Konsum von Kindern ist natürlich, weil es-angeblich-sinvoll ist. In "Journal" ist die Gründung der "Akademie für militärische Erinnerungen" ( $\left.\mathrm{W}_{3}, 228\right)$ sinnvoll, 
weil sie-angeblich-einem natürlichen kulturellen und völkischen Verlangen entspricht.

Ein satirischer Text ist ohne Herausfordererfigur zweifellos weniger komplex. Treffen die Subjekt- und Objektsphären in der Persönlichkeit aufeinander, so verdeutlicht sich die satirische Dialektik im psychologischen Sinne. Die Selbstenthüllung des Objekts, wie sie "Journal" zeigt, ist darum aber nicht notwendigerweise ein Mangel in der satirischen Praxis. Nach Herder ließe sich sogar das Gegenteil behaupten. Auf dem Wege des sich verfeinernden Geschmacks sieht er die Satire in einem Objektivierungsprozeß, der vom nachahmenden Spott ausgehend über Persiflage und Parodie in der Ironie als Endpunkt mündet. Da dieser "alle Gestalten zu Gebot" stehen, meint sie das Zurücktreten des Autors und seiner Persona; ${ }^{1}$ sie erscheint also im sich selbst enthüllenden Objekt.

Dieses Modell erlaubt eine ungebrochene Ausbreitung der Ironie, weil ihr keine Normfiguren im Weg stehen. Es erlaubt also den satirischen Ton ohne schwächende Modulationen. Ist der Ton schon satirisch hochgradig extensiv und intensiv, so meint das auch wiederum nicht, daß "Journal" eine bessere Satire ist als etwa "Der Wegwerfer." Je stärker der satirische Ton, desto leichter ist zwar ein Text als Satire zu erkennen, wichtiger ist jedoch, wie der Ton die Stilelemente des Textes prägt. Es wäre wohl müßig, die Überlegenheit des einen oder anderen Modells beweisen zu wollen. ${ }^{2}$ Vergleicht man "Journal" mit "Der Wegwerfer," oder Swifts "A Modest Proposal" mit A Tale of a $T u b$, so handelt es sich zwar um verschiedene Satire-Modelle, aber doch wohl um Gleichwertiges.

In der Selbstdarstellung des satirischen Objekts anhand des abscheulichen Miles gloriosus Machorka-Muff gelingt es Böll, einen genauen Abriß von Zeit und Ort zu entwickeln. Der Leser zweifelt nicht einen Moment daran, daß es um die Bewaffnung der Bundesrepublik geht, daß die gemeinte Hauptstadt Bonn ist. Bölls Aggressivität macht hier keine Umwege. Der Grad seiner Empörung schlägt sich schon darin nieder, daß Böll in dieser als einziger unter seinen Satiren der fünfziger Jahre zu obszönen Anspielungen greift, um seinen Feind zu vernichten. Selbst Bur-Malottke in "Doktor Murkes gesammeltes Schweigen" ist relativ menschlich im Vergleich zu der Erzählerfigur in "Journal." Als Oberst a.D., wird diese als Gründungsoberhaupt der "Akademie für militärische Erinnerungen" in die Hauptstadt berufen. Den Geist des Ortes findet Machorka-Muff äußerst zuträglich. Man zollt ihm und seinesgleichen hohen Respekt und befördert ihn unverzüglich zum General. Ein Kollege verdeutlicht ihm, daß eine Demokratie, in der die Mehrheit des Parlaments auf der Seite von Leuten seines Schlages ist, dem Militarismus auf die 
Dauer mehr nützt als eine Diktatur. Es grassiert, wie Iring Fetscher formuliert, die "Doppelzüngigkeit, die uns zugleich den 20. Juli feiern und den Henkern des Dritten Reiches hohe Pensionen zahlen läßt." ${ }^{3}$ Die Kräfte der Opposition sind schwach. Der Familie, zu der Muff gehört, "hat noch keiner widerstanden" (231). Diese Feststellung aus dem Munde der Braut der Erzählerfigur verweist auf die Hauptstütze des Militarismus im Staate. Sein Partner ist der Kapitalismus, den die Braut, deren Name Zaster-Pehnunz an sich schon alles über ihren Stammbaum sagt, vertritt. Die finstere Prognose für sein Land eröffnet der Satiriker allerdings hauptsächlich durch die Selbsterhöhung des Sprechers. Selbst als Ego- und Megalomane ist dieser erstaunlich. Aus seinem Munde birst ein unvorstellbares Trommelfeuer des Wortes ich. Das Ungeheuerlichste an dieser Figur jedoch und zentrale Metapher des Textes ist ein Traum, in dem sich Muff auf Tausenden, in Reih und Glied stehenden Sockeln als Monument sieht. Da die Ehre eines Offiziers, wie es heißt, nach der Verlusthöhe seiner Truppe bestimmt wird, gründet sich die Kolossal-Ehrung Muffs, von der er träumt, auf den Tod Tausender. Der Denkmalpark, in dem er sich sieht, enthüllt sich als Soldatenfriedhof. Er steht auf den Gräbern seiner Mannschaften. Darüber hat er im Traum zu lachen, "und tausendfach kam das Lachen aus meinem eigenen Munde auf mich zurück." Hier lacht Muff über den Tod, oder genauer, über die Opfer, auf die sich sein Ruhm gründet. Sein Lachen ist in Anbetracht der Umstände für den Leser derart schaurig, daß es allein schon zur Selbstauslöschung Muffs genügen würde. Wäre Muff nur im Traum dieser Unmensch, so könnten wir ihm möglicherweise als mildernden Umstand anrechnen, daß man über seine Träume nicht verfügen kann. Aber auch als er erwacht, ist dieser Unhold nicht etwa entsetzt, sondern "[v]on einem tiefen Glücksgefühl erfüllt" (223), aufgrund dessen er sein schauriges Lachen fortsetzt.

In der Vernichtung seines Gegenstandes beschränkt sich Böll fast ausschließlich auf die Technik des Blähens. Was der Traum Muffs im großen leistet, liegt im Prinzip auch im kleinen. Schon die Namen der Offiziere sind häßliche Spreizungen. Neben Erich von MachorkaMuff gibt es einen Marschall Emil von Hürlanger-Hiß, einen Divisionskommandeur Welk von Schnomm und einen Murcks-Maloche. Die Zaster-Pehnunz, "aus jungem Adel, aber altem Geschlecht" (223), zählt drei Offiziere unter ihren sieben vormaligen Ehemännern. Das alles nennt sie ihre "Familie" (231) und meint damit ein Raubtiergenus, dessen Gedeih der Tod anderer ist. Der in Mißkredit geratene Hürlanger-Hiß ist rehabilitiert, wenn erwiesen wird, daß seine Verluste an Menschen doch das vorgeschriebene hohe Soll erfüllt haben. Machorka-Muff erhöht sich auf Kosten der Mannschafts- 
dienstgrade, die ihm auch als Zivilisten noch "Untergebene" (224) sind. Für Heffling, einen Vertreter dieser Kategorie, bestellt er einen Schnaps, sich selber und Murcks-Maloche hingegen Cognac. Die extreme Spreizung des satirischen Gegenstandes ist möglich, weil sich die Aggressivität des Satirikers im Selbstlob des Objekts verbirgt. Die Überziehung der Linien ins Groteske ist darüberhinaus nötig, weil die Gefahr nicht von der Hand zu weisen ist, daß weite Publikumskreise diesen Generälen trotz allem ergeben bleiben könnten. Man ist gewohnt, "großen Männern," gleich welchen Schlages, den Respekt zu wahren.

Ist besonders die Zerstörung Muffs eine Glanzleistung, so rechtfertigt sie sich fast völlig aus der Schubkraft des satirischen Zorns. Die Fixierung einer Norm fehlt. Die Hinweise auf den allzu hektischen Lebensfluß der Hauptstadt, den Muff bewundert- "wie das brodelt, pulsiert, fast überkocht" - und den er noch gesteigert sehen will"da stecken Energien, die noch nicht alle freigelegt sind" (223) — sind nicht sehr gezielt eingesetzt als Bestimmung des Chaos, das die militaristisch-kapitalistische Ordnung hier darstellt. Die Begriffe “Demokratie" und "Opposition," die Böll als Gegengewicht hätte heranziehen können, fallen als Niederschlag der Norm aus; Böll rechnet sie zum Objekt. Die Situation ist restlos anstößig, das letzte Wort hat die Pehnunz, die den uneingeschränkten Erfolg ihrer "Familie" bestätigt. So ist Böll in "Journal" in weitaus aufgebrachterer wie auch bedrückterer Stimmung als in "Doktor Murkes gesammeltes Schweigen," wo der Subjektbereich figurativ das letzte Wort behält. Festzustellen ist, daß Böll in "Journal" die Tendenz zur freien Entfaltung satirischer Aggressivität vorantreibt. Er ist hier schon beinahe so boshaft wie in Entfernung von der Truppe und Die verlorene Ehre der Katharina Blum. So setzt er hier alles daran, klare Fronten herzustellen. Darum entwickelt er nicht etwa auch eine Dialektik, die wie in den Herausforderersatiren die Gegensätze auf höherer Ebene aufhebt.

Mit "Der Wegwerfer" und "Hauptstädtisches Journal" scheint Bölls Interesse an der Kurzsatire vorerst zu erlöschen. Einerseits spiegelt sich darin das allgemeine Desinteresse an Kurzprosa in dieser Zeit, andererseits ist Böll mit einem Roman, Billard um halb zehn (1959), beschäftigt, in dem er mit einer strukturellen Konzentration arbeitet, die sich bislang nur in der Kurzgeschichte fand. Was die Kurzsatiren "Der Bahnhof von Zimpren" (1958) und "Keine Träne um Schmeck" (1962) betrifft, so scheint Böll für sie kein volles Maß Anspannung übrig zu haben. Es beginnen mit ihnen auch die Auflösung und der Abbau des Herausforderermusters und damit des Satiretypus der fünfziger Jahre. Einer der entscheidenden Anlässe zur Preisgabe des gewohnten Musters ist der Gedanke der Veränderbarkeit der Welt, auf den 
Klaus Jeziorkowski in Bezug auf Böll verwiesen hat. Steht Theodor W. Adorno, wie Jeziorkowski vermutet, ${ }^{4}$ hier Pate, so dürften seine Gedanken zur Satire erhellend sein. In Minima Moralia erklärt Adorno alle traditionell zur Satire gehörenden Waffen gegen das Objekt als überholt. Dieses hat alles grundlegend und restlos vereinnahmt: "Gegen den blutigen Ernst der totalen Gesellschaft, die ihre Gegeninstanz eingezogen hat als den hilflosen Einspruch, den ehedem Ironie niederschlug, steht einzig noch der blutige Ernst, die begriffene Wahrheit." Es beruft heute "die Welt noch in der radikalen Lüge sich darauf, daß es eben so sei, und solcher einfache Befund koinzidiert ihr mit dem Guten. Kein Spalt im Fels des Bestehenden. . .." Ist Bölls Satirekonzept möglicherweise überholt, dann aus folgenden Erwägungen. Der Herausforderer im Heldenmythus deutet zwar auf Außerordentliches, aber gerade darum ist die Gefahr groß, daß er rezeptiv nicht als Norm für die Wirklichkeit begriffen, sondern als Fiktion, als Kunstinhalt abgetan wird. Die Unverbindlichkeit in Bezug auf die Veränderung der Wirklichkeit steigert sich, wenn der Held zum Versager wird. Steht dessen Abstieg im Vordergrund der Perzeption, so ist der mythische Rahmen des Geschehens dann nicht nur Kunst, sondern ewige Befindlichkeit, ist Schicksal, das man bedauern, jedoch nicht ändern kann. So gesehen ist der Heldenmythus nicht etwa Sprengstoff im "Fels des Bestehenden," sondern Hindernis auf dem Weg zur Veränderung der Welt.

Sehen wir vorderhand von der Möglichkeit ab, daß Satire die Welt verändern, und bescheiden wir uns damit, daß sie zu deren Erkennung führen kann, so beruht eine mögliche Fehlrezeption der Böllschen Satire in den fünfziger Jahren auf der Mißachtung zentraler Stilelemente. Das wichtigste ist zweifellos der satirische Ton. Da in diesem-wennschon meistens ironisierend-das Elegische mitschwingt, ist die Gefahr falschen, auf Katharsis ausgerichteten Lesens gegeben. Hinzu kommt, daß die Verfremdung des Versagers zum Pfuscher falsch begriffen werden kann. Zwar ist die Logik des Pfuschens, daß dieses auf das Richtigmachen zielt, aber dieser Schluß mag ungeleistet bleiben. Man mag den Pfuscher mit dem Kauz verwechseln, dem man soziale Verantwortlichkeit nicht im Ernst zumutet, besonders wenn er zum Lachen ist. Günter Blöcker sieht diese Gefahren sehr scharf, wenn er vermutet: "Die Schläge, die [Böll] austeilte, waren nicht allzu weit entfernt von Absolutionen, und manch einer, der ihn als Satiriker bejubelte, drückte damit seine Erleichterung aus, so billig davongekommen zu sein." ${ }^{6}$ Auch mit dem Pfuscher als Kauz erschöpfen sich leider die möglichen Aspekte des falschen Verstehens noch nicht. Obwohl Bölls Heldennorm antielitär ist, sein David nie gekrönt wird, kennzeichnet die Herausfordererkonstellation 
ein inhärenter Individualismus. Dieser wiederum wird als Normwert in unserer Gesellschaft vornehmlich, ja zwangsläufig verbunden mit der Ansiedlung der Person innerhalb elitärer Strukturen.

Messen wir also Bölls Satiren des Herausforderermusters am Kriterium einer zu verändernden Welt, so sind fundamentale Fehlverständnisse nicht ausgeschlossen. Es nimmt somit nicht wunder, daß Böll nach neuen Ausdrucksmöglichkeiten sucht. Leicht ist ihm dies anscheinend nicht geworden, denn er läßt das "Murke"-Muster nicht etwa kurzerhand fallen, sondern thematisiert bisweilen seine $\mathrm{Ab}$ kehr. Was diese meint und nicht meint, hat ausgeführt zu werden: Das individualistische Element wird herabesetzt; der Protest formt sich allmählich zum unaufwendig betriebenen Störungsfaktor um, und das bisweilen in Verbindung mit kollektiver Hilfe. In "Veränderungen in Staech" ist der Störfaktor sogar die Summe einzelner winziger Tätigkeiten. Das persönliche Entscheidungsmoment wird herabgespielt. Böll hat dem herausfordernden Individuum jedoch nicht ein für alle Male abgeschworen, wie z.B. seine jüngste Kurzprosa, "Du fährst zu oft nach Heidelberg" (1977) und "Geständnis eines Flugzeugentführers" (1977) zeigt. Wichtig ist jedoch, daß diese Herausforderer nichts mit der alten Heldennorm gemein haben. Die Preisgabe des Heldenmythus bedeutet das Entfallen der hohen Norm. Die Protagonisten sind keine Versager und darum auch keine Pfuscher. Es wird hinter ihnen kein verurteilender Satiriker sichtbar. Sie stiften nicht etwa Verwirrung im Leser an, indem sie die Objektund Subjektsphäre dadurch vermischen, daß der Satiriker sie auch zum Teil des Objekts macht. Er lädt vielmehr das Publikum ein, über die Protagonisten zu richten, denn diese tun bisweilen sehr fragwürdige Dinge. Die Norm beschränkt sich auf die Erfahrungswelt, und dieser genügen Bölls neue "Helden" weitgehend trotz ihres oft sehr verfänglichen Tuns. Vornehmlich ist der Typ eines sehr positiv gesehenen Schelms auszumachen, der sich nicht grundlegend vom Vir bonus unterscheiden läßt. Die Erfolgslinie ist demnach nicht mehr fallend. Fehlt der Protagonist alten Stils, so auch der Anker für die Wortpaartechnik in ihrem dialektischen Sinne. Ist in der Abkehr vom alten Muster noch ein Wortpaar auszumachen, so betont es das Auseinanderklaffen der Subjekt- und Objektsphäre. Die utopische Komponente einer vorgestellten Aufhebung der Gegensätze entfällt. In dieser Schwundform ist die Wortpaartechnik ausschließlich Kampfmittel, nicht auch Friedensfahne.

Bölls Abkehr vom Heldenmythus meint nun keineswegs die Preisgabe des Archetypischen an sich. In "Der Bahnhof von Zimpren" stellt Böll einen Mutter-Archetypus auf, in "Keine Träne um Schmeck" den des Magiers; in "Briefe aus dem Rheinland" zeichnet der Sprecher als 
Lohengrin, in "Briefe an einen Freund jenseits der Grenzen" als Loki; in Entfernung von der Truppe erscheint ein Engel, in Die verlorene Ehre der Katharina Blum eine Art Madonna. In jedem Falle ist das Archetypische jedoch stark verfremdet. Es ist ausdrücklich Kunstinhalt und -mittel, deutlich als solche gekennzeichnete Ikonographie, nicht Wirklichkeitsinhalt wie der Heldenmythus. Es kann darum von vorneherein richtig aufgenommen werden. Es ist nicht prinzipieller Normwert für das Verhalten des Protagonisten wie der Heldenmythus, sondern fast ausschließlich Metapher zur Färbung eines Typus, der so als zur Subjektsphäre gehörend ausgewiesen wird. Der Heldenmythus hingegen ist nicht Bild, sondern Plot-Archetypus. Dieser ist hypothetischer Meßwert als Wirklichkeitsinhalt. Der Held im Plot-Archetypus agiert in einem festgelegten Handlungsszenario, während der Bildarchetypus nicht die Grundstruktur der Handlungsszene bestimmt. So ist bei Böll die formale Wichtigkeit des Bildarchetypus nicht mit der des Heldenmythus zu vergleichen.

Was für Böll gilt, mag für die plot-ausgerichtete Satire im allgemeinen behauptet werden. Sie greift mit Vorliebe zum Heldenkonzept. Denken wir z.B. an Heines Deutschland. Ein Wintermärchen oder Brechts Leben des Galilei. Trotz seiner Popularität ist der Heldenmythus jedoch ein sehr sperriges Fiktionselement. Er ist einerseits attraktiv als Normwert und Spiegel des Satirikers selber, andererseits fragwürdig, da er sich immer wieder falsch realisiert. Was diese Verfälschung betrifft, so hat man in erster Linie an Brechts Bemühungen um den Helden zu denken. Für Brecht ist das Prinzip Held durch seine geschichtliche Prägung und die Geschichtsschreibung weitgehend entwertet. Die Kategorie wird durch die "großen Töter" usurpiert, da man diese immer wieder romantisiert und Größe nach der Fülle des vergossenen Blutes und der Anzahl der Opfer-wie in "Hauptstädtisches Journal" - bestimmt." So eng man heute Brecht mit den Bemühungen um die Klärung des Heldenprinzips verbindet, so ist er nicht der erste Satiriker, der die Usurpation des Helden durch den Bösewicht erkannt hat. Es geht eine direkte Linie von Brecht-anhand der Dreigroschenoper-zu Gay und dessen Heldenparodie in The Beggar's Opera und weiter zu Swift, auf den die Grundidee zu Gays Werk vermutlich zurückgeht. ${ }^{8}$ Schon in A Tale of $a$ Tub, wo Swift wohl am Helden mißt, ist dieser ihm desgleichen durchaus nicht geheuer:

But Heroick Virtue it self hath not been excempt from the Obloquy of Evil Tongues. For it has been objected, that those Antient Heroes, famous for their Combating so many Giants, and Dragons, and Robbers, were in their own Persons a greater 
Nuisance to Mankind, than any of those Monsters they subdued; and therefore, to render their Obligations more Compleat, when all other Vermin were destroy'd, should in Conscience have concluded with the same Justice upon themselves: as Hercules most generously did, and hath upon that Score, procured to himself more Temples and Votaries than the best of his Fellows. ${ }^{9}$

Swift hält die Kategorie zunächst hoch als etwas, das nur böse Zungen lästern können. Aber gerade diese Zungen, zu denen Swift mit vorgehaltener Hand gehört, erkennen die fast zwangsläufige Mauserung des Helden zum Unhold. Die böse Zunge ist die wahre, wie die Heldentugend meistens in Wahrheit ein Laster ist. ${ }^{10}$ Das letztere wird fortan bestimmend für Böll. Kann sich das Heldische nicht realisieren, obwohl es hypothetisch durchaus intakt bleiben mag, so muß es als Meßwert ausfallen.

In "Der Bahnhof von Zimpren," und vor allem in "Keine Träne um Schmeck" und Entfernung von der Truppe stellt Böll neben der Thematisierung der Abkehr vom Heldenmythus auch Gegenkriterien für richtiges, d.h. auf Veränderung zielendes Verhalten auf. So wird, was z.B. landläufig Feigheit wäre, jetzt zu Mut; was man als Beschränktheit zu bezeichnen geneigt wäre, wird zum Wappen. Bölls Bemühungen dieser Art erstrecken sich jedoch nicht auf Ansichten eines Clowns und sind überdies nicht in jedem Falle künstlerisch erfolgreich. Sie haben Verwirrung in der Kritik ausgelöst. Das läßt sich insbesondere über Die verlorene Ehre der Katharina Blum sagen, worauf später eingegangen werden soll.

Eine Möglichkeit der Preisgabe des Heldischen ist die Parodie. Sie entleert aber nicht den Archetypus, sondern dessen entwertete Schematisierung. Machorka-Muff in "Hauptstädtisches Journal" stellt nicht den Held, sondern den Unhold im Heldenrock dar. Den PlotArchetypus des Helden als Herausforderer könnte die Parodie jedoch nur aufheben im Sinne eines fundamentalen Konservatismus. Sie hätte aus der Sicht des Bestehenden hervorzugehen, von wo aus die Forderung des Neuen die Tat eines Usurpators wäre. Dieser Blickwinkel fehlt bei Böll.

In "Der Bahnhof von Zimpren" (1959) verkauft die Bäuerin Klipp ihren Grund und Boden nicht, obwohl man ihr höchste Preise anbietet. Sie glaubt nicht an die Unerschöpflichkeit des Erdöls, das man in Zimpren findet, und aufgrund dessen mit explosiver Schnelle eine Konjuktur am Orte entsteht. Die Standfestigkeit der Klipp ist eine Art Kleben am Grund und Boden. Darin erschöpft sich der Anspruch auf die Subjektsphäre. Das Chthonische an der Figur läßt Böll jedoch 
nicht unverfremdet. Sie ist zwar ein Orakel, aber ihr Spruch "Trauet der Erde nimmer, nimmer trauet ihr, denn einhundertacht Zentimeter tief" paßt nicht zu dieser Erdmutter, einmal, weil Erdmütter der Erde trauen und zum anderen nicht wie Ingenieure mit Meßwerten aufwarten, wo zudem die Bedeutung der hundertundacht Zentimeter völlig im dunklen bleibt. So leistet sie nichts im Sinne eines PlotArchetypus. Fest steht, daß dieses Urbild zum Lachen ist. So ist sie und auch ihr schwachsinniger, ebenfalls unkender Knecht Goswin ihrer Mitwelt eine "stete Quelle der Heiterkeit" (W3, 283). Der Humor stützt diese Figuren, da sie zwar Bedrohte, aber auch Veränderer sind. Wenn das Öl versiegt, gelingt es der Klipp, fast den ganzen, spottbillig gewordenen Grund und Boden im Ort aufzukaufen. Daraus dreht ihr der ihr wohlwollende Satiriker keineswegs einen Strick. Der neue Besitz wird nicht als Bereicherung hingestellt. Es heißt nämlich, daß Flora Klipp keine Kräfte zur Bearbeitung ihrer neuerworbenen Ländereien gewinnen kann. Sie bleibt allein auf ihnen sitzen. Wenn wir ihren Landerwerb als Spekulieren auf Profit und somit als ein Selbst-Kompromittieren zu verstehen suchen, so hilft uns der Text nicht weiter. Nichts deutet z.B. auf einen Bruch im Bewußtsein hin, wie wir ihn an der Sprechern der Ich-Satiren, an Murke in "Doktor Murkes gesammeltes Schweigen" oder auch schon an Franz dem Boxer in "Nicht nur zur Weihnachtszeit" erkennen können.

Böll nimmt sich in "Zimpren" seine konjunkturseligen Landsleute vor. Er gerät dabei m.E. jedoch strukturell gesehen auf Abwege. Statt sich in seiner Analyse auf die Konjunktur zu beschränken, macht er einen zweiten Anlauf und beschreibt deren Folgen, nämlich den zurückbleibenden, im Windschatten des wirtschaftlichen Aufschwungs entstandenen Bürokratismus. Man baut einen großen Bahnhof in Zimpren und unterhält diesen in voller Beamtenbesetzung auch dann noch, als für ihn so gut wie kein Bedarf mehr besteht. Es liegt hierin zwar eine sehr legitime satirische Spitze, nämlich der Hinweis auf das Entstehen eines Verwaltungsapparats, der ein Mumiendasein fristet, nachdem das Innere des Körpers längst vergangen ist. Doch beschreibt Böll im Bezug auf die gemeinte Wirklichkeit nur vorweggenommene Folgen, nicht die Gegenwart der sechziger Jahre. Der Lebensfluß dieser Zeit war zu schnell, nicht versandet. Es entsteht dadurch beim Vergleich der Anstößigkeiten der beiden EtappenKonjunktur und Bürokratismus-leider ein Gefälle, das den Bürokratismus zu völliger Harmlosigkeit reduziert und die Verkehrtheit der vorgeführten Welt stark beeinträchtigt.

Von der für Böll typischen satirischen Technik ist nur wenig vorhanden. Es finden zwar die steigenden und fallenden Grundstückspreise und -aktien Erwähnung-im Sinne der Micromegas-Technik 
komplementiert dieses Wortpaar auch in etwa der wachsende und abnehmende Durchmesser der Ölstrahlen-, aber es handelt sich hier darum keineswegs um ein ausgefeiltes Wortpaar. Es hat keine dialektische Funktion und darüberhinaus keine Beziehung zu dem Textteil, in dem über den Bahnhof referiert wird. Somit läßt sich hier in Bölls satirischer Signatur ein der Abkehr vom ambivalenten Protagonisten gemäßes Vorgehen wie auch wohl abnehmende Konzentration erkennen.

In "Keine Träne um Schmeck" (1962) plagiiert der Großordinarius Schmeck das Dissertationsprojekt seines Assistenten Müller. Darauf beschließen Müller und Marie, seine Geliebte, den Ausbeuter zusammenzuschlagen. Hier leuchtet der Herausforderungstopos so unverfremdet auf wie in noch keinem der vorhergehenden satirischen Texte. Was sich an Gewalttätigkeit anbahnt, ist das Destillat des Heldenmythus in seiner Rohform. Müllers Tat ist berechtigt. Es steht der David gegen den Goliath. Das Vorhaben war sogar ursprünglich, Schmeck umzubringen. Böll bietet jedoch diesen Kern nicht als Normwert an, sondern verhüllt ihn schrittweise, um ihn so von aller mißverständlichen und falschen Aggressivität hinweg zu verfremden. Er folgt dabei in großen Zügen der von Freud skizzierten Linie der sozialisierten menschlichen Aggression vom Physischen zum Verbalen. An die Stelle des Primitiv-Kämpfers Müller tritt der Magier, der seinen Widerpart mit seinen Augen "auslöscht." Dem Magier folgt der haßerfüllte Kritiker, der eine "kritische Würdigung" $\left(W_{4}, 64\right)$ an Schmecks Werk vornehmen wird. Böll beginnt demnach mit dem Plot-Archetypus in Urform. Statt es jedoch bei dessen Ablauf bewenden zu lassen, verwandelt er ihn zivilisatorisch, so daß am Ende eine vom Heldenmythus verfremdete Aggressionsperspektive, Müllers Schreiben gegen Schmeck, übrigbleibt. Der Plot-Archetypus des Helden verliert sich damit. In den Vordergrund tritt der Provokateur und dessen Zweck, Schmeck im geistigen Raum zu schädigen. Es entfällt zwangsläufig auch die hohe Norm. So kann Müller durchaus leisten, was er sich vornimmt, nämlich eine Kritik des Schmeckschen Werkes. Er wird nicht zum Versager, sondern zum Vir bonus.

Die Abkehr vom "Murke"-Muster erhellt sich besonders daran, daß "Schmeck" unverkennbar ein Pendant zu "Doktor Murkes gesammeltes Schweigen" ist. Es lassen sich weitgehende Entsprechungen an den Personen feststellen. Wichtig sind aber vor allem die Unterschiede. Müller wird Schritt für Schritt in die Subjektsphäre gerückt, während Murke den umgekehrten Weg zu gehen hat. Zunächst ist das bildlich der Fall, wenn Müller im Sinne einer Befreiung die Stufen am Universitätsportal hinuntergeht, nachdem er sich in seiner Enttäuschung über seinen Chef erbrochen hat. Murke geht die 
Erfolgsleiter hoch im Sinne einer Verstrickung. Müller ist um seine Mutter besorgt; er redet aufs eingehendste mit seiner Freundin. Wo Murke eine Beherrschungstaktik gegen Rina anwendet, massiert Müller seiner Freundin die Füße.

Eine sehr wichtige Parallele liegt in dem Haß, den sie gegen ihre Widersacher hegen. Murke sozialisiert diesen falsch, Müller hingegen richtig, wenn er seinen Haß nicht auf die Person richtet. Haß kann darum "gute Tinte" (66) sein, wie Müller erkennt. Hier eröffnet sich eine freie Sicht sozialer Aggression. Sie ist mehr als nur lebenspendende Energie, die sich bislang in Bölls Herausforderern leider in der Verwirklichung immer wieder entwertete, sondern sie ist auch als destruktive Energie wertvoll, sofern sie defensiv ist und sich gegen eine empörende Idee richtet, wie Müller diese zweifellos in Schmecks Werk aufweisen kann. Der Protagonist als Vir bonus ist eine neue Erscheinung in der Satire Bölls. Als Normträger ist sein Haß sozial richtig. Der rechte Lebensfluß kann nun Haß als Mittel zur Klarstellung der Fronten und zur Zersetzung empörender Ideen aufnehmen.

Vornehmlich meint der Lebensfluß aber auch in diesem Text die Liebe. Sie vermag es, vermittelbare Gegensätze zu überbrücken, besonders als Sprache. In den "Frankfurter Vorlesungen" räumt ihr Böll diese Funktion ein: "Ich gehe von der Voraussetzung aus, daß Sprache, Liebe, Gebundenheit den Menschen zum Menschen machen, daß sie den Menschen zu sich selbst, zu anderen, zu Gott in Beziehung setzen" (ESR2, 37). Diese Gebundenheit besteht zwischen Müller und Marie trotz scharfer herkunftbedingter Spannungen. Marie ist Baronin, hat ihrer Klasse zwar den Rücken gekehrt, verfängt sich aber immer wieder in Denkweisen nackter Aggressivität. Geistige Waffen lehnt sie ab, da sie bezweifelt, daß es sie je gegeben hat. Müller, das Arbeiterkind, glaubt hingegen an Waffen dieser Art, obwohl auch er nicht frei ist von den negativen Stereotypen seiner Gesellschaft. So denkt er in Geschlechterrollen, nennt Marie seine "Gehilfin" (66), stürmt zu seiner Freundin als ginge es um eine Eroberung und ist sogar noch gerührt über die Heftigkeit seiner Gefühle.

Die zentralen Wörter in diesem Text sind Haß und Liebe. Das erstere meint "gute," das letztere die "schlechteste Tinte" (66) im Vorhaben Müllers, seinen Widerpart kritisch zu entlarven. Der Haß ist legitimer und rechter Impuls für Kritik, die Liebe hingegen entschärft diese, wäre ungemäß wie etwa die "Träne um Schmeck." Die Liebe beschränkt sich auf die Subjektsphäre, innerhalb dieser hat sie dialektische Funktion, jedoch nicht in Bezug auf die Objektsphäre. So vermittelt Bölls abgewandelte Signatur die Fronten nicht mehr, sondern bemüht sich ausschließlich, diese klarzustellen.

Eingangs mutet "Schmeck" sehr satirisch an, da Böll energisch in 
der Blähung Schmecks von Micromegas Gebrauch macht. Allerdings verschwindet dieser Unhold auf lange Strecken von der Bühne und mit ihm auch Micromegas. Die Thematisierung der Abkehr vom alten Satiremuster des Heldischen und auch die Darstellung der Gebundenheit Maries und Müllers in Liebe und Sprache werden derart wichtige Anliegen, daß der satirische Ton sich weitgehend verflüchtigt.

Im Zeitraum Dezember 1962 bis September 1963 veröffentlichte Böll in der Zeit neunzehn fingierte "Briefe aus dem Rheinland." Sie richten sich an einen "Freund" und sind mit dem Namen "Lohengrin" signiert. Im Zeitraum Dezember 1963 bis Juli 1964 wiederholt Böll im Prinzip die Übung. Diesmal sind es sieben "Briefe an einen Freund jenseits der Grenzen;" der Absender ist "Loki." Die Briefgruppen bilden unverkennbar je eine Einheit und sind ebenso unverkennbar satirisch im Ton. Die Absender berichten über ihr gegenwärtiges Leben. Die Geschehnisse meinen nicht unerhörte, mythisierte Begebenheiten und schon gar nicht Entscheidungsmomente. Zwar wäre zu diesen durchaus Anlaß. Eine Familie wird aufgegeben, Stellungen gehen verloren. Aber diese Dinge sind nicht an sich wichtig, sondern nur als Ansatz zu gesellschaftskritischen Kommentaren der spottgeladenen Sprecher. Die Briefe sind eine Art Füllhorn satirischer Früchte, ein Gemengsel von Witz, Humor und Bosheit mischenden Einfällen, so daß hier etwa der Terminus "Satura" angebracht wäre im Sinne der römischen Satire als "Vermischtes." Vermischt sind auch Fiktionales und Reales. Als das erstere erscheint die vordergründige Handlung, die in ihrer lockeren Zusammensetzung sich jedoch nicht mehr als Plot bezeichnen läßt, als das letztere die satirisch verzeichneten, faktisch-existierenden Gegenstände, die aber wiederum in einem karikierend-phantastischen Spiegel stehen.

Lohengrin ist zunächst Dorfschullehrer, der sein Amt verliert und seine Familie verläßt; er wird Halbtagsimker bei Nonnen, ergibt sich dem Trunk, verliert wieder die Stellung und beschließt seine Briefserie als Hilfssakristan. Loki ist DDR-Flüchtling, Zoologie-Student, Background-Informant für die versnobten Kunden einer Pelzwarenhandlung, Hundebetreuer bei einer versnobten Dame, Züchter und Trainer von Hausfliegen als leicht mitnehmbaren Reisebegleitern, Nutznießer einer Steuerhinterziehung und eifriger Student der Hyäne, über die er zu promovieren gedenkt. Diese an sich schon höchst skurrilen und holprigen Lebensläufe verschwinden jedoch fast hinter den Kaskaden brillanter Glossen über die Tagesereignisse und die darin auftretenden Zeitgenossen. Die Stöße erfolgen mit atemberaubender Schnelle, z.B. gegen das Christentum im Rheinland, die CDU, die rheinische Künstlerschaft, die Literaturkritik, die Intellektuellen, die Presse, den Kapitalismus, die alten Nazis in wich- 
tigen Stellungen, Spitzelei, die Deutschen als Touristen, den Geschmackskult, die SPD, den Proporz, die Spießbürger, die Snobs, die Nationalisten, den Konsum. Neu ist das gepfropft volle Panoptikum der mit Namen genannten Personen. Zum ersten Mal schreibt Böll hier eine Art Personalsatire. Unter negativen Vorzeichen erscheinen u.a. Adenauer, Barzel, Franz-Joseph Strauß, Hindenburg und Wilhelm Busch, dazu die Kritiker Krämer-Badoni und Marcel (ReichRanicki).

Lohengrin greift Adenauer als einen Sprecher von Nichtigkeiten und Praktikanten schlechter Rhetorik an:

Was mich betrifft, so arbeite ich fleißig an meiner Studie über den inneren Monolog in der Politik. Stell Dir vor, der Bundestagspräsident würde ankündigen: "Es folgt nun der innere Monolog des Bundeskanzlers."

K.A. würde aufs Podium gehen, etwa fünfundzwanzig Minuten schweigend im inneren Monolog verharren, anschließend würde der Bundestagspräsident fünf Minuten für inneres Buh und inneren Beifall freigeben (ESR1, 485).

Lohengrin ist Mitarbeiter an einem von Papen-Drama: "Das Stück soll ein Drei-Personen-Stück werden: von Papen und die beiden Hindenburgs, das Vokabularium des abendfüllenden Dramas soll auf fünfundachtzig Worte beschränkt werden ..." (497). Barzel wird morphologisch zum Super-Streber aufgebaut und zerstückelt:

Man bezeichnet diesen jungen Mann als "aufstrebend", aber ich weiß nicht recht, ob man nicht hier das Partizipium Präsens durch das des Perfekts ersetzen sollte: aufgestrebt.

Das Verbum streben hat so viele Zweige: Im Bergbau kennt man den Streb, in Schule und Berufsleben den Streber, es gibt das Adjektiv strebsam (das einer meiner Schüler übrigens einmal auf eine hübsche Weise irrend in "strebig" verwandelte), es gibt das häßliche Substantiv Streberei, gibt das Strebertum, schließlich gibt es Verstrebungen, und ob dieser junge Mann sich nicht eigentlich ver-strebt hat, wird die rasch ablaufende Geschichte zeigen" (487).

Besonders die Lohengrin-Briefe sind voll von Einfällen dieser Art. Trotzdem sind die Loki-Briefe gewichtiger. Böll entwickelt hier eine Klammerperspektive, in der sich die verschiedenen satirischen $\mathrm{Ob}$ jekte bündeln, und zwar im Sinne eines Prinzips, das ihnen einen unverkennbaren Gegenwartsstellenwert vermittelt. Wo in dem Lohengrinzyklus ein Feuerwerk das Aktuelle schlagartig aber kurz 
beleuchtet, dringt Böll in den Loki-Briefen weiter zur Wirklichkeit vor, die, wie er in dem Aufsatz "Der Zeitgenosse und die Wirklichkeit" anführt, "immer ein wenig weiter als das Aktuelle" (ESR1, 73) liegt. Diese Wirklichkeit ist gekennzeichnet durch das Prinzip der Austauschbarkeit der Person und der Sache als Ware. Wenn Loki im Pelzgeschäft aufgetragen wird, den Kunden 'tüchtig 'background' 'rein [zupfeffern]," so erfährt man, daß der Mensch auf groteske Weise Teil der Ware wird: "Die Händler wissen zu berichten, daß pro Fell das Leben von eineinhalb tibetanischen Hirten zu beklagen sei" (ESR1, 571-72). Es werden also hier Tier und Mensch ausgebeutet, wobei die Ausbeuter sich als Pelz-Träger vertieren und andererseits Tiere behandelt werden, als seien sie Menschen. Der Hund bekommt aufwendige Menschenkost, der Mensch ißt Hundefutter und findet den Geschmack "raffiniert" (586). Verkauf und Konsum werden durch das Herrschaftsprinzip organisiert. Der Herr des von Loki betreuten Hundes, den Loki "unser 'Herrchen'" nennt, ist von Beruf Verkäufer und "Vertreter jener Herrenrasse, die hier wie das Fett oben schwimmt." Was er verkauft, sind Dinge, deren Sinn darin besteht, "die Mülleimer hier noch mehr zu verstopfen." Zum Müll gehören dem "Herrchen" nicht nur der kranke Hund, sondern auch seine "Alte," die er "loswerden" (577) will. Die Austauschbarkeit gilt der Gesellschaft als Stärke und Einheit. Loki ironisiert dies und, konsequenterweise, sich selber: "Du siehst: ich bin völlig angepaßt. Ich bilde jene Einheit, auf der die Vorherrschaft der westlichen Welt beruht, die Einheit von Wissenschaft und Industrie, von Forschung und Konsum" (586). Leider hält Böll dieses Strukturprinzip gegen Ende des Loki-Zyklus nur lässig durch. Das Aktuelle beginnt zu überwiegen.

Der Satiriker mag in den Lohengrin-Briefen nicht so weit zum Wirklichen vorstoßen wie im Loki-Zyklus; wie aber die angeführten Beispiele des inneren Monologs Adenauers und die Streb-Phänomenologie Barzels verdeutlichen, wird das Aktuelle selbst hier weitgehend komisch verfremdet. Das wird weiterhin durch einen biedermeierisch-archaisierenden Sprach-Gestus erreicht. Da wird vom Schreiber die Frage gestellt, "warum betreibst Du auch ein so selbstmörderisch Werk" (490), da hören wir "ein vieltönig Brausen, das da über Land geht" (507). Es herrscht eine Vorliebe für Genitivwendungen. Man befleißigt sich "eines Minimums an Ehrlichkeit" (485), da ist man "des Hamburger Magazins . . . beraubt" (523). Die Schreiber scheinen die Bibel und den Erbauungskalender jederzeit zur Hand zu haben: Man fordert den Adressaten auf, "auf dem Pfad der Gerechtigkeit zu wandeln" oder verordnet "Geh in Dich und sage mir, wo Dein Herz ist" (485); weise verrät man uns: "Gar mancher 
Fromme ist schon gestolpert" (487); da läßt sich "den Menschen nicht ins Herz schauen" (501), und man soll "die Perlen nicht vor die Säue werfen" (517). Es wird mit Klischees großer Aufwand getrieben, wie der "heimlichen Liebe" (485) und dem "lieblich murmelnden Bach" (517).

Die Technik der Verzerrung des Objekts im Tiervergleich ist als die wichtigste neben der in der Komik zu bezeichnen. Böll wendet sie allerdings nur im zweiten Zyklus ausführlich an. Sie gipfelt in den Fliegen "Wie" und "Was," die Loki als Reisebegleiter für eine Freundin seiner versnobten Arbeitgeberin betreut. Im Fliegen-Einfall liegt ein besonders wirkungsvolles Indiz gegen Lokis Arbeitgeber. "Wie" und "Was" meinen die Reduktion aufs Insektenhafte in diesen Menschen; "Was" sind sie anders als Tiere? "Wie" leben sie anders als Parasiten? Die Tierperspektivität ist hier eine besonders gelungene Technik, weil das Prinzip der Verdinglichung des Menschen zur Ware sie komplementiert.

Im ersten Lohengrin-Brief, dem wohl gewichtigsten dieser Serie, greift Böll zu Micromegas, um Adenauer zu verunglimpfen. Im Gegensatz zum "Murke"-Muster ist festzuhalten, daß der Sprecher hier bewußten Anteil an dieser Technik hat. Blähung und Schrumpfung stammen aus seinem Munde. Zunächst verfremdet er Adenauer, indem er ihn neben Marx stellt, der auch ein rheinischer Denker sei. Dabei schon wird das erwartungsgemäße Vorstellungsverhältnis des bundesdeutschen Lesers verunsichert, der gewohnt ist, Adenauer als über Marx gestellt zu sehen. Der Sprecher erläutert dann das Wort Denker. Marx war "Dialektiker," Adenauer spricht "Dialekt" (484). Hier schießt Marxs Wert in die Höhe, Adenauers wird gemindert. Dasselbe Schicksal trifft Krämer-Badoni, einen Böll nicht geneigten Kritiker. Er wird unter dem gemeinsamen Nenner des Provinzialismus Goethe an die Seite gestellt und dadurch lächerlich klein. Dem reduzierten Adenauer werden wiederum die Proportionen eines Atlas gegeben, der die Börsenkurse auf den Schultern trägt. Schwankt Adenauer, so auch die Kurse, "ist er fest, bleiben diese fest; wird er noch fester, steigen dieselben." Es heißt weiter: "Nach dem Prinzip der einfachen Umkehrung kann ich nun aus den Aktienkursen ersehen, wie es K. A. jeweils gut geht" (484).

Wo es in den Lohengrin- und Loki-Zyklen vornehmlich um das Experiment mit der Frage zu gehen scheint, wie weitgehend die Satire Aktuelles aufnehmen kann, ehe sie ihren literarischen Charakter verliert, so stehen diese Texte nichtsdestoweniger noch in einem wichtigen Zusammenhang mit Bölls satirischer Praxis der fünfziger Jahre. Er will andeuten, was er in den Kurzsatiren hinter sich gelassen hat, nämlich den Heldenmythus. So erklären sich die seltsamen Brief- 
zeichner Lohengrin und Loki. In der Lohengrin-Signatur spielt Böll auf den Kern der Lohengrin-Sage an, nämlich den Helden, der in Frage gestellt wird und infolgedessen verschwindet. Der LohengrinVerweis spiegelt sich hier nicht etwa als Plot-Archetypus und Wirklichkeitsinhalt im Text. Dem Sprecher ergeht es nicht wie Lohengrin. Er verschwindet unter Druck, nicht aus freien Stücken, ist nicht Held, sondern Wegläufer, der allerdings weiter "kampfbereit" (496) ist und durchaus nicht versagt. Der Lohengrin-Verweis ist somit auf das Thematisieren der Abkehr vom Helden gerichtet, ist also BildArchetypus, dazu als solcher verfremdet zum ausdrücklichen Kunstmittel, das nicht vom Leser unbewußt aufgenommen werden kann, sondern erkannt werden muß. ${ }^{11}$

Ist Lohengrin der verschwindende Held, so zeichnet Loki als der Nachfolger des Helden. Er ist, so geben die Lexika an, der Schelm, der Typ des listenreichen Spaßmachers; er ist der Einbrecher in die Versammlung der Götter, wo er kräftig schimpft und schmäht, ist Anführer der Kräfte, die den Untergang der Götter herbeiführen. Loki ist der Urzersetzer, und Zersetzen ist die Norm des Loki- wie auch des Lohengrin-Zyklus. So klagt Loki: "[W]er nachdenkt, gilt hier schon als Intellektueller, und wer gar gewisse Schlüsse aus seinen Gedanken zieht, hat jede Chance, als zersetzender Intellektueller den Unwillen von Kirche und Staat zu erregen" (572). Staat und Kirche werden in einem Atem genannt, da sie wie alles in diesem Text unter die Rubrik Austauschbarkeit fallen. Der Sinn des Zersetzens liegt darin, sie zu trennen, "Spalten im Fels des Bestehenden" zu erzeugen. Eine ambivalente Figur wäre der zersetzende Schelm, wenn der Leser fälschlich eine hohe Norm von außerhalb des Textes an ihn herantrüge. Da der Schelm jedoch im Bereich der niederen Norm agiert, ist die Entfernung zwischen Potenz und Leistung, zwischen Erwartung und Erfüllung gering. Wenn Lohengrin und Loki den Vir bonus markieren, so ist das keine Maske, die sich vom wahren Gesicht gegenteilig unterscheidet. An der Erfahrungswelt gemessen vollbringen die Sprecher an Zersetzung ungefähr das, was sich erwarten läßt. Außerdem ist im Gegensatz zum Gewohnten Selbstironie bei diesen Sprechern im Spiel. Dadurch werden sie weitgehend immun gegen eine Verurteilung durch den Leser, obwohl sie sich akkommodieren. Wenn somit Loki betont, "ganz und gar mit dem Leben hier verschmolzen" (575) zu sein, so loben wir seine Offenheit angesichts unserer Erkenntnis, daß er Sand im Getriebe darstellt. Wie der Held des früheren Satiremusters einen Protest erheben muß, bei dem er zwangsläufig versagt, so geht dagegen der Schelm einfach zu weit. Das ist das Maß der Zersetzung als sozialer Beitrag. Der "geistliche Freund" Lohengrins bestätigt diesem: "Manche Leute gehen wirklich zu weit. Aber man 
muß sehr weit gehen, um herauszufinden, wie weit man gehen kann" (530). Das Zersetzen ist somit eine Dehnung des Erlaubten, eine Überbeanspruchung der Sozialstruktur im Kleinen, forcierte Evolution, der Einsichtslosigkeit der Mehrheit zum Trotz. Es ist Auflösungstaktik, die vom Objekt als unerwünscht und sogar gefährlich, jedoch nicht als fundamentale Herausforderung begriffen wird. Das Zersetzen bedeutet darum ein tragbares Risiko für seinen Vertreter. 


\section{Ausblick auf die satirischen Langformen}

Es ist sicherlich nicht abwegig zu vermuten, daß eine der Ursachen für Bölls weitgehende Preisgabe der Kurzprosa ein sehr persönliches Element ist, nämlich der Zwang, sich zu überbieten. Damit hat Böll sich schon 1956 in dem Aufsatz "Das Risiko des Schreibens" beschäftigt:

So wie für den fortgeschrittenen Bankräuber, den fortgeschrittenen Boxer jeder neue Einbruch, jeder neue Kampf bitterer und gefährlicher wird als der vorhergehende--denn die Unschuld ist nun einmal verloren und an ihre Stelle das Wissen gerückt-, so müßte es für den Schriftsteller sein, und ich bin sicher: für viele ist es so, obwohl der Meisterbrief mit dem Siegel der Innung in ihrer Bibliothek hängt" (ESR1, 205).

Der auf der Hand liegende Anlaß zum Abschluß des alten Musters ist "Der Wegwerfer." Selbstüberbietung nach dieser, seinem eigenen Erachten nach besten Geschichte dürfte Böll als unwahrscheinlich erschienen sein. In diesem Sinne sind "Der Bahnhof von Zimpren" und "Keine Träne um Schmeck" als Bemühungen des Autors zu begreifen, gegen den gewohnten Strich zu schreiben und überdies einen Einstieg in die satirischen Langformen zu finden, die mit $\mathrm{An}$ sichten eines Clowns (1963) beginnen.

Wichtiger jedoch als all dies ist der Gedanke der Veränderbarkeit der Welt, der in Bölls Werken der sechziger Jahre zunehmend ins Auge fällt. Die Überzeugung, daß eine Umformung der Gesellschaft möglich ist, reflektiert das politische und soziale Klima der Zeit unter den Intellektuellen. Klaus Jeziorkowski verweist auf die Frankfurter Schule als ausschlaggebend für die Wendung der Zeit von existentialistischen Denkschemata $\mathrm{zu}$ zeitkritischen Positionen und bestimmt Theodor W. Adornos Jargon der Eigentlichkeit (1964) als das die neuen Vorstellungen popularisierende Werk. ${ }^{1}$ Diese Vorstellungen zielen nicht auf grandiose Systeme oder den großen Umbruch, sondern auf die Praxis und Taktik der kleinen Schritte. Es geht darum, im sozialen Bau Risse und Sprünge zu erwirken oder diese zu erweitern. Wenige sind im Grunde an Dynamit interessiert oder halten es für anwendbar.

Die Prämisse einer Umformung der Gesellschaft schlägt sich in 
Bölls satirischen Langformen skizzenhaft umrissen wie folgt nieder: Sie zeigen Abkehr von einem Ästhetisieren, das dem Publikum dahingehend mißverständlich sein könnte, daß es den Text als fiktionale Wirklichkeit sui generis aufnimmt und gewissermaßen als Genußware abtut, anstatt den im Werk vorgestellten Protest nachzuvollziehen. Gegen eine auf diese Weise angeeignete Kunst wendet sich Böll scharf in "Die Freiheit der Kunst" (1966) und wirft dabei die Technik der Verfremdung als Gegenmittel auf. Es heißt, daß Kunst nur frei sein kann,

wenn das von ihr erst geordnete und geformte (was gleichbedeutend ist mit: erst in Unordnung gebrachte und deformierte) Material erkannt wird; ja, geordnet und geformt, in Unordnung gebracht oder deformiert-nicht eingeordnet und formiert. Das ist es, was die Gesellschaft mit ihr unternimmt: einordnen, formieren in die Marschordnungen der freien Marktwirtschaft hinein-die Freiheit zu Freiheiten zerstückeln" (ESR2, 228).

Dementsprechend versucht Böll in seinen späteren satirischen Texten, die veränderbare Wirklichkeit mit einem eindrücklichen Appellcharakter zu spiegeln. Er bemüht sich, durch Darstellung aktueller Ereignisse die Distanz zwischen Werkwelt und Wirklichkeit zu verringern und somit den Publikumskreis auszudehnen und diesen so anzusprechen, daß der Leser sich als Mitwirkender an der Werkstruktur begreift. Bölls Kurzsatiren des "Murke"-Musters kommen dem aufgrund besonders ihres plot-archetypischen Kerns nicht entgegen. Der Heldenmythus mag nicht als wirklichkeitsbezogen, sondern als nur im Werk geltend aufgenommen werden. Für Johann N. Schmidt geht das Problem noch weiter. Selbst die Technik der Verfremdung, die gerade der Fehlrezeption vorbeugen soll, mag kulinarisch begriffen werden:

Anzumerken bleibt . . . daß die ästhetische Verfremdung sich selbst widersprüchlich wurde, sobald sie, statt aufzudecken, in die Kunst nur mehr als attraktive Metapher einging. . . . Hieraus mag sich die Zuwendung moderner (vor allem politischer) Satiriker zur semidokumentarischen Verfahrensweise erklären, die eine Abwehr gegen die Vereinnahmung durch rein künstlerische Maßstäbe darstellt. ${ }^{2}$

Der Proteus Satire ist unter diesen Aspekten ganz besonders im Rahmen der Kurzprosa, selbst der realistisch geprägten, fragwürdig, da dieser Rahmen besonders im deutschen Sprachraum durch die Traditionen der Novelle, auf die Böll hinweist, ${ }^{3}$ weitgehend als Kunst vorbestimmt ist. Der realistische Roman hingegen, der als Satire ipso 
facto einen hohen Grad des Aktuellen hat, bietet durch seine Wirklichkeitsfülle, seine epische Breite im Gegensatz zur Konzentration, wie sie eine novellistisch geprägte Kurzprosa verlangt, durch seine Aufsaugfähigkeit heterogenen Materials erweiterte Möglichkeiten. Er kann z.B. Dokumentarisches zwangloser als die Kurzprosa aufnehmen, die ähnlich de-ästhetisiert sehr leicht zum Bericht oder Essay werden könnte. Hinzu kommt, daß Böll sich ganz besonders in seinen längeren Erzählungen einer Art von Realismus verschreibt, die "zur Identifikation einlädt," wie Rainer Nägele sagt, da Bölls Welt "wie . . . alltäglich perzipiert wird." ${ }^{4}$ Auch die Romanform selber ist rezeptionsfreundlicher als die der Kurzprosa. Im Gegensatz zum 18. Jahrhundert, wo etwa die Satire als Kleinform durch deren Übernahme in den Roman diesem zu Ansehen verhalf, ${ }^{5}$ genießt der Roman heute das größte Prestige unter den Formen und findet darum überdies $\mathrm{Zu}$ gang zu breiteren Leserschichten als die Kurzformen. Die wichtigere Größe ist der Roman auch für die Kritiker. Man vergleiche z.B. in den Monographien zu Bölls Werk den Raum, den Ende einer Dienstfahrt mit dem, den "Der Wegwerfer" beansprucht. Obwohl es sich im letzteren Falle um eine sehr gelungene Arbeit, im ersteren um einen allgemein als verhältnismäßig schwach bezeichneten Text handelt, findet sich zu Ende einer Dienstfahrt sicherlich das Zehnfache an Gesagtem.

Die Roman-Satire Ansichten eines Clowns (1963) kommt allerdings Bölls dokumentaristisch-appellativem Konzept noch keineswegs voll entgegen. Das hauptsächlich, weil Böll auf den Plot-Archetypus des Helden zurückgreift. Böll definiert ihn selber, sogar als Mythologem. Als die Zeitschrift Labyrinth, zu deren Herausgebern Böll gehörte, eingestellt werden mußte, entschlossen sich diese zu Erklärungen für das Scheitern. Böll gab seine in Form einer Interpretation der Theseus-Sage: "[D]iese Interpretation war der Plot für den Roman. Es ist eigentlich die Geschichte von Theseus und Ariadne: Theseus im Labyrinth, Ariadne schneidet den Faden ab und da sitzt er da. Und das Labyrinth, und das kann ich in dem Fall wirklich sagen, weil ich den Zusammenhang, den Kontext kenne, ist der politische deutsche Katholizismus" (I, 159). Geht Böll in seinem Wunsch, in Clown das Theseus-Mythologem erkannt zu sehen, möglicherweise zu weit, so ist der Plot-Archetypus des Helden unverkennbar. Daß Böll ihn verwendet, ist an sich erstaunlich in Hinsicht auf die aufwendige Abkehr vom Heldenmythus in den Kurzsatiren. Aber es ist nicht zu vergessen, daß der Heldenarchetypus Jahre hindurch Kern des Satiremusters Bölls war. Ungeachtet der möglichen Quellen zur Fehlrezeption der Kurzsatiren der fünfziger Jahre zeugen diese von großem Können, wie man Böll immer wieder bestätigt hat. So ist begreiflich, daß er den Strukturkern seiner Glanzleistungen in Clown übernimmt, 
besonders da eine so namhafte Stimme wie Hans Magnus Enzensberger ihn in einer Rezension der Kurzsatiren um "Doktor Murkes gesammeltes Schweigen" dazu aufzufordern scheint. ${ }^{6}$ Indem Böll, der sich wie jeder Schriftsteller gern bestätigt sieht, ${ }^{7}$ den auf Lob fußenden Forderungen Enzensbergers nachkommt, schreibt er jedoch keine simple Dehnungsversion seiner Kurzsatiren. Clown enthält zwar Phantastisches, wie Schniers Fähigkeit, über das Telefon Gerüche wahrzunehmen, ist aber unvergleichlich realistischer als die Kurzsatiren. Der Fiktionalitätsgrad liegt sehr viel tiefer. ${ }^{8}$ Wenn die Sprecher der Kurzsatiren erzählen, so lesen sie gewissermaßen vom Blatt, Hans Schnier hingegen spricht nicht mit Distanz, sondern mit hoher emotionaler Direktheit. Wichtig ist vor allem der starke Aggressivitätsgehalt dieses Textes. Er zwingt den Leser, den Plot-Archetypus, der sich in den intensiv strukturierten Kurzsatiren möglicherweise als Kunstinhalt abtun läßt, hier als Wirklichkeitsinhalt anzuerkennen. Das gelang vielleicht allzusehr. Ein beachtlicher Teil der Kritik unterscheidet nicht einmal zwischen dem Sprecher und dem Autor und kreidet alles vom Protagonisten Schnier Verlautbarte kurzerhand Böll an. ${ }^{9}$

Schnier ist Außenseiter, der in einen antagonistischen Raum eindringt. Er gehört einer protestantischen Familie an, ist erklärter Ungläubiger, in seinem Milieu somit Einzelgänger, entreißt aber die Katholikin Marie dem Kreis um Sommerwild, Kinkel und Züpfner, der für einen verdorrten Katholizismus steht. Schnier schaltet in seiner Brautnahme auch einen Nebenbuhler in Züpfner aus. Das MythusMuster erscheint in verschiedener Form. Zunächst einmal trägt die Gewinnung Maries unverkennbare archetypische Züge. Man darf eigentlich nicht von Vergewaltigung und Verführung, sondern muß von der Selbstverständlichkeit eines Urvorgangs sprechen. Wenn sich Schnier wie hier nicht asozial, aber außerhalb jeder Konventionalität bewegt, liegt als deren Gegensatz das Archetypische besonders nahe. Es heißt:

Ich war einundzwanzig, sie neunzehn, als ich eines Abends einfach auf ihr Zimmer ging, um mit ihr die Sachen zu tun, die Mann und Frau miteinander tun. . . . als ich reinging, steckte oben Marie den Kopf in den Flur und rief "Hallo, ist da jemand?"- "Ja", rief ich, "ich bin's" - ich rannte die Treppe hinauf, und sie sah mich erstaunt an, als ich sie, ohne sie anzurühren, langsam in ihr Zimmer zurückdrängte. Wir hatten nicht viel miteinander gesprochen, uns immer nur angesehen und angelächelt, und ich wußte auch bei ihr nicht, ob ich du oder Sie sagen sollte. . . . sie hatte gewußt, daß ich kommen würde, 
jedenfalls war sie nicht vollkommen überrascht $\left(\mathrm{W}_{4}, 91\right.$, 94-95).

Böll stellt in der Eroberung Schnier in den Mittelpunkt eines mythopoeischen Assoziationsfeldes, in dem das Muster Held, Braut und Nebenbuhler greifbar wird. Besonders ausdrücklich wird dies im Verweis auf die Nibelungensage und deren Dreigespann Siegfried, Brunhilde und Gunther $(96,149,228)$. Schnier gewinnt Marie, verliert sie jedoch an Züpfner. Er erklärt sich wiederholt bereit zum Kampf und hat Angst weder vor dessen geistiger wie körperlicher Form. Der Kampf gilt einem durchaus nicht alltäglichen Feind. Einige Mitglieder des Kreises um Sommerwild gehören zur Spitze des deutschen Katholizismus, Schnier bezeichnet Marie nach ihrer Heirat als dessen "first lady" (241). Schnier weiß, daß es für ihn als Clown nur die Alternative "Gosse oder Schloß" (71) als Zukunft gibt. So ist er im archetypischen Substrat des Textes der potentielle junge König, Marie die Königsbraut, der gute Papst der alte König, der auch gleichzeitig in Schniers Vorstellung als der Schatz fungiert, den die falschen Katholiken hüten (169). Züpfner und Marie haben Privataudienz beim Papst, der, so vermutet Schnier, nicht erkennt, daß Marie mit einem unrechtmäßigen Mann vor ihm steht. So träumt Schnier davon, den Papst über die falschen Katholiken aufzuklären. In diesem Wunschbild schlägt sich Schniers hypothetische Rolle als Herausforderer nieder. Er ist aber Pfuscher und Versager. Das erstere ist er schon als der schlechte Clown, nachdem Marie ihn verläßt, und auch innerhalb des Mythus-Schemas. Die Gewinnung der Jungfrau ist verkehrt. Sie hätte Preis des geleisteten Kampfes zu sein. Jedoch tritt Schnier erst dazu an, nachdem sie seine Geliebte geworden ist. Diese Verkehrung läßt sich auch als mangelndes Zeitgefühl, als Form der "Takt"-losigkeit sehen. Schnier ist trotz aller Aggressivität ein ungenauer, den rechten Augenblick versäumender Kämpfer. Die Assoziation zu Siegfried weicht der zum Ritter, der sich, dem höfischen Topos gerecht, "verliget." Schnier verbringt sehr viel Zeit im Bett, die Sache, wie er formuliert, tuend oder an sie denkend. Das wird so zwanghaft, daß er sich in die Badewanne legt, um Marie selbst bei der Toilette zusehen zu können. Schon sofort nach der Eroberung heißt es: "Ich wäre am liebsten hier geblieben und hätte [im Laden von Maries Vater-E.F.] bis an mein Lebensende Bonbons und Sütterlinhefte verkauft, mich abends mit Marie oben ins Bett gelegt und bei ihr geschlafen, richtig geschlafen bei ihr..." (103). Er macht seinen Schläfertraum auch weitgehend wahr. Im ersten Jahr bleibt er zum Ärgernis seiner Wirtin jeden Morgen mit Marie bis zehn oder elf im Bett. Wenn Schnier sich entschließt, seine Versäumnisse nach- 
zuholen, ist es zu spät. Er hat Marie an den Kreis und an Züpfner verloren. Er will sie jedoch dem Zug abtrotzen, mit dem sie von der Hochzeitsreise aus Rom kommt. Hier finden sich Anklänge an die frühe Geschichte "An der Angel," wo der Zug unverkennbar ein schnaubender Drache ist, dem der Protagonist die Jungfrau entreißen will. Schnier selber versteht, daß ihm zum Herausforderer das richtige Zeitgefühl fehlt. Er entläßt seinen schwerreichen Vater aus der Wohnung, ohne diesen zu bewegen, ihm das dringend benötigte Geld zu geben. Er bezeichnet sich deswegen als dumm: "Im entscheidenden Augenblick... hätte ich sagen müssen: 'Raus mit dem Geld' oder 'Her mit dem Geld'. Im entscheidenden Augenblick geht es immer primitiv zu, barbarisch" (205).

Wichtiger als der Narr Schnier ist der ernste Versager. Auch dieser ist als der sich verliegende Kämpfer zu umreißen, der in jetzt streng christlicher Perspektive gesehen durch Kampf Gottes Werk tun sollte. Schniers Seinsgrund ist jedoch Marie, der er sexuell derart verfallen ist, daß sie ihm eher Venus als Maria zu sein scheint. Zwanghaft denkt er an "die Sache," und zwar ausschließlich in Verbindung mit Marie. Er bezeichnet diese als seine "Seele," die er "verloren" habe und "wiederhaben will" (185). Auch sein Kämpfen geht letztlich um Marie: "Ich wollte Marie zurückhaben und hatte angefangen zu kämpfen, auf meine Weise, nur um der Sache willen, die in ihren Büchern als 'fleischliches Verlangen' bezeichnet wird" (90).

Fragt man sich, warum Schnier als Liebender eine derart starke Abneigung gegen die Kirche entwickeln kann, so hat ein Gedanke Theodor Haeckers, der hier auf Böll gewirkt haben mag, Bezug. In "Dialog über die Satire" heißt es: "Wer heute liebt, ohne zu glauben, der wird als geistiger Mensch notwendig zum erbarmungslosen, ja zum gehässigen Satiriker am Bestehenden, auch an der 'Kirche', oder als Mensch der Tat zum Revolutionär." ${ }^{10}$ Haecker sieht hier eine Zwangsläufigkeit, in der Liebe auch im weitesten Sinne gemeint ist. Diese Liebe zum Menschen bewegt Schnier, wie er betont, und darin ist er zweifellos identisch mit dem Satiriker. Da aber Marie als sexuelles Wesen im traditionellen christlichen Sinne der falsche Seinsgrund wäre, ist Schniers "Marienverehrung" eigentlich ein Venuskult, und Schnier nicht der Gotteskämpfer oder der Revolutionär, der er sein sollte. Dabei wird der Versager auch wieder zum Narren und Pfuscher. Marie begreift sich nicht etwa im selben Sinne wie Schnier sie sieht. Er bestätigt ihr, daß sie gläubige Katholikin im positiven Sinne sei, und somit entzündet er sich am falschen Gegenstand.

Trotz allem ist aber der Narr Schnier durch Marie auf der rechten Spur, wenngleich auf Umwegen. Sie verleiht ihm einen Schwerpunkt im Sinne der Kleistschen Marionette; damit sind seine Handlungen 
zwar ohne Grazie, weil er nicht seinem eigenen Schwerpunkt folgt, aber Marie als seine "Seele" ermöglicht es ihm, unbewußt Gottes Werk zu tun. Schniers instinktive Aggressivität findet durch Marie ihr primäres und richtiges Objekt. Sie ist es, die ihm den Zugang zum Kreis der Katholiken eröffnet. Trotzdem wäre Marie nicht Mittlerin zu Gott, sondern Surrogat und damit die Ursache der Verblendung Schniers, die ihn an der Wahrheit vorbeisehen läßt. ${ }^{11}$ Diese, so verdeutlicht der Text, wäre Christus, der Schnier einen eigenen Schwerpunkt vermitteln könnte und auch das Fundament, auf dem eine dauernde Bindung mit Marie hätte fußen können. Schniers Blindheit für Christus als Wahrheit wird dem Leser unter dem Aspekt einer traurigen Ironie vermittelt. Schnier versucht, seinen Bruder im Priester-Seminar anzurufen, muß sich aber in eine Unterhaltung mit einem redseligen Mönch einlassen. Dieser gibt ihm schrullige Ratschläge und errät, daß Schnier ungläubig ist. Er zitiert deshalb aus dem Römerbrief die Stelle, die Böll als Motto seinem Buch voranstellt: “'Hören Sie gut zu: Die werden es sehen, denen von ihm noch nichts verkündet ward, und die verstehen, die noch nichts vernommen haben. ... Haben Sie verstanden?'" Darauf Schnier: "'Ja', sagte ich matt" (220). Schnier hört die Botschaft im physischen Sinne, wie das Verstehen am Telefon hier gemeint ist, aber es ist auch ein mattes Hören, ein Verstehen ohne Glauben. Es ist dabei letztlich kein Blindsein, sondern Blindspielen, wie das, mit dem er einmal seinen Vater erschreckt.

Somit geht Schniers Unglauben auf seine eigene Kappe, ist Verstocktheit. Schnier kämpft mit selbstverbundenen Augen und ist darum der Versager, der sich gewissermaßen als Krüppel anbietet, um sich als ungefährlich, wehrlos und bemitleidenswert darzustellen. Um Schniers Konterfei als Versager zu erhärten, soll hier ausdrücklich auf die Marionetten-Metapher verwiesen werden, die als die zentrale des Textes bezeichnet werden kann. Schnier ist Marionette. ${ }^{12}$ Ehe Marie ihn verläßt, und so lange er noch nicht weiß, daß sie ihn verlassen hat, um Züpfner zu heiraten, sind die Fäden der Marionette intakt. Danach aber reißen sie, und es heißt: "Jeder Versuch, die Marionettenfäden wieder zu knüpfen und mich daran hochzuziehen, würde scheitern" (237). In dem Bild liegt zum einen, daß Schnier glaubt, selber die Fäden zu halten, und zum anderen verrät sich dies als die Münchhausen-Illusion, daß man sich an den eigenen Haaren hochziehen könne. Eine Marionette kann ihre eigenen Fäden nicht zerreißen. Schnier ist aber nicht gewillt zuzugeben, daß diese Fäden nicht von ihm gehalten werden, obwohl er vor seinen beruflichen Auftritten, wenn er zur Marionette wird, eine ungeheure Angst verspürt. Er sieht den Prozeß "als eine verzweifelte Kälte, mit 
der ich mich zur Marionette machte." Die Angst wäre dadurch zu erklären, daß er nicht sich selber, sondern einer anderen Macht ausgeliefert ist, die die Fäden hält: "[S]chlimm übrigens, wenn der Faden riß und ich auf mich selbst zurückfiel" (69). Da er permanent auf sein Selbst zurückfällt, wenn Marie ihn verläßt, so wäre sie die Hand, durch die Schniers Fäden laufen. Obwohl sie Schnier berechtigterweise fallen läßt, weil er sie, in streng christlicher Sicht gesehen, in eine blasphemische Rolle als Gottes-Surrogat drängt, so verweist sie als Ersatz auf Gott, in dessen Hand letztlich Marie wie auch die Fäden der Marionette Schnier zu sehen wären. Das jedoch will Schnier nicht wahrhaben, obwohl er es selber hinter seinem eigenen Rücken beweist. Er erkennt den Vorgang des Marionettenwerdens als mystisch: "Wahrscheinlich existieren Mönche im Zustand der Kontemplation ähnlich." Die Wörter "leer" und "nichts" (69), die in der mystischen Literatur, von der Schnier redet, vorkommen, meinen aber wohl etwas anderes. Sie sind Teil einer Selbstbereitung für Gott, nicht Angst vor dessen Inbesitznahme des Selbsts. Wenn Schnier in einem anderen Kontext, beim Mensch-ärgere-dich-nicht-Spielen zur Marionette wird, entsteht diese Spannung nicht. Es zerreißen keine Fäden, weil das Spielen Entspannung-im doppelten Sinne-für Schnier ist, und er nicht auf das Fädenhalten zielt. Schnier macht sich also nicht zur Marionette, er wird in einen Zustand versetzt, wo er diese sein könnte. Es entsteht keine Besitznahme, sondern nur Bereitschaft. Schnier verspürt dann keine Angst. Sein Entrückungszustand ist das Bewußtsein einer "großartigen Leere" (145). Schniers Versagen hat zweifellos einen tragischen Aspekt. Sehen wir ihn als potentiellen Gotteskämpfer, so liegt Überheblichkeit in seiner Illusion, die Fäden zu halten, aber da er ohne gläubig zu sein dennoch als Gottes Instrument aufgefaßt werden muß, ist er der in der Satire so vielfach anzutreffende mechanische Mensch. Er ist es aber in einem anderen Sinne als die Katholiken, die fälschlicherweise Gottes Werk zu tun glauben. Schnier hat zwar wenig Grazie, jedoch nicht die erbärmlich Glätte eines Sommerwilds.

Die Marionette hat somit in Clown einen doppelten Wert. Sie ist nicht nur negativ, was auch schon die Hinweise auf Kleist im Text andeuten, sondern verweist auch auf ein normatives Menschenbild. Die Metapher ist jedoch nicht dialektisch in dem Sinne der Wortpaarstrategie in den Kurzsatiren. Sie hebt die Gegensätze nicht auf, sondern unterstreicht sie. Hierin verfährt Böll also wie in den vom früheren Schema sich lösenden Texten. Zentral ist die Metapher, weil sie die Konfrontation zweier Menschenbilder hinstellt, die sich einerseits als Homo ex machina dei und andererseits als Homo ex machina bezeichnen lassen. Diese Bilder stehen einander in Schnier gegenüber. 
Das erstere ist er, zwar wider Willen, in seinen besten Augenblicken. Das letztere ist er während des Karnevals, d.h. als Narr, dessen Torheit sich nicht von der seiner Mitwelt unterscheidet, und der seine Kapitulation als Außenseiter und Herausforderer überdenkt.

Obwohl die Metapher der Marionette als "Kunst" verstehbar wäre, ist sie nicht nur Kunstinhalt, sondern im Hinweis auf Kleists Essay "Über das Marionettentheater" ausdrückliches Kunstmittel. Sie fordert zur vergleichenden Reflexion auf. Was dabei an Harmonie anfällt, ist nicht Vorstellung, sondern Kenntnis des Kleistschen Essays und trifft auf die Marionette Schnier nicht $\mathrm{zu}^{13}$

Im Gegensatz zu Schnier bleiben die Protagonisten in den folgenden satirischen Erzählungen Entfernung von der Truppe (1964) und Die verlorene Ehre der Katharina Blum oder: Wie Gewalt entsteht und wohin sie führen kann (1974) satirisch unverzeichnet, und ihre Provokationen zeigen Wirkung als Stör- und Zersetzungsmomente. Böll versucht hier tunlichst zu vermeiden, was möglicherweise als Ästhetisierung rezipiert werden könnte. So gibt die Erzählerfigur in Truppe zwar unumwunden $z u$, Torheiten begangen zu haben, während im früheren Schema die Sprecher alles daransetzen, die ihnen vom Satiriker verabreichte Narrenkappe zu verbergen, aber das Bekenntnis ist nicht Teil eines Portraits, in dem der Held sich als Pfuscher entpuppt, sondern gehört zum positiv zu verstehenden Schelm. Wenn Böll Leben als Bewegung versteht, so hat der Schelm dem Helden einiges voraus. Der Held kann sich entweder zum Triumph oder zur Niederlage bewegen, die Bestimmung des Schelms hingegen ist nicht eindimensional. Ihm gelingt es, sich über Wasser zu halten, selbst wenn er dabei viel zu schlucken hat. Seine Bewegung ist nicht fixiert. Der Leser kann jedoch nicht umhin, ihn als fragwürdigen Typus zu sehen, wenn er zu weitgehend schwankt und momentan eindeutig der Objektsphäre zuzurechnen ist. Wenn der Satiriker ihn desungeachtet nicht verurteilt, so kommt das einem Verschwinden des Satirikers gleich. David Worcester bezeichnet dies gerade als Charakteristikum der modernen Satire: "The author deliberately contracts the point of view of his characters and does so in full view of the readers . . . and has shrunk entirely out of sight." ${ }^{14}$ Was Worcester auf geistige Hilflosigkeit zurückführt, ist jedoch nicht unbedingt ein Manko. Wenn der Erzähler in Truppe zurücktritt, so bleiben Subjekt- und Objektsphäre dennoch klar getrennt. Der schwankende Schelm tut hier im Gegensatz zur Protagonistin in Blum nicht etwa Dinge, die mit der Norm der freien Lebensentfaltung unvereinbar wären. Es entsteht in Truppe beim Leser keine Verwirrung, wenn er der intendierten Konsequenz des verschwundenden Erzählers nachkommt und selber den Urteilsprozeß übernimmt. 
Um den Leser die Trennung zwischen Subjekt- und Objektbereich leichter zu machen, verwendet Böll von ihm bislang nicht verwendete Elemente, so Fäkales und Brutalität als Schocktaktiken. In Truppe werden die Protagonisten gezwungen, zur Demütigung auf dem Bauch zu kriechen und Dienst als "Scheiße"-Träger zu tun. In Blum bedient sich Böll drastischer sexueller Formulierungen, die Vertretern der Objektsphäre in den Mund gelegt werden. Somit verbaut Böll den "Genuß" und beläßt dem Leser als einzig möglichen Standort eine auf Grauen und Angewidertsein basierende Position der Entfremdung vom Objekt. Der "neue" Satiriker Böll paßt allerdings nur in dieses Schema, wenn man Ende einer Dienstfahrt (1966) nicht als Satire etikettiert. Schwer ist das nicht; man hat nur dem Großteil der Kritik zu folgen. Sie sieht, wie Nägele formuliert, einen Widerspruch in Birglar als kleiner, guter Welt, die "gleichzeitig Spiegelung und Antithese der großen bösen Welt" sein solle. ${ }^{15}$ So erscheint alles affirmiert in einem undifferenzierten Humor. Auch Truppe hat kaum enthusiastische Anerkennung in der Kritik gefunden, dies jedoch nicht in Bezug auf die generische Einordnung, sondern auf die Qualität als Satire. Für die ablehnende Kritik ist besonders Wilhelm Emrich wichtig, weil seine Vorbehalte hauptsächlich auf die Perspektive des entleerten Mythischen zielen. ${ }^{16}$ Er sieht es zum Klischee verwandelt. Besonders in Anschluß an das zu "Keine Träne um Schmeck" Erörterte läßt sich jedoch dieser Prozeß in Truppe nicht mit Emrich als Hilflosigkeit des Geistes, sondern als Abkehr vom Archetypischen und als Schritt zur appellativen Satire begreifen.

Es soll deshalb zunächst die Frage erörtert werden, inwieweit Truppe dem Konzept der Veränderbarkeit der Welt entgegenkommt. Der Appellcharakter schlägt sich in der ausdrücklichen Aufforderung zur "Entfernung von der Truppe" nieder. Daraus ergibt sich von vorneherein ein beträchtlicher Kommunikationsradius, da zur Erscheinungszeit dieses Werkes-1964-die Wiederbewaffnung der Bundesrepublik bedrohliche Ausmaße angenommen hatte. Bölls Aufforderung ging z.B. in die Richtung von Studenten, die nach Berlin übersiedeln konnten, um der Wehrpflicht zu entkommen. Bölls Parole war darum höchst aktuell. Der Verweis auf die Tagesfragen stellt sich dar in einem rezeptionsfreundlichen, mit einer gewissen Ironie gehandhabten (pseudo-)dokumentaristischen Stil. Böll simuliert Reportage-Technik, indem er Äußerungen der Personen im Wortlaut sowie auch aus fingierten Akten und aus Zeitungen zitiert. Im Zitat entlarvt sich, wie schon in Ansichten eines Clowns, das satirische Objekt selber. Besonders augenfällig sind Bölls Versuche, den Leser zum Mitwirken am Muster zu bewegen. Ingrid Hantsch geht so weit, diesen Vorgang generell als Aktivierungsrequisit der Satire zu 
bezeichnen: "Der Rezipient ist Adressat der satirischen Aussprache. In ihm vollzieht sich das eigentliche Funktionieren der Satire. Er wird damit zum aktiven Mitschöpfer des Werkes. Die zur Überzeugung angewandte Taktik wird vom Ziel vorbestimmt." ${ }^{17}$ Das Mitwirken ist in Truppe ein "Mitmalen," zu dem eine häufig abgewandelte, manieriert-breit eingesetzte Metapher auffordert. Der Erzähler erläutert deren Funktion:

Nicht nur was mich, auch was alle anderen in diesem Erzählwerk auftretenden Personen betrifft, möchte ich es nicht als fertige Niederschrift anlegen, sondern wie eines jener Malhefte, die uns allen noch aus unserer glücklichen Kindheit bekannt sind. . . . Schon bei der Verbindung der Linien herrschte künstlerische Freiheit. . . . Ich biete also ein paar Striche, ein paar Punkte, die der Leser als Malvorlage für die Ausschmückung des Rohbaus jener Gedächtniskappelle verwenden mag, als die dieses kleine Erzählwerk gedacht ist" (W4, 275-77).

Um den Leser zu überzeugen, daß diesem nichts vorenthalten bleibt, wird ihm eine "fix und fertige Moral" versprochen und "auch eine Interpretation, die allen Interpreten vom Obertertianer bis zum Meisterinterpreten im Oberseminar Seufzen und Nachdenken ersparen wird. Sie wird so abgefaßt sein, daß auch der einfache, der unbefangene Leser sie 'mit nach Hause nehmen kann' . . ." (282). Der Erzähler liefert die Interpretation wie versprochen, verspottet aber darin allerlei Arten von spitzfindig abwegiger Exegetik. Sinn der Strategie ist, den Text nicht einfach als Handlung und Unterhaltung, sondern als kritisch Anzugehendes anzubieten. Indem der Sprecher sich über die verschiedenen Schul-Exegetiken lustig macht und somit zum guten Teil ausklammert, baut er dem einfachen unbefangenen Leser die Brücke zu einer fundamentalen Frage, die noch von diesem zu beantworten ist und die der Sprecher als letzten Punkt seiner Vorinterpretation mitgibt: "Der Erzähler verbirgt etwas, Was?" (322). Unter anderem gehört besonders das ästhetische Moment zum Rätsel. Es wird nicht glatt vermittelt, sondern ist sperrig. Es muß vom Publikum analytisch erkannt werden. Wird es auf diese Weise Kunstmittel, so kann die Erkenntnis auch auf die Intention schließen: Das Ästhetische ist Verweis auf die Wirklichkeit. So erhält der Leser nicht, was er an "Kunst" erwartet, sondern was er als solche selber mitdefiniert. Sein Bewußtsein durchläuft einen Entschematisierungsprozeß. Auch in diesem Sinne gilt die Aufforderung zur "Entfernung von der Truppe."

In dieser nachdrücklich auf Aktivierung des Lesers gerichteten Struktur ist offensichtlich kein Raum für die Vorstellung einer aufge- 
hobenen Dialektik. Die "Entfernung von der Truppe" stellt als Parole die Fronten derart klar, daß eine Wortpaartechnik als Verweis auf Gegensätzliches nicht vonnöten wäre. Dieses wird zudem in dem ausgesprochen aufreizend-aggressiven Sprechstil suggeriert. Die Aufforderung zum Denken wird durch Provokation vermittelt. Der Leser wird dahin gebracht, indem er sozusagen am Ohr gezerrt wird. Auch das Mythische liegt derart verquer, daß sich der Leser mit ihm auseinanderzusetzen hat, damit der richtige Wirklichkeitsbezug erfolgen kann. Verfremdet Böll in "Keine Träne um Schmeck" den Heldenarchetypus, indem er ihn als Plot progressiv zum Bild des Kritikers hin "zivilisiert," so ist der Archetypus in Truppe von Anfang an ganz Bild, und dazu ein höchst verfremdetes. Bewerkstelligt wird dies anhand zweier Mittelpunktfiguren. Die eine ist der Sprecher. Er steht ganz und gar außerhalb jeglichen mythischen Rahmens, obwohl er Herausforderungsgesten, und zwar wirkungsvolle, zeigt; die andere ist ein "Engel." Obwohl dieser "strahlend" wirkt, dazu auch noch leidet, stellt er sich nicht im Sinne des Engels vor, der in den frühen, angehend satirischen Geschichten greifbar ist. Er ist vielmehr der Kunst abgeschaut. Er sieht aus wie ein "Lochnerengel," ist "fast goldhaarig" (285). Wenn dieser Engel ausdrücklich eine "mythische Gestalt" (283) genannt wird, ist schon klar, daß er nicht suggerierter Archetypus und Wirklichkeitsinhalt, sondern Kunstinhalt und Ikonographie ist. Als Kunstmittel verweist der Engel auf die Person, diese geht nicht etwa im Archetypus auf. Die Person ist Engelbert, aus Köln stammend, wo man den Namen eben auf Engel kürzt. Die Engel-Ikonographie deutet zwar auf intakte Menschlichkeit, aber Engelbert ist kein Engel. Es heißt ausdrücklich: "Engel(bert) ist kein Symbol für einen Engel, obwohl er so heißt, als so aussehend bezeichnet wird" (322). Um der Fehlidentifizierung nicht nur durch Kommentar, sondern "ästhetisch" vorzubeugen, vervollständigt Böll, was er dem Auge gibt, mit dem, was er der Nase zuführt. Engel stinkt. Er ist "Scheißeträger" in der Wehrmacht. Seine Gloriole ist ein Fäkaliendunstkreis. Hier liegt zweifellos ein humoristisches Element, und zwar ein stützendes. Der stinkende Lochnerengel ist zum Lachen. Die-moralische-Makellosigkeit Engelberts als Lochnerengel steht im "unästhetischen" Rahmen des Fäkalischen. Wo der Herausforderer in dem Plot-Archetypus der Satiren vom "Murke"-Schema letztlich als Urbild eingeht, ist die Ikonographie des zersetzenden Protagonisten, und das ist Engel schon durch sein Dasein, letztlich als Menschenbild zu perzipieren.

Menschenbild ist auch die Erzählerfigur, Engelberts Pendant. Obwohl beide in der SA waren, die Erzählerfigur dies unumwunden als Makel zugibt, sich überdies als Narren hinstellt, nimmt der Satiriker 
keineswegs abwertend Stellung. Die wenngleich nicht sonderlich vorbildliche Menschlichkeit des Sprechers bleibt voll intakt. Seine und auch Engelberts allerdings wesentlich eindeutigere Humanität ergibt sich in erster Linie aus der Stellung der Protagonisten als Außenseiter und Bedrohte. Zum richtigen Leben gehört die "Entfernung von der Truppe," die hier nicht Feigheit, sondern natürliches Verhalten meint. Dieses umschreibt Böll mit einer Metapher, die einen sehr geglückten Ausdruck seiner "niedrigen" Norm darstellt. Diese wird nicht etwa nur wie in den Kurzsatiren vorgeführt im Assoziationsradius der idyllisch-natürlichen, einfachen Lebensformen, wie z.B. im kommunalen Essen, was immerhin sehr leicht als erwartungserfüllend vom Leser mißverstanden werden kann, sondern bezieht sich auf eine Variante des "natürlichen" Lebens, deren kulinarische Aufnahme unmöglich sein sollte. Metapher flüssig gemachten Lebens ist die in Eimern getragene, zur Düngung verwendete "Scheiße." Sie ist Analogon zu den sozial gedemütigten Protagonisten als im figurativen Sinne etwas von der Truppe Gefressenem und Ausgeschiedenem. Darin liegt ein Schutz für die Protagonisten. Es heißt, daß die Erzählerfigur aus den Fäkalieneimern einen Ring um sich verschüttet, wenn ihr ein Vorgesetzter "menschlich" (273) nahetritt. Das Scheißetragen ist somit ein "Entfernen von der Truppe;" Scheißeträger sein meint sich zum Abfall rechnen, der allerdings hervorragend zur Düngung taugt und auch in Truppe im realen Sinne dieser Bestimmung zugeführt wird. Was Böll die Menschen bedeuten, die gemeinhin zum Abfall gehören oder sich zum Abfall machen, und inwiefern sie in Verbindung zur Norm des Lebensflusses stehen, zeichnet sich in seinem Gespräch mit Christian Linder ab:

Abfall ist ja vieles in unserer Gesellschaft . . . Auch Menschen; abfällig im sozialen wie auch juristischen Sinne. Und zwar weil sie zum Beispiel einfach nicht von der Mode vorgeschriebenen Klischees folgen. . . . Und so produziert unsere-aber nicht nur unsere-Gesellschaft natürlich permanent abfällige Existenzen, die man als Abfall betrachtet, und sie sind, meine ich, der wichtigste Gegenstand der Literatur, der Kunst überhaupt. Weil, jetzt negativ ausgedrückt: die Nicht-Abfälligen die Nichtmehr-Lebenden sind.

Lebende sind für Böll diejenigen, die den Überbau in Frage stellen und dadurch "Leben ... erhalten, oder Leben in die Bude ... . bringen" (I, 411, 408). Die Norm des Lebensflusses im Abfall ist hier nicht mehr Ideal, sondern Gegensatz zum falschen Leben; als solcher ist sie, besonders in der "Scheiße," Sicherung gegen das Vereinnahmen durch das Objekt und damit letztlich Maßnahme und Waffe. 
Auch in Blum wendet Böll das Prinzip der Entliterarisierung an. Er betreibt diese jedoch durchaus nicht so künstlerisch-exakt wie bisher. Er bezeugt dies selber, wenn er von "Schwächen" des Textes spricht und eröffnet, die negative Kritik träfe ihn hier nicht so schmerzlich wie an "rein literarischen Arbeiten." Worauf es Böll bei Blum ankommt, ist die Rezeption. Er ist "befriedigt von der Wirkung, die das Buch hat. Und auch mit der, sagen wir, gewissen Bewegung in der deutschen Presse, die jetzt doch gerade auf bestimmte Phänomene gerade der Bild-Zeitung aufmerksam wird" (I, 344). Vornehmliches Mittel zur Entliterarisierung ist wieder der fingierte Dokumentarstil. Er greift auf präzis angegebene Quellen zurück und spiegelt ein Höchstmaß an Aktualität. Anlaß des Werkes, den Böll übrigens in seinen Äußerungen zu Blum herunterspielt (I, 390), waren die Hetzmanöver der Springer-Presse, denen sich Böll infolge seines im Spiegel erschienenen Aufsatzes "Will Ulrike Meinhof Gnade oder freies Geleit" ausgesetzt sah. ${ }^{18}$ Böll greift hier in höchster Aufgebrachtheit die Springer-Presse an ("nackter Faschismus, Verhetzung, Lüge, Dreck," ESR2, 545), deren Schürtaktiken ihm für die Massenhysterie über den Terrorismus in der Bundesrepublik maßgebend verantwortlich schienen. Blum macht sich somit ein breites Feld journalistischliterarischen Geschehens zunutze und erweitert es gleichzeitig. Mit Hilfe einer regen Reklamekampagne und eines Spiegel-Vorabdrucks erlangte das Buch eine erstaunliche Absatzhöhe. Innerhalb von sechs Wochen waren schon um 150 ooo Exemplare verkauft. ${ }^{19}$

Böll arbeitet wie in Truppe mit einer Mega-Metapher, deren komplexe Aufwendigkeit schon allein dafür sorgen sollte, daß sie nicht kulinarisch aufgenommen wird. Der Erzähler stellt seine recherchierende und berichterstattende Arbeit in das Bild der Wasserführung und -drainage. Wenn der Malkasten in Truppe jedoch den Leser vornehmlich zum Mitwirken am Text auffordert, meint die Wasserdrainage die Schwierigkeiten beim verantwortungsbewußten Schreiben. ${ }^{20}$ Das Bild ist damit ein Indiz gegen das Objekt. Darüberhinaus ist die Wasserdrainage Teil des "mitreflektierten Kompositionsprinzips" ${ }^{21}$ und Normmedium. Mit Hilfe von Haupt- und Nebenquellen (das Wasserbild nimmt aus der Formulierung "Informations-Quelle" seinen Ausgang) sowie verwickelten "Konduktions"-Verfahrensweisen erwirkt der Erzähler endlich eine "Trockenlegung." Das ist ihm ein "ausgesprochener Ordnungsvorgang." Wenn es in den Bemühungen des Sprechers, das Pfützenwasser abzuführen, "Stauungen, Versandungen, mißglückte Konduktionen und Quellen, die 'zusammen nicht kommen können', außerdem unterirdische Strömungen u.s.w." gibt, so bittet er um Nachsicht. Was Böll hier wieder betreibt, ist eine Umformung der Norm des Lebens- 
flusses. Er führt sie nicht mehr als Darstellung vom Rechten an, sondern macht sie zur Schreib-Waffe. Diese dient ihm zur Trockenlegung des Objekts, d.h. zum Korrektiv am falschen Fluß der Dinge. Dabei beugt Böll einer etwaigen Fehlrezeption der Wassermetapher als "Kunst" ausdrücklich vor, indem er seine Tätigkeit genau bestimmt. Diese ist nicht "Komposition," sondern "Konduktion" (W5, 386). Der Satiriker will nicht als Künstler, sondern gewissermaßen als HydroTechniker des Lebensflusses verstanden werden. Wenn Böll die Norm des Lebensflusses zur Waffe verwandelt und den Verweis auf das rechte Leben abzieht, so drückt sich darin der Wunsch des Satirikers aus, sein Publikum total gegen das Objekt einzunehmen und zu aktivieren. Da die Vorstellung des "Positiven" möglicherweise kathartisch wirken könnte, wird sie vermieden. So ist die Wassermetapher nicht Maßgabe des rechten Lebens, sondern ausschließlich Maßnahme am falschen.

Was immer jedoch falsches Leben in Blum ist, so klammert der Satiriker das Leben der Protagonistin davon aus. Obwohl sie jemand tötet, erscheint sie nicht etwa als Mörderin, sondern als Opfer. Schon ihr Name Katharina (griech. die Reine) erhebt sie deutlich. Von Ironie gegenüber dieser "reinen Blume" ist nichts zu verspüren, obgleich sie Böll im Nachhinein durchaus nicht als Heldin gesehen wissen will: "Sie ist keine Heilige, und sie ist erst recht keine Heldin" (I, 328). Nichtsdestoweniger hat man eher Manfred Durzak und Linder zu folgen, die sich an der Kritiklosigkeit des Sprechers gegenüber Katharina im Werk stoßen (I, 323-34, 386).

Böll setzt in Blum Micromegas ein, um die Bild-Zeitung zum Monstrum zu vergrößern, das in Katharina das Kleine schlucken will. So bläht die Zeitung verzerrend alles ihr Unpassende nach Maßgabe ihrer eigenen anstößigen Größe auf. Im Maßnehmen des Abstandes zwischen der Wahrheit und dem Gedruckten reduziert der Satiriker die Schwellung und rückt somit das Kleine vor das Große. Das beschränkt sich nicht auf die Wertungsperspektive im Leser, denn Katharina behauptet sich in der Wirklichkeit. Sie zerbricht nicht etwa an der Affäre, sondern sieht guten Muts und in Vorfreude auf ein Wiedersehen mit ihrem Geliebten ihrer Entlassung aus dem Gefängnis entgegen. Sie ist ohne Reue, "fast unangefochten, lediglich in ihrer Freiheit eingeschränkt" (466). Hier zeigt sich der Satiriker als Taktiker der Veränderbarkeit. Selbst eine Tat wie Katharinas bedeutet kein untragbares Risiko.

Die Boshaftigkeit, die man dem Genus Satiriker immer wieder bescheinigt, bricht in Blum mit Macht durch. Haß ist hier die Tinte. Allerdings ist diese ungeeignet, Schattierungen herzustellen. Böll macht sich nicht einmal die Mühe, die Zeitungsleute unter irgend einen 
falschen Schein der Menschlichkeit zu rücken. Sein Animus duldet hier keinen Ansatz zur Versöhnlichkeit. So macht der Sprecher nur eine sehr kleine Verbeugung in Richtung einer Apologie. Er muß den Gegebenheiten, die auf Klarstellung der Fronten drängen, freien Lauf lassen: "Es ist natürlich äußerst bedauerlich, daß hier zum Ende hin so wenig Harmonie mitgeteilt und nur sehr geringe Hoffnung auf solche gemacht werden kann. Nicht Integration, Konfrontation hat sich ergeben" (469). 


\section{Ix. Die neue Kurzsatire: Typologische Varianten}

Nach fünfjährigem Schweigen findet Böll 1969 in "Veränderungen in Staech" zur Kurzsatire zurück. Darin liegt jedoch nicht etwa der Auftakt zu einem Stadium intensiven Schaffens in diesem Genre. So vergeht fast derselbe Zeitraum bis Böll 1975 in "Berichte zur Gesinnungslage der Nation" und "Erwünschte Reportage" weitere satirische Kurzprosa folgen läßt. An diesen drei Texten ist vornehmlich festzuhalten, daß Böll die dokumentaristischen Tendenzen, die in den satirischen Langformen und in "Briefe aus dem Rheinland" und "Briefe an einen Freund jenseits der Grenzen" zu ermitteln waren, fortführt. In seiner bislang letzten satirischen Arbeit, "Geständnis eines Flugzeugentführers" (1977), ist das Dokumentaristische sehr schwach, weil äußerst unwahrscheinlich, aber den Schelm und die Norm des Zersetzens behält Böll bei. Legt er sich in der neuen Kurzsatire schon nicht auf ein so deutliches Muster wie in den "Murke"Texten fest, wo er sich zweifellos durch Wiederholung derselben Formel steigert, so sind seine jüngsten Arbeiten beachtliche und bislang weitgehend unbeachtete Leistungen.

In "Veränderungen in Staech" entwickelt Böll die aufwendigste seiner Scheinidyllen. In der Nähe der Hauptstadt liegt eine Benediktinerabtei, die das Protokollamt der Regierung hochgestellten Auslandsgästen vorzuführen pflegt. Für die Protokollbeamten ist Staech das "Abendland in einer seiner kultiviertesten Artikulationen" (W4, 514). Die Abtei liegt inmitten einer sehr angenehmen Landschaft. Man bietet Spazierwege unterschiedlicher Länge, das Kloster die feierlichen Riten des Katholizismus. Alles in allem sind die Abtei und Umgebung eine auf Kultiviertheit getrimmte Massageörtlichkeit höchsten Ranges, in der die Mönche den Dienst am Publikum leisten. Sie spielen jedoch ihre Rolle mit einer Einschränkung, die höchste kirchliche Kreise, das Staatsoberhaupt und reisende Majestäten beunruhigt und verwirrt. Die Mönche begeben sich häufig auf Reisen, um diesem Luxus-Idyll zu entkommen. So ist es schon vorgekommen, daß von der schon an sich unerheblichen Schar von siebenundvierzig Gottesmännern "bei der nachmittäglichen Non nur elf, einmal sogar nur neun anwesend waren" (516). Wenn sich dem Druck höchster Stellen zufolge das Reisefieber vorübergehend senkt, zeigt sich, wie 
wahrhaft therapiebedürftig die Insassen der Anstalt sind. Es kommt zu "Kleptomanie und Exhibitionismus" (519). Elf Mönche müssen in einer psychiatrischen Klinik untergebracht werden.

Da die Abtei energisch vom Staat unterstützt wird, legt man dem Abt nahe, Staech stets "einsatzbereit" zu halten, weil nämlich "oft kurzfristig besichtigungsfreudige Gäste anreisten, etwa Ostblockjournalisten." Der Abt steht jedoch zu seinen Untergebenen und läßt sie wieder reisen. Es kommt zur "Staech-Krise," als eines Tages unangemeldet Staatsoberhaupt und Bischof zugleich erscheinen und den Abt zur Rechenschaft ziehen, da nur vierzehn Mönche anwesend sind. Der Abt, der nicht abgesetzt werden, sondern nur von seinen Mönchen abgewählt werden kann, erklärt sich mit diesen solidarisch, die Honoratioren-Besuche für widerwärtig und schlägt als listiger Zersetzer vor, daß man, wenn man wolle, "auf Schauspieler zurückgreifen" könne. Es ist dann auch beim nächsten Staatsbesuch die stattliche Zahl von achtundsiebzig Kuttenträgern zugegen, zum Großteil durch maskierte Studenten gestellt. Es handelt sich um verhaftete Demonstranten, die sich durch ihr Mitwirken in Staech loskaufen. Man hält das "Staech-Problem für gelöst" (519-20).

Wenn Staatsoberhaupt und Bischof zugleich und zum selben Zweck auftreten, so ist dieses Gespann Hauptvertreter der Objektsphäre. Staat und Kirche bilden eine unheilige Allianz, die sogar über die "Fast-Kongruenz von CDU und Kirche" (ESR1, 271) geht, die Böll 1958 in seinem "Brief an einen jungen Katholiken" Sorge macht. Staat und Kirche sind in "Staech" völlig eines Sinnes. Die Zusammengehörigkeit dient dazu, die Belange des Staates als auf kulturell-politischer Homogenität beruhend hinzustellen. Das satirische Objekt ist letztlich ein Staat, der sich stark zu machen versucht, indem er alles Heterogene glatt, aber zwanghaft integriert, um eine antagonismenfreie Struktur vorzutäuschen.

Was der Satiriker jedoch sichtbar macht, ist die Verkehrtheit dieser Bemühungen. Die Gegensätzlichkeiten von Staat und Kirche sind als Dialektik verstanden sozial wünschenswert. Schaltet man sie aus, um einen glatten Funktionalismus zu erwirken, so mag das bestenfalls den falschen Schein einer befriedeten Gesellschaft herstellen. Unter der Oberfläche gärt es jedoch. Die Mönche kehren dem Paradies den Rücken, indem sie weiterhin reisen. Was gärt, ist gleichzeitig Technik des Satirikers. Schein-Harmonie und Schein-Idylle zersetzt er in Bildern des falschen Schönen und falschen Wertvollen. Diese Technik hat in "Staech" eine nachdrücklich dokumentaristische Note. Das Aufzudeckende erscheint im eigenen Zitat. Der Satiriker distanziert sich und setzt gleichzeitig dadurch Glanzlichter, deren Streuungsradius das gesamte Feld des Erzählten ironisch beleuchtet. 
Neu für die Kurzsatire ist, daß sich das Anstößige vorwiegend im Klischee darbietet. Es reflektiert jedoch nicht etwa ein Klischeedenken des erzählenden Autors, weil das Klischierte innerhalb des Zitats sich so eng mit dem satirischen Gegenstand verbindet, so charakteristisch wirkt, daß auch das Klischee außerhalb des Zitats synekdochisch dem Gegenstand zu Lasten geht. So spricht der Satiriker hier weitgehend durch das satirische Objekt, ergreift aber bisweilen, worauf später eingegangen werden soll, in eigener Sache offen das Wort. Die Protokollbeamten als Vertreter der Objektsphäre bezeichnen Staech als "schlechthin wonnig." Das meint z.B. Folgendes: "Ein höherer oder gar der höchste Beamte des Protokolls soll einmal gesagt haben: 'Was wollen wir mehr? Das Abendland in einer seiner kultiviertesten Artikulationen liegt fünfzig Mercedesminuten von uns entfernt'" (514). Es geht um Qualitätsanspruch. In anderen Worten: Wir sind und haben das Beste. Das Abendland, an sich schon ideologisch ein übel befrachteter Terminus, wird gleichsam zum Hoheitsgebiet der Hauptstadt. Das Objekt bläht sich hier im Sinne des Micromegas-Prinzips ins Phantastische, indem es sich das gesamte Abendland einverleibt. Sieht man sich diese Diplomatenphrase noch einmal genau an, so dreht sie sich um die Achse eines vom Satiriker ironisch eingesetzten "Kultur"-Symbols. Es ist dies das Mercedes-Automobil, der Welt ein Gütezeichen deutschen Könnens und im Lande selber Zeichen der Zugehörigkeit zur Führungschicht und Sinnbild für anspruchsvollen Lebensstil. Die "Mercedesminuten" sind das Medium, durch das sich Staech für die Hauptstadt verwirklicht. Die Optik verschiebt sich von Kultur auf Kultiviertheit, und Staech wird zum Ausdruck von Lebensstil.

Den Protokollbeamten nach ist die Natur eine "geradezu unersetzliche Spazierumgebung." Man "macht einen je nach Zeit, Laune und Ausdauer temporierten Spaziergang durch die ohne jede Einschränkung herrlichen Wälder, nimmt nachmittags an der Non oder der Vesper teil, trinkt Tee und kehrt, mit tiefem innerem Frieden erfüllt, in die Hauptstadt zurück" (515). Helmut Arntzen sieht besonders in der Satire dieses Jahrhunderts mit Recht schon im Gefüge von Adjektiv und Nomen das Klischee: "Aussichten sind immer schön, Trauer ist immer tief, eine Note immer persönlich." ${ }^{1}$ Besonders in der Floskel vom "tiefen inneren Frieden" erscheint das Thema der Harmonisierung in der Nuance. Die Wirklichkeit wird zu einem Übereinstimmungs-Code reduziert, wo sich Signal und Erwartung entsprechen. Das Kommunizierte ist hier höchster Qualitätsanspruch. Die Wälder sind "ohne Einschränkung" herrlich. Sie sind das Beste vom Besten. Ihre therapeutische Qualität ist allerdings nur, was man sich schuldig ist, ähnlich wie in Ansichten eines Clowns, wo sich 
Schniers Vater als hochkultivierter Leistungsmensch nicht mit dem zweitbesten Kunstkritiker oder Herzspezialisten abgeben würde. Die "herrlichen Wälder" haben Ausrufungswert, zu hören aus den Kehlen derer, die den einmaligen deutschen Wald genießen. Dazu wird ihnen noch "tiefer innerer Frieden" beschert, also etwas, was möglicherweise nur in der Romantik echte Münze war, aber bis heute unentwegt weiterklingelt.

Staech ist zweifellos von höchstem Niveau. Man nimmt "edelgekleidete Mönche," "Mönche in edlem Gewand," "in edlen Kutten" wahr, "von denen immer der eine oder andere betend, meditierend oder im Gespräch mit einem Gast Landschaft oder Garten schmückt" (514-17). Man kann sich in Staech versenkend reinigen und sogar an den klischierten Darbietungen in der Rolle des Mönches teilnehmen: "Tatsächlich: Staech wäre wohl kaum zu ersetzen; elftes (vielleicht auch zehntes oder zwölftes) Jahrhundert, graue rheinische Romantik, Gregorianischer Choral; die Gelegenheit, Mönch auf Zeit zu werden oder in einem Luxushotel zu wohnen und gleichzeitig aller Wonnen der Liturgie und der Tröstungen fast sämtlicher Sakramente teilhaftig zu werden" (514-15). Die Herabsetzung des Religiösen geschieht in diesem Zitat durch die Variante der Verfremdungstaktik, die Heterogenes zusammenzwingt. ${ }^{2}$ Mönch und Luxushotel sind ein Paar, das dem Leser nicht einleuchtet, wie den Staecher Mönchen selber der klischierte Betrieb ihrer Abtei derart unlieb ist, daß sie sich so oft wie möglich fernhalten. Zusammen mit dem beliebten Abt bilden sie ein Schelmenkollektiv, deren Tätigkeiten auf die Zersetzung von Staat und Kirche als "Fels des Bestehenden" zielt.

Eine echte Mittelpunktfigur fehlt in diesem Text. Zwar steht der Abt seiner Stellung entsprechend exponiert, aber selbst er trägt kaum individuelle Züge. In diesem Sinne entfernt sich Böll in diesem Text am weitesten von seinem früheren Muster. Nicht nur fehlt in "Staech" das persönliche Entscheidungsmoment, sondern auch das Einzelgängertum der Schelme der jüngeren Texte. Statt dessen kennzeichnet die Subjektsphäre hier ein solidarischer Kollektivismus. Böll stützt damit den Gedanken der Veränderbarkeit der Welt, aber ein Personalkollektiv lädt den Leser, der als Einzelwesen auftritt, nicht recht zur Identifikation ein. Es läßt sich darum an "Staech" eine gewisse Farblosigkeit nicht verkennen, die auch darum nicht abnimmt, daß man sagen könnte, der Schelm brauche eben Deckung.

Was den Schutz durch den Satiriker betrifft, so scheint der Schelm ihn hier überhaupt nicht nötig zu haben. Wenn der Abt vorschlägt, man solle Schauspieler als Lückenbüßer bei den Feierlichkeiten in Staech einstellen, so spricht der Erzähler bei diesem Vorschlag von "zynischer Offenheit" (520). Die Wendung ist nicht etwa Reaktion der 
Kirchenbehörde im Zitat, es geht wirklich um Zynismus, der aber jetzt durchaus kein Manko für Bölls Figur bedeutet, sondern Erscheinungsform der berechtigten Aggressivität eines "zu weit gehenden" Schelms ist.

Auch das Reisen ist-in sehr wörtlichem Sinne-ein "Zu-weit-Gehen." Ein Mönch eilt nach Norddeutschland, um dort den Übertritt eines "namhaften Physikers" zum Katholizismus zu verhindern. Ein anderer fährt nach Holland: "Grund: Studium der Veränderungen im holländischen Katholizismus." Einige Brüder nehmen teil an einer Literaturtagung, die sich um das Thema "Darstellungen des Orgasmus in der jüngeren deutschen Literatur" bemüht. Sie begründen und rechtfertigen ihre merkwürdigen Interessen mit einem Klischee: “Wir müssen Kontakt zu den fortschrittlichen Kräften unseres Vaterlandes suchen" (517-18). Im Kern ihrer "fortschrittlichen" Aussage steht als Überzeugungsfaktor der Terminus Vaterland, also ein eher reaktionäres Konzept. Schelme die sie sind, ahmen sie Denk- und Sprachhaltung des Staates nach. Zweifellos schätzt dieser nationalistische Kategorien. Das Lob eines südwesteuropäischen Diktators, der von der Menge der Mönche in Staech beeindruckt ist, fällt nicht auf taube Ohren. Ahnungslos darüber, daß es sich zum Teil um verkappte Protestler handelt, schwärmt er: "Diese Deutschen! Nicht zu schlagen! Sogar ihr Nachwuchs an asketischen jungen Mönchen ist nicht zu überbieten" (520). Wie bei einem Diktator nicht anders zu erwarten wäre, zeigen diese Formulierungen Verständnis für die Grundanliegen des Staates: Es geht um nationalen Daseinskampf. Dazu hat auch Staech Truppen zu stellen, "einsatzbereit" zu sein, was sich namentlich auf Besucher aus dem Ostblock richtet. Hinter den offiziell betriebenen Vortäuschungen von staatsinterner Harmonie und Idylle steht also letztlich ein Zusammenwirken gegen äußere Feinde; im übertragenen Sinne wird Krieg geführt, hier mit den Mitteln der Kultur, die, zur Waffe umgeschmiedet, eine Perversion darstellen. Für interne Antagonismen ist folglich bei Menschen, die für ein geliebtes Vaterland streiten, kein Raum, oder nur am Rande, jenseits alles Ernstzunehmenden, wie etwa der Literatur. Darauf verweist Böll schon ganz zu Anfang des Textes, indem er die Assoziationsnähe von Literatur und Philologie ausnutzt: "Antagonismen" und "heftiger Streit" (514) bestehen nur unter den Philologen, die sich uneins sind, ob das "ae" in Staech eindeutig germanischen, das "ch" keltischen Ursprung beweist.

Ginge dem Leser etwa diese ironische Technik, die die Idyllentorm parodiert, nicht auf, so spricht der Satiriker in eigener Sache mit einer Direktheit, die in den Kurzsatiren alten Stils nicht vorkommt. Allerdings geht Böll auch nicht mit einem Großraumplakat vor. Es handelt 
sich in einem Falle um das kleine Wort "nicht," das auch dem für Ironie Schwerhörigen, aber aufmerksam Lesenden eindeutig anzeigt, worum es geht. Es heißt, "Staech ist, was es nicht sein sollte: abhängig vom Staat und von der Kirchenprovinz" (416-17).

$\mathrm{Daß}$ dies durchaus nicht so sein müßte, zeigt die ökonomische Perspektive, die Böll anführt. Die Abtei ist auch landwirtschaftlicher Betrieb. Manche Mönche sind in "mit Kuhfladen bekleckerten Arbeitskutten" zu sehen: "[D]as seltsame ist: diese arbeitenden Mönche sind nicht etwa gestellt, sie sind echt" (515). Sie machen dem Leser die "edlen Kutten," die die Szene vornehmlich zieren, erträglicher und lassen punktuell die Norm des rechten Lebens aufleuchten. Bestimmend ist aber die Perspektive des Abbaus falschen Lebens, das Zersetzen. Was Böll damit genau meint, hat voll ausgeführt zu werden, schon weil seine Ausführungen die sozial-förderliche Aggressivität seiner gewandelten Normvorstellung betonen und auch, weil deutlich wird, daß das Zersetzen letztlich ein lebensfördernder Prozeß ist. In Bölls Gespräch mit Christian Linder spricht dieser von "Destruktion," die darin liege, daß Böll "den Überbau kaputtzumachen" versuche. Darauf Böll:

[I]ch würde sagen: zersetzen. . . . Daß das, was wir jetzt destruktiv nennen und wahrscheinlich objektiv auch destruktiv ist, der Wunsch ist, Leben zu erhalten, oder Leben in die Bude zu bringen, eben auch durch Infragestellung des Überbaus. Und Leben kann ja nur durch Zersetzung entstehen, allein auch schon biologisch-Sie müssen zersetzen und kaputtmachen dann auch als chemischen beziehungsweise physikalischen Vorgang nehmen. Die Physiker würden das wahrscheinlich Prüfung des Materials nennen: man setzt das Material-in diesem Fall das Material Autorität oder Überbau-Prüfungen aus, wie man etwa ein Metall chemischen beziehungsweise physikalischen Prüfungen aussetzt; im Fall Literatur sind es sprachliche Prüfungen in und am Material Sprache. . . . (I, 408).

Das Zersetzen ist aktivierte und zu erzwingende Norm, eher eine Maßnahme als eine Idee. Zwar besteht im großen und ganzen die Objektsphäre am Ende des Textes trotz ihrer ästhetischen Zerstörung weiterhin in ihrer Scheinglorie, aber es zeigt auch die Wirklichkeit "Veränderungen in Staech," die Gutes hoffen lassen. Das Reisen der Mönche, die vornehmliche Einkleidung der Norm, ist wohl eine kreisförmige "Entfernung von der Truppe," denn man kehrt zurück, aber es läuft trotzdem auf Unterwanderung hinaus. Sind die Mönche abwesend, so haben Ersatzleute sie zu vertreten, von denen einige das Ritual auf sehr unorthodoxe Weise behandeln. Die Reise als To- 
pos der Satire findet sich z.B. schon bei Horaz (Satire I, 5). Sie taugt besonders zur Normvermittlung, wie etwa auch im Sucherroman. Das Prinzip Beweglichkeit als Reisen hat übrigens bei Böll auch privaten Charakter und läßt sich daher als Normingredienz sehen. Im Gespräch mit Linder redet er von der Vorliebe seines Vaters für häufige Umzüge, sogar innerhalb derselben Wohnung (I, 378), und auch von seiner eigenen Gewohnheit, "immer einen Koffer auf dem Bett . . . für die nächste Reise" (372) zu haben. Geht diese "Beweglichkeit" in Bölls Norm ein, so rührt sie existentiell aus einer negativen Grunderfahrung. Böll identifiziert sie als den "Zerfall der bürgerlichen Gesellschaft... in den zwanziger und dreißiger Jahren" (377). Was Böll somit damals eine Not war, wird ihm in einer restaurativen, sich zusehends verhärtenden und erstarrenden Gegenwartsgesellschaft zur normativen Tugend. So liegt in dem Grunderlebnis der wirtschaftlichen und gesellschaftlichen Zerrüttung auch eine Erklärung der anarchistischen Tendenzen Bölls. Die Erfahrungen mit "Pfandhäusern, Gerichtsvollziehern, das gehörte alles zum Alltag" und generierte den "Anarchismus als eine immanente Verachtung bürgerlicher Formen" (379-80).

Dieser Anarchismus regt sich auch in Staech. Die Zersetzung dringt in die Kultusdarbietungen. Mit den angeheuerten Mönchsattrappen versteht sich der "Abt von Staech ... gut, einige junge Leute-es sollen bisher sieben sein-sind schon als Novizen eingetreten, und daß sie beim Chordienst dem gregorianischen Rhythmus hin und wieder ein Ho Tschi Minh unterlegen, ist bisher niemandem aufgefallen" (521). Der Eintritt dieser höchst ungewöhnlichen Novizen in das Schelmenkollektiv deutet zweifellos auf Auflösung des Objektraums. So winzig deren Momente erscheinen mögen, so sind sie besonders im historischen Sinne das rechte. Die Zeit für den Helden und zur Revolution ist vorüber. Diese erklärt Böll schon 1960 in dem Aufsatz "Zeichen an der Wand" für nicht mehr zeitgemäß: "Der Schnitt, der uns von der Vergangenheit trennen könnte, ist nicht vollzogen worden. Es hätte einer Revolution bedurft, uns von ihr zu trennen; die äußere Revolution hat nicht stattgefunden, die innere scheitert an dem mangelnden Mut, uns von politischen Traditionen zu trennen, die in [der] unbewältigten Vergangenheit wurzeln" (ESR1, 346). Zeitgemäß ist die Tätigkeit des Schelms. In den "Notstandsnotizen" heißt es 1968: "Zersetzung ist . . . die einzig mögliche Form der Revolution" (ESR2, 296).

Das Revolutionäre dieser Prägung hat sich für Böll inzwischen radikalisiert. Er hält jetzt auch Handgreiflichkeiten nicht für ausgeschlossen. Im Gespräch mit Manfred Durzak (1975) sagt er: "Es wird darauf hinauslaufen, daß man ein paar Freunde haben wird . . . und 
ein paar Feinde, denen man, wenn man ihnen begegnet, möglicherweise in die Fresse haut" $(I, 339)$. Ließe Böll seinen Protagonisten fortan derart freie Hand, so würde das eine Spielart des Schelms bedeuten, die über das in der bürgerlichen Literatur Gewohnte hinausgeht. Für Dieter Arendt ist der bürgerliche Schelm "nichts anderes als der artikulierte Widerspruch gegen den anmaßenden Ernst bürgerlicher Ideologie und ist, intendiert oder nicht intendiert durch den Autor, als Selbstkarikatur des immerhin kritisch gebliebenen bürgerlichen Bewußtseins ein in der humorvollen Satire verhüllter Ernst." ${ }^{3}$ Trotz aller Sympathie für den Schelm haftet diesem bei Arendt noch etwas vom Versager an. Bölls Schelme der sechziger und siebziger Jahre sind aber mehr als nur Chiffren des Widerspruchs; sie sind letztlich ernstzunehmender als ihre Vorgänger vom Schlage Murkes, die mit hohem Panier, aber kleinem Mut die Sache des Satirikers verfechten. So agieren die Protagonisten des neuen Satiretypus zwar auf einer weniger hohen Normebene als die der "Murke"-Texte, aber dennoch ist die in ihnen reflektierte satirische Position unversöhnlicher als die frühere.

Bölls unversöhnliche Haltung äußert sich in "Berichte zur Gesinnungslage der Nation" (1975) in einer Form der Ironie, wie wir sie schon aus "Hauptstädtisches Journal" kennen. Der Satiriker spricht in der Stimme des Objekts. Dessen Vertreter äffen die Norm des Zersetzens nach. Drei Spitzel der Regierung treten als "Sympathisanten der Radikalen" auf, um diese ausfindig zu machen. Ihr Schnüffeln und Denunzieren ist eine negative Variante des Zersetzens. Sie ist in falscher Weise destruktiv, weil sie nicht auf "Festgefügtes" zielt, sondern dessen Stützung beabsichtigt und nur angeblich aus der "Anarchoszene" $\left(\mathrm{W}_{5}, 481\right)$ herrührt. Da aber dieses Zersetzen auf einem inneren Widerspruch beruht, ist es fruchtlos. Wenn es sich gegen die "Anarchoszene," also gegen schon Bewegtes richtet, hat es keinen Gegenstand, ist ziel- und wirkungslos. So nimmt nicht wunder, daß die Spitzel in gegenseitiger Unkenntnis ihrer Identität ihre Energien aneinander verschwenden. Verstehen wir hingegen das Zersetzen als Waffe des Satirikers im Sinne der Micromegas-Technik, so ist es allerdings sehr wirkungsvoll. Der Satiriker spielt dem Objektbereich die Waffe gewissermaßen in die Hand, aber sie verhilft den Spitzeln nicht zum Triumph, sondern zur Niederlage.

Wie Böll in "Hauptstädtisches Journal" mit verstellter Stimme gegen die Wiederaufrüstung kämpft, indem er einem Militaristen das Wort erteilt, reagiert er hier auf die Radikalenerlasse aus der Bewußtseinslage derer, die sie gutheißen. Wie in dem früheren Text der General Machorka-Muff die Heldennorm usurpiert, versuchen die Unholde hier ebenfalls unter der Maske der Norm aufzutreten. Indem 
der Objektbereich seine Herausforderer zu Extremisten stempelt, versucht er alles im Bereich der Vernunft Liegende zu vereinnahmen. So scheinbar im Besitz der Norm vermeint er seine Herausforderer in die Defensive zu drängen. Dem trägt Bernd Balzer Rechnung, wenn er den Text ein "Versteck des Widerstands" nennt. ${ }^{4}$ Das ästhetische Versteck ist möglich, eben weil trotz aller Bedrohlichkeit der Staat ins Leere greift und damit die eigene Radikalität insofern erweist, als seine Maßnahmen ein der Situation unangemessener Aufwand sind. Böll setzt wie in Die verlorene Ehre der Katharina Blum eine "Kunst"Metapher ein, um dies klarzumachen. Der Spitzel "Rotgimpel" war Anarchist und tritt jetzt unter dem Deckmantel des Feuer-Künstlers auf, als welcher er stark beachtet ist. Er erfindet das Konzept "Ignition-art" (475). Auf den ersten Blick scheint es sich hier um ein Antidot der Wasser- und Flußmetaphorik zu handeln, die Böll als Normchiffre des Zersetzens in der Blum-Satire verwendet. Er griffe somit zurück zum Feuer als Ausdruck der Norm, wie es sich in Ende einer Dienstfahrt (1966) findet, wo ein Jeep der Bundeswehr in einem zu befürwortenden Sinne-als Happening - in Brand gesteckt wird. Dagegen spricht, daß der Feuer-Künstler Rotgimpel ein Spitzel ist, der die Zündschnur "um die ganze Welt legen" (488) will und sein Handwerk als "Feuerwerker" dem Wehrdienst verdankt, den er "regelrecht absolviert" (477) hat. Wenn hinter der Anarchisten-Maske etwa der junge Gruhl aus Ende einer Dienstfahrt lauerte, so wäre der zu weit gehende Schelm als "Feuerkünstler" inzwischen zum Pyromanen geworden. Die Feuer-Spielerei Rotgimpels meint nicht Zersetzung, sondern das wahre Anstößige, die repressive reaktionäre Radikalität. Da man bekanntlich Feuer mit Wasser bekämpft, entsteht die rechte Normvorstellung gleichsam von selber im Leser. Da Böll sich zu den durch die Radikalenerlasse Angegriffenen zählt, gibt er das Etikett "radikal" dem Staat wieder zurück.

Böll gewährt sich in diesem Text eine Prämie für seine Berühmtheit, da er die Wasser-Norm nicht direkt im Text anlegt, sondern sie aus Die verlorene Ehre der Katharina Blum voraussetzt. Da die Wirkung dieses Textes sowohl in der Diskussion wie im Verkauf ein gegenwärtiges Phänomen war, als "Berichte" erschien, ist Bölls Rückbezug auf seinen vorangehenden Bestseller durchaus statthaft. Er ist sogar angebracht, denn es wird dabei klar, daß die "unradikale" Zersetzungsnorm des Wassers nicht Tarnungsreaktion auf die Radikalenerlasse ist, sondern auf Früheres in Bölls Werk zurückgeht und ihn als "Wasser-Techniker" im Gegensatz zum Pyromanen ausweist.

Der Feuer-Künstler Rotgimpel findet Anklang. Es ist "das gesamte Szenario . . . nach Kunst geradezu ausgehungert" (475). Indem Böll so die Aufnahmebereitschaft für Kunst unterstreicht, stellt er indirekt 
seine Genugtuung dar über die Wirkung des Blum-Textes und seinen Glauben an den Zusammenhang von Kunstweise und politischer Aktion, von dem in seinem Gespräch mit Heinz Ludwig Arnold einmal die Rede ist (I, 155). Der Künstler darf das Vakuum nicht dem Scharlatan überlassen; er muß eingreifen. Der Spitzel "Ackergaul" sieht das als Gefahr, da ihm "die Kunstszene hier spärlich, man könnte fast sagen ärmlich besetzt ist. . . . Ich fürchte, hier ist wirklich Unheil im Anzug" (481-82). Wie die normgerechte Zersetzung durch den Schelm bewirkt wird, so geschieht das angebliche und falsche Zersetzen durch dessen negativen Doppelgänger, den Spitzel. In Rotgimpel findet sich beides. Er war ursprünglich Schelm, gehörte zur "Anarchoszene" und war inhaftiert. Ist der Schelm belustigend, so werden die Spitzel zu höchst lächerlichen Narren. Sie versuchen anderen Fallen zu stellen, in die sie aber dann selber geraten. Verkehrte Schelme sind sie auch darin, daß sie ihren Auftraggebern hörig sind und sie nicht verunglimpfen. Rotgimpel meldet weiter an jemand namens "Rotkopfwürger," der zweite Agent "Ackergaul" hat "Stallmeister" zum Vorgesetzten; der dritte, eine Frau, ist "Rotmolch," ihr Herr ist "Majordomus." Daß die Spitzel verhaftet und sogar "peinlich" (492) verhört werden, stört ihre Loyalität-oder genauer, Servilität—nicht.

Man sinnt darauf, die Anstrengungen in der Radikalenjagd zu verschärfen, indem man die Gesinnung der Bevölkerung schon am Gesichtsausdruck ermitteln und ein Forschungsinstitut für "Gesinnungsphysiognomik" (499) gründen will. Hier deutet Böll auf den totalen Staat. Man denkt an die frühe Geschichte "Mein trauriges Gesicht," wo der falsche Gesichtsausdruck-in Orwells 1984 ist es "Facecrime" - die Menschen zu hart bestraften Staatsfeinden macht. Glaubt man, die Menschen mechanisch einstufen zu können, so ist vorauszusetzen, daß man selber Roboter ist. Das gilt für die Spitzel. Sie marschieren starr in die programmierte Richtung und zeichnen sich aus durch die Fähigkeit, alles und jedes auf eine lächerliche, aber auch beängstigende Mechanei zu reduzieren. Es wimmelt in ihren Berichten von Abkürzungen: "rb; sb; bb" (475); "undiff.; diff.; überdiff.; superdiff.," von Aufzählungen: "Personen: kannten Sartre 204 / davon schätzten Sartre 78 / verteidigten Sartre 23" (498), von Zahlen und Reihungen:

Während ich mit Rotmolch 3 die Diskussion bestritt, verließen Rotmolch 2, 4 und 5 unauffällig die Szene und erkundeten in den Klassenzimmern die Lehrerpulte, soweit sie nicht verschlossen waren. Es wurden an insgesamt 7 Schulen 112 Pulte erkundet. Ergebnis: 4 Fotos von Rosa Luxemburg. Ziemlich 
viele Unterlagen über den Bauernkrieg, 1848, 1918; DDRBroschüren, einschlägige Zeitungen. Leninismus. Plakate und Postkarten von Staeck. Wagenbach, Wallraff, Konkret, das da (491).

Böll setzt weiterhin Jargon zur Verzeichnung des Objekts ein. Man bewegt sich überall auf irgendeiner "Szene." Das Wort erscheint allein oder im Kompositum fünfzehnmal, so z.B. als "Sympathisantenszene," "rf-Szene," "Kunstszene," "Anarchoszene" oder "Pornoszene" (477-83). Der Jargon im Munde der Spitzel ist Böll Mittel zur Dechiffrierung und Diffamierung des Objekts. Das Wort Szene ist zunächst einmal Bölls beleuchtendes Code-Wort für die Lage der Nation. Sie ist in Anbetracht der für unnotwendig erachteten Radikalenerlasse etwas Inszeniertes, In-Szene-Gesetztes. Das Wortfeld enthält aber auch einen positiven Aspekt, damit einen Hinweis auf die erhoffte Kurzfristigkeit der Lage. Szenen gibt es besonders im Drama. Dort sind sie Perioden kurzer Dauer, im allgemeinen Sprachgebrauch sind sie sogar nur Zwischenfälle.

Zur Verzeichnung der Spitzel greift Böll, wie schon mehrfach in seinen Satiren, zum Tierbezug. Die Namen der Spitzel-Rotgimpel, Ackergaul, Rotmolch-schrumpfen diese, besonders im Hinblick auf ihr unterwürfiges Verhältnis zu ihren Vorgesetzten, deren Machtstatus sich schon in ihren Namen Rotkopfwürger, Stallmeister, Majordomus verrät. ${ }^{5}$

Böll führt seine Orientierung am Aktuellen in diesem Text fort. Wie in "Hauptstädtisches Journal" gibt das spezifische historische Ereignis den Anlaß. Das Dokumentaristische erscheint in der Form des fingierten Berichts und Zitats, vergleichbar mit der Brief-Form in "Briefe aus dem Rheinland" und "Briefe an einen Freund jenseits der Grenzen." So sehr sich Bölls dokumentaristische Satireform vom alten Muster unterscheidet, so steht er keineswegs außerhalb satirischer Traditionen. Die journalistische, sich auf Tagesphänomene beziehende und darum oft kurzlebige Satire findet sich bekanntlich bei Karl Kraus, Heine und auch wieder bei Swift. Unter den Irish Tracts ist zum mindesten ein Text, "A Modest Proposal," der die Zeiten so gut überdauert hat wie die mythus-geprägten Werke Swifts. Ob Bölls dokumentaristischen Arbeiten ein langes Leben beschieden ist, mag bezweifelt werden. Schon die Menge der tagesbezogenen Fakten und Anspielungen dürfte ausschlaggebend sein. Im Gegensatz etwa zu "A Modest Proposal" sind sie in den "Brief"-Satiren und hier in "Berichte" so zahlreich und detailliert, daß sie das Gedächtnis des Lesers zweifellos schon heute strapazieren.

In "Erwünschte Reportage" (1975) liegt kein einschneidendes poli- 
tisches Ereignis vor. Aktuelles und sehr Ungewöhnliches existiert jedoch insofern, als Böll hier von einer Reportage über einen Landund Forstarbeiter namens Heinrich Sohlweg spricht, der eine tarifliche Lohnerhöhung zurückgewiesen und das Geld seinem Arbeitgeber, einem Grafen Kleroth, "nicht demonstrativ, sondern überzeugt" $\left(\mathrm{W}_{5}, 500\right)$ zurückgegeben habe. Die Überzeugungen Sohlwegs sind höchst erstaunlich: "Der Graf, so sagt er, sei nun einmal sein Herr, der Besitz seines Herrn sei ihm heilig, und jeder Groschen, den die Roten seinem Herrn abknöpften, sei eine Verminderung des Herrentums, dem er sich freiwillig, fröhlich unterwerfe" (503). Diese pathetische Erklärung bietet dem Leser zwei Möglichkeiten. Entweder ist Sohlweg ein Irrer, der sein Glück in der Restauration feudalistischer Leibeigenschaft wähnt, oder seine Formel hat gegen den Strich gelesen $\mathrm{zu}$ werden. Das erstere ist so gut wie ausgeschlossen, denn seine Familie stützt ihn, obwohl sie völlig zurechnungsfähig zu sein scheint: "Nun könnte man annehmen wollen, daß die Familie Sohlweg duckmäuserisch oder gar muffig sei: das Gegenteil ist der Fall" (502).

Die Frage ist nun, wie ist Sohlwegs "Philosophie" (503) gegen den Strich zu lesen und was bezweckt sie? Zunächst sticht ins Auge, daß Sohlweg das Verhältnis von Arbeiter und Herr auf seine feudalistische Basis zurückwirft. Dadurch fördert er den Kern der Dinge zutage, um die es zwischen Arbeiter und Arbeitgeber geht, nämlich das Herrschaftsprinzip. In seinem Tun und Reden demonstriert Sohlweg bewußt und konkret an einem feudalistischen Modell, was die Gewerkschaften und Arbeiter abstrakt und unbewußt tun, wenn sie um Lohnerhöhungen kämpfen. Sie unterwerfen sich zwar nicht einem persönlichen Herrn, aber dem übergreifenden Prinzip der Herrschaft, die sie vom Arbeitgeber auf sich übertragen wollen. Wichtig ist, daß Sohlweg die Lohnerhöhung ablehnt, "nur weil er sie gewerkschaftlichen Tarifverhandlungen verdankt" (500). Anstößig an den Gewerkschaften ist eben, daß sie nach demselben Prinzip und im selben Bewußtsein antreten wie die Arbeitgeber. Dazu erklärt Sohlweg: "Nicht mein Herr soll mir unterworfen sein, sondern ich ihm" (502): Indem Sohlweg aber in diesem pathetischen Satz offensichtlich " $\mathrm{zu}$ weit geht," verweist er auf den Modus operandi in einer Gesellschaft, wo es um Beherrschte und Herrschende geht. Die Arbeiter sind sich dieses Faktums allerdings nicht bewußt. Man sieht unklar. So geben einige $\mathrm{zu}$, daß ihnen Sohlwegs "Grundgedanken nicht unsympathisch sind," sie "schämen" (503) sich aber, es ihm gleichzutun. Dahinter liegt ein unerkanntes Paradox: Man sieht den Herrn als Feind, nicht aber das Herrschaftsprinzip. Bleibt dieses intakt, so dauert auch die materielle Ungleichheit an. Jeder Sieg der Gewerkschaften stützt 
somit das Herrschaftsprinzip. Der Unterschied ist nur, daß das Herrschen von Zeit zu Zeit in andere Hände übergeht. So gesehen hat Sohlwegs Ablehnung der Lohnerhöhung einen Sinn. Er lehnt die Mentalität ihrer Gewinnung ab.

In historischer Perspektive ist Sohlwegs Manifest nicht so inkriminierend für einen Leibeigenen wie die Mentalität der heutigen Arbeiter im Lohnkampf. Dem Leibeigenen stand kein Gegenmodell zur Verfügung, wie dem heutigen Arbeiter; überdies begreift sich dieser im Gegensatz zum Leibeigenen als frei, sollte aber gerade am letzteren lernen, was Freiheit wäre. Sohlweg selber fällt keineswegs ins Mittelalter zurück, bezweckt das auch nicht für andere. Sein Tun ist Symbol. Er will ein "Zeichen" (503) setzen. Vom Geist der Leibeigenschaft ist, wie gesagt, außer seiner Eulenspiegelei nichts an ihm und seiner Familie zu entdecken. Sohlweg lehnt es ab, mit dem Grafen zu trinken, die Kinder "weigern sich, Geld und Geschenke anzunehmen, die die junge Gräfin ihnen gelegentlich zustecken möchte." Überdies wird von Äußerungen der Kinder berichtet, die nicht gerade mit den Tönen, die ihr Vater in der Öffentlichkeit anschlägt, übereinstimmen. So soll die zwölfjährige Tochter gesagt haben: "Diesem feudalistischen Ausbeuterschwein die Piepen zurückzugeben!" (502). Sohlwegs Aktion bezweckt nicht Restauration feudalistischen Denkens, sondern ein Bewußtmachen, daß dieses Denken noch existiert. Man hat an die Formel des Wegwerfers zu denken. Auch Sohlweg wirft weg, um im Konzentrat ein anstößiges Prinzip zu entlarven. Allerdings tut Sohlweg bewußt, was die Wegwerferfigur nicht voll begreift.

Es fragt sich jedoch, warum Sohlweg seine zur Erkenntnis verhelfende Aktion so verhohlen anlegt. Warum sagt er nicht etwa rundheraus, was er meint? Zum einen bilden faszinierende Ungereimtheiten-Sohlweg ist sogar "unheimlich," und zwar "allen Beteiligten, Interessierten und Betroffenen" (503)—das Bewußtsein wirksamer, wenn sie vom Leser selbst durchschaut werden; zum anderen spiegelt Sohlwegs Tun das des Satirikers, der durch Verstellung zur Wahrheit und Norm führt.

Da wir in Sohlweg keinen monumentalen Narren sehen können, ist er zwangsläufig ein genialer Schelm und somit Praktikant der Zersetzungsnorm. Seine Klugheit zeigt sich auch darin, daß er erkennt, wie wichtig die Tarnung für ihn ist. Das macht er anscheinend auch seiner Familie klar. Die Kinder "leugnen" (502) die ihnen zugeschriebenen Äußerungen. Notwendig ist die Tarnung, weil der Sinn der Aktion Sohlwegs im Bewußtsein des einzelnen aufgehen muß, um dieses zu verändern. Das scheint auch der Sprecher zu erkennen, 
wenn er sich der Explikation enthält. Die Entdeckung Sohlwegs als Schelm in der Presse würde den Fokus von der Sache auf den Schelm verschieben, und die Sache könnte leicht als kapitaler Spaß belacht werden.

Um den Leser bei der "Sache" zu halten, ist Sohlweg eine sehr unprofilierte Figur. Sie bleibt im flachen Licht der journalistischen Berichterstattung. Wieder hat der Text eine dokumentaristische Note. Es werden Erklärungen im Wortlaut zitiert. Dem Berichterstatter geht es um journalistische Genauigkeit. Er kennt sich in der Presse aus und gehört ihr vermutlich an. Er ist der Sprecher, der im großen und ganzen von der Bewußtseinswarte des Satirikers berichtet, wie der in Die verlorene Ehre der Katharina Blum und in "Veränderungen in Staech," aber hier ganz besonders objektiv und zurückhaltend zu sein hat, damit der Leser selber zu einem Bild kommt_-anstelle eines verabreichten, wie eben in den Praktiken der Bild-Zeitung. An diese hat man schon im Titel zu denken. Es geht um "Reportage" und unter dem Titel heißt es: "Georg Weerth zum Gedächtnis und Günter Wallraff gewidmet" (500). Wallraff ist Praktikant zersetzender Reportagen über den Gerling-Konzern und Melitta, der Enttarner in Portugal und, 1977, sogar Unterwanderer der Bild-Zeitung, deren "unerwünschte" Reportage-Praktiken er aufdeckte; ${ }^{6}$ darum ist er Verbündeter Bölls in "erwünschter" Reportage, wie dieser sie hier vorlegt. In all seinen Eskapaden ist Wallraff der geniale Schelm und damit ein Hinweis auf das richtige Verständnis Sohlwegs. Kommt der Schelm von Wallraff, so der denkende Arbeiter von Weerth, dem die deutsche Literatur in Fragment eines Romans ihren ersten klassenbewußten Arbeiter verdankt.

Die Technik der dokumentaristischen Berichterstattung ist so sehr auf Objektivität geeicht, daß an Micromegas-Technik nur die fundamentale Verstellung Sohlwegs anfällt. Er geht den "tiefen Weg," wie sein Name zu deuten wäre. Außer Sohlwegs.Aktion findet sich keine Verzerrung ins Unwahrscheinliche. Wie Sohlweg stehen die übrigen Personen in flacher Beleuchtung und sind fast völlig frei von Verzeichnung. Allerdings kann man nicht umhin, dem gräflichen Fossil Kleroth ein " $S$ " vor den Namen zu denken. Der satirische Ton bleibt gewissermaßen unterschwellig, solange wir nicht über Sohlwegs Schelmenstück im klaren sind. Es komplementiert also der Stil die Schelmenfigur, die sich erst dann als solche zeigen darf, wenn die intendierte Unheimlichkeit zum Denken gereizt und zum Erkennen geführt hat. Zwar hat dieses etwas von dem der Parabel, aber es ist letztlich doch satirisch, weil es auf Verstellung und Spott beruht. Sohlweg als Maske Bölls ist nur ein invertierter Paraboliker, aber ein 
echter Schelm; er macht seine Pointe im Gegensatz zum echten Paraboliker nicht nur zum Zwecke der Erkenntnis, sondern auch zur Verhöhnung des Herrschaftsprinzips als Objekt.

Den soweit letzten Schelm stellt Böll in "Geständnis eines Flugzeugentführers" (1977) vor. Ein Sowjetbürger versucht, sich einen Urlaub in Kopenhagen zu verschaffen. Versehen mit einer Holzpistole will er ein Flugzeug entführen. Sein Ansinnen mißlingt. In seinem "Geständnis" ist vor allem seine extreme Lobhudelei des Staates wichtig. Selbst die sowjetische Schuhkrem, mit der er seine Holzpistole schwärzte, preist er als "unvergleichlich" (H, 76). Das ist selbst dem Ankläger zu viel. Er hakt hier ein, um den Flugzeugentführer als einen Lügner zu entlarven, der nicht Urlaub machen, sondern flüchten wollte, denn jedermann wisse, daß die sowjetische Schuhkrem "wenn nicht gerade schlecht, so doch nicht so gut sei, wie der Angeklagte vorgebracht habe" (77). Aber damit deckt der Ankläger unwillentlich die Kardinallüge des Staates auf, die in dessen Perfektionsanspruch besteht, und aufgrund dessen er seine Bürger zu ihrem vermeintlich eigenen Guten davon abhält, das Paradies zu verlassen.

Der Flugzeugentführer ist derselbe Schelm wie Sohlweg in "Erwünschte Reportage." Seine konsequente "Affirmation" deckt das anstößige Prinzip, hier die Unfreiheit, auf. In diesem Text wendet sich Böll wieder stärker einer Mittelpunktfigur zu. Das Geständnis malt den Charakter des Schelms breit aus. In seinem Zersetzungsbestreben versucht er noch energischer als die Mönche in "Veränderungen in Staech" "zu weit zu gehen." Das bedeutet hier zwar ein sehr großes Risiko, jedoch wird es durch die Klugheit des Schelms geringer. Die Anlage des Geständnisses ist erfolgreich. Der Ankläger fordert "nicht die Höchst-, aber eine hohe Strafe" (77).

Im Gegensatz zu den früheren gebrochenen Figuren zeigt der Schelm einen Satiriker, der sich seiner Position und Sache prinzipiell sicher ist. Die Aufforderung zur "Entfernung von der Truppe" gilt unvermindert weiter. Sie vollzieht sich jedoch in deren Mitte, gewissermaßen unter der Hand, bisweilen sogar mit höflicher Miene, aber nicht zu besänftigendem Grimm. 


\section{x. Schluß}

Einer der schwerwiegendsten Vorwürfe, den man gegen einen Schriftsteller erheben kann, ist, ihm ein Auseinanderklaffen von Intention und Leistung anzulasten. Ist er Satiriker, und man verdächtigt ihn, seine Angriffe verwirklichten sich strukturell als Stützen des Gemeinten, so entzieht man ihm geradezu seinen Innungsschein. Auch Böll ist dieser Abwertung sehr nahegekommen, wenn man vermutet hat, seine Schläge seien nicht allzufern von Absolutionen. Nicht, daß gemeint wäre, Böll sei sich bewußt, unter der Hand ein sklerotischbürgerliches Establishment zu befürworten. Das Indiz richtet sich keineswegs gegen ausdrücklich vertretene Werte. Man glaubt bisweilen, daß die gute Gesinnung, die man Böll nicht abstreitet, in seinem Werk nicht struktur-integral wird.

An den Satiren gemessen läßt sich dieses Indiz gegen Böll sehr weitgehend entkräften. Die Ausnahme ist Die verlorene Ehre der Katharina Blum. Hier sind die Signale in der Tat verwirrend. Interessanterweise handelt es sich bei diesem Werk um einen dem Augenschein nach sehr harten Text. Der allgemeiner suspekte Böll ist jedoch der frühere und, dem Anschein nach, sanftere der fünfziger Jahre. Aber gerade dieser ist insofern ohne satirisches Fehl, als das Bezugssystem der strukturellen Polaritäten derart stimmig ist, daß ohne Schwarzweißmalerei dennoch klare, wennschon komplexe und dialektische Unterscheidungen dargestellt werden. Böll urteilt und verurteilt, er erkennt jedoch auch die in der Erfahrungswelt nötigen Relativierungen des Urteils. Aber was milde wirkt, ist keine Absolution. Er erteilt sie selbst den "positiven" Personen nicht. Auch diese werden trotz aller ihrer Bedrohtheit "ästhetisch" im Humor bestraft, weil sie sich in einer empörenden Welt akkommodieren.

Böll ist vor Mißverständnissen insofern nicht geschützt, als seine großen Unterscheidungen in subtilen Nuancen erscheinen. Besonders in den "Murke"-Texten macht er es sich nicht leicht. Begründet ist seine Komplexität, wie die aller Satiriker von Rang, im Verantwortungsgefühl und dem Bewußtsein, sowohl Angreifer wie auch Teil des Angegriffenen sein zu müssen. Nichtsdestoweniger erfordert das Handwerk des Satirikers, der sich einer hohen Norm verschreibt, die resolute Vernichtung des Anstößigen. So ist er Sieger, aber auch, an der Wirklichkeit und Erfahrungswelt gemessen, in seiner Erscheinungsform als Protagonist der Versager und weiterhin der Pfuscher, 
der sich um den Rang des Vir bonus bemüht. Man wird dem Satiriker Böll der fünfziger Jahre nicht gerecht, wenn man sich nicht über die genaue Konfiguration seiner doppelbödigen Norm im klaren ist.

Das komplexe Wertgefüge der "Murke"-Texte baut der breiteren Rezeption keine goldenen Brücken. Man mag es übersehen und das Satirische auf einen genüßlich $\mathrm{zu}$ konsumierenden Humor reduzieren. Verschließt man sich aber dieser leichtfertigen Sicht, so mag möglicherweise Walter Jens schon das endgültige Urteil über den Satiriker Böll gefunden haben, wenn er glaubt, daß dessen Schaffen in den "Murke"-Satiren gipfelt. Selbst wenn diese Fixierung zum Konsens der zukünftigen Kritik werden sollte, so würde man weiterhin Verständnis für Bölls Zuwendung zu einem unkomplexeren Satiremuster aufzubringen haben. Überspitzt formuliert schließt sich Böll in den sechziger und siebziger Jahren der allgemeinen Sicht an, daß der Mißerfolg der Kunst im Prozeß der sozialen Veränderung sich daraus erkläre, daß Kunst eben traditionell, als nur Kunst, nicht aber als Faktor der Wirklichkeit begriffen wird. Für Bölls späteres Satiremuster meint das eine Vereinfachung der Norm. Um Mittel zur Veränderung der Welt sein zu können, ist sie jetzt einsträngig, denn sie mißt ausschließlich am Möglichen in der Erfahrungswelt.

$\mathrm{Zu}$ den erlaubten Perspektiven in der Ermittlung literarischen Ranges gehört die Bezugsetzung eines Autors zu den Klassikern und den Traditionen seines Metiérs. Obwohl diese Studie keineswegs eingehende Vergleiche z.B. zu Swift betreibt, so kann jedoch kein Zweifel bestehen, daß der in Bölls publizistischem und fiktionalem Werk wiederholt erscheinende Swift seinen Schatten auf die Satiren des "Murke"-Musters geworfen hat.

Es liegt verständlicherweise nahe, über Bölls weiteres Schaffen zu mutmaßen. Mit Sicherheit dürfte nur anzunehmen sein, daß er sich weiterhin als Satiriker äußern wird. Hier liegt seine vornehmliche Anlage. Eine Rückkehr zu seinem früheren Satiretypus ist jedoch unwahrscheinlich. Zwar ließe sich die Wiederkehr des versagenden Helden als Apologie für den Schelm denken, sofern auch dieser sich als untauglich zur Veränderung der Welt erweisen sollte, aber ausschlaggebend dürfte ein anderes Moment sein. Die Wiederbelebung des alten Strukturtypus wäre ein epigonaler Rückfall. Gäbe es nicht "Doktor Murkes gesammeltes Schweigen," "Der Wegwerfer" oder auch Ansichten eines Clowns, so könnte Böll diese Texte vielleicht noch schreiben, denn Epigone seiner selbst ist man wohl kaum, solange man sich steigert. Wenn es mir scheint, daß Böll als Satiriker diese Arbeiten unter Wiederaufnahme ihres Musters nicht in den Schatten stellen kann, so spricht das nicht gegen Böll, sondern für diese großen Satiren. 


\section{Anmerkungen}

\section{Einleitung}

1. Siehe den kritischen Überblick über die Böll-Rezeption von Rainer Nägele, Heinrich Böll: Einführung in das Werk und in die Forschung (Frankfurt: Athenäum Fischer, 1976), S. 40-70.

2. Hierzu einige Stimmen, die sich auf den Band Doktor Murkes gesammeltes Schweigen und andere Satiren (Köln: Kiepenheuer und Witsch, 1958) beziehen: Wilhelm Westecker, "Gesammeltes Schweigen," Christ und Welt, Stuttgart, 31. 7. 1958: "Zeitsatiren von Format ... [Die Lust zu verspotten] macht die Satiren zu kleinen Meisterwerken ... denen die deutsche Literatur heute nichts an die Seite zu setzen vermag," Helmut Ullrich, "Aus der Welt der Schrörschnauzaschenbecher," Neue Zeit, Berlin, 30. 1. 1959: "[Böll] zeigt eine Seite seines Talents, die allein schon genügte, ihn als einen Meister der Literatur auszuweisen," Wolfgang Kraus, "Böll als Satiriker," National-Zeitung, Basel, 8. 5. 1958: "Seine Satiren . . . sind schlechthin Meisterwerke ihrer Art," James Henderson Reid, Heinrich Böll: Withdrawal and Re-emergence (London: Oswald Wolff, 1973), S. 62: "Satire like Nicht nur zur Weihnachtszeit, Doktor Murkes gesammeltes Schweigen and Der Wegwerfer . . . must be ranked among Böll's most unreservedly successful works."

3. Walter Jens, Deutsche Literatur der Gegenwart (München: Piper, 1961), S. 147.

4. Theodor W. Adorno, "Keine Würdigung," in In Sachen Böll, Hrsg. Marcel Reich-Ranicki, 3. Aufl. (Köln: Kiepenheuer und Witsch, 1970), S. 10.

5. Werner Koch, "Ein paar Stichworte: Personen und Situationen: Ein Gespräch mit Heinrich Böll," in Der Schriftsteller Heinrich Böll, Hrsg. Werner Lengning, 4. Aufl. (München: Deutscher Taschenbuch Verlag, 1973), S. 104.

6. Hans Magnus Enzensberger, Einzelheiten (Frankfurt: Suhrkamp, 1962), S. 220 .

7. Theodore Ziolkowski, "Heinrich Böll: Conscience and Craft," Books Abroad, 34 (1960), 215.

8. Rainer Nägele, Heinrich Böll: Einführung, S. 85 .

9. Wolfdietrich Rasch, "Lobrede und Deutung," in Der Schriftsteller Heinrich Böll, S. 10.

10. Hans Joachim Bernhard, Die Romane Heinrich Bölls (Berlin: Rütten und Loening, 1970), S. 19, 117, 119, 150, 210, 304. 


\section{II. "Doktor Murkes gesammeltes Schweigen": Paradigmatische Linien}

1. Böll hat dies in einem Brief an Klaus Jeziorkowski ausgedrückt. Klaus Jeziorkowski, Rhythmus und Figur (Bad Homburg: Gehlen, 1968), S. 41.

2. Cesare Cases, "'Die Waage der Baleks', dreimal gelesen," in In Sachen Böll, S. 225.

3. Enzensberger, S. 219; siehe auch Bernhard, S. 303.

4. Edgar Johnson, Hrsg., "The Nature and Value of Satire," in A Treasury of Satire (New York: Simon and Schuster, 1945), S. 3.

5. Robert C. Elliott, The Power of Satire: Magic, Ritual, Art (Princeton: Princeton University Press, 1960); Northrop Frye, Analyse der Literaturkritik, Übers. Edgar Lohner und Henning Clewing (Stuttgart: Kohlhammer, 1964); Ronald Paulson, The Fictions of Satire (Baltimore: The Johns Hopkins Press, 1967).

6. Peter Demetz, "Zur Situation der Germanistik: Tradition und aktuelle Probleme," in Die deutsche Literatur der Gegenwart, Hrsg. Manfred Durzak (Stuttgart: Reclam, 1971), S. 326.

7. Jürgen Brummack, "Zu Begriff und Theorie der Satire," Deutsche Vierteljahresschrift für Literaturwissenschaft und Geistesgeschichte, 45, Sonderheft (1971), 349.

8. Jonathan Swift, A Tale of a Tub, in The Prose Works of Jonathan Swift, Hrsg. Herbert Davis, (Oxford: Shakespeare Head Press, 1939), I, Vorstellblatt. Eng verwandt ist Bur-Malottke auch mit dem Kapitalisten Arnheim in Musils Der Mann ohne Eigenschaften. Wie dieser ist er ein Hans-Dampf-in-allen-Gassen des Intellektualismus. Wie Musils stark verzeichnete Figur Geld zu Dichtung macht, erhöht Bur-Malottke das "Kulturwort" zu Kulturmystik.

9. Theodor W. Adorno, Jargon der Eigentlichkeit, 5. Aufl. (Frankfurt: Suhrkamp, 1970), S. 18.

10. Sehr stark klingt hier eine Stelle bei André Gide-Les Faux-Monnayeurs (Paris: Gallimard, 1925), S. 498-an: "J'ai souvent pensé que la Parole de Dieu, c'était la création tout entière. Mais le diable s'en est emparé. Son bruit couvre à présent la voix de Dieu. Oh! dites-moi: est-ce que vous ne croyez pas que, tout de même, c'est à Dieu que restera le dernier mot?"

11. Stefan Heym, "Das Establishment und die Verantwortung," in In Sachen Böll, S. 195.

12. Heinrich Böll, "Eine Welt ohne Christus," in Was halten Sie vom Christentum? 18 Antworten auf eine Umfrage, Hrsg. Karlheinz Deschner (München: Paul List, 1957), S. 22.

13. Bernhard, S. 38.

14. Sören Kierkegaard, "Der Begriff der Angst," in Gesammelte Werke (Jena: Diederichs, 1923), V, 36-37. Die Angst, die dem Augenblick der Entscheidung vorausgeht-bei Murke wäre dieser das Nachdenken über Bur-Malottkes Gottesvorstellung - - besteht nach Kierkegaard aus Repulsion und Attraktion. Sie hat für ihn "psychologische Zweideutigkeit. . . . Angst ist eine sympathetische Antipathie und eine antipathetische Sympathie... Denn wer durch Angst schuldig wird, ist ja unschuldig; es war ja nicht er selbst, son- 
dern die Angst, eine fremde Macht, die ihn ergriff, eine Macht, die er nicht liebte, vor der er sich vielmehr abängstete; und doch ist er schuldig: er versank in der Angst, die er doch liebte, während er sich fürchtete. Es gibt in der Welt nichts Zweideutigeres als dies. . . ."

15. In Murkes Alptraum und der Angst seiner Paternosterfahrten liegt zweifellos auch etwas von der "bedrohlichen Wirklichkeit," die Ulrich GaierSatire: Studien $z u$ Neidhart, Wittenweiler, Brant und zur satirischen Schreibart (Tübingen: Niemeyer, 1967), S. 341, 344-als das Urobjekt der Satire requiriert. Sie ist zunächst "gestalt- und gesichtslos." Traum und Paternoster wären dann Beispiel für die vom Satiriker eingesetzte Metapher der bedrohlichen Wirklichkeit. Verstehen wir aber gleicherweise Bur-Malottke nur als deren Einschränkung Pars pro toto (erst in Metapher und Synekdoche kann nach Gaier das "Urböse" greifbar werden), so können wir Gaier nicht folgen. Man stellt ein Moment der Verschiebung ins Abstrakte fest, das dem im romantischen Humor ähnlich ist. Ist das wahre Objekt derart kosmisch, so verschwindet dahingegen die Person, und es wird in der Leserrezeption einem unerwünschten kathartischen Element Vorschub geleistet, da der Feind sich in seiner Winzigkeit nur als Opfer und Einstand für das unfaßbare Böse begreifen ließe. So könnte die auch bei Gaier vom Satiriker geforderte Rückübersetzung des repräsentionalen Objekts in die gemeinte Wirklichkeit sehr leicht statt dessen zu einer Rück-Bezugsetzung auf das unfaßbare Böse führen. In "Dr. Murke" wäre etwa das satirische Objekt nicht das von Menschen geschaffene und darum abschaffbare Herrschaftsprinzip, sondern nichts geringeres als etwa die gefallene Welt.

16. Böll, "Eine Welt ohne Christus," S. 22.

17. Hans Werner Richter, "Warum schweigt die junge Generation?" Der Ruf, 1. 9. 1946.

18. Dieter E. Zimmer, "'Doktor Murkes gesammeltes Schweigen'," in In Sachen Böll, S. 271.

19. Siegfried Lenz, "Sein Personal," in In Sachen Böll, S. 39.

20. Hans Mayer, Zur deutschen Literatur der Zeit (Reinbek bei Hamburg: Rowohlt, 1967), S. 313.

21. Reid, Heinrich Böll: Withdrawal and Re-emergence, S. 28.

22. So befremdlich vorderhand die Heldenkategorie gerade im Falle Bölls anmutet, so liegt darin möglicherweise gerade etwas Typisches bei Menschen seines Schlages. So heißt es bei Thomas Mann-Joseph und seine Brüder in Gesammelte Werke (Frankfurt: Fischer, 1960), V, 1799- "Es ist merkwürdig: die Schwäche der Sanften und Geistigen ist die Schwäche fürs Heldische."

23. Friedrich von Schiller, "Über naive und sentimentalische Dichtung," in Werke: Nationalausgabe, XX, Hrsg. Benno von Wiese (Weimar: Hermann Böhlaus, 1962), 449.

24. Jörg Schönert, Roman und Satire im 18. Jahrhundert (Stuttgart: J. B. Metzler, 1969), S. 9; Friedrich Sengle, Die literarische Formenlehre (Stuttgart: J. B. Metzler, 1967), S. 28-37; Paulson, The Fictions of Satire, S. 4.

25. Paulson, The Fictions of Satire, S. 7.

26. Frye, S. 133-243: Die Vorbedingungen zum Schema Fryes sind nach 
Ronald Paulson-Hrsg., Satire: Modern Essays in Criticism (Englewood Cliffs: Prentice Hall, 1971), S. XII-folgende: "[T]he writers on satire in the 1940s and 1950 attempted to distinguish "satire" as a form from "satiric" - a general tone. The beginnings of this development, however, were in anthropology and classical philology, with exploration of the magic powers of the satirist and the meaning of satura - the term designating Roman formal verse satire. With the impact of Fraser's Golden Bough and F. M. Cornford's Origin of Attic Comedy, the form of the fertility ritual affected theories of all the major genres. If the ritual combat (agon) between the Old Year and the New, Summer and Winter, Rainfall and Drought, the Old King and the New, is divided into segments, a series of actions can be formulated. The death of the oldthe element of sacrifice-is the chosen province of tragedy; the victory of the new (becoming associated with the true) is the focus of comedy; and the exorcising of the old, sterile, and false (process rather than, as in the other two cases, drama) is that of satire."

27. Frye, S. 195.

28. Frye, S. 232.

29. Frye, S. 232.

30. Frye, S. 232.

31. Schiller, S. 442-43.

32. Alexander Pope, "Imitations of Horace," in The Twickenham Edition of the Poems of Alexander Pope, Hrsg. John Butt, 2. Aufl. (London: Methuen, 1953), IV, 324 .

33. Schiller, S. 442.

34. Samuel Butler, Characters and Passages from Note-Books, Hrsg. A. R. Waller (Cambridge: Cambridge University Press, 1908), S. 469.

35. Elliott, S. 19.

36. Zimmer, S. 272.

37. Alvin B. Kernan, "A Theory of Satire," in Satire: Modern Essays in Criticism, S. 270. Der anstößige Zustand bleibt in der dargestellten Wirklichkeit nur dann nicht intakt, wenn das Werk stark zur Komödie tendiert, wie z.B. Wolf Biermanns Der Dra-Dra.

38. Astrid Swift, Hrsg., Einleitung, Die englische Satire (Heidelberg: Quelle und Meyer, 1974), S. 30.

39. Paulson, The Fictions of Satire, S. $76,75$.

40. Helmut Arntzen, "Deutsche Satire im 20. Jahrhundert," in Deutsche Literatur im 20. Jahrhundert: Strukturen und Gestalten, Hrsg. Otto Mann und Wolfgang Rothe, 5. Aufl. (Bern und München: Francke, 1967), I, 235.

41. Paulson, The Fictions of Satire, S. 140, 196.

42. Jonathan Swift, "Verses on the Death of Dr. Swift," in The Poems of Jonathan Swift, Hrsg. Harold Williams, 2. Aufl. (Oxford: Clarendon Press, 1958), II, 571.

43. Siehe hierzu Bernd Balzer, Hrsg., "Vorwort: Heinrich Bölls Werke: Anarchie und Zärtlichkeit," in Heinrich Böll: Werke: Romane und Erzählungen (Köln: Kiepenheuer und Witsch, 1977), I, [9]-[128]; Joachim Kaiser, "Heinrich Bölls Charme," in Der Schriftsteller Heinrich Böll, S. 76; Karl Korn, "Heinrich Bölls 
Beschreibung einer Epoche," in Der Schriftsteller Heinrich Böll, S. 112; Carl Amery, "Eine christliche Position," in In Sachen Böll, S. 124.

44. Amery, S. 124.

45. Schiller, S. 442.

46. Wyndham Lewis, "The Greatest Satire is Nonmoral," in Satire: Modern Essays in Criticism, S. 71.

47. Sehr eklatant stoßen wir auf die ästhetische Verletzung der Person als Teil des Humors auch in der Szene in Gruppenbild mit Dame, wo Leni eine Toilette entstopft. Sie fährt mit dem Arm bis über den Ellbogen hinein und kommentiert: "Unsere Dichter sind die mutigsten Kloreiniger gewesen," W5, S. 87 . Leni wäre nicht sie selber, wenn sie ihre Bemerkung nur figurativ meinen würde. Ihr Kloakenreinigen, komisch im Hinblick auf ihren bedeutungsschwangeren Kommentar, ist wie das figurative Kloakenreinigen der Dichter etwas mit Widerwillen zu Leistendes im Sinne einer Verletzung oder Beschmutzung der Person, obwohl diese moralisch makellos ist. Leni und die Dichter sind in ihrer Tätigkeit solidarisch, sie sind sowohl Subjekt des Verletzens wie Objekt der Verletzung. Als literarische Figur ist Leni jedoch nur Objekt. Der Dichter bürdet ihr die Beschmutzung auf. Das "Un-ästhetische," so hat betont zu werden, ist allerdings kein Wert an sich. Auch das geht sehr genau aus dieser Episode hervor. Leni nimmt die Beschmutzung an, aber sie unterzieht sich danach einer derart übersorgfältigen Reinigung, daß man nicht umhin kann, sie als verletzt zu sehen. Wichtig ist hier, daß Leni nicht im satirischen Kontext steht, und darum nimmt der Dichter die Verletzung zurück, oder, umgekehrt, er gibt Leni, nachdem sie ihre parabolische Pointe geleistet hat, was er ihr genommen hatte, das "Ästhetische," figurativ zurück. Nachdem sie sich wieder und wieder gewaschen hat, reibt sie ihre Arme überdies mit Kölnisch-Wasser ab. Seinen satirischen Figuren läßt Böll im Gegensatz zu Leni keine Waschung zuteil werden. Der ästhetische Makel gehört zu ihnen, wie sie zur Satire gehören.

48. Marie Collins Swabey, Comic Laughter (New Haven and London: Yale University Press, 1961), S. 88.

49. Klaus Lazarowicz, Verkehrte Welt (Tübingen: Niemeyer, 1963), S. 248, 253.

50. Akzeptiert die Forschung den Terminus "erhabener Humor," den Böll in Anlehnung an Jean Paul als Kennzeichen des stützenden Humors entwickelt, so muß festgehalten werden, daß die Formel nicht von Jean Paul stammt. Bei diesem ist der Humor die Inversion des Erhabenen, bei Böll das Erhabene im Kleinen (d.h. gesellschaftlich abfällig Behandelten). Die Divergenz beruht auf einem Zitatfehler. In "Frankfurter Vorlesungen" zitiert Böll Jean Paul: "'Der Humor als das umgekehrt Erhabene vernichtet nicht das Einzelne, sondern das Endliche durch den Kontrast mit der Idee'," ESR2, S. 88. Bei Jean Paul_-"Vorschule der Aesthetik," in Sämtliche Werke (Weimar: Hermann Böhlaus, 1935), XI, 112, 94, 92-93-heißt es aber: "Der Humor, als das umgekehrte Erhabene, vernichtet. . . ." Und weiter: "[E]r erniedrigt das Große . . . und erhöhet das Kleine . . . um ihm das Große an die Seite zu setzen und so beide zu vernichten, weil vor der Unendlichkeit alles gleich ist 
und Nichts." Das Erhabene hat im subjektiven Humor Jean Pauls keinen Platz. Er definiert es "als das angewandte Unendliche." Es vernichtet das Endliche nicht, ist also dem Humor eher entgegengesetzt. So ist das "Lachen," bzw. das "Lächerliche," das Jean Paul als das "unendliche Kleine" definiert, der "Erbfeind des Erhabenen," während das "Verlachen" sich mit der "erhabenen Empfindung" verträgt. Um Bölls Humor von dem Jean Pauls abzusetzen, wofür auch spricht, daß Bölls satirische Praxis dem Konzept nicht gerecht wird, soll vorgeschlagen werden, Bölls Humor, sofern er der Subjektsphäre gilt, als "stützend" oder mit Wilhelm H. Grothmann- "Zur Struktur des Humors in Heinrich Bölls Gruppenbild mit Dame," German Quarterly, 50 (1977), 150-als "schützend" zu bezeichnen. Bölls Zitatfehler erklärt sich meines Erachtens auch als Teil der Apologie seiner Werke der fünfziger Jahre. Wenn er das Kleine mit dem Erhabenen identifiziert, so verknüpft er es gewissermaßen auch mit dem Heldischen, das Böll zur Zeit der "Frankfurter Vorlesungen" schon hinter sich gelassen hat. Möglich macht Jean Paul diesen Schritt, wenn er das Erhabene im Heldengedicht ansiedelt, allerdings nicht unter Einbeziehung des Kleinen. Böll spricht schon einige Jahre früher, 1960, in dem Aufsatz "Über den Roman" vom erhabenen Humor. Er verleiht ihm "metaphysische Qualität," bezieht ihn aber noch nicht auf das "Kleine" der behandelten Person, sondern den Künstler, der fähig sein sollte, "über seine Kunst erhaben zu sein," ESR2, S. 357.

51. Helmut Arntzen, Hrsg., "Nachricht von der Satire," in Gegen-Zeitung (Heidelberg: Wolfgang Rothe, 1964), S. 17.

52. Schönert, S. 31 .

53. Lazarowicz, S. 316-17.

54. Gilbert Cannan, Satire (New York: Doran, 1914), S. 38.

55. Bur-Malottke duldet keinen Herrn über sich und stellt somit eine Extremform des Narrentums dar, die für Böll- "Die Sprache als Hort der Freiheit," ESR1, S. 304-ins Unmenschliche umschlägt: "Ein Narr, der hin und wieder von seinem launischen Herrn Prügel für seine Frechheiten einstecken muß, die Zeichen seiner Narrheit immer deutlich sichtbar bei sich trägt . . . ist eine menschenwürdige Existenz, verglichen mit dem, der auf dem Podium der öffentlichen Meinung sich wie eine Marionette bewegt, die ständig zum Purzelbaum bereit ist."

56. Alvin B. Kernan, The Plot of Satire (New Haven and London: Yale University Press, 1965), S. 30.

57. Adorno, Jargon der Eigentlichkeit, S. 9-43.

58. Hard Times, in The Writings of Charles Dickens, Hrsg. Edwin Percy Whippel u.a. (Boston-New York: Houghton-Mifflin, 1894), XXVI, 14.

59. Anne Louise Murray-"Satirical Elements in the Narrative Prose of Heinrich Böll," Diss. Indiana University 1972, S. 129-30-interpretiert Bölls Namentechnik im selben Sinne: "Bur-Malottke . . . gets his name from the Nordic languages" (Norwegisch bur =brüllen, ljot=hässlich). Murrays Vermutung ist plausibel nicht nur, weil sie zum "echten Brüller" und den "Schrörschnauzaschenbechern" paßt, sondern auch, weil Böll Namen verwendet wie Huglieme und Krochy, die nicht deutsch anmuten. Murray, S. 129, und 
auch James Henderson Reid-“Böll's Names," Modern Language Review, 69 (1974), 581-weisen auf die Bedeutung von Murkes Namen als "schlechte Arbeit machen." Reid kommt dabei dem Verständnis des Murksens als dem Pfuschen des Herausforderers nahe: "Böll is searching for ways of breaking out of the sterility of a purely artistic revolt against society. Murke's murksen is 'ineffective work' since it remains within the cultural confines of Broadcasting House."

6o. Läßt sich dieser "Fehler" erklären, so zwei weitere nicht. Es heißt, Murke träumt von der Rutschbahn in der Nacht von Dienstag auf Mittwoch. Zehn Zeilen weiter liest man: "Jetzt war Mittwoch, und er hatte in der Nacht nichts von Seife, nichts von Rutschbahnen . . . geträumt," W3, S. 175. (Den Hinweis verdanke ich John Griffin.) Beim Einkleben der Formel "jenes höhere Wesen" erklärt der Techniker, er habe für jeden Kasus einen Kasten. Bei seiner Aufzählung vergißt er jedoch die Nominative. Diese benötigen zwar keinen eigenen Kasten, da sie mit den Akkusativen identisch sind, wären aber immerhin erwähnenswert, da es zehn Nominative, aber nur fünf Akkusative gibt.

61. Paulson, The Fictions of Satire, S. 9.

62. Wie alles, was man "verfeaturet," sind auch Tundra and Taiga austauschbar als Konstituenten der Sendezeit. Aber selbst diese geographischen Referenzen sind für Böll nicht beliebig, sondern verweisen auf das Motiv der Austauschbarkeit des Menschen. Tundra und Taiga bedeuten Böll Regionen menschlicher Versklavung und Qual, sind also Probleme, die dem Funkhaus nicht weniger wichtig sein sollten als die Seele des Hundes. In dem Essay "Der Zeitgenosse und die Wirklichkeit," ESR1, S. 71-72, betont Böll, daß nur das Kind den "Brief" der Wirklichkeit souverän ignorieren kann, da sie ihm nur im Augenblick liege. Der Erwachsene hingegen hat den Brief zu öffnen: "Da durchblättert man möglicherweise einmal einen alten Schulatlas und berührt gleichgültig jene öde erscheinenden grünlichen Flächen im nördlichen Teil Rußlands. . . . Man hat einmal etwas von Tundra, etwas von Taiga gehört-und doch, diese . . . Flächen werden erst wirklich, wenn wir darüber lesen: 'Es ist das Land mit der niedrigsten Temperatur: etwa 70 Grad unter Null. Die Verschiffung von Sklaven und Kolonisten nach Kolyma . . . umfaßt vierhundert- bis fünfhunderttausend Menschen jährlich. Die Sterblichkeit beträgt 20-25 Prozent jährlich. Vorsichtige Berichte nennen zehn Millionen Gefangene.'"

63. Helmut Arntzen, Literatur im Zeitalter der Information (Frankfurt: Athenäum, 1971), S. 194 .

64. Brummack, S. 282.

65. Alvin B. Kernan, "Aggression and Satire: Art Considered as a Form of Biological Adaptation," in Literary Theory and Structure, Hrsg. Frank Brady u.a. (New Haven and London: Yale University Press, 1973), S. 117.

66. Paulson, The Fictions of Satire, S. 9-11.

67. Karl Kraus, "Literatur und Lüge," in Werke, Hrsg. Heinrich Fischer (München: Kösel, 1958), VI, 333.

68. Siehe hierzu Ludwig Bieler, Geschichte der römischen Literatur, Sammlung 
Göschen, 4051, 3. Aufl. (Berlin: de Gruyter, 1972), I, 34; und Elliott, S. 257-75. 69. Elliott, S. 271.

70. Wird der Fluch ausdrücklich, so vermischt er sich besonders gern mit Metaphern des Heldischen, wie bei Pope, S. 324-25:

Yes, I am proud; I must be proud to see

Men not afraid of God, afraid of me:

Safe from the Bar, the Pulpit, and the Throne,

Yet touch'd and sham'd by Ridicule alone.

O sacred Weapon! Left for Truth's defence,

Sole Dread of Folly, Vice and Insolence!

To all but Heav'n-directed hands deny'd.

Noch gewaltiger spielt sich Heine in Deutschland. Ein Wintermärchen-Sämtliche Werke, Hrsg. Jost Perfahl und Werner Vordtriede (München: Winkler, 1969), I, 478-auf:

Beleid'ge lebendige Dichter nicht,

Sie haben Flammen und Waffen,

Die furchtbarer sind als Jovis Blitz,

Den ja der Poet erschaffen.

Beleid'ge die Götter, die alten und neu'n,

Des ganzen Olymps Gelichter,

Und den höchsten Jehovah obendrein-

Beleid'ge nur nicht den Dichter!

Kein Gott, kein Heiland erlöst ihn je

Aus diesen singenden Flammen!

Nimm dich in acht, daß wir dich nicht

$\mathrm{Zu}$ solcher Hölle verdammen.

71. Maynard Mack, "The Muse of Satire," The Yale Review, 41 (1951), 80-92. Macks Beispiele für den Gegenfluch sind aus der Pope-Kritik:

"[T]hat infusion of personal venom"; "the poet is writing under some bitter mortification"; he is "trying with concentrated malice to sting his adversary" .. . (Sir Leslie Stephen). . . . "spoonsful of boiling oil, ladled out by a fiendish monkey at an upstairs window upon such of the passers-by whom the wretch had a grudge against" (Lytton Strachey). . . . "impossible to admire . . . without an unenviable pleasure in sheer spite"; "the tone of furious indiscriminate hatred"; "the halfcrazed misanthropy of the whole poem" . . . (Gilbert Highet). S. $82-83$.

72. Paulson, The Fiction of Satire, S. 9.

73. Zimmer, S. 271.

74. Georg Büchner, Leonce und Lena, in Sämtliche Werke und Briefe, Hrsg.

Werner R. Lehmann (Hamburg: Wegner, [1967]), I, 116. 
75. Frye, S. 228.

76. Kernan, "Aggression and Satire," S. 118, 120.

\section{Frühe satirische Versuche; Abgrenzungen zur Parabel}

1. Lenz, S. 34 .

2. Amery, S. 122.

3. Bernhard, S. 138.

4. Jeziorkowski, Rhythmus und Figur, S. 94, 84. Seine Einordnungen sind wie folgt: Utopische Satiren- "Über die Brücke," "Mein trauriges Gesicht," "Der Lacher," "Bekenntnis eines Hundefängers," "Es wird etwas geschehen," "Der Wegwerfer," "Hauptstädtisches Journal." Nicht-utopische Satiren- "An der Brücke," "Mein teures Bein," "Der Zwerg und die Puppe," "Nicht nur zur Weihnachtszeit," "Die unsterbliche Theodora," "Im Lande der Rujuks," "Hier ist Tibten," "Doktor Murkes gesammeltes Schweigen," "Wie in schlechten Romanen," "Der Bahnhof von Zimpren." Erzählungen satirischen Charakters- "Der Mann mit den Messern," "Wanderer, kommst du nach Spa . . . ," "So ein Rummel," "Abenteuer eines Brotbeutels," "Die schwarzen Schafe," "Mein Onkel Fred," "Unberechenbare Gäste," "Eine Kiste für Kop."

5. Damit erschöpft sich die Liste dessen, was sich als Parabel einordnen läßt, nicht. Es wären möglicherweise hinzuzufügen: "Abenteuer eines Brotbeutels," "Der Zwerg und die Puppe," "Meines Bruders Beine," "Wie in schlechten Romanen," "Eine Kiste für Kop."

6. Vgl. Werner Brettschneider, Die moderne deutsche Parabel: Entwicklung und Bedeutung (Berlin: Erich Schmidt, 1971), S. 10; und Wolfgang Kayser, Das sprachliche Kunstwerk, 15. Aufl. (Bern und München: Francke, 1971), S. 123.

7. Vgl. Reinhard Dithmar, Hrsg., Fabeln, Parabeln, Gleichnisse: Beispiele didaktischer Literatur (München: Deutscher Taschenbuch Verlag, 1970), S. 17; Erwin Leibfried, Fabel (Stuttgart: J. B. Metzler, 1967), S. 5-6; Clemens Heselhaus, "Parabel," Reallexikon der deutschen Literaturgeschichte, Ausg. 1966, S. 7-12.

8. Dithmar, S. 11-12; Brettschneider, S. 14-15.

9. Heselhaus, S. 9.

10. Brettschneider, S. 9.

11. Heselhaus, S. 10.

12. Norbert Miller, "Die moderne Parabel," Akzente, 6 (1959), 209.

13. Alfred Bourk, "Geste und Parabel," Akzente, 6 (1959), 220.

14. Miller, S. 211, 200; Dithmar, S. 230-45.

15. Hans Schwab-Felisch, "Der Böll der frühen Jahre," in In Sachen Böll, S. 219.

16. R. Hinton Thomas und Wilfried van der Will, Der deutsche Roman und die Wohlstandsgesellschaft (Stuttgart: Kohlhammer, 1969), S. 61.

17. Marcel Reich-Ranicki, "Heinrich Böll zum 6o. Geburtstag: Mehr als ein Dichter," Frankfurter Allgemeine Zeitung, 17. 12. 1977.

18. Heinrich Böll, "Unberechenbare Gäste," Akzente, 2 (1955), 45-50; auch 
in Unberechenbare Gäste: Heitere Erzählungen (Zürich: Arche, 1956), S. 7-18. 19. Theodor Haecker, Essays (München: Kösel, 1958), S. 364-65.

\section{IV. "Nicht nur zur Weihnachtszeit": Durchbruch als Satiriker}

1. Aristoteles, "Nikomachische Ethik," in Werke, Hrsg. Ernst Grumach, 4. Aufl. (Berlin: Akademie Verlag, 1967), VI, 90.

2. Johann Wolfgang von Goethe, Torquato Tasso, in Werke: Hamburger Ausgabe, 2. Aufl. (Hamburg: Wegner, 1955), V, 100.

3. H. M. Waidson, "Die Romane und Erzählungen Heinrich Bölls," in Der Schriftsteller Heinrich Böll, S. 34 .

4. Frye, S.237-38.

5. Astrid Swift, S. 30.

6. Thomas Mann, "Tristan," in Gesammelte Werke (Frankfurt: Fischer, 1960), VIII, 217.

7. Enzensberger, S. 217-18.

8. Günter Blöcker, “Heinrich Böll als Satiriker,” Bücherkommentare, 7 (1958), 2.

\section{Die Berufssatiren: Selbstabrechnungen des Satirikers}

1. Eine Berufsproblematik liegt schon in einigen der frühen Texte, wie z.B. in "Der Mann mit den Messern" vor, jedoch ist in keiner dieser Arbeiten der Beruf so präzise Chiffre des Satirikers. Es läßt sich vermuten, daß die Ausgefallenheit der Berufe auf Chestertons The Club of Queer Trades zurückgeht. Chesterton war dem jungen Böll Lieblingsautor, ESR3, S. 226.

2. Elliott, S. 222; siehe auch Paulson, The Fictions of Satire, S. 75-128.

3. Aristoteles, S. 90. Vgl. auch Frye, S. 230.

4. Böll erinnert sich in seinem Gespräch mit Christian Linder, daß er "nicht zerstörte Städte gar nicht ertragen konnte." "[D]ie zertrümmerte Stadt hatte auch etwas sehr Friedliches," und zwar im Sinne einer "Hoffnung auf einen .. . Neubeginn," I, S. 396.

5. Robert Musil, Der Mann ohne Eigenschaften, in Gesammelte Werke in Einzelausgaben, Hrsg. Adolf Frisé (Hamburg: Rowohlt, 1952), S. 416.

6. C. G. Jung, "Zur Psychologie der Schelmenfigur," in Pikarische Welt, Hrsg. Helmut Heidenreich (Darmstadt: Wissenschaftliche Buchgesellschaft, 1969), S. 247.

7. Gottfried Benn, "Probleme der Lyrik," in Gesammelte Werke in acht Bänden, Hrsg. Dieter Wellershoff (Wiesbaden: Limes, 1968), IV, 1059.

8. Verwirrend ist auf den ersten Blick, daß Käte Barutzki im Verkauf, den man normalerweise mit der Objektsphäre liiert, tätig ist. Man hat hier zu dif- 
ferenzieren: Sie arbeitet nicht etwa im Literaturgeschäft, sondern in "Beckers billigem Laden." Das Epithet "billig" ist ausschlaggebend. Es erwirkt eher Distanz als Identifikation in Bezug auf die Leistungs- und Verbrauchergesellschaft. Erfolgsmenschen kaufen nicht bei Becker. Das deutet der Sprecher wie folgt an: "Auch als [Bodo] berühmt war, das Geld nur so floß, kaufte er immer in 'Beckers billigem Laden', um nur oft dieses hübsche Mädchen zu sehen," W2, S. 67.

9. Jadwigas Verhältnis zu ihrem Vater ist wie das des jungen Königs vom Mythusschema diktiert. Auch sie trauert nicht, wenn sie von der Hinrichtung ihres Vaters hört.

10. Arntzen, "Nachricht von der Satire," S. 15.

11. Paulson, The Fictions of Satire, S. 70.

12. Z. B. schreibt Gulliver als Sprachrohr Swifts-The Prose Works of Jonathan Swift, XI, 6-seinem Vetter: "[I]nstead of seeing a full Stop put to all Abuses and Corruptions, at least in this little Island, as I had Reason to expect: Behold, after above six Months Warning, I cannot learn that my Book hath produced one single Effect according to mine Intentions."

13. Peter Thorpe, "The Economics of Satire: Towards a New Definition," Western Humanities Review, 23 (1969), 187-96.

14. Vgl. Musil, der aufs deutlichste ausführt, was Böll hier andeutet. In Der Mann ohne Eigenschaften, S. 253, heißt es: "Die These, daß der große Umsatz an Seife von großer Reinlichkeit zeugt, braucht nicht für die Moral zu gelten, wo der neuere Satz richtiger ist, daß ein ausgeprägter Waschzwang auf nicht ganz saubere innere Verhältnisse hindeutet."

15. Der Ausgangspunkt des Böllschen Textes mag zu einer Szene in Musils Der Mann ohne Eigenschaften, S. 603, in Beziehung gesetzt werden. In der Planung der großen Jubiläumsaktion, die weder echten Grund noch Sinn hat, ruft der Graf Leinsdorf aus: "Es muß etwas geschehen!" Da ihm jedoch auch darum kein Einfall kommt, wiederholt er "aber trotzdem muß etwas geschehen!"

16. Vgl. Fritz Egger, "Es wird etwas geschehen," in Interpretationen zu Heinrich Böll, Hrsg. Rupert Hirschenauer und Albrecht Weber, 4. Aufl. (München: Oldenbourg, 1973), II, 97.

17. Vgl. Egger, S. 98-99.

18. In Hinsicht auf Bölls Bewunderung für Wolfgang Borchert ist es nicht abwegig, hinter dem Berufstrauernden die Gestalt des larmoyant trauernden Gottes in Draußen vor der Tür zu vermuten.

\section{VI. "Der Wegwerfer": System- und Berufssatire}

1. Jeziorkowski, Rhythmus und Figur, S. 17-95.

2. Brief von West an Jack Conroy, zitiert von Richard B. Gehman, Introd., The Day of the Locust, by Nathanael West (New York: New Directions, 1956), S. IX-X.

3. Jeziorkowski, Rhythmus und Figur, S. 43, 45. 
4. Jeziorkowski, Rhythmus und Figur, S. 36.

5. Vance Packard, The Waste Makers (New York: McKay, 1960), S. 41. Auf The Waste Makers haben schon R. Hinton Thomas und Wilfried van der Will, S. 6o, hingewiesen. Ein interessantes Analogon findet sich auch bei Frederik Pohl_- "The Midas Plague," in The Case Against Tomorrow (New York: Ballantine, 1957). Konsum und Verschleiß werden hier zum gesellschaftlichen Mandat für die tiefstehenden Schichten. Hochleistungsverbraucher steigen gesellschaftlich auf und entkommen so dem verhaßten Verbrauchszwang. Pohls Geschichte spielt in einer Zukunft, in der es von Robotern wimmelt. Der Protagonist verfällt auf eine Wegwerfformel, indem er, "arm" wie er ist, seine Haus-Roboter programmiert, die ihm auferlegten Verbraucherquoten zu überziehen. Er wird darob in eine höhere soziale Kategorie befördert und schafft durch seinen brillanten Einfall der Gesellschaft endlich die Einsicht, daß Verbrauch mit Verschwendung identisch ist. Nicht aber, daß Pohls Welt nun zur Sparsamkeit zurückkehrte; sinnloser Verbrauch, d.h. Verschwendung, wird enttabuiert. Rohstoffe werden total reklamiert und Pohls Pointe läuft auf eine absurde Selbstbefreiung des Menschen vom Verbrauch hinaus, da man diesen auf die Roboter überträgt.

6. Vgl. Schönert, S. 147-48.

7. Man hat an Rabelais-Le Tiers Livre, Kap. 2-zu denken, wo Panurge eine gewaltige, mit Daten und Kategorisierungen untermauerte Lobrede auf die Verschwendung hält.

8. E. F. Schumacher - Small Is Beautiful (New York: Harper and Row, 1973)entwickelt ein solches Bewahrungskonzept. Gegen das explosive ökonomische Wachstum stellt er die Theorie auf, daß kleine, energiesparende Produktionseinheiten menschlichen Ansprüchen eher gerecht werden können. Theodore Roszak nennt Schumacher in der Einführung den "Keynes of postindustrial society," S. 5, und kategorisiert sein Denken als der anarchistischen Tradition zugehörig, S. 4.

9. In Entfernung von der Truppe und Gruppenbild mit Dame transponiert Böll die Wegwerf- zur Bewahrungsformel. Im menschlichen Abfall der Gesellschaft residiert das $\mathrm{zu}$ bewahrende Humane.

10. Schwab-Felisch, S. 216-17.

11. Im selben Jahr, 1957, verbindet Böll dieselben kleinen Sorgen mit dem Konzept "Zu Hause." In dem Aufsatz "Im Ruhrgebiet" ist die Frage, "ob die Tomaten reif geworden sind und die Kaninchen fett," ESR1, S. 229, Ausdruck der Verbundenheit der von einer Reise zurückkehrenden Sprecherin mit ihrer Welt, die für sie trotz allen objektiven Kontrasts zu den unterwegs gesehenen Schönheiten die Matrix des Humanen ist.

12. Zum Sprachstil des Textes siehe Jeziorkowskis hochdifferenzierte Analyse: Rhythmus und Figur, S. 58-83. 


\section{Kurzsatire und Muster: Ausnahme, Abkehr und Neuansatz}

1. Johann Gottfried Herder, "Kritik und Satyre," in Sämmtliche Werke, Hrsg. Bernhard Suphan (Berlin: Weidmann, 1886), XXIV, 188-97.

2. Die Kritik hat bisher die Ausnahmestellung der Struktur in "Journal" kaum beachtet. Nur H. M. Enzensberger, S. 218, der die Arbeit für relativ schwach hält, scheint auf Strukturelles zu zielen: "Übrigens ist in diesem Stück die Schärfe der Beobachtung geringer, die Entfernung von Realität nimmt zu und die satirische Wirkung im gleichen Maße ab." Dem entgegen kommen aus der DDR Stimmen einmütiger Anerkennung, was in Anbetracht des Sujets verständlich ist. Siehe z.B. Bernhard, S. 180; Hanne-Lore Skrzypczak, "Der Gehalt der Satire und satirischer Elemente im Werk Heinrich Bölls," Staatsexamensarbeit. Humboldt-Universität, Berlin 1961, S. 30; Helmut Ullrich, "Aus der Welt der Schrörschnauzaschenbecher;" $\mathrm{H}$.

B. 1964 . , "Attacken gegen ausgehöhlte Traditionen," Neue Zeit, Berlin, 5. 7.

3. Iring Fetscher, "Menschlichkeit und Humor: 'Ansichten eines Clowns'," in In Sachen Böll, S. 277.

4. Klaus Jeziorkowski, "Heinrich Böll: Die Syntax des Humanen," in Zeitkritische Romane des 20. Jahrhunderts, Hrsg. Hans Wagener (Stuttgart: Reclam, 1975), S. 310.

5. Theodor W. Adorno, Minima Moralia (Frankfurt: Suhrkamp, 1951), S. $282-83$.

6. Günter Blöcker, "Der letzte Mensch," in Der Schriftsteller Heinrich Böll, S. 72.

7. Vgl. Anmerkungen zu Bertolt Brecht, Der aufhaltsame Aufstieg des Arturo $U i$, in Stücke (Frankfurt: Suhrkamp, 1957), IX, 372. Es ist nicht abwegig anzunehmen, daß Brecht hier auf Böll gewirkt hat. Fest steht, daß die Kluft zwischen dem frühen Böll und Brecht, wie Rainer Nägele- "Heinrich Böll: Die große Ordnung und die kleine Anarchie," in Gegenwartsliteratur und Drittes Reich, Hrsg. Hans Wagener (Stuttgart: Reclam, 1977), S. 190-betont, nicht mehr existiert. In Gruppenbild mit Dame gehören Brecht-Texte zu Lenis bevorzugtem Lesestoff.

8. In einem Brief an Pope spricht Swift-The Correspondence of Jonathan Swift, Hrsg. Harold Williams (Oxford: Clarendon Press, 1963), II, 215-von einem "Newgate pastoral, among the whores and thieves there" als Vorschlag für Gay.

9. Swift, The Prose Works of Jonathan Swift, I, 57.

10. David Worcester-The Art of Satire, 2. Aufl. (New York: Russel and Russel, 1960), S. 82, 88-durchleuchtet den großen Mann anhand eines Katalogs von zermalmenden Analysen, die man dem Helden angelegt hat. Daraus zwei Auszüge-zitiert nach Worcester-, der erste aus J. L. Peacocks Maid Marian:

[Y]our hero sacks a city, while your thief sacks a cellar: your hero marauds on a larger scale, and that is all the difference, for the principle 
and the virtue are one: but two of a trade cannot agree: therefore your hero makes laws to get rid of your thief, and gives him an ill name that he may hang him: for might is right, and the strong make laws for the weak, and they that make laws to serve their own turn do also make morals to give colour to their laws.

Hier wird das Heldische als die Vergoldung eines Herrschaftssystems angeprangert. In Fieldings Jonathan Wild ist das Heldische Menschheitsgeißel: "When I consider whole nations rooted out only to bring tears into the eyes of a great man, not indeed because he hath extirpated so many, but because he had no more nations to extirpate, then truly I am almost inclined to wish that Nature had spared us this her MASTERPIECE, and that no GREAT MAN had ever been born into the world."

11. Böll verwendet den Namen Lohengrin schon einmal in "Lohengrins Tod" (1950). Daß Eltern einem Kind 1933 den Namen Lohengrin geben, ist ein Verweis auf den Heroenkult und damit alle Manien der Zeit, deren indirekten Folgen das Kind in der Nachkriegszeit zum Opfer fällt, wenn es beim "Kohlenklauen" verunglückt. Im Auge zu behalten ist hier, daß Bölls Distanz nicht dem "Helden Lohengrin" an sich in dieser frühen Zeit gilt, sondern seiner Kontaminierung durch die Nazis. Reid- “Böll's Names," S. 579-verweist darauf, daß es sich um den "purest knight of the Holy Grail" handelt, dessen Namen die Eltern wählen "damals, als die ersten Bilder Hitlers auf den Bayreuther Festspielen durch alle Wochenschauen liefen," W1, S. 249.

\section{Ausblick auf die satirischen Langformen}

1. Jeziorkowski, "Heinrich Böll: Die Syntax des Humanen," S. 310.

2. Johann N. Schmidt, Satire: Swift und Pope (Stuttgart: Kohlhammer, 1977), S. 44 .

3. Koch, S. 104.

4. Nägele, Heinrich Böll: Einführung, S. 171.

5. Vgl. Schönert, S. 104.

6. Enzensberger, S. 220.

7. Siehe "Die Sprache als Hort der Freiheit," ESR1, S. 301.

8. Frank Trommler-“"Der zögernde Nachwuchs: Entwicklungsprobleme der Nachkriegsliteratur in Ost und West," in Tendenzen der deutschen Literatur seit 1945, Hrsg. Thomas Koebner (Stuttgart: Kröner, 1971), S. 107-sieht in Clown zurecht eine Abkehr von "Literarisierung und Symbolisierung" und eine Hinwendung zum "direkten Raisonnement."

9. Nägele, Heinrich Böll: Einführung, S. 141.

10. Haecker, S. 371.

11. Trotz allen Fehlverhaltens ist jedoch nicht zu übersehen, daß Schniers Einstellung zu Marie mit einer Herausforderung konventionalisierter Ehevorstellungen verbunden ist. So gehört er zu denen in Bölls Werk, die nach Robert Conard- "The Humanity of Heinrich Böll: Love and Religion," Boston Uni- 
versity Journal, 21 (1973), 37-den Mut haben "to oppose convention when it stifles freedom and to opt for a new theology of love and marriage." Leider wäre diese "Theologie" Schniers ohne Christus als Seinsgrund falsch konzipiert. So verstanden ist Schnier der Nachfahre des traurigsten "Helden" der mittelalterlichen Narrenliteratur, wo die übelste Narrheit das Verscherzen des ewigen Lebens ist.

12. $\mathrm{Zu}$ Schnier als Marionette vgl. E. Friedrichsmeyer, The Major Works of Heinrich Böll: A Critical Commentary (New York: Monarch, 1974), S. 29-32; und Ralf Nicolai, "Die Marionette als Interpretationsansatz zu Bölls 'Ansichten eines Clowns'," University of Dayton Review, 13 (1976), 25-32. Nicolai mißt Schnier sehr eng an Kleists Essay "Über das Marionettentheater" und übersieht m.E. darum in der Böllschen Marionette die Variante, in der die Gläubigkeit die Stufe der neugewonnenen Harmonie als Gottesnähe ermöglicht. In der Kleistschen geht es um Gottesgleichheit.

13. Aus diesem Kontext heraus ist auch Schniers mystische Fähigkeit, über das Telefon Gerüche wahrzunehmen, keine belustigend-karthartische "Kunst"-Metapher, zumal die Gerüche überwiegend unangenehm sind, sondern Irritationselement, da es die Form des realistischen Romans sprengt. Es ist mystisch, da es Moralisches im physischen Sensorium wirklich macht.

14. Worcester, S. 167-68.

15. Nägele, Heinrich Böll: Einführung, S. 147.

16. Wilhelm Emrich, "Selbstkritisches Erzählen: 'Entfernung von der Truppe'," in In Sachen Böll, S. 296.

17. Ingrid Hantsch, Semiotik des Erzählens: Studien zum satirischen Roman des 20. Jahrhunderts (München: Fink, 1975), S. 55.

18. Siehe hierzu Heinrich Böll: Freies Geleit für Ulrike Meinhof: Ein Artikel und seine Folgen, Hrsg. Frank Grützbach (Köln: Kiepenheuer und Witsch, 1972).

19. Vgl. Nägele, Heinrich Böll: Einführung, S. 159-60.

20. Vgl. Manfred Durzak, "Entfaltung oder Reduktion des Erzählers?" in Böll: Untersuchungen zum Werk, Hrsg. Manfred Jurgensen (Bern und München: Francke, 1975), S. 35.

21. Nägele, Heinrich Böll: Einführung, S. 161.

\section{Die neue Kurzsatire: Typologische Varianten}

1. Arntzen, "Nachricht von der Satire," S. 13.

2. Zu dieser Taktik im allgemeinen siehe Reinhold Grimm, "Verfremdung: Beiträge zu Wesen und Ursprung eines Begriffs," Revue de littérature comparée, 35 (1961), 207-36.

3. Dieter Arendt, Der Schelm als Widerspruch und Selbstkritik des Bürgertums (Stuttgart: Klett, 1974), S. 6.

4. Balzer, S. [125].

5. Zur Entstehung dieses Textes siehe I, S. 443 und 659. Z. B. Namen wie 
210 Anmerkung zu Seite 191

Rotmolch, u.s.w., stammen aus Grimms Wörterbuch. Die sich niederschlagenden Leseerfahrungen sind Briefe der Dunkelmänner-daraus die Idee zum fiktiven Bericht-, Juvenal, Aristophanes, Swift.

6. Siehe hierzu Günter Wallraff, Der Aufmacher-Der Mann, der bei Bild Hans Esser war (Köln: Kiepenheuer und Witsch, 1977). 


\section{Literaturverzeichnis}

\section{Werke-Interviews}

Böll, Heinrich. Werke: Romane und Erzählungen. Hrsg. Bernd Balzer. 5 Bde.

Köln: Kiepenheuer und Witsch, 1977.

- Werke: Essayistische Schriften und Reden. Hrsg. Bernd Balzer. 3 Bde.

Köln: Kiepenheuer und Witsch, 1978.

- Werke: Interviews. Hrsg. Bernd Balzer. Köln: Kiepenheuer und

Witsch, 1978.

- Werke: Hörspiele, Theaterstücke, Drehbücher, Gedichte. Hrsg. Bernd Balzer. Köln: Kiepenheuer und Witsch, 1978.

—. Du fährst zu oft nach Heidelberg. Bornheim-Marten: Lamuv, 1979.

. "Unberechenbare Gäste." Akzente, 2 (1955), 45-50.

. "Eine Welt ohne Christus." In Was halten Sie vom Christentum? 18 Antworten auf eine Umfrage. Hrsg. Karlheinz Deschner. München: Paul List, 1957, S. 21-24.

Koch, Werner. "Ein paar Stichworte: Personen und Situationen: Ein Gespräch mit Heinrich Böll." In Der Schriftsteller Heinrich Böll. Hrsg. Werner Lengning. 4. Aufl. München: Deutscher Taschenbuch Verlag, 1973, S. 99-110.

\section{Quellen und Forschungsliteratur}

Adorno, Theodor W. Minima Moralia: Reflexionen aus dem beschädigten Leben. Frankfurt: Suhrkamp, 1951.

_. Jargon der Eigentlichkeit: Zur deutschen Ideologie. 5. Aufl. Frankfurt: Suhrkamp, 1970.

-. "Keine Würdigung." In In Sachen Böll: Ansichten und Einsichten. Hrsg. Marcel Reich-Ranicki. 3. Aufl. Köln: Kiepenheuer und Witsch, 1970, S. 9-10.

Amery, Carl. "Eine christliche Position." In In Sachen Böll: Ansichten und Einsichten. Hrsg. Marcel Reich-Ranicki. 3. Aufl. Köln: Kiepenheuer und Witsch, 1970, S. 119-27.

Arendt, Dieter. Der Schelm als Widerspruch und Selbstkritik des Bürgertums: Vorarbeiten zu einer literatur-soziologischen Analyse der Schelmenliteratur. Stuttgart: Klett, 1974 .

Aristoteles. Werke. Hrsg. Ernst Grumach. 4. Aufl. Berlin: Akademie Verlag, 1967. Bd. VI. 
Arntzen, Helmut, Hrsg. Gegen-Zeitung: Deutsche Satire des 20. Jahrhunderts. Heidelberg: Wolfgang Rothe, 1964.

-. "Deutsche Satire im 20. Jahrhundert." In Deutsche Literatur im 20. Jahrhundert: Strukturen und Gestalten. Hrsg. Otto Mann und Wolfgang Rothe. 5. Aufl. Bern und München: Francke, 1967, S. 235-54.

- Literatur im Zeitalter der Information. Frankfurt: Athenäum, 1971.

B.__ H. H__ . "Attacken gegen ausgehöhlte Traditionen." Neue Zeit, Berlin, 5. 7. 1964.

Balzer, Bernd, Hrsg. Heinrich Böll: Werke: Romane und Erzählungen. Köln: Kiepenheuer und Witsch, 1977. Bd. I.

Benn, Gottfried. Gesammelte Werke in acht Bänden. Hrsg. Dieter Wellershoff. Wiesbaden: Limes, 1968. Bd. IV.

Bernhard, Hans Joachim. Die Romane Heinrich Bölls: Gesellschaftskritik und Gemeinschaftsutopie. Berlin: Rütten und Loening, 1970.

Bieler, Ludwig. Geschichte der römischen Literatur. Sammlung Göschen, 4051. 3. Aufl. Berlin: de Gruyter, 1972. Bd. I.

Blöcker, Günter. "Heinrich Böll als Satiriker." Bücherkommentare, 7 (1958), 2.

- "Der letzte Mensch." In Der Schriftsteller Heinrich Böll: Ein biographisch-bibliographischer Abriß. Hrsg. Werner Lengning. 4. Aufl.

München: Deutscher Taschenbuch Verlag, 1973, S. 72-75.

Bourk, Alfred. "Geste und Parabel." Akzente, 6 (1959), 214-20.

Brecht, Bertolt. Stücke. Frankfurt: Suhrkamp, 1957. Bd. IX.

Brettschneider, Werner. Die moderne deutsche Parabel: Entwicklung und Bedeutung. Berlin: Erich Schmidt, 1971.

Brummack, Jürgen. "Zu Begriff und Theorie der Satire.” Deutsche Vierteljahresschrift für Literaturwissenschaft und Geistesgeschichte, 45, Sonderheft (1971), 275-377.

Büchner, Georg. Sämtliche Werke und Briefe. Hrsg. Werner R. Lehmann. Hamburg: Wegner, [1967]. Bd. I.

Butler, Samuel. Characters and Passages from Note-Books. Hrsg. A. R. Waller. Cambridge: Cambridge University Press, 1908.

Cannan, Gilbert. Satire. New York: Doran, 1914.

Cases, Cesare. "'Die Waage der Baleks', dreimal gelesen." In In Sachen Böll: Ansichten und Einsichten. Hrsg. Marcel Reich-Ranicki. 3. Aufl. Köln: Kiepenheuer und Witsch, 1970, S. 224-32.

Conard, Robert. "The Humanity of Heinrich Böll: Love and Religion." Boston University Journal, 21 (1973), 35-42.

Demetz, Peter. "Zur Situation der Germanistik: Tradition und aktuelle Probleme." In Die deutsche Literatur der Gegenwart: Aspekte und Tendenzen. Hrsg. Manfred Durzak. Stuttgart: Reclam, 1971, S. 322-36.

Dickens, Charles. The Writings of Charles Dickens. Hrsg. Edwin Percy Whipple u.a. Boston-New York: Houghton-Mifflin, 1894. Bd. XXVI.

Dithmar, Reinhard, Hrsg. Fabeln, Parabeln, Gleichnisse: Beispiele didaktischer Literatur. München: Deutscher Taschenbuch Verlag, 1970.

Durzak, Manfred. "Entfaltung oder Reduktion des Erzählers?" In Böll: Untersuchungen zum Werk. Hrsg. Manfred Jurgensen. Bern und München: Francke, 1975. S. 31-53.

Egger, Fritz. "Es wird etwas geschehen." In Interpretationen zu Heinrich Böll. 
Hrsg. Rupert Hirschenauer und Albrecht Weber. 4. Aufl. München: Oldenbourg, 1973. Bd. II, S. 94-101.

Elliott, Robert C. The Power of Satire: Magic, Ritual, Art. Princeton: Princeton University Press, 1960.

Emrich, Wilhelm. "Selbstkritisches Erzählen: 'Entfernung von der Truppe'." In In Sachen Böll: Ansichten und Einsichten. Hrsg. Marcel Reich-Ranicki.

3. Aufl. Köln: Kiepenheuer und Witsch, 1970, S. 290-97.

Enzensberger, Hans Magnus. Einzelheiten. Frankfurt: Suhrkamp, 1962.

Fetscher, Iring. "Menschlichkeit und Humor: 'Ansichten eines Clowns'." In In Sachen Böll: Ansichten und Einsichten. Hrsg. Marcel Reich-Ranicki. 3.

Aufl. Köln: Kiepenheuer und Witsch, 1970, S. 275-84.

Friedrichsmeyer, Erhard. The Major Works of Heinrich Böll: A Critical Commentary. New York: Monarch, 1974.

Frye, Northrop. Analyse der Literaturkritik. Übers. Edgar Lohner und Henning Clewing. Stuttgart: Kohlhammer, 1964.

Gaier, Ulrich. Satire: Studien zu Neidhart, Wittenweiler, Brant und zur satirischen Schreibart. Tübingen: Niemeyer, 1967.

Gehman, Richard B., Introd. The Day of the Locust. By Nathanael West. New York: New Directions, 1956.

Gide, André. Les Faux-Monnayeurs. Paris: Gallimard, 1925.

Glade, Henry. "Soviet Views of Heinrich Böll." Arcadia, 7 (1972), 65-73.

Goethe, Johann Wolfgang von. Werke: Hamburger Ausgabe. 2. Aufl. Hamburg: Wegner, 1955. Bd. V.

Grimm, Reinhold. "Verfremdung: Beiträge zu Wesen und Ursprung eines Begriffs:" Revue de littérature comparée, 35 (1961), 207-36.

Grothmann, Wilhelm H. "Zur Struktur des Humors in Heinrich Bölls Gruppenbild mit Dame." German Quarterly, 50 (1977), 150-59.

Grützbach, Frank, Hrsg. Heinrich Böll: Freies Geleit für Ulrike Meinhof: Ein Artikel und seine Folgen. Köln: Kiepenheuer und Witsch, 1972.

Haecker, Theodor. Essays. München: Kösel, 1958.

Hantsch, Ingrid. Semiotik des Erzählens: Studien zum satirischen Roman des 20. Jahrhunderts. München: Fink, 1975.

Heine, Heinrich. Sämtliche Werke. Hrsg. Jost Perfahl und Werner Vordtriede. München: Winkler, 1969. Bd. I.

Herder, Johann Gottfried. Sämmtliche Werke. Hrsg. Bernhard Suphan. Berlin: Weidmann, 1886. Bd. XXIV.

Heselhaus, Clemens. "Parabel." Reallexikon der deutschen Literaturgeschichte, Ausg. 1966.

Heym, Stefan. "Das Establishment und die Verantwortung." In In Sachen Böll: Ansichten und Einsichten. Hrsg. Marcel Reich-Ranicki. 3. Aufl. Köln: Kiepenheuer und Witsch, 1970, S. 195-98.

Jauß, Hans Robert. Literaturgeschichte als Provokation der Literaturwissenschaft. 2. Aufl. Konstanz: Verlagsanstalt Konstanz, 1969.

Jean Paul. Sämtliche Werke: Historisch-Kritische Ausgabe. Weimar: Hermann Böhlaus, 1935. Bd. XI.

Jens, Walter. Deutsche Literatur der Gegenwart: Themen, Stile, Tendenzen. München: Piper, 1961.

Jeziorkowski, Klaus. Rhythmus und Figur: Zur Technik der epischen Konstruk- 
tion in Heinrich Bölls "Der Wegwerfer" und "Billard um halb zehn." Bad Homburg: Gehlen, 1968.

- "Heinrich Böll: Die Syntax des Humanen." In Zeitkritische Romane des 20. Jahrhunderts: Die Gesellschaft in der Kritik der deutschen Literatur. Hrsg. Hans Wagener. Stuttgart: Reclam, 1975, S. 301-18.

Johnson, Edgar, Hrsg. A Treasury of Satire. New York: Simon and Schuster, 1945.

Jung, Carl Gustav. "Zur Psychologie der Schelmenfigur." In Pikarische Welt. Hrsg. Helmut Heidenreich. Darmstadt: Wissenschaftliche Buchgesellschaft, 1969, S. 245-54.

Kaiser, Joachim. "Heinrich Bölls Charme." In Der Schriftsteller Heinrich Böll: Ein biographisch-bibliographischer Abriß. Hrsg. Werner Lengning. 4 Aufl. München: Deutscher Taschenbuch Verlag, 1973, S. 76-79.

Kayser, Wolfgang. Das sprachliche Kunstwerk: Eine Einführung in die Literaturwissenschaft. 15. Aufl. Bern und München: Francke, 1971.

Kernan, Alvin B. The Cankered Muse: Satire of the English Renaissance. New Haven and London: Yale University Press, 1959.

. The Plot of Satire. New Haven and London: Yale University Press, 1965.

- "A Theory of Satire." In Satire: Modern Essays in Criticism. Hrsg. Ronald Paulson. Englewood Cliffs: Prentice Hall, 1971, S. 249-77.

"Aggression and Satire: Art Considered as a Form of Biological Adaptation." In Literary Theory and Structure: Essays in Honor of William K. Wimsatt. Hrsg. Frank Brady u.a. New Haven and London: Yale University Press, 1973, S. 115-29.

Kierkegaard, Sören. Gesammelte Werke. Jena: Diederichs, 1923. Bd. V.

Korn, Karl. "Heinrich Bölls Beschreibung einer Epoche." In Der Schriftsteller Heinrich Böll: Ein biographisch-bibliographischer Abriß. Hrsg. Werner Lengning. 4. Aufl. München: Deutscher Taschenbuch Verlag, 1973, S. $111-16$.

Kraus, Karl. Werke. Hrsg. Heinrich Fischer. München: Kösel, 1958. Bd. VI.

Kraus, Wolfgang. "Böll als Satiriker." National-Zeitung, Basel, 8. 5 . 1958.

Lazarowicz, Klaus. Verkehrte Welt: Vorstudien zu einer Geschichte der deutschen Satire. Tübingen: Niemeyer, 1963.

Leibfried, Erwin. Fabel. Stuttgart: J. B. Metzler, 1967.

Lenz, Siegfried. "Sein Personal." In In Sachen Böll: Ansichten und Einsichten. Hrsg. Marcel Reich-Ranicki. 3. Aufl. Köln: Kiepenheuer und Witsch, 1970, S. 32-42.

Lewis, Wyndham. "The Greatest Satire is Nonmoral." In Satire: Modern Essays in Criticism. Hrsg. Ronald Paulson. Englewood Cliffs: Prentice Hall, 1971, S. 66-79.

Ley, Ralph. "Compassion, Catholicism, and Communism: Reflections on Bölls Gruppenbild mit Dame." University of Dayton Review, 10 (1973), 25-40.

Mack, Maynard. "The Muse of Satire." Yale Review, 41 (1951), 8o-92.

Mann, Thomas. Gesammelte Werke. Frankfurt: Fischer, 1960. Bde. V und VIII. Matthaei, Renate, Hrsg. Die subversive Madonna: Ein Schlüssel zum Werk 
Heinrich Bölls. Köln: Kiepenheuer und Witsch, 1975.

Mayer, Hans. Zur deutschen Literatur der Zeit. Reinbek bei Hamburg:

Rowohlt, 1967.

Meidinger-Geise, Inge. "Franz Kafka und die junge Literatur." Welt und Wort, 7 (1952), 189-94.

Miller, Norbert. "Die moderne Parabel." Akzente, 6 (1959), 200-13.

Murray, Anne Louise. "Satirical Elements in the Narrative Prose of Heinrich Böll." Diss. Indiana University 1972.

Musil, Robert. Gesammelte Werke in Einzelausgaben. Hrsg. Adolf Frisé. Hamburg: Rowohlt, 1952.

Nägele, Rainer. Heinrich Böll: Einführung in das Werk und in die Forschung.

Frankfurt: Athenäum Fischer, 1976.

—. "Heinrich Böll: Die große Ordnung und die kleine Anarchie." In Gegenwartsliteratur und Drittes Reich: Deutsche Autoren in der Auseinandersetzung mit der Vergangenheit. Hrsg. Hans Wagener. Stuttgart: Reclam, 1977, S. 183-204.

Nicolai, Ralf. "Die Marionette als Interpretationsansatz zu Bölls 'Ansichten eines Clowns'." University of Dayton Review, 13 (1976), 25-32.

Packard, Vance. The Waste Makers. New York: McKay, 1960.

Paulson, Ronald. The Fictions of Satire. Baltimore: The Johns Hopkins Press, 1967.

, Hrsg. Satire: Modern Essays in Criticism. Englewood Cliffs: Prentice Hall, 1971.

Pohl, Frederik. The Case Against Tomorrow. New York: Ballantine, 1957.

Pope, Alexander. The Twickenham Edition of the Poems of Alexander Pope. Hrsg. John Butt. 2. Aufl. London: Methuen, 1953. Bd. IV.

Rasch, Wolfdietrich. "Lobrede und Deutung." In Der Schriftsteller Heinrich Böll: Ein biographisch-bibliographischer Abriß. Hrsg. Werner Lengning. 4. Aufl. München: Deutscher Taschenbuch Verlag, 1973, S. 7-15.

Reich-Ranicki, Marcel. "Heinrich Böll zum 6o. Geburtstag: Mehr als ein Dichter." Frankfurter Allgemeine Zeitung, 17. 12. 1977.

Reid, James Henderson. Heinrich Böll: Withdrawal and Re-emergence. London: Oswald Wolff, 1973.

_. "Böll's Names." Modern Language Review, 69 (1974), 575-83.

Richter, Hans Werner. "Warum schweigt die junge Generation?" Der Ruf, 1. 9. 1946.

Rosenheim, Edward W. Jr. Swift and the Satirist's Art. Chicago: University of Chicago Press, 1963.

Schiller, Friedrich von. Werke: Nationalausgabe. Bd. XX. Hrsg. Benno von Wiese. Weimar: Hermann Böhlaus, 1962.

Schmidt, Johann N. Satire: Swift und Pope. Stuttgart: Kohlhammer, 1977.

Schönert, Jörg. Roman und Satire im 18. Jahrhundert: Ein Beitrag zur Poetik. Stuttgart: J. B. Metzler, 1969.

Schumacher, E. F. Small is Beautiful: Economics as if People Mattered. New York: Harper and Row, 1973.

Schwab-Felisch, Hans. "Der Böll der frühen Jahre." In In Sachen Böll: Ansichten und Einsichten. Hrsg. Marcel Reich-Ranicki. 3. Aufl. Köln: 
Kiepenheuer und Witsch, 1970, S. 213-23.

Sengle, Friedrich. Die literarische Formenlehre: Vorschläge zu ihrer Reform. Stuttgart: J. B. Metzler, 1967.

Skrzypczak, Hanne-Lore. "Der Gehalt der Satire und satirischer Elemente im Werk Heinrich Bölls." Staatsexamensarbeit. Humboldt-Universität, Berlin 1961.

Swabey, Marie Collins. Comic Laughter: A Philosophical Essay. New Haven and London: Yale University Press, 1961.

Swift, Astrid, Hrsg. Die englische Satire. Heidelberg: Quelle und Meyer, 1974.

Swift, Jonathan. The Poems of Jonathan Swift. Hrsg. Harold Williams. 2. Aufl. Oxford: Clarendon Press, 1958. Bd. II.

- The Prose Works of Jonathan Swift. Hrsg. Herbert Davis u.a. Bd. I. Oxford: Shakespeare Head Press, 1939. Bd. XI. Oxford: Shakespeare Head Press, 1959.

- The Correspondence of Jonathan Swift. Hrsg. Harold Williams. Oxford: Clarendon Press, 1963. Bd. II.

Thomas, R. Hinton und Wilfried van der Will. Der deutsche Roman und die Wohlstandsgesellschaft. Stuttgart: Kohlhammer, 1969.

Thorpe, Peter. "The Economics of Satire: Towards a New Definition." Western Humanities Review, 23 (1969), 187-96.

Trommler, Frank. "Der zögernde Nachwuchs: Entwicklungsprobleme der Nachkriegsliteratur in Ost und West." In Tendenzen der deutschen Literatur seit 1945. Hrsg. Thomas Koebner. Stuttgart: Kröner, 1971, S. 1-116.

Tronskaja, Maria. Die deutsche Prosasatire der Aufklärung. Berlin: Rütten und Loening, 1969.

Ullrich, Helmut. "Aus der Welt der Schrörschnauzaschenbecher." Neue Zeit, Berlin, 30. 1. 1959.

Waidson, H. M. “Die Romane und Erzählungen Heinrich Bölls.” In Der Schriftsteller Heinrich Böll: Ein biographisch-bibliographischer Abriß. Hrsg. Werner Lengning. 4. Aufl. München: Deutscher Taschenbuch Verlag, 1973, S. 31-40.

Wallraff, Günter. Der Aufmacher-Der Mann, der bei Bild Hans Esser war. Köln: Kiepenheuer und Witsch, 1977.

Welsford, Enid. The Fool: His Social and Literary History. New York: Farrar and Rinehart, 1936.

Westecker, Wilhelm "Gesammeltes Schweigen." Christ und Welt, Stuttgart, 31. 7. 1958.

van der Will, Wilfried. Pikaro heute: Metamorphosen des Schelms bei Thomas Mann, Döblin, Brecht, Grass. Stuttgart: Kohlhammer, 1967.

Wirth, Günter. Heinrich Böll: Essayistische Studie über religiöse und gesellschaftliche Motive im Prosawerk des Dichters. 2. Aufl. Berlin: Union, 1969.

Wölfel, Kurt. "Epische und satirische Welt: Zur Technik des satirischen Erzählens." Wirkendes Wort, 10 (1960), 85-98.

Worcester, David. The Art of Satire. 2. Aufl. New York: Russel and Russel, 1960. 
Zimmer, Dieter E. “'Doktor Murkes gesammeltes Schweigen'." In In Sachen Böll: Ansichten und Einsichten. Hrsg. Marcel Reich-Ranicki. 3. Aufl. Köln: Kiepenheuer und Witsch, 1970, S. 268-72.

Ziolkowski, Theodore. "Heinrich Böll: Conscience and Craft." Books Abroad, 34 (1960), 213-22.

- "Heinrich Böll: Nobel Prize for Literature: The Inner Veracity of Form." Books Abroad, 48 (1973), 17-24. 



\section{Personenregister}

Adenauer, Konrad, 157-59

Adorno, Theodor W., 4, 10, 40, 149, 162

Allen, Woody, 3

Amery, Carl, 29, 51, 199

Arendt, Dieter, 185

Aristophanes, 39, 210

Aristoteles, 67, 87

Arnold, Heinz Ludwig, 187

Arntzen, Helmut, 26, 34, 46, 107, 180

Bachmann, Ingeborg, 59

Balzer, Bernd, 186, 198

Barzel, Rainer, 157, 158

Beckett, Samuel, 59

Benn, Gottfried, 59, 97

Bernhard, Hans Joachim, 5, 15, 196, 203, 207

Bieler, Ludwig, 201

Biermann, Wolf, 50, 198

Bloch, Ernst, 59

Blöcker, Günter, 83, 149

Borchert, Wolfgang, 205

Bourk, Alfred, 58

Brecht, Bertolt, 58, 59, 151, 207

Brettschneider, Werner, 57, 203

Brummack, Jürgen, 8, 46

Buber, Martin, 59

Büchner, Georg, 49

Busch, Wilhelm, 157

Butler, Samuel, 23

Calvin, Jean, 28

Camus, Albert, 59

Cannan, Gilbert, 37

Cases, Cesare, 7

Chesterton, G. K., 204

Conard, Robert, 208

Cornford, F. M., 198

Demetz, Peter, 8

Dickens, Charles, 41

Dithmar, Reinhard, 59, 203

Dürrenmatt, Friedrich, 119

Dulles, John Foster, 17

Durzak, Manfred, 176, 184, 209
Egger, Fritz, 205

Eliot, T. S., 59

Elliott, Robert C., 7, 23, 47, 84, 202

Emrich, Wilhelm, 171

Enzensberger, Hans Magnus, 4, 5, 7, 83, 165,207

Erasmus von Rotterdam, 39, 49

Fetscher, Iring, 147

Fielding, Henry, 208

Fitzgerald, F. Scott, 3

Frazer, James George, 198

Freud, Sigmund, 154

Frisch, Max, 59

Frye, Northrop, 8, 21-23, 27, 49, 75, 76, 89,204

Gaier, Ulrich, 197

García Lorca, Federico, 59

Gay, John, 151

Gide, André, 196

Goethe, Johann Wolfgang v., 19, 72, 159

Grass, Günter, 22

Grimm, Reinhold, 209

Grosz, Georg, 46

Grothmann, Wilhelm H., 200

Haecker, Theodor, 60, 167

Hantsch, Ingrid, 171

Hayworth, Rita, 116

Hebel, Johann Peter, 57

Heine, Heinrich, 22, 84, 151, 188, 202

Herder, Johann Gottfried, 146

Heselhaus, Clemens, 203

Heym, Stefan, 13, 49

Highet, Gilbert, 202

Hindenburg, Paul v., 157

Hitler, Adolf, 27, 73

Hobbes, Thomas, 41

Hoffmann, E. T. A., 99

Horaz, 27, 47, 123, 184

Huxley, Aldous, 70, 125, 133

Ionesco, Eugéne, 58 
Jean Paul, 33, 199, 200

Jens, Walter, 4, 194

Jeziorkowski, Klaus, 56, 131, 132, 143 ,

149, 162, 196, 206

Johnson, Edgar, 7

Joyce, James, 59

Jung, Carl Gustav, 96

Juvenal, 22, 27, 44, 123, 210

Kafka, Franz, 57-59, 65

Kaiser, Joachim, 198

Kayser, Wolfgang, 203

Keller, Gottfried, 7, 81

Kernan, Alvin B., 24, 39, 46, 50

Keynes, John Maynard, 206

Kierkegaard, Sören, 15, 196

Kleist, Heinrich v., 57, 167, 169, 170, 209

Koch, Werner, 195, 208

Korn, Karl, 198

Krämer-Badoni, Rudolf, 157, 159

Kraus, Karl, 4, 7, 39, 47, 188

Kraus, Wolfgang, 195

Lazarowicz, Klaus, 33, 34

Leander, Zara, 116

Leibfried, Erwin, 203

Lenz, Siegfried, 19, 51

Lessing, Gotthold Ephraim, 84

Lévi-Strauss, Claude, 8

Lewis, Wyndham, 31

Linder, Christian, 66, 174, 176, 183, 184, 204

Liscow, Christian Ludwig, 84, 134

Lukian, 26

Mack, Maynard, 48

Mahler, Gustav, 3

Mann, Thomas, 19, 46, 81, 197

Marx, Karl, 159

Mayer, Hans, 19

Miller, Norbert, 58

Murner, Thomas, 44

Murray, Anne Louise, 200

Musil, Robert, 95, 196, 205

Nägele, Rainer, 5, 164, 171, 195, 207-209

Nicolai, Ralf, 209

Orwell, George, 45, 70, 187
Packard, Vance, 133

Papen, Franz v., 157

Paulson, Ronald, 8, 20, 21, 25, 28, 44, 46, $48,108,198,204$

Peacock, J. L., 207

Pohl, Frederik, 206

Pope, Alexander, 22, 202, 207

Pound, Ezra, 59

Proust, Marcel, 19

Rabelais, François, 206

Rabener, Gottlieb Wilhelm, 84, 134

Rasch, Wolfdietrich, 5

Reich-Ranicki, Marcel, 59, 157

Reid, James Henderson, 19, 195, 201, 208

Richter, Hans Werner, 18

Roon, Albrecht v., 136

Roszak, Theodore, 206

Schiller, Friedrich v., 20, 22, 23, 29, 108

Schlieffen, Alfred v., 136

Schmidt, Johann N., 163

Schneider, Rolf, 50

Schönert, Jörg, 20, 34, 206, 208

Schubert, Franz, 25

Schumacher, E. F., 206

Schwab-Felisch, Hans, 59, 137

Schweitzer, Albert, 112

Sengle, Friedrich, 20

Shakespeare, William, 133

Skrzypczak, Hanne-Lore, 207

Solschenizyn, Alexander, 47

Stendhal, 19

Stephen, Leslie, 202

Stifter, Adalbert, 25

Strachey, Lytton, 202

Strauß, Franz-Joseph, 157

Swabey, Marie Collins, 32

Swift, Astrid, 24, 76

Swift, Jonathan, 7, 8, 9, 22, 28, 38, 49, 70, $74,86,111,112,125,141,145,146,151$, $152,188,194,205,210$

Thomas, R. Hinton, 59, 206

Thorpe, Peter, 123

Trommler, Frank, 208

Ullrich, Helmut, 195, 207

Voltaire, 37, 86 
Wagner, Richard, 95 Waidson, H. M., 73

Wallraff, Günter, 191

Weerth, Georg, 191

West, Nathanael, 132

Westecker, Wilhelm, 195
Wieland, Christoph Martin, 134 van der Will, Wilfried, 59, 206

Worcester, David, 170, 207

Zimmer, Dieter, 18, 23, 48, 50

Ziolkowski, Theodore, 5 




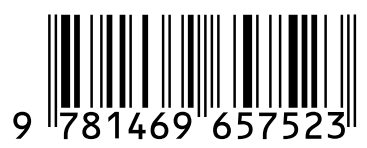

